\title{
Culture matters in medical schools: how values shape a successful curriculum change
}

Citation for published version (APA):

Jippes, M. (2013). Culture matters in medical schools: how values shape a successful curriculum change. [Doctoral Thesis, Maastricht University]. Maastricht University. https://doi.org/10.26481/dis.20130201mj

Document status and date:

Published: 01/01/2013

DOI:

10.26481/dis.20130201mj

Document Version:

Publisher's PDF, also known as Version of record

\section{Please check the document version of this publication:}

- A submitted manuscript is the version of the article upon submission and before peer-review. There can be important differences between the submitted version and the official published version of record.

People interested in the research are advised to contact the author for the final version of the publication, or visit the DOI to the publisher's website.

- The final author version and the galley proof are versions of the publication after peer review.

- The final published version features the final layout of the paper including the volume, issue and page numbers.

Link to publication

\footnotetext{
General rights rights.

- You may freely distribute the URL identifying the publication in the public portal. please follow below link for the End User Agreement:

www.umlib.nl/taverne-license

Take down policy

If you believe that this document breaches copyright please contact us at:

repository@maastrichtuniversity.nl

providing details and we will investigate your claim.
}

Copyright and moral rights for the publications made accessible in the public portal are retained by the authors and/or other copyright owners and it is a condition of accessing publications that users recognise and abide by the legal requirements associated with these

- Users may download and print one copy of any publication from the public portal for the purpose of private study or research.

- You may not further distribute the material or use it for any profit-making activity or commercial gain

If the publication is distributed under the terms of Article $25 \mathrm{fa}$ of the Dutch Copyright Act, indicated by the "Taverne" license above, 
Culture matters in medical schools

How values shape a successful curriculum change 
The research reported here was carried out at

\section{Mastricht University in Leanning!}

in the School of Health Professions Education

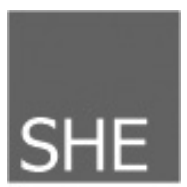

ISBN: $978-90-819874-0-0$

Copyright (c) M. Jippes, The Hague, The Netherlands, 2012 Cover design and lay-out: Eva Malschaert Printed by Optima Print All rights reserved. No parts of this thesis book may be reproduced or transmitted in any form or any means, without previous written permission from the author. 
Culture matters in medical schools:

How values shape a successful curriculum change

\author{
PROEFSCHRIFT
}

ter verkrijging van de graad van doctor aan de Universiteit Maastricht, op gezag van de Rector Magnificus, Prof. dr. L.L.G. Soete

volgens het besluit van het College van Decanen,

in het openbaar te verdedigen

op vrijdag 1 februari 2013 om 14.00 uur

door

Mariëlle Jippes 
Promotor:

Copromotores:
Prof.dr. C.P.M. van der Vleuten

\author{
Dr. E.W. Driessen \\ Dr. G.D. Majoor
}

Beoordelingscommissie: Prof.dr. A.J.J.A. Scherpbier (voorzitter) Prof.dr. T. Dornan

Prof.dr. A.D.C. Jaarsma

Dr. W.N.K.A. van Mook

Prof.dr. F. Scheele 
"It is not the strongest of the species that survives, nor the most intelligent, but rather the one most responsive to change."

Charles Darwin (February 12, 1809 - April 19, 1882) 
Paranimfen:

Caroline Broos

Erik Jippes 


\section{Contents}

CHAPTER 1 General introduction 8

CHAPTER 2 Influence of national culture on the adoption of integrated and problem-based curricula in Europe. Published in Medical Education 2008; 42(3):279-85. 28

CHAPTER 3 Influence of national culture on the adoption of integrated medical curricula.

Published in Advances in Health Sciences Education Theory and Practise 2011; 16(1):5-16. 42

CHAPTER 4 Impact of national context and culture on curriculum change: A case study.

Accepted for publication Medical Teacher. 60

CHAPTER 5 Medical schools' Organisational Readiness for curriculum Change: Development and validation of a questionnaire (MORC).

Under editorial review.

82

CHAPTER 6 Culture matters in successful curriculum change: the influence of national and organisational culture tested with multilevel structural equation modeling.

Under editorial review. 106

CHAPTER 7 General discussion 136

Summary 164

Samenvatting $\mathbf{1 7 1}$

Dankwoord $\mathbf{1 7 8}$

About the author $\mathbf{1 8 6}$ 


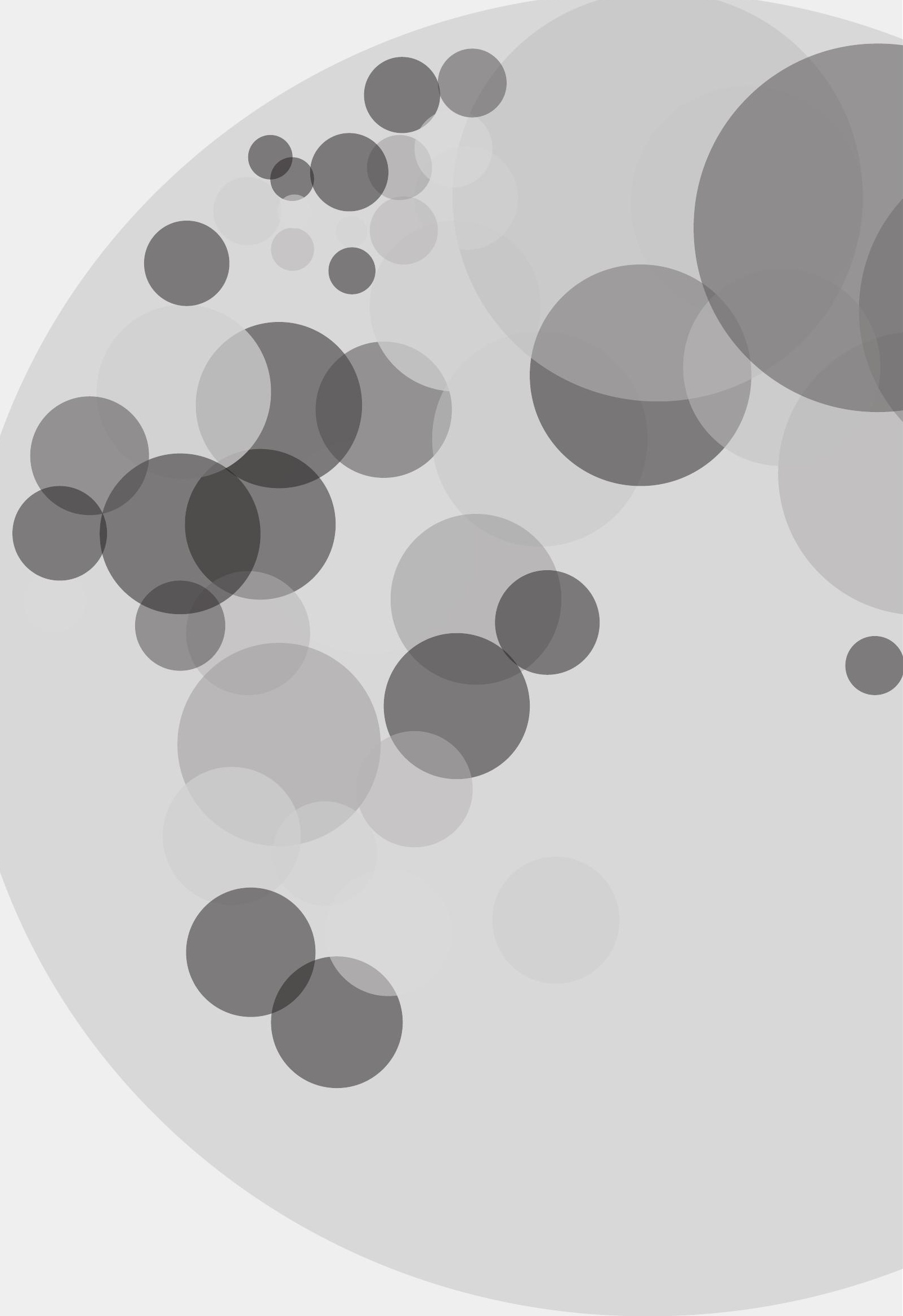




\section{CHAPTER 1}

GENERAL INTRODUCTION 


\section{Topics and relevance of this thesis}

The central topic of this thesis is the influence of culture on curriculum change in medical schools. Renovations of medical curricula are a worldwide phenomenon, often triggered by societal dissatisfaction with doctors and the health care system, sparked by doctors' inadequate communication skills, insufficient accountability, rising costs of health care, and a perceived excess of medical errors ${ }^{1}$. Another important motor for change is the explosion in medical knowledge that occurred in the second half of the $20^{\text {th }}$ century facilitated by the rapid increase in ease of access, compilation and flow of information and knowledge ${ }^{2}$. The huge advances in knowledge have given a strong impetus to technology-driven (sub)specialization, to the expense of primary health care $^{3-5}$. It is illustrative that in the 1970s four out of five doctors in the US were specialists ${ }^{5}$. One of the effects of the knowledge explosion was that the undergraduate curriculum became overloaded. As graduates were expected to 'know everything' about all the disciplines in the curriculum, more and more information was packed into medical curricula. Subjects were taught by discipline, mainly through lectures, while patient encounters were few or quite late in the curriculum. The continuing expansion of knowledge coupled with the compartmentalization of discipline-oriented teaching created a favorable climate for curricular innovations, such as Problem-Based Learning (PBL), with a strong focus on active learning in small groups, integration of basic and clinical sciences, and teaching students to 'know how' (Table 2)1. Worldwide interest in innovative curricula was followed by widespread implementation. The varying success rates of innovation projects ${ }^{1,5-31}$, however, sparked a desire for more insight into factors determining the chances of successful implementation. Increased knowledge of factors predicting successful change is expected to help prevent or ameliorate frustrating and costly failures and increase the chance of favorable outcomes of change efforts.

Studies have extensively described factors that appear to be at work when a new curriculum is introduced ${ }^{32}$ and how curriculum changes are best implemented ${ }^{33-36}$. The vast majority of those studies was undertaken in Western settings, but it is increasingly realized that it is of prime importance that educational methods and curricula should be in alignment with the local context and culture ${ }^{2,3,37,38}$. After all, countries differ not only in health, such as the prevalence of diseases and health 
care problems, but also in values and practices related to teaching and communication ${ }^{39-41}$, academic and operational management ${ }^{42,43}$, political context ${ }^{44}$, financial resources and openness to change ${ }^{45}$. Although it seems logical to expect these cultural differences to be at work in medical curricula and any changes therein, no results emerged from a search of the literature for studies presenting empirical evidence that cultural values and practices constitute a factor that really matters in relation to the implementation of a curricular innovation. The research in this thesis into the relationship between cultural factors and curriculum change therefore started from the problem statement: does culture have an impact on processes of curriculum change in medical schools? In anticipation of an affirmative answer, the following problem statement was: how does culture impact on curriculum change processes in medical schools? These two questions have shaped the research presented in this thesis (Table 1 ).

\begin{tabular}{|l|l|c|}
\hline Problem statements & Research questions & Chapters \\
\hline $\begin{array}{l}\text { Does national culture } \\
\text { impact on medical cur- } \\
\text { riculum innovation? }\end{array}$ & $\begin{array}{l}\text { Is there a correlation between national } \\
\text { cultural characteristics and the percent- } \\
\text { age of medical schools with an innovative } \\
\text { curriculum in a country? }\end{array}$ & 2,3 \\
\hline $\begin{array}{l}\text { How does national } \\
\text { culture impact on the } \\
\text { curriculum change } \\
\text { processes in medical } \\
\text { schools? }\end{array}$ & $\begin{array}{l}\text { How do medical schools in a cultural en- } \\
\text { vironment that is unconducive to change } \\
\text { successfully manage the transition to an } \\
\text { innovative curriculum? }\end{array}$ & 4 \\
\hline $\begin{array}{l}\text { How can we measure predictors of suc- } \\
\text { cessful curriculum change? }\end{array}$ & 5 \\
\hline $\begin{array}{l}\text { How do national and organizational cul- } \\
\text { ture interact to influence the successful } \\
\text { implementation of curriculum change? }\end{array}$ & 6 \\
\hline
\end{tabular}

Table 1: Overview of the problem statements and research questions of this thesis

As an introduction to the studies that constitute the core of the thesis, an overview is presented of the literature on cultural influences on curriculum change in medical schools. The findings from two literature studies are reported: one on medical curriculum change and one on cultural influences on change processes, followed by a discussion of literature considered to be of relevance to the impact of culture on medical curriculum change. An overview of the main concepts used in this introduction and their definitions is presented in Table 2. 


\section{Medical curriculum change}

Categorization of the medical education reforms in the past century reveals that there were actually two generations of reforms ${ }^{3,48}$. The first one started with the Flexner report, published in 1910, advocating for a more prominent place for basic science teaching in the USA medical curricula ${ }^{2},{ }^{53}$. This generation of reforms was characterized by the introduction of the familiar curriculum structure of 2-5 years of basic science teaching followed by clinical science and practice in the final years. Some fifty years later, however, questions began to be raised about the wisdom of the separation of basic science, clinical science, and clinical practice. In 1962, Miller ${ }^{54}$ demonstrated that students, even before graduating, had forgotten most of the basic science knowledge they had been taught. It was also shown that a few years after a basic science exam, students receiving high grades on that exam showed no superior basic science knowledge compared to students who had done less well. It was therefore deemed desirable to integrate basic sciences (horizontal integration) and basic and clinical sciences (vertical integration $)^{4,46,55}$. At the same time the traditional teacher-centered methods, relying mostly on learning from lectures and textbooks, came under attack ${ }^{1}$. New insights from the psychology of learning highlighted the benefits of student-centered learning through active problem solving. Needham and Begg ${ }^{56}$ demonstrated that students who used newly acquired knowledge to solve a new problem in $90 \%$ of cases were able to apply that knowledge to solve a problem in another setting (i.e. transfer). By contrast, students who only memorized the initial problem succeeded in only $60 \%$ of cases to successfully transfer their new knowledge to a new situation ${ }^{56,57}$. These insights harnessed support for the development of integrated, student-centered, and problem-based approaches to medical education, and this heralded the arrival of the second generation of educational reforms (Table 2$)^{57,58}$. Among the new integrated, student-centered curricula47, 59 were Problem-Based Learning curricula, pioneered at McMaster in Canada in $1968^{60}$. Soon, this new educational approach was adopted by many schools all over the world, first in industrialized countries (Maastricht, The Netherlands, 1974 and Newcastle, Australia, 1975) but very quickly followed by developing countries (Gezira, Sudan, 1975; Suez Canal, Egypt, 1977). Opponents of integrated and problem-based approaches expressed strong doubts, particularly regarding the knowledge base of graduates of these new curricula ${ }^{61}$, but their fears appear to have been unfound- 
ed. A recent systematic review of thirteen studies found no difference in knowledge base between graduates of traditional and PBL curricula, while graduates of PBL curricula were shown to have better skills for communication and self-directed learning ${ }^{62,63}$. National ${ }^{64-66}$ and international organizations, including the World Health Organization ${ }^{37}$ and the World Federation of Medical Education ${ }^{67}$, called upon medical schools to introduce integrated, student-centered curricula which catered to local health care needs. Although there was little doubt about the benefits of change, successful implementation of curriculum renewal proved to be fraught with difficulties ${ }^{68-71}$. Changing a medical curriculum is a complex process which will inevitably meet with some resistance ${ }^{4,72}$. Also, it involves a variety of factors, including investment of time and money, both scarce commodities, especially since most basic scientists and clinicians tend to prioritize research and patient care over education ${ }^{4}$. Furthermore, changing a curriculum requires extensive communication between disciplines as well as central control, thereby encroaching on the territorial domains of individual departments depriving them of their exclusive responsibility for the teaching in their domain ${ }^{4,25}$, 32. In a systematic review, Bland et al. ${ }^{32}$ identified thirteen factors influencing curriculum change, including 'mission and goals', 'history of change in the organization', 'need for change', 'participation by the organization's members', 'politics', 'cooperative climate', 'communication', and 'leadership'. Although some of these factors seem universally valid, such as the importance of communication and participation, countries and cultures most likely will differ with regard to other factors, such as leadership style and politics. In medical curriculum reform therefore, these culturally dependant factors should be expected to play out in different ways, depending on the national and cultural context of the curriculum change.

\section{Cultural influences on change}

Change processes comprise three main phases: initiation, implementation, and institutionalization (Table 2 ) $^{73}, 74$. Similar to Lewin's ${ }^{75}$ 'unfreezing phase', the initiation phase is characterized by disturbance of the existing organizational equilibrium fuelling motivation for change $\mathrm{e}^{76}$. During this phase, organizational members become dissatisfied with the status quo and convinced of the necessity of change. At this point, an organization is ready to move to a new position through the implementation of change (i.e. the adoption phase), which includes restruc- 
turing of the previously held assumptions and beliefs ${ }^{76}$. The final 'institutionalization phase' resembles Lewin's 'refreezing phase' in which the new procedures are internalized by the organization to become the generally accepted norm in a new equilibrium ${ }^{73}$. Several authors have pointed to cultural differences to explain differential rates of adoption of organizational innovations across countries ${ }^{77-79}$. The most frequently cited quantitative attempts at defining national culture and its effects on organizations was undertaken by Hofstede ${ }^{48,77}$ in the 1970 s and 1990s. Based on data from surveys of employees of IBM branches (an American multinational technology and consulting corporation) in eighty countries, Hofstede arrived at five cultural dimensions underlying differences between countries: Power distance, Individualism/collectivism, Uncertainty avoidance, Masculinity/femininity and Short-/ long-term orientation (Table 2). The dimensions range from zero to around one hundred, with culture determining a country's position on the scale of every dimension. The Power distance dimension reflects "'the extent to which the less powerful members of institutions and organisations within a country expect and accept that power is distributed unequally." Organizations in countries with a large power distance tend to be quite hierarchic and favor highly centralized and less participative decision-making, whereas the opposite holds for cultures on the other end of the scale. Individualism "pertains to societies in which the ties between individuals are loose: everybody is expected to look after themselves and their immediate family." Individualistic cultures generally emphasize autonomy, individual achievement, and freedom to make decisions. On the other end of the scale, collectivism "'pertains to societies in which people from birth onwards are integrated into strong, cohesive in-groups, which throughout people's lifetime continue to protect them in exchange for unquestioning loyalty." Masculinity "pertains to societies in which social gender roles are clearly distinct, i.e. men are supposed to be assertive, tough, competitive and focused on material success, whereas women are supposed to be more modest, tender and concerned with the quality of life." On the other end of the scale, femininity "pertains to societies in which social gender roles overlap, i.e. both men and women are supposed to be modest, tender and concerned with the quality of life." Uncertainty avoidance reflects "the extent to which the members of a culture feel threatened by uncertain or unknown situations." Countries that score high on uncertainty avoidance try to control uncertainty through technology, rules and 
regulations, and religion. Cultures on the low end of this dimension are more tolerant of ambiguity, and people are willing to take more risks and are more open to new ways. The dimension short-term/long-term orientation ranges from emphasis on "values associated with long-term orientation, such as thrift and perseverance", to short term orientation, with emphasis on values like respect for tradition, fulfilling one's social obligations, and saving 'face'.

As we will discuss in Chapter 7, Hofstede's work is not uncontroversial, but his dimensions of culture have been used successfully to explain differences in adoption rates of innovations across countries. Various studies have found that in countries with higher levels of uncertainty avoidance organizations engage less frequently in change processes than in countries where these levels are relatively low ${ }^{80-84}$. In societies with high uncertainty avoidance, organizations may shy away from the risks associated with change, possibly because change threatens to conflict with the commonly strict rules and regulations in such societies. Organizations in countries with high national levels of power distance also tend to be less inclined to adopt change ${ }^{85,86}$, although some studies have demonstrated a positive effect of large power distance, especially during the implementation stage. This paradoxical finding may be attributable to a beneficial effect of clear decision structures and tight control associated with high levels of power distance ${ }^{74,80,85,87}$. During the initiation phase, on the other hand, low levels of power distance stimulate employees to make suggestions to their superiors, which facilitates the adoption of innovations ${ }^{74}$. A mixed impact has also been shown for individualism and masculinity. While high levels of individualism have been found to promote adoption of change ${ }^{83,85}$, low levels of individualism appeared to be beneficial in the later phases of the change process due to emphasis on teamwork and consensus $^{74,87,88}$. Organizations in countries with high levels of masculinity are expected to place high value on wealth, goal orientation, achievement, and success, factors that are typically conducive to the adoption of innovations ${ }^{81,88}$, but low levels of masculinity with a focus on people and an environment of trust and supportive relationships have shown positive effects in the initiation phase ${ }^{74}$. Long-term orientation appears to promote the adoption rate of innovations, because it is characterized by factors that enhance receptivity to change, such as persistence, adaptation of traditions to new circumstances, and a focus on results in the future ${ }^{89}$. 


\begin{tabular}{|c|c|}
\hline Concept & Definition \\
\hline Curriculum & $\begin{array}{l}\text { "A series of planned activities which are intended to bring about spe- } \\
\text { cific learning outcomes in the students" }(p .7)^{38} \text {. The curriculum covers } \\
\text { the courses and the course schedule for the } 4-7 \text { years of undergradu- } \\
\text { ate medical education. }\end{array}$ \\
\hline $\begin{array}{l}\text { Integrated } \\
\text { curriculum }\end{array}$ & $\begin{array}{l}\text { Integrated teaching of different basic sciences (horizontal integra- } \\
\text { tion) and of basic and clinical sciences (vertical integration) }{ }^{51} \text {. PBL is } \\
\text { one of the different types of an integrated curriculum }{ }^{56} \text {. In this thesis } \\
\text { curricula are labeled as integrated when the curriculum does not in- } \\
\text { clude more than one basic science course (anatomy, biochemistry, or } \\
\text { physiology). }\end{array}$ \\
\hline $\begin{array}{l}\text { Problem- } \\
\text { Based Learn- } \\
\text { ing (PBL) }\end{array}$ & $\begin{array}{l}\text { A teaching method focusing on active learning in small groups, the } \\
\text { activation of prior knowledge through brainstorming, and self-study } \\
\text { to fill identified knowledge gaps (self-directed learning). }\end{array}$ \\
\hline $\begin{array}{l}\text { National cul- } \\
\text { ture }\end{array}$ & $\begin{array}{l}\text { "The collective programming of the mind which distinguishes the } \\
\text { members of one human group from another" }(p .25)^{118} \text {. }\end{array}$ \\
\hline $\begin{array}{l}\text { Power dis- } \\
\text { tance }\end{array}$ & The degree of tolerance of hierarchical or unequal relationships. \\
\hline $\begin{array}{l}\text { Uncertainty } \\
\text { avoidance }\end{array}$ & $\begin{array}{l}\text { The degree of acceptance of uncertainty and willingness to take risks. } \\
\text { It is expressed in the emphasis on predictability, achieved through } \\
\text { written and unwritten rules. }\end{array}$ \\
\hline Individualism & $\begin{array}{l}\text { The degree of emphasis placed on individual accomplishments. This } \\
\text { dimension ranges between the opposites of individualism and collec- } \\
\text { tivism. }\end{array}$ \\
\hline Masculinity & $\begin{array}{l}\text { The importance attached to materialism and assertiveness. The op- } \\
\text { posite of this dimension is femininity. }\end{array}$ \\
\hline $\begin{array}{l}\text { Organization- } \\
\text { al culture }\end{array}$ & $\begin{array}{l}\text { Organizational culture affects in a major way how members of an } \\
\text { organization think, feel, and act }{ }^{49} \text {. Three different levels of culture } \\
\text { can be recognized: 1) superficial artifacts and creations, 2) the more } \\
\text { manifest values, and } 3 \text { ) the deep basic assumptions. }\end{array}$ \\
\hline $\begin{array}{l}\text { Initiation } \\
\text { phase }\end{array}$ & $\begin{array}{l}\text { In the initiation phase organizational members come to accept that } \\
\text { change is needed. }\end{array}$ \\
\hline $\begin{array}{l}\text { Adoption } \\
\text { phase }\end{array}$ & $\begin{array}{l}\text { During the adoption phase, organizational members implement the } \\
\text { change. }\end{array}$ \\
\hline $\begin{array}{l}\text { Institutional- } \\
\text { ization phase }\end{array}$ & $\begin{array}{l}\text { During the institutionalization phase, the changes become internal- } \\
\text { ized as the new norm. }\end{array}$ \\
\hline Innovation & $\begin{array}{l}\text { The effective application of processes and products that are new to } \\
\text { the organization and designed to benefit the organization and its } \\
\text { stakeholders }{ }^{119} \text {. }\end{array}$ \\
\hline $\begin{array}{l}\text { Organization- } \\
\text { al Readiness } \\
\text { for Change }\end{array}$ & $\begin{array}{l}\text { The motivation and ability of organizational members to accept and } \\
\text { implement change. }\end{array}$ \\
\hline Diffusion & $\begin{array}{l}\text { The passive spread of an innovation within a social system through } \\
\text { interaction of participants via certain communication channels ("let it } \\
\text { happen") })^{119,120} \text {. }\end{array}$ \\
\hline $\begin{array}{l}\text { Key change } \\
\text { agents }\end{array}$ & People actively involved in the change process. \\
\hline
\end{tabular}

Table 2: Overview of the main concepts and their definitions 
Several studies have attributed variations in success rates of curriculum innovation not only to national ${ }^{81,89}$ but also to organizational culture (Table 2) ${ }^{82,90-93}$. It makes intuitive sense that national values, beliefs, and practices (i.e. national culture) should influence the values, beliefs,

and behavior of organizations within a country (i.e. organizational culture $)^{94,95}$, but empirical research on this relationship is sparse ${ }^{95,96}$, and, as far as we know, completely lacking in the field of medical education. In essence, differences between organizations within the same country are expected to be smaller than differences between organizations in different countries ${ }^{95}$. The continuous struggle to disentangle the effects of cultural and other factors will be further elaborated on in the Discussion (Chapter 7). A questionnaire study conducted by Hofstede in twenty units of ten organizations in Denmark and the Netherlands confirmed that, compared to differences between organizations, betweencountry differences explained more of the variance in the answers to value-related questions ${ }^{96}$. The study also showed that personal values varied more by nation than by firm, while organizational practices, learned through socialization in the workplace, varied more by firm than by nation. This points to a fundamental tension in the relationship between national and organizational culture. Organizations have to innovate in order to survive, and the struggle for survival may offer a powerful incentive to override national values and behaviors which would normally militate against change ${ }^{95}$.

\section{Influence of culture on medical curriculum change}

Differences between countries in the rate of diffusion of innovations in organizations have been attributed to differences in national cultural characteristics (Table 2) ${ }^{81,89,97,98}$. Diffusion is the process whereby an innovation spreads among the members of a social system ${ }^{99}$. The decision to adopt an innovation is generally based on a cost-benefit analysis in which uncertainty is the main factor on the cost side. Where medical curricula are concerned, uncertainty about a new and unknown situation is reflected in questions like: Will the innovative curriculum bring improvement over the current situation? Are we able to implement the innovative curriculum? Is the innovative curriculum compatible with the sociocultural values of our medical school, its past experiences, and its needs? With uncertainty being so closely bound up with change processes, it seems logical that medical schools in countries with high levels of uncertainty avoidance should expect to have to overcome 
strong resistance to curriculum reform. Despite the absence of published studies specifically addressing the influence of culture on the diffusion of medical curriculum change, several studies have described findings that seem worth considering in relation to medical curriculum reform. Sanson-Fisher and Lynagh ${ }^{100}$ described characteristics of the diffusion process of Problem-Based Learning, but did not consider cultural influences. Greenhalgh et al. ${ }^{51}$ conducted an impressive review of over 6000 articles on diffusion of innovations, including innovations in the health care sector, and distilled six broad categories of influential factors: 1) the innovation itself; 2) the adoption/assimilation process; 3) communication and influence; 4) the inner (organizational) context; 5) the outer (interorganizational) context and 6) the implementation process. The same authors identified in addition thirteen research traditions that have provided evidence on diffusion of innovations, ranging from sociology, anthropology, psychology, and economics to interdisciplinary research traditions. The interdisciplinary tradition that seemed to be the most promising approach for the research questions of this thesis is 'Studies of organizational process, context, and culture' (bridging organization and management, anthropology, and sociology). This research tradition focuses on non-structural aspects of organizations that influence innovations, including leadership style, power balances, social relations, and attitudes towards risk-taking inherent in the prevailing culture and climate, but a search for research in this tradition related to innovations in medical schools proved futile. In a case study of transnational cooperation between non-medical faculties in Thailand and Australia and the influence of national culture on academic and operational management in higher education, Eldridge \& Cranston $^{43}$ found that culture influenced the approaches to teaching, assessment, communication, and procedures and regulations in the universities.

In order to answer our two problem statements, four research questions were formulated and investigated in five studies, which constitute chapters 2-6 of this thesis (Figure 1, Table 1). For each research question we briefly summarize the related study or studies.

Research question 1: Is there a correlation between national cultural characteristics and the percentage of medical schools in a country with an innovative curriculum? 
To answer this question the first two studies in this thesis (Chapters 2 and 3) used a quantitative approach to analyze, in different countries, the relationship between scores on Hofstede's cultural dimensions and the percentages of medical schools with an integrated curriculum in place (Table 2).

\section{Research question 2:}

How do medical schools in a cultural environment that is unconducive to change successfully manage the transition to an innovative curriculum?

Some cultural characteristics, including high level of uncertainty avoidance, were hypothesized to have a negative influence on the adoption of innovative curricula. Studying schools that had successfully implemented change despite a change-aversive cultural environment was expected to yield insights into how culture impacts on curriculum change and how barriers to change can be overcome. A qualitative approach seemed most appropriate as it enables in-depth study of a phenomenon. It was also assumed that information from key change agents (Table 2) in these schools would offer the most useful insights on the change processes. Chapter 4 describes a study in which we interviewed key change agents in medical schools that had successfully changed their curriculum in a potentially unfavorable cultural environment.

\section{Research question 3: $\quad$ How can we measure predictors of suc- cessful curriculum change?}

Change failures in business organizations are generally estimated at 20 to $70 \%{ }^{101,102}$. Such percentages are not available for medical schools, but they may be assumed to be of a similar order of magnitude. Given the high failure rate of change attempts, it seemed worthwhile to identify cultural predictors of successful curriculum change. In business and health care organizations, 'Organizational Readiness for Change' has been identified as a major predictor of successful change (Table 2) $)^{101}$, 103-105. Organizational Readiness for Change depends on the motivation and ability of the members of the organization: to what extent are they willing and able to change ${ }^{106}$. Motivation is determined by belief in the necessity and effectiveness of the proposed change to improve the cur- 
rent situation and ability to change is influenced by organizational capacity (i.e. financial and human resources and staff development) and confidence that it will be put to effective use. In view of the absence of instruments for measuring readiness for change in medical schools a questionnaire to measure 'Medical school Organizational Readiness for curriculum Change (MORC)' was developed and validated (Chapter 5). The preliminary instrument, containing elements of existing questionnaires for business and health care organizations that were assumed to be applicable to medical schools, was submitted to a Delphi panel of experts on medical curriculum change. After the panel had established the applicability of MORC in medical schools, psychometric tests were conducted among a population of medical schools in different countries that were undergoing curriculum change.

\section{Research question 4:}

How do national and organizational culture interact to influence the successful implementation of curriculum change?

The validated MORC enabled further exploration of the impact of national culture on curriculum change. In addition to national culture, organizational culture is also claimed to play a critical role in effective change interventions and strategies ${ }^{91}$. The study described in Chapter 6 examined the hypothesis that organizational culture plays a role in the relationship between national culture and successful curriculum change.

According to the most-cited definition of organizational culture, formulated by Schein ${ }^{49}$, organizational culture affects in a major way how members of an organization think, feel, and act. Three different levels of culture can be identified: 1) superficial artifacts and creations, 2 ) the more manifest values, and 3) the deep basic assumptions ${ }^{49}$. Artifacts are visible, but often not consciously perceived, elements of the physical and social environment: the physical space, the language spoken, and overt behaviors of the organization's members. Values reflect the way things 'ought to be', often embodied in mission statements. Since organizational members are usually more aware of the organizational values than of the basic assumptions and artifacts, values are the target of most surveys of organizational culture. Basic assumptions constitute the deepest level of organizational culture. They consist in self-evident beliefs, encompassing implicit assumptions 
about how people ought to perceive, think, and feel. By definition, the basic assumptions are non-confrontable and non-debatable. From this perspective it seems quite understandable why change should so often be met with resistance, for organizational change touches not only the more superficial organizational procedures but also the underlying values and assumptions. Because of its compactness and wide usage - including in educational and health care settings - Quinn and Spreitzer's ${ }^{91}$ Competing Values Framework seemed the most appropriate choice from the existing measurement instruments for organizational culture ${ }^{107}$ to be used in investigating organizational culture in medical schools. The study described in Chapter 6 used multilevel structural equation modeling to analyze the interaction between Hofstede's national culture dimensions, Quinn's organizational culture framework, and MORC's organisational readiness for change dimensions (Figure 1).

Table 1 summarizes the two main problem statements and the four research questions with the chapters in which they are addressed. As these chapters consist of journal articles, some repetition of information across chapters was inevitable.

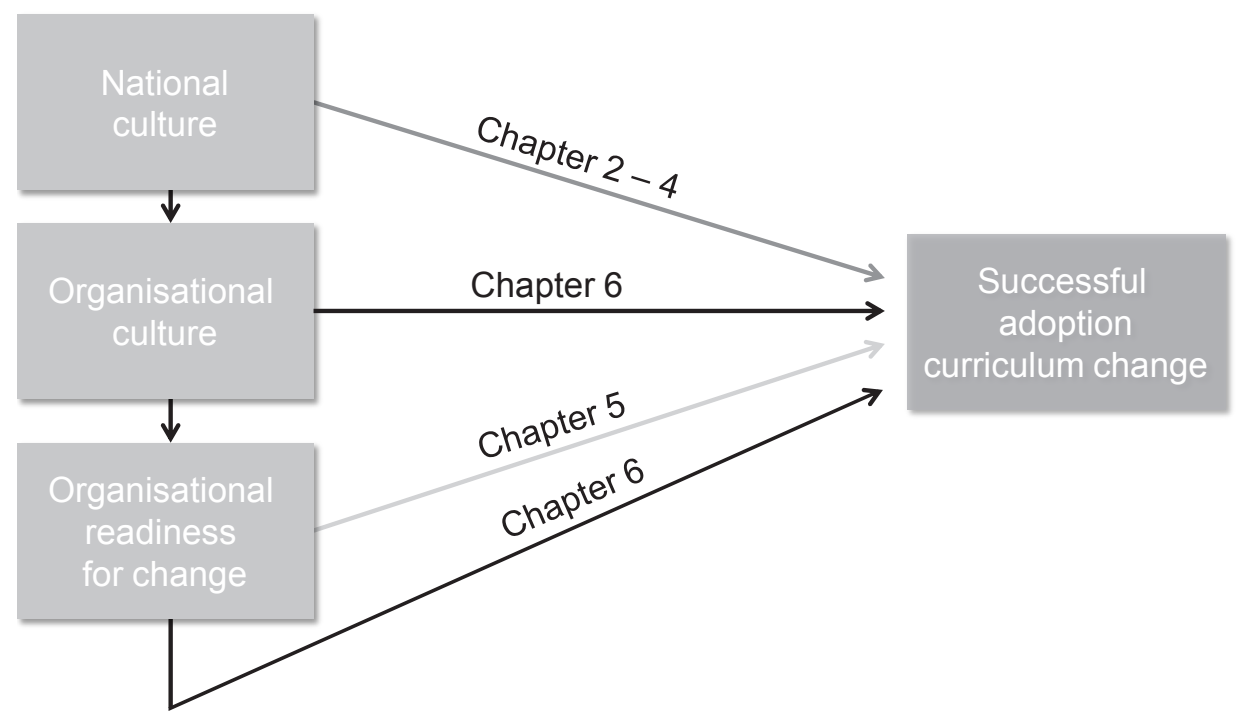

Figure 1: Conceptual model of thesis. The different shades of gray represent the relations studied in the different chapters. 


\section{References}

1. Jones R, Higgs R, de Angelis C, Prideaux D. Changing face of medical curricula. Lancet. 2001;357(9257):699-703.

2. Frenk J, Chen L, Bhutta ZA, Cohen J, Crisp N, Evans T, et al. Health professionals for a new century: transforming education to strengthen health systems in an interdependent world. Lancet. 2010;376(9756):1923-58.

3. WHO. Community-based education of health personnel. Geneva: WHO 1987.

4. Bloom SW. Structure and ideology in medical education: an analysis of resistance to change. Journal of Health and Social Behavior. 1988;29(4):294-306.

5. Amin Z, Hoon Eng K, Gwee M, Dow Rhoon K, Chay Hoon T. Medical education in Southeast Asia: emerging issues, challenges and opportunities. Medical Education. 2005;39(8):829-32.

6. Azila NM, Sim SM, Atiya AS. Encouraging learning how to fish: an uphill but worthwhile battle. Annals Academy of Medicine Singapore. 2001;30(4):375-8.

7. Carrera LI, Tellez TE, D'Ottavio AE. Implementing a problem-based learning curriculum in an Argentinean medical school: implications for developing countries. Academic Medicine. 2003;78(8):798-801.

8. Bernier G, Adler S, Kanter S, Meyer WJ. On changing curricula: lessons learned at two dissimilar medical schools. Academic Medicine. 2000;75(6):595-601.

9. Chandra D, Sharma S, Sethi G, Dkhar S. Pharmacotherapeutic education through problem based learning and its impact on cognitive and motivational attitude of Indian students. European Journal of Clinical Pharmacology. 1996;51(1):1-5.

10. Ghosh S, Pandya H. Implementation of Integrated Learning Program in neurosciences during first year of traditional medical course: Perception of students and faculty. BMC medical education. 2008;8(1):44.

11. Gwee MC, Tan CH. Problem-based learning in medical education: the Singapore hybrid. Annals of Academic Medicine Singapore. 2001;30(4):356-62.

12. Hoat LN. Moving the mountain: renovating medical education in a changing Vietnam [PhD thesis]. Amsterdam: VU 2008.

13. Iputo JE. Impact of the problem-based learning curriculum on the learning styles and strategies of medical students at the University of Transkei. South African Medical Journal. 1999;89(5):550-4.

14. Khoo HE. Implementation of problem-based learning in Asian medical schools and students' perceptions of their experience. Medical Education. 2003;37(5):4019.

15. Kinkade SMDM. A Snapshot of the Status of Problem-Based Learning in U. S. Medical Schools, 2003-04. Academic Medicine. 2005;80(3):300-1.

16. McKendree J. Experiences of problem-based learning in the UK. Clinical Teacher. 2010;7(4):262-5.

17. Villamor MC. Problem-based learning ( $P B L$ ) as an approach in the teaching of biochemistry of the endocrine system at the Angeles University College of Medicine. Annals of Academic Medicine Singapore. 2001;30(4):382-6.

18. Vyas R, Jacob M, Faith M, Isaac B, Rabi S, Sathishkumar S, et al. An effective integrated learning programme in the first year of the medical course. National Medical Journal of India. 2008;21(1):21-6.

19. Yu HY, Wu ZA, Su MS, Yen DJ, Luk HR, Chao YC, et al. Problem-based, smallgroup tutorial learning in clinical neurology for second-year medical students. Zhonghua Yi Xue Za Zhi (Taipei). 2000;63(8):598-604.

20. Anderson MB, Kanter SL. Medical education in the United States and Canada, 2010. Academic Medicine. 2010;85:S2-18.

21. Beni Hani I, Al Saudi K, Alkafagel a. Innovative learning approaches in an established medical school: the experience at JUST in Jordan. Eastern Mediterranean Health Journal. 2003;9:1084-92. 
22. Edgren G, Haffling A-C, Jakobsson U, McAleer S, Danielsen N. Comparing the educational environment (as measured by DREEM) at two different stages of curriculum reform. Medical Teacher. 2010;32:e233-8.

23. Hamdy H, Telmesani aW, Al Wardy N, Abdel-Khalek N, Carruthers G, Hassan $F$, et al. Undergraduate medical education in the Gulf Cooperation Council: a multi-countries study (Part 1). Medical Teacher. 2010;32:219-24.

24. Lloyd-Jones G, Ellershaw J, Wilkinson S, Bligh JG. The use of multidisciplinary consensus groups in the planning phase of an integrated problem-based curriculum. Medical Education. 1998;32:278-82.

25. Lindberg M. The process of change: stories of the journey of change. Academic Medicine. 1998;73:S4-10.

26. Muller JH, Jain S, Loeser H, Irby DM. Lessons learned about integrating a medical school curriculum: perceptions of students, faculty and curriculum leaders. Medical Education. 2008;42:778-85.

27. Onishi H, Yoshida I. Rapid change in Japanese medical education. Medical Teacher. 2004;26:403-8.

28. Schrauth M, Nikendei C, Weyrich P, Ju J. Medical education in Germany. Medical Teacher. 2009;31:591-600.

29. Shehnaz SI, Sreedharan J. Students' perception of educational environment in a medical school experiencing curricular transition in United Arab Emirates. Medical Teacher. 2011;33:e37-42.

30. Shimura T, Aramaki T, Shimizu K, Miyashita T, Adachi K, Teramoto A. Implementation of integrated medical curriculum in japanese medical schools. J Nippon Med Sch. 2004;71:11-6.

31. Snelgrove H, Familiari G, Gallo P, Gaudio E, Lenzi A, Ziparo V, et al. The challenge of reform: 10 years of curricula change in Italian medical schools. Medical Teacher. 2009;31:1047-55.

32. Bland CJ, Starnaman S, Wersal L, Moorehead-Rosenberg L, Zonia S, Henry R. Curricular change in medical schools: how to succeed. Academic Medicine. 2000;75(6):575-94.

33. Gale R, Grant J. AMEE Medical Education Guide No. 10: Managing change in a medical context: Guidelines for action. Medical Teacher. 1997;19(4):239-49.

34. Kern D. Curriculum development for medical education: a six-step approach. Baltimore: Johns Hopkins Univ. Press 2009.

35. Prideaux D. Curriculum design. ABC of learning and teaching in medicine. BMJ. 2003;326:268-70.

36. Bandaranayake RC. How to Plan a Medical Curriculum. Medical Teacher. 1985; 7:7-13.

37. WHO. Changing medical education. An agenda for action. Geneva: World Health Organisation 1991.

38. Blizard PJ. International standards in medical education or national standards/ primary health care--which direction? Social Science \& Medicine. 1991;33:116370.

39. Gwee MC. Globalization of problem-based learning (PBL): cross-cultural implications. Kaohsiung Journal of Medical Sciences. 2008;24(3 Suppl):S14-22.

40. Wong AK. Culture in medical education: comparing a Thai and a Canadian residency programme. Med Educ. 2011;45(12):1209-19.

41. Frambach JM, Driessen EW, Chan L-C, van der Vleuten CPM. Rethinking the globalisation of problem-based learning: how culture challenges self-directed learning. Medical Education. 2012;46:738-47.

42. Segouin C, Hodges B. Educating doctors in France and Canada: are the differences based on evidence or history? Medical Education. 2005;39(12):1205-12.

43. Eldridge K, Cranston N. Managing transnational education: does national culture really matter? Journal of Higher Education Policy and Management. 2009;31(1):67-79. 
44. Bordage G, Harris I. Making a difference in curriculum reform and decisionmaking processes. Medical Education. 2011;45(1):87-94.

45. Simunovic VJ, Hren D, Ivanis A, Dorup J, Krivokuca Z, Ristic S, et al. Survey of attitudes towards curriculum reforms among medical teachers in different socio-economic and cultural environments. Medical Teacher. 2007;29(8):8335.

46. Barrows HS, Tamblyn RM. Problem-Based Learning: An Approach to Medical Education. New York: Springer Publishing Company 1980.

47. Harden RM. The integration ladder: a tool for curriculum planning and evaluation. Medical Education. 2000;34:551-7.

48. Hofstede G. Culture's consequences: International Differences in Work-related values. London: Sage Publications 1980.

49. Schein EH. Organizational culture and leadership. San Francisco: Jossey-Bass 2004.

50. Jippes $E$. The role of social communication networks in implementing educational innovations in healthcare [PhD thesis]. Groningen RUG 2012.

51. Greenhalgh T, Robert G, Macfarlane F, Bate P, Kyriakidou O. Diffusion of innovations in service organizations: systematic review and recommendations. Milbank Quarterly. 2004;82(4):581-629.

52. Papa FJ, Harasym PH. Medical curriculum reform in North America, 1765 to the present: a cognitive science perspective. Academic Medicine. 1999;74(2):15464.

53. Flexner A. Medical Education in the United States and Canada. A Report to the Carnegie Foundation for the Advancement of Teaching. New York: Arno Press 1910.

54. Miller GE. An inquiry into medical teaching. Journal of medical education. 1962;37:185-91.

55. Harden RM, Sowden S, Dunn WR. Educational strategies in curriculum development: the SPICES model. Medical Education. 1984;18(4):284-97.

56. Needham DR, Begg IM. Problem-oriented training promotes spontaneous analogical transfer: memory-oriented training promotes memory for training. Memory \& cognition. $1991 ; \mathbf{1 9}(6): 543-57$.

57. Norman GR, Schmidt HG. The psychological basis of problem-based learning: a review of the evidence. Academic Medicine. 1992;67(9):557-65.

58. Dornhorst AC, Hunter A. Fallacies in medical education. Lancet. 1967;2(7517):666-7.

59. Margery $\mathrm{RMH}$, Davis $\mathrm{H}$. The continuum of problem-based learning. Medical Teacher. 1998;20(4):317-22.

60. Neufeld VR, Barrows HS. The "McMaster Philosophy": an approach to medical education. Journal of medical education. 1974;49(11):1040-50.

61. Dochy FSMVdBP, Gijbels D. Effects of problem-based learning: a meta-analysis. Learning and Instruction. 2003;13:533-68.

62. van den Hurk MM, Wolfhagen IHAP, Dolmans DHJM, van der Vleuten CPM. The impact of student-generated learning issues on individual study time and academic achievement. Medical Education. 1999;33(11):808-14.

63. Koh GC-H, Khoo HE, Wong ML, Koh D. The effects of problem-based learning during medical school on physician competency: a systematic review. Canadian Medical Association Journal. 2008;178:34-41.

64. Metz J. Blueprint 1994: training of doctors in The Netherlands : objectives of undergraduate medical education. Nijmegen: University of Nijmegen University Publication Office 1994.

65. General Medical Council. Tomorrow's Doctors. Recommendations on undergraduate medical education. London: 1993.

66. AMA. Future Directions for Medical Education: A Report of the Council on Medical education. JAMA. 1982;248(24):3225-39. 
67. Warren K. World Conference On Medical Education, Edinburgh. Lancet. 1988;332(8608):462-.

68. Torsoli A, Frati L. Breve storia del canale parallelo Romano e dei suoi risultati [The Rome parallel track: short history and outcomes]. Medic. 2002;10:16-22.

69. De Benedictis G. The definition of educational objectives on the basis of the problem-solving process in the Curriculum Parallelo Sperimentale in the Medical School of Bari, Italy. Annals of Community Oriented Education. 1990;3:223-5.

70. Binetti PA PI, Santini D. Experienze di tutorato al Campus Bio-Medico di Roma [Experiences with tutorships at the Campus Biomedico University, Rome]. Medic. 1998;6:213-8.

71. Baron M. Innovation in Spanish medical education: hopes and frustrations. In: Majoor G, van der Vleuten C, Vluggen P, Hansen P, editors. MedEd-21: An Account of Initiatives for Change in Medical Education in Europe for the 21st Century. Amsterdam: Thesis Publishers; 1997.

72. Lane IF. Change in higher education: understanding and responding to individual and organizational resistance. Journal of veterinary medical education. 2007;34(2):85-92.

73. Armenakis Aa, Harris SG. Crafting a change message to create transformational readiness. Journal of Organizational Change Management. 2002;15:169-83.

74. Nakata C, Sivakumar K. National Culture and New Product Development: An Integrative Review. Journal of Marketing. 1996;60(1):61-72.

75. Lewin K. Field Theory in Social Science; Selected Theoretical Papers. New York: Harper 1951.

76. Agius SJ, Willis SC, McArdle PJ, O'Neill PA. Managing change in postgraduate medical education: still unfreezing? Medical Teacher. 2008;30(4):e87-e94.

77. Hofstede G. Culture's Consequences. Comparing Values, Behaviors, Institutions, and Organizations across Nations. New York: Sage Publications 2001.

78. Trompenaars F, Woolliams P. Business across cultures. West Sussex: Capstone publishing 2005.

79. House R, Hanges P, Javidan M, Dorfman P, Gupta V. Culture, Leadership and Organizations. The GLOBE Study of 62 Societies. New York: Sage publications 2004.

80. Kollmann T, Kuckertz A, Breugst N. Organizational readiness and the adoption of electronic business: the moderating role of national culture in 29 european countries. ACM SIGMIS Database. 2009;40:117.

81. Singh S. Cultural differences in, and influences on, consumers' propensity to adopt innovations. International Marketing Review. 2006;23:173-91.

82. McLean LD. Organizational Culture's Influence on Creativity and Innovation: A Review of the Literature and Implications for Human Resource Development. Advances in Developing Human Resources. 2005;7:226-46.

83. Shane SA. Why do some societies invent more than others? Journal of business venturing. 1992; 7:29-46.

84. Shane S. Cultural influences on national rates of innovation. Journal of business venturing. 1993;8:59-73.

85. Chakrabarti AK, Rubenstein AH. Interorganizational transfer of technology - A study of adoption of NASA innovations. IEEE Transactions on Engineering Management. 1976 (EM-23):20-34.

86. Warkentin M, Gefen D, Pavlou PA, Rose GM. Encouraging Citizen Adoption of e-Government by Building Trust. Electronic Markets. 2002;12(3):157-62.

87. Herbig PA, Miller JC. Culture and Technology. Journal of Global Marketing. 1993; 6(3):75-104.

88. Jones GK, Davis HJ. National culture and innovation: Implications for locating global R \& D operation. Management International Review. 2000;40(1):11-39.

89. Everdingen $Y v$, Waarts $E$. The effect of national culture on the adoption of innovations. Marketing Letters. 2003;14(3):217-32. 
90. Wang S, Guidice R, Tansky J, Wang Z-m. The moderating role of organizational culture in innovation: evidence from China. Academy of management proceedings. 2009; Suppl 1.

91. Quinn R, Spreitzer G. The psychometrics of the competing values culture instrument and an analysis of the impact of organizational culture on the quality of life. Research in organizational change and development. 1991;5:115-42.

92. Jaskyte K, Dressler W. Organizational Culture and Innovation in Nonprofit Human Service organizations. Administration in Social Work. 2005;29:23-41.

93. Susanj Z. Innovative climate and culture in manufacturing organizations: differences between some European countries. Social Science Information. 2000;39:349-61.

94. van Oudenhoven JP. Do organizations reflect national cultures? A 10-nation study. International Journal of Intercultural Relations. 2001;25(1):89-107.

95. Nelson RE, Gopalan S. Do Organizational Cultures Replicate National Cultures? Isomorphism, Rejection and Reciprocal Opposition in the Corporate Values of Three Countries. Organization Studies. 2003;24:1115-51.

96. Hofstede G, Neuijen B, Daval Ohayv D, Sanders G. Measuring Organizational Cultures: A Qualitative and Quantitative Study across Twenty Cases. Administrative Science Quarterly. 1990;35:286-316.

97. Tellis GJ, Yin E, Bell S. Global Consumer Innovativeness: Cross-Country Differences and Demographic Commonalities. Journal of International Marketing. 2009; 17:1-22.

98. Yaveroglu IS, Donthu N. Cultural Influences on the Diffusion of New Products. Journal of International Consumer Marketing. 2002;14(4):49-63.

99. Rogers E. Diffusion of Innovations. 4th ed. New York: Free Press 1995.

100. Sanson-Fisher RW, Lynagh MC. Problem-based learning: a dissemination success story? Medical Journal of Australia. 2005;183(5):258-60.

101. Weiner BJ, Amick H, Lee SYD. Conceptualization and measurement of organizational readiness for change - A review of the literature in health services research and other fields. Medical Care Research and Review. 2008;65(4):379436.

102. DeLong Goldman G. Initial Validation of a Brief Individual Readiness for Change Scale (BIRCS) for Use With Addiction Program Staff Practitioners. Journal of Social Work Practice in the Addictions. 2009;9(2):184-203.

103. Jones RA, Jimmieson NL, Griffiths A. The impact of organizational culture and reshaping capabilities on change implementation success: The mediating role of readiness for change. Journal of Management Studies. 2005;42(2):361-86.

104. Armenakis AA, Harris SG, Mossholder KW. Creating readiness for organizational change Human Relations. 1993;46(6):681-703.

105. Kotter JP. Leading Change. Boston: Harvard Business School Press 1995.

106. Holt DT, Helfrich CD, Hall CG, Weiner BJ. Are You Ready? How Health Professionals Can Comprehensively Conceptualize Readiness for Change. Journal of General Internal Medicine. 2010;25:50-5.

107. Scott T, Mannion R, Davies H, Marshall M. The Quantitative Measurement of Organizational Culture in Health Care: A Review of the Available Instruments. Health Services Research. 2003;38:923-45. 
GENERAL INTRODUCTION | 27 


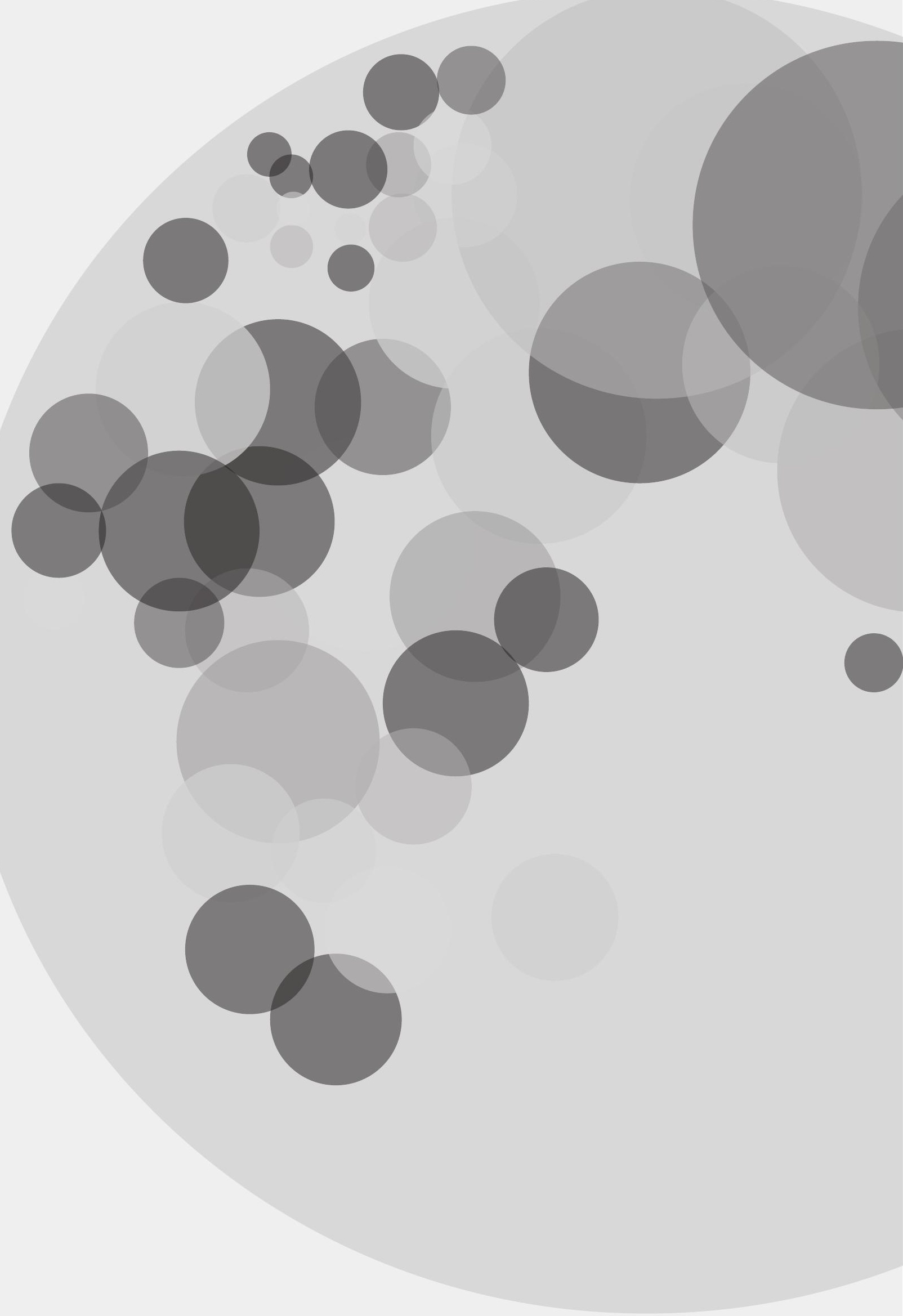




\section{CHAPTER 2}

INFLUENCE OF NATIONAL CULTURE ON THE ADOPTION OF INTEGRATED AND PROBLEM-BASED CURRICULA IN EUROPE 


\section{Abstract}

Context: There is an evident misbalance in the existince of medical schools with problem-based learning (PBL) curricula in northern versus southern Europe. This study explores the hypothesis that national culture influences the flexibility of medical schools in terms of their propensity to adopt integrated and PBL curricula.

Method: National culture was defined by a country's scores on indexes for 4 dimensions of culture as described by Hofstede, defined as: power distance; individualism/collectivism; masculinity/femininity, and uncertainty avoidance. Non-integrated medical curricula were defined as those that included courses in 2 of the 3 basic sciences (anatomy, biochemistry and physiology) in the first 2 years; otherwise, by exclusion, curricula were assumed to be integrated. The medical curricula of 134 of the 263 schools in the 17 European countries included in Hofstede's study were examined.

Results: Correlations were calculated between the percentage of integrated medical curricula in a country and that country's scores on indexes for each of the 4 dimensions of culture. Significant negative correlations were found between the percentage of integrated curricula and scores on the power distance index (correlation coefficient [CC]: $-0.692 ; P=0.002$ ) and the uncertainty avoidance index (CC: $0.704 ; P$ $=0.002)$. No significant correlations were found between the percentage of integrated curricula and scores on the indexes for individualism/ collectivism and masculinity/femininity.

Conclusions: A medical school which is considering adopting an integrated or PBL curriculum and which is based in a country with a high score on Hofstede's power distance index and/or uncertainty avoidance index must a priori design strategies to reduce or overcome the obstructive effects of these dimensions of culture on the school's organisation.

Keywords: curriculum; problem based learning; education, medical/ organization \& administration; Europe; culture; multicenter study. 


\section{Introduction}

Until the 1970s, medical curricula were composed of separate courses in the basic sciences and clinical disciplines. This traditional approach was challenged by the construction of integrated curricula ${ }^{1,2}$. Integration could be applied to curricula that included disciplines originally confined to the pre-clinical or clinical phases of the curriculum (referred to as horizontal integration) or to the integration of clinical disciplines with basic sciences and vice versa (vertical integration) ${ }^{3}$. In integrated medical curricula, the various disciplines were incorporated into educational units devoted to, for example, organ systems or medically relevant content domains ${ }^{4}$. The next milestone in the evolution of medical education were curricula featuring problem-based learning (PBL), introduced for the first time in 1968 at McMaster University in Canada ${ }^{5}$. The very nature of the problem-oriented approach meant that PBL curricula were classified as integrated ${ }^{6,7}$.

Since the 1970s, the number of medical schools adopting integrated and PBL curricula has grown steadily all over the world. Within Europe, however, a geographical misbalance has been noted with respect to the distribution of medical schools with integrated and PBL curricula: schools in northern Europe more commonly use integrated curricula than schools in southern Europe. There are some records of attempts to introduce PBL in medical schools in Spain and Italy, but there is no documentation of sustained success ${ }^{8-11}$. On the contrary, failure to sustain PBL in a Spanish medical school has been documented $^{9}$.

Integrated curricula require an organisational structure very different from that associated with curricula that are constructed from separate disciplinary courses. Whereas in traditional curricula decisions about the content and organisation of courses are fully delegated to the heads of the school's various departments, integrated curricula require a shift from departmental control over course content, to control over the education programme by committees composed of representatives from various departments ${ }^{4,12}$. Some observers have assumed the rigidity of the organisational structure of traditional medical schools to be an obstacle to the introduction of integrated and PBL curricula9, 13 . The combination of the latter suggestion with the observed misbalance in the frequencies of integrated and PBL medical curricula in northern versus southern Europe yielded the hypothesis that national culture influences the flexibility of a (medical) school in terms of its propensity to 
adopt an integrated or PBL curriculum. Confirmation of this hypothesis would imply that, in some countries, attempts by (medical) schools to introduce integrated or PBL curricula should firstly focus on overcoming cultural obstacles in the institution, prior to addressing the didactic aspects of such curricula.

To test the hypothesis presented above, operational definitions had to be designed for integrated and PBL curricula and differences between national cultures. With respect to the classification of curricula, PBL curricula are too widely varied to permit the designation of satisfactory criteria for definition ${ }^{14,15}$. However, it is a shared characteristic of PBL and integrated curricula that traditional monodisciplinary courses can no longer be identified within them. Because this difference may be most evident in the pre-clinical phases of traditional and integrated curricula, we focused on the first 2 years of medical programmes to discriminate integrated from non-integrated programmes. In traditional curricula, we expect to see courses in the first 2 years that address the classical pre-clinical disciplines of anatomy, biochemistry and physiology ${ }^{16}$. In integrated curricula, we would instead expect to find educational units, for example, The cardiovascular system or Locomotion. Thus, we defined medical curricula which included more than one classical pre-clinical discipline as specified above as not integrated. Otherwise, by exclusion, curricula without this characteristic were assumed to be integrated.

For an operational definition of culture we selected the empirical work of Hofstede ${ }^{17}$. Using data collected from questionnaires distributed to subordinates of the International Business Machines (IBM) group in 66 countries all over the world, Hofstede identified 5 dimensions of culture, which he defined as: power distance; individualism/collectivism; masculinity/femininity; uncertainty avoidance and shortterm/ longterm orientation. Hofstede used the first 4 dimensions to calculate scores on indexes for each country included in his study and hence we restricted this study to those 4 dimensions. In 1991 Hofstede $^{18}$ defined these dimensions as described below.

Power distance is the extent to which the less powerful members of institutions and organisations within a country expect and accept that power is distributed unequally. In this definition medical schools are comprised in institutions. Individualism pertains to societies in which the ties between individuals are loose: everybody is expected to 
look after him/herself and his/her immediate family. Collectivism as its opposite pertains to societies in which people from birth onwards are integrated into strong, cohesive ingroups, which throughout people's lifetime continue to protect them in exchange for unquestioning loyalty. Masculinity pertains to societies in which social gender roles are clearly distinct (i.e. men are supposed to be assertive, tough, and focused on material success, whereas women are supposed to be more modest, tender, and concerned with the quality of life). Femininity pertains to societies in which social gender roles overlap (i.e. both men and women are supposed to be modest, tender and concerned with the quality of life). Uncertainty avoidance is the extent to which the members of a culture feel threatened by uncertain or unknown situations. This feeling is, among other things, expressed through nervous stress and in a need for predictability: a need for written and unwritten rules ${ }^{18}$.

Among the 66 countries for which Hofstede assessed these 4 dimensions of culture were 17 European countries, including Austria, Belgium, Denmark, Finland, France, Germany, Greece, Ireland, Italy, Netherlands, Norway, Portugal, Spain, Sweden, Switzerland, Turkey and the UK. We restricted our study to these 17 European countries and defined cultural differences among them according to their scores on Hofstede's indexes for the 4 dimensions of culture.

Using the operational definitions, our hypothesis can be rephrased to state that we surmised a correlation between one or more of Hofstede's dimensions of national culture and the relative number of medical schools with integrated curricula. We imagined in particular the dimension power distance to influence the rigidity or flexibility of the organisational structure of a medical school and thereby to prohibit or facilitate the multi-disciplinary co-operation pivotal in the implementation of an integrated or PBL curriculum.

\section{Method}

\section{Analysis of curricula}

Medical schools in the 17 European countries specified above were retrieved from the World Directory of Medical Schools ${ }^{19}$. In these 17 countries the total number of medical schools listed was 263; the number of schools per country ranged from 3 to 45 (Table 1 ). For countries with less than 12 schools, all schools were included; for countries with more than 12 medical schools, a random sample of 12 was drawn. 
This procedure yielded a sample of 134 of 263 medical schools to be included in this study. Information about curricula was sought from Internet sites accessed between 1 June and 1 September 2006. If no satisfactory information was found, attempts were made to obtain information by approaching the curriculum administrators of each school, either directly or - if a language barrier hampered communication indirectly via bilingual colleagues. Curriculum outlines in Turkish were translated by a medical student of Turkish origin enrolled in the medical school at Maastricht University in the Netherlands.

Descriptions or timetables for the first 2 years of the curricula were independently examined by the first and second authors for the occurrence of courses in anatomy, physiology and biochemistry. For the vast majority of the curricula, both authors agreed to their classification as non-integrated or integrated. Only in a few cases were problems encountered, where deviant names were substituted for the selected basic sciences courses, such as when Functional morphology was used to designate an anatomy course or Molecular chemistry was used to designate biochemistry. These problems were jointly solved by both authors by analysis of more detailed information on the contents of those courses.

\section{Country scores on dimensions of culture}

Hofstede specified individual scores on indexes for each of the 4 dimensions of culture for each of the 17 countries included in this study ${ }^{18}$. These scores were used in this study without modification. It should be noted that the indexes for the dimensions may have different ranges.

\section{Statistical analysis}

We used SPSS Version 15 (SPSS Inc., Chicago, IL, USA) to draw scatter plots and calculate correlation coefficients (CCs) (Spearmans rho) for the percentage of integrated medical curricula in a country and that country's score on the respective indexes of each of the 4 dimensions of culture. Correlations were considered significant if $P<0.01$ (2-tailed). 


\begin{tabular}{|c|c|c|c|c|c|c|c|}
\hline \multirow[t]{2}{*}{ Country } & \multirow{2}{*}{$\begin{array}{l}\text { Num- } \\
\text { ber of } \\
\text { medical } \\
\text { schools* }\end{array}$} & \multirow{2}{*}{$\begin{array}{l}\text { Schools } \\
\text { includ- } \\
\text { ed in } \\
\text { study }\end{array}$} & \multirow{2}{*}{$\begin{array}{l}\text { Schools } \\
\text { with in- } \\
\text { tegrated } \\
\text { curricu- } \\
\text { la }(\%)\end{array}$} & \multicolumn{4}{|c|}{ Dimensions of culture ${ }^{*}$} \\
\hline & & & & $\begin{array}{c}\text { PD } \\
\text { score }\end{array}$ & $\begin{array}{c}\text { IND } \\
\text { score }\end{array}$ & $\begin{array}{l}\text { MAS } \\
\text { score }\end{array}$ & $\begin{array}{c}\text { UA } \\
\text { score }\end{array}$ \\
\hline Austria & 3 & 3 & $3(100)$ & 11 & 55 & 79 & 70 \\
\hline UK & 27 & $12^{\uparrow}$ & $11(92)$ & 35 & 89 & 66 & 35 \\
\hline $\begin{array}{l}\text { The Neth- } \\
\text { erlands }\end{array}$ & 8 & 8 & $7(88)$ & 38 & 80 & 14 & 53 \\
\hline Sweden & 6 & 6 & $4(67)$ & 31 & 71 & 5 & 29 \\
\hline Finland & 5 & 5 & $3(60)$ & 33 & 63 & 26 & 59 \\
\hline Switzerland & 5 & 5 & $3(60)$ & 34 & 68 & 70 & 58 \\
\hline Norway & 4 & 4 & $2(50)$ & 31 & 69 & 8 & 50 \\
\hline Turkey & 33 & $11^{\text {I\# }}$ & $5(45)$ & 66 & 37 & 45 & 85 \\
\hline Ireland & 5 & 5 & $2(40)$ & 28 & 70 & 68 & 35 \\
\hline Belgium & 11 & $10^{i}$ & $1(10)$ & 65 & 75 & 54 & 94 \\
\hline Denmark & 3 & 3 & $1(33)$ & 18 & 74 & 16 & 23 \\
\hline Germany & 39 & $12^{\natural}$ & $4(25)$ & 35 & 67 & 66 & 65 \\
\hline France & 45 & $12^{\pi}$ & $0(0)$ & 68 & 71 & 43 & 86 \\
\hline Greece & 7 & 7 & $0(0)$ & 60 & 35 & 57 & 112 \\
\hline Italy & 31 & $12^{\pi}$ & $0(0)$ & 50 & 76 & 70 & 75 \\
\hline Portugal & 5 & $4^{\#}$ & $0(0)$ & 63 & 27 & 31 & 104 \\
\hline Spain & 26 & $12^{\pi}$ & $0(0)$ & 57 & 51 & 42 & 86 \\
\hline Total & 263 & 131 & $46(35)$ & & & & \\
\hline
\end{tabular}

Table 1 Integrated medical curricula in 17 European countries and their scores on Hofstede's indexes for 4 dimensions of culture.

* According to the World Directory of Medical Schools ${ }^{19}$

$¥$ Dimensions and scores according to Hofstede ${ }^{18}$

If Random sample from total number of schools per country

\# No data were available for 1 university in this country

$¿$ Except 1 university which did not offer pre-clinical training

$\mathrm{PD}=$ power distance $; \mathrm{IND}=$ individualism; $\mathrm{MAS}=$ masculinity $; \mathrm{UA}=$ uncertainty avoidance

\section{Results}

Adequate data on the first 2 years of the curriculum were collected for 131 of the 134 medical schools included in the sample. The curriculum of 1 school in Belgium had to be omitted because the institution did not offer pre-clinical training (which is offered by another university in the same city). We failed to retrieve data on the curricula of 1 medical faculty in Portugal and 1 in Turkey. None of the medical schools examined in 5 of the 17 European countries included in the study had integrated 
curricula, and all 3 medical schools in another country had integrated curricula. Overall, we classified 46 of the 131 medical curricula examined as integrated (35\%).

Scatterplots for the variables 'percentage of integrated curricula in a country' and that country's scores on the indexes for each of the 4 dimensions of culture are presented in Fig. 1. Correlations between these variables were calculated and are given in Fig. 1. Significant (negative) correlations were found between the percentage of integrated curricula and scores on the power distance index (CC: -0.692 ; $P=0.002$ ) and uncertainty avoidance index (CC: $-0.704 ; P=0.002$ ). The scatterplot pertaining to the percentage of integrated curricula and the score on the power distance index suggested a strong influence of the data-point representing the country in which all 3 medical schools had integrated curricula and which had the lowest score on Hofstede's power distance index. However, correlation remained significant after elimination of this stray value (CC: $-0.697 ; P=0.003)$. No significant correlation was found between the percentage of integrated curricula in a country and its scores on the indexes for individualism/collectivism and masculinity/femininity.
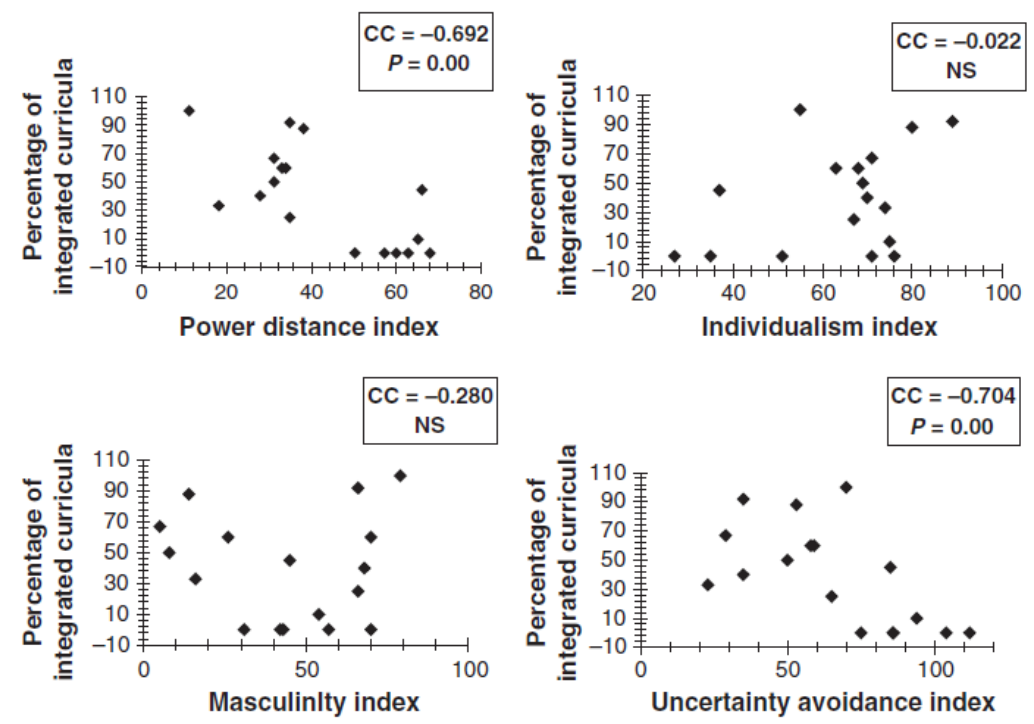

Figure 1 Scatterplots of scores of 17 individual European countries on indexes for each of 4 dimensions of culture ${ }^{17}$ and percentages of integrated medical curricula. $\mathrm{CC}=$ correlation 


\section{Discussion}

We found a negative correlation between 2 dimensions of a country's culture defined by Hofstede ${ }^{18}$ as power distance and uncertainty avoidance, and the percentage of integrated curricula in medical schools in that country. Thus, in countries where power distance is an important dimension of culture, and in countries where the national culture shows strong uncertainty avoidance, medical schools are less likely to adopt integrated curricula. Power distance may allow (heads of) departments of a medical school to reject the notion of co-operating with other departments in interdisciplinary committees to design an integrated programme, and they may be subject to very little social pressure to change their stance. In countries that rank highly with respect to uncertainty avoidance, faculty inclined to adopt change are unlikely to take action because their initiatives would not comply with existing rules and might have unpredictable consequences. In this study, these dimensions of culture also showed a significant mutual correlation (CC: $0.828 ; P<0.000$ ). Thus, they may often both apply to the same country and may explain the strong barriers in some medical schools against changing to integrated and PBL curricula. Hofstede ${ }^{20}$ also noted that scores on the power distance and uncertainty avoidance indexes tend to be correlated for European and Western countries. Hofstede ${ }^{18}$ earlier stated that power distance and uncertainty avoidance particularly affect our thinking about organisations because: Organising always demands the answering of 2 questions: (1) who has the power to decide what; and (2) what rules or procedures will be followed to attain the desired ends? The answer to the first question is influenced by cultural norms of power distance; the answer to the second question, by cultural norms about uncertainty avoidance ${ }^{18}$.

The necessity to adopt some definition of culture and to design a criterion with which to discriminate between integrated and non-integrated medical curricula may have negatively affected the reliability of this study. Others have criticized Hofstede's operational definition of culture $^{21}$. One of the objections cites the cultural homogenization of countries in Hofstede's approach. For example, we may wonder whether it is correct to calculate a single score on any cultural dimension for a country like Switzerland, which harbours 3 populations which speak different languages. Repeating this study with a different operational definition of culture might help us obtain an impression of the impact 
of our choice of Hofstede's model of culture on our findings.

Several problems were encountered with respect to the analysis of the curricula of 134 medical schools distributed over 17 countries. Almost all schools provided general information and many also gave detailed information about their curricula on the Internet, but often only in the national language. However, with the help of colleagues, and, in the case of Turkish, a medical student, we succeeded in interpreting the relevant information in the 13 languages. We also found that some schools presented detailed information about the curriculum only in an internal electronic learning environment, such as through software provided by Blackboard. Such intranets cannot be accessed by visitors beyond the academic community of that particular university. In those cases we had to request school administrators to send us the relevant documentation as electronic or printed files.

Our criterion for discriminating between integrated and non-integrated medical curricula could be applied without ambiguity. Nevertheless, we felt uneasy about the classification of 3 of the 131 curricula examined. These medical curricula were classified as non-integrated because 2 or 3 classical basic sciences courses were taught in the schools Year 1 programmes, but the pre-clinical curricula of Year 2 of these schools appeared to be well integrated. However, the number of curricula that challenged our discriminatory criterion was too small to change the outcomes of this study. It would be interesting to verify the outcomes of this study by repeating it on a global scale and including all 50 countries for which Hofstede reported individual characterisations of culture.

How can initiatives for the adoption of integrated and PBL curricula in (medical) education benefit from the outcomes of this study? Obviously, a (medical) school which is considering the adoption of an integrated or PBL curriculum and which is based in a country with a high score on Hofstede's power distance index and/or uncertainty avoidance index must try to reduce or overcome the obstructive effects of these dimensions of culture on organisational flexibility in the institution. A similar conclusion was drawn from a comparison of medical education systems in France and Canada22. To this aim there are many resources providing guidance with respect to strategies with which to change an organisation, either in general ${ }^{23}$ or, specifically, in the domain of education of health professionals 24,25 . 


\section{References}

1. Dornhorst AC, Hunter A. Fallacies in medical education. Lancet. 1967;2(7517):666-7.

2. Humphreys AH, Post TR, Ellis AK. Interdisciplinary methods, a thematic approach. Santa Monica, California: Goodyear Publishing Company 1981.

3. Harden RM, Sowden S, Dunn WR. Educational strategies in curriculum development: the SPICES model. Medical Education. 1984;18(4):284-97.

4. Papa FJ, Harasym PH. Medical curriculum reform in North America, 1765 to the present: a cognitive science perspective. Academic Medicine. 1999;74(2):15464.

5. Neufeld VR, Barrows HS. The "McMaster Philosophy": an approach to medical education. Journal of medical education. 1974;49(11):1040-50.

6. Barrows HS, Tamblyn RM. Problem-Based Learning: An Approach to Medical Education. New York: Springer Publishing Company 1980.

7. Schmidt H. Introduction (to Part 1: Problem-based learning: a rationale). In: Schmidt $H$, De Volder M, editors. Tutorials in Problem-based Learning A New Direction in Teaching the Health Professions. Assen: Van Gorcum 1984. p. 13-4.

8. De Benedictis $G$. The definition of educational objectives on the basis of the problem-solving process in the Curriculum Parallelo Sperimentale in the Medical School of Bari, Italy. Annals of Community Oriented Education. 1990;3:223-5.

9. Barón M. Innovation in Spanish medical education: hopes and frustrations. In: Majoor G, van der Vleuten C, Vluggen P, Hansen P, editors. MedEd-21: An Account of Initiatives for Change in Medical Education in Europe for the 21st Century. Amsterdam: Thesis Publishers; 1997.

10. Binetti PA PI, Santini D. Experienze di tutorato al Campus Bio-Medico di Roma [Experiences with tutorships at the Campus Biomedico University, Rome]. Medic. 1998;6:213-8.

11. Torsoli A, Frati L. Breve storia del canale parallelo Romano e dei suoi risultati [The Rome parallel track: short history and outcomes]. Medic. 2002;10:16-22.

12. Bouhuijs P. Innovation in Medical Education. An Evaluation of its Present Status. In: Nooman Z, Schmidt H, Ezzat E, editors. The maintenance of educational innovations in medical schools. New York: Springer; 1985. p. 175-88.

13. Mpofu D. Introducing Problem-based Learning into a Traditional Medical School. Student and Staff Perceptions of the United Emirates University's Innovation. [PhD thesis ]. Maastricht: Maastricht University 1999.

14. Barrows HS. A taxonomy of problem-based learning methods. Medical Education. 1986;20:481-6.

15. Margery $\mathrm{RMH}$, Davis $\mathrm{H}$. The continuum of problem-based learning. Medical Teacher. 1998;20(4):317-22.

16. Aziz. International Handbook of Medical Education. Westport CT: Greenwood Press 1994.

17. Hofstede G. Culture's consequences: International Differences in Work-related values. London: Sage Publications 1980.

18. Hofstede G. Culture's and Organisations: Software of The Mind. London: McGraw-Hill 1991.

19. WHO. World Directory of Medical Schools. 7th ed. Geneva: World Health Organisation 2000.

20. Hofstede G. Culture's Consequences. Comparing Values, Behaviors, Institutions, and Organizations across Nations. New York: Sage Publications 2001.

21. McSweeney B. Hofstede's Model Of National Cultural Differences And Their Consequences: A Triumph Of Faith - A Failure Of Analysis. Human Relations. 2002;55(1):89-118.

22. Segouin C, Hodges B. Educating doctors in France and Canada: are the differences based on evidence or history? Medical Education. 2005;39(12):1205-12. 
23. Kotter JP. Leading Change. Boston: Harvard Business School Press 1995.

24. Neufeld V KS, Bramble L, Simpson J. Leadership for Change in the Education of Health Professionals. Maastricht: Network Publications 1995.

25. Bland CJ, Starnaman S, Wersal L, Moorehead-Rosenberg L, Zonia S, Henry R. Curricular change in medical schools: how to succeed. Academic Medicine. 2000;75(6):575-94. 
NATIONAL CULTURE'S IMPACT ON CURRICULUM INTEGRATION IN EUROPE $\mid \mathbf{4 1}$ 


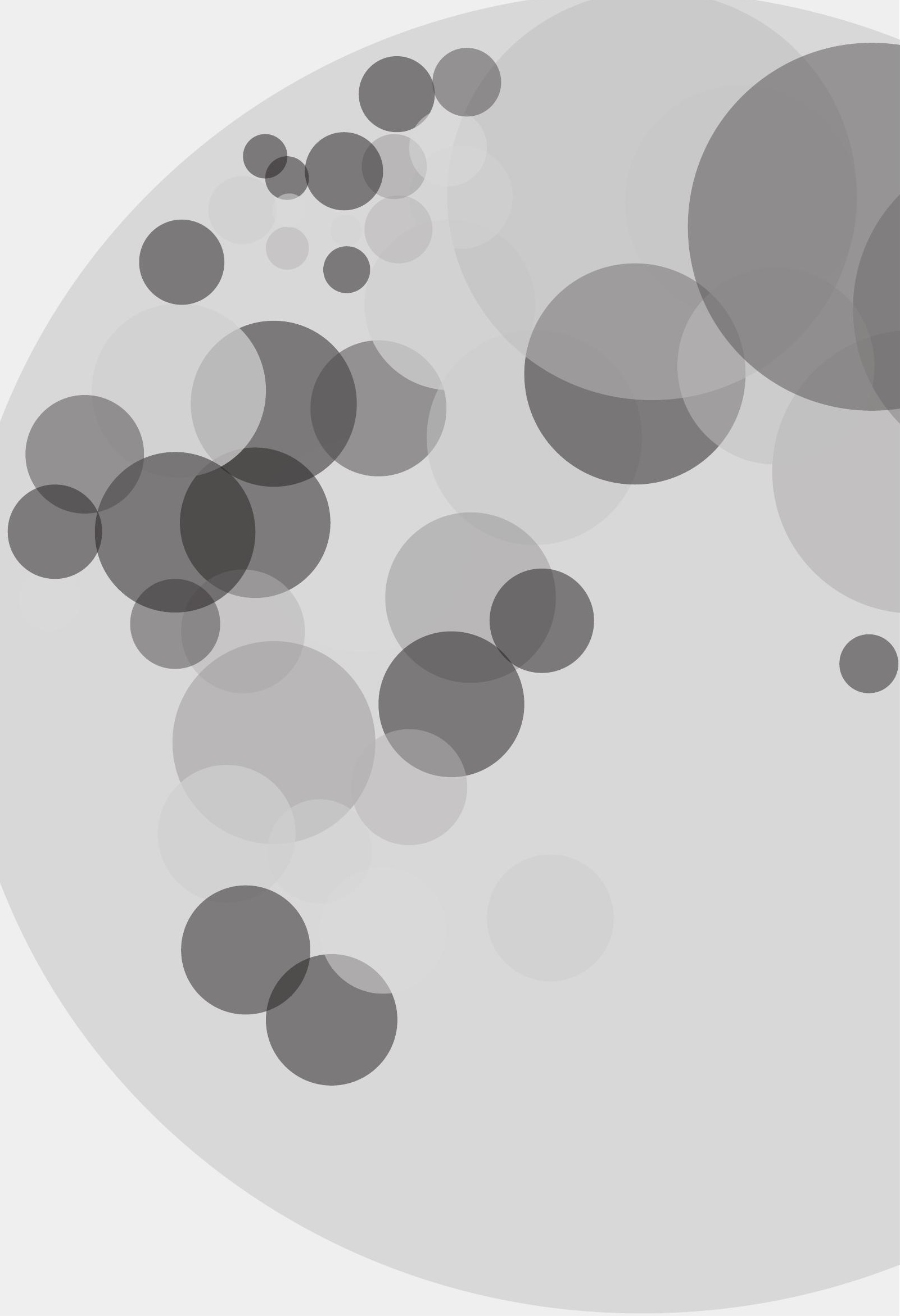




\section{CHAPTER 3}

INFLUENCE OF NATIONAL CULTURE ON THE ADOPTION OF INTEGRATED MEDICAL CURRICULA

Mariëlle Jippes \& Gerard D. Majoor Published in Advances in Health Sciences Education Theory and Practise 2010;16(1):5-16 


\section{Abstract}

Context: Integrated curricula have been implemented in medical schools all over the world. However, among countries different relative numbers of schools with integrated curricula are found. This study aims to explore the possible correlation between the percentage of medical schools with integrated curricula in a country and that country's cultural characteristics.

Method: Curricula were defined as not integrated if in the first 2 years of the program at least two out of the three monodisciplinary courses Anatomy, Physiology and Biochemistry were identified. Culture was defined using Hofstede's dimensions Power distance, Uncertainty avoidance, Masculinity/Femininity, and Individualism/Collectivism. Consequently, this study had to be restricted to the 63 countries included in Hofstede's studies which harbored 1,195 medical schools. From each country we randomly sampled a maximum of 15 schools yielding 484 schools to be investigated.

Results: In total $91 \%$ (446) of the curricula were found. Correlation of percent integrated curricula and each dimension of culture was determined by calculating Spearman's Rho. A high score on the Power distance index and a high score on the Uncertainty avoidance index correlated with a low percent integrated curricula; a high score on the Individualism index correlated with a high percent integrated curricula. The percentage integrated curricula in a country did not correlate with its score on the Masculinity index.

Discussion: National culture is associated with the propensity of medical schools to adopt integrated medical curricula. Consequently, medical schools considering introduction of integrated and problem-based medical curricula should take into account dimensions of national culture which may hinder the innovation process.

Keywords: National culture, Curriculum innovation, Integrated curricula 


\section{Introduction}

Globalization has confronted higher education with cross-cultural issues. For instance, currently students from developing countries may enrol in higher education in industrialized countries. Apart from adapting their daily lives to another culture, these students also may have to adapt to a pedagogical approach which may be different from that encountered in their secondary school education ${ }^{1}$. One may also wonder whether new didactic approaches, like problem-based learning (PBL) developed in industrialized countries, can also be applied in different cultural settings ${ }^{2}$. The current interest of universities in developed countries to incept satellite institutions in developing countries has added cross-cultural management of education to the issues pertaining to cross-cultural teaching and learning ${ }^{3}$. In this study we aim to investigate the impact of national culture on the propensity of educational institutions to adopt educational innovations. We explored whether national culture is related with the relative number of medical schools in a country that adopted integrated medical curricula.

As of the middle of the previous century medical curricula based on monodisciplinary courses in basic and (pre-)clinical sciences have been challenged. Major disadvantages identified for this disciplinebased curriculum model were (1) exclusion of contacts of students with patients in the pre-clinical phase; (2) the haphazard sequence of presentation of basic sciences courses frustrating integration in a knowledge-base relevant for clinical contexts; and (3) departmental autonomy over the courses yielding programs to educate mini-scientists $^{4}$. In response, innovative curricula were constructed built from educational units focusing on organ systems or clinical problem areas like pain or blood loss. For such 'integrated curricula' both integration of basic sciences ('horizontal integration') and of basic sciences with clinical sciences ('vertical integration') was advocated5'. Integrated curricula have been implemented by a growing number of medical schools all over the world, including schools based in industrialized and in developing countries. However, differences exist between countries with respect to the relative number of medical schools that adopted integrated curricula. Focusing on Europe a preponderance of schools with problem-based learning (PBL) curricula was observed in the North of Europe and few successful implementations of such curricula in the European Mediterranean countries. An impact of national culture on the successful implementation of PBL and integrated curricula was sup- 
posed6,7. In our 2008 study we demonstrated for 17 European countries a correlation between the relative number of medical schools with integrated curricula and two out of four dimensions of culture as defined by Hofstede ${ }^{6,8}$. According to him, Power distance is 'the extent to which the less powerful members of institutions and organizations within a country expect and accept that power is distributed unequally'. A high score on the sliding scale of the Individualism/Collectivism index indicates Individualism and 'pertains to societies in which the ties between individuals are loose: everybody is expected to look after him/ herself and his/her immediate family'. A low score on the Individualism/Collectivism index indicates Collectivism and 'pertains to societies in which people from birth onwards are integrated into strong, cohesive in-groups, which throughout people's lifetime continue to protect them in exchange for unquestioning loyalty'. A high score on the sliding scale of the Masculinity/ Femininity index indicates Masculinity and 'pertains to societies in which social gender roles are clearly distinct (i.e. men are supposed to be assertive, tough, and focused on material success, whereas women are supposed to be more modest, tender, and concerned with the quality of life)'. A low score on the Masculinity/ Femininity index indicates Femininity and 'pertains to societies in which social gender roles overlap (i.e. both men and women are supposed to be modest, tender and concerned with the quality of life)'. Uncertainty avoidance is 'the extent to which the members of a culture feel threatened by uncertain or unknown situations. This feeling is, among others, expressed through nervous stress and in a need for predictability: a need for written and unwritten rules'. European countries scoring high on Hofstede's indexes for the dimensions 'Power distance' and/or 'Uncertainty avoidance' had relatively less medical schools with integrated curricula. No correlation was found with two other of Hofstede's dimensions of culture, i.e. 'Individualism/Collectivism' and 'Masculinity/Femininity'.

Based on a literature review in 2000 Bland et al. ${ }^{9}$ identified 13 factors contributing to successful curriculum change. Some of these factors were also emphasized in a book chapter published by Davis and White ${ }^{10}$. As indicated by the latter authors, studies like these may be biased towards North America and thus almost eliminate the possible impact of different national cultures. On the other hand, world-wide medical schools consider or attempt to introduce integrated and PBL curricula. Being aware of the potential impact of culture on the innova- 
tion process and trying to circumvent possible negative aspects may help to prevent frustration and waste of time and money. Therefore, this study aims to investigate at global scale whether a relation exists between the relative number of medical schools with integrated curricula in a country and that country's scores on Hofstede's indexes for four dimensions of culture. Based on our findings for Europe we hypothesized countries scoring high on Hofstede's indexes for the culture dimensions 'Power distance' and/or 'Uncertainty avoidance' to have relatively less medical schools with integrated medical curricula than countries scoring low on the indexes for these dimensions. No relation was presumed with the culture dimensions 'Individualism/Collectivism' and 'Masculinity/Femininity'.

\section{Methods}

To investigate the influence of national culture on the adoption of integrated medical curricula 'national culture' and 'integrated curricula' had to be defined and operationalised. A representative sample of medical schools from all over the world was needed that would allow for testing the above hypothesis.

\section{Definition of national culture}

In the 1970's Hofstede surveyed through questionnaires employees of IBM branches in 80 countries dispersed over the world to record their perception of organizational culture in the office. Criticism on Hofstede's derived construct of dimensions of culture includes the restricted population sample of IBM employees and his presumption that each country harbours one culture. Nevertheless, Hofstede's dimensions of culture are widely adopted and suited to perform our studies. Fourty individual countries were included in his initial studies ${ }^{11}$. Later another 10 countries and 3 clusters of countries were added: Arab World, seven countries; East-Africa, four countries; and West-Africa, three countries. Clusters of countries were created because countries therein did not meet Hofstede's inclusion criteria for individual countries ${ }^{8}$. From his data Hofstede extracted the four dimensions of culture quoted in the Introduction and a fifth one: Short/ Long term orientation. In principle for each country and each cluster of countries scores on semi-quantitative indexes for each dimension of culture were calculated. However, the dimension 'Short/long term orientation' could not be included in this study because only a limited number of countries were assessed 
on that dimension. Furthermore, Yugoslavia was deleted from Hofstede's selection of individual countries because the country does not exist anymore.

\section{Assessment of integrated and non-integrated curricula}

The first 2 years of the curricula of medical schools were assessed to differentiate between integrated and non-integrated curricula. The curriculum was scored as non-integrated if at least two of the common preclinical disciplines Anatomy, Physiology and Biochemistry were presented as individual courses ${ }^{12}$. If none or only one of these courses was found the curriculum was assumed to be integrated. Screening of curricula was performed independently by both authors. Disconcordant classifications of curricula (41 out of 461 cases) were re-examined and discussed to reach consensus.

\section{Sample of medical schools}

The design of this study dictated that only medical schools based in the 64 countries investigated by Hofstede (minus Yugoslavia) could be used to sample medical schools from. According to the World Directory of Medical Schools (WDMS) in 2003 these countries and clusters of countries harbored 1,184 medical schools ${ }^{13}$. In that directory Taiwan was not represented. For Taiwan 11 medical schools were sampled from the International Medical Education Directory (IMED) of the Foundation for Advancement of International Medical Education and Research (FAIMER) ${ }^{14}$, yielding a total number of 1,195 medical schools. If the number of medical schools in an individual country did not exceed 15 all schools were included. From 19 countries with more than 15 medical schools (range 16-148) 15 schools were sampled at random representing at least $10 \%$ of the total number of schools in that country. Four countries assigned by Hofstede to the cluster East- Africa (Ethiopia, Kenya, Tanzania and Zambia) contained eight medical schools which were all included. Seven countries included in the cluster 'Arab World' (Egypt, Iraq, Kuwait, Lebanon, Libya, Saudi-Arabia and the United Arab Emirates) harbored 40 medical schools from which a stratified random sample of 15 was drawn. The same procedure was applied to the 19 medical schools based in the three countries assigned to the cluster West-Africa (Ghana, Nigeria and Sierra Leone). These sampling procedures yielded a final sample of 484 medical schools based in 63 countries representing all continents. 


\section{Collection of information on curricula}

Websites of sampled medical schools were searched for specification of their curriculum of the first 2 years. Information on most European schools was collected from June-August 2006 and on all other schools from June-October 2008. If a school's website could not be found, or if the website did not yield adequate information that medical school was contacted by e-mail. In case the request by e-mail elicited no response a fax was sent, if necessary followed by a surface mail. If all attempts to establish contact failed colleagues in the same country as the unresponsive school were asked for help to retrieve information.

Websites and electronic files provided in languages not mastered by us were translated into English through the website 'www.translate. google.com'. The languages of Thailand and Indonesia were not supported by this site; for that purpose, respectively, 'www.thai2english. $\mathrm{com}^{\prime}$ and 'www.yyy.sederet.com/translate.php' were used. If translation programs did not yield adequate information bilingual colleagues were contacted to translate the essential information to English.

\section{Statistical analysis}

SPSS version 15 was used to calculate Spearman's Rho: correlation coefficients (CC) between the percent medical schools with an integrated curriculum in a country and that country's scores on the respective indexes of four of Hofstede's dimensions of culture. A correlation was considered significant if $\mathrm{P}<0.05$ (2-tailed).

\section{Results}

Satisfactory information on the first 2 years of the curriculum could be collected from 466 of the 484 medical schools included in the sample $(91 \%)$. The curricula of nine medical schools in Iran could not be directly accessed. However, two colleagues in Iran independently assured us that medical schools in their country all had similar, nonintegrated curricula.

In Venezuela information on only five out of the nine medical schools in that country was obtained and therefore this country was excluded from further analyses. Eventually a total of 461 medical curricula were included in the analysis. In 14 countries none of the medical schools examined had an integrated curriculum and in 6 countries all medical schools had integrated curricula. Overall 134 of the 461 medical curricula examined (29\%) were classified as integrated (Table 1). 


\begin{tabular}{|c|c|c|c|c|c|c|c|}
\hline \multirow[t]{2}{*}{ Country } & \multirow{2}{*}{$\begin{array}{l}\text { Num- } \\
\text { ber of } \\
\text { medical } \\
\text { schools }^{\text {a }}\end{array}$} & \multirow{2}{*}{$\begin{array}{l}\text { Schools } \\
\text { includ- } \\
\text { ed in } \\
\text { study }\end{array}$} & \multirow{2}{*}{$\begin{array}{c}\text { Schools } \\
\text { with in- } \\
\text { tegrated } \\
\text { curricula } \\
(\%)\end{array}$} & \multicolumn{4}{|c|}{ Dimensions of culture ${ }^{b}$} \\
\hline & & & & $\begin{array}{c}\text { PD } \\
\text { score }\end{array}$ & $\begin{array}{c}\text { IND } \\
\text { score }\end{array}$ & $\begin{array}{l}\text { MAS } \\
\text { score }\end{array}$ & $\begin{array}{c}\text { UA } \\
\text { score }\end{array}$ \\
\hline Arab World & 40 & $14^{c, d}$ & 29 & 80 & 38 & 52 & 68 \\
\hline Argentina & 14 & $13^{d}$ & 15 & 49 & 46 & 56 & 86 \\
\hline Australia & 11 & 11 & 100 & 36 & 90 & 61 & 51 \\
\hline Austria & 3 & 3 & 100 & 11 & 55 & 79 & 70 \\
\hline Belgium & 11 & $10^{e}$ & 10 & 65 & 75 & 54 & 94 \\
\hline Brazil & 82 & $12^{c, d}$ & 17 & 69 & 38 & 49 & 76 \\
\hline Canada & 16 & $15^{c}$ & 73 & 39 & 80 & 52 & 48 \\
\hline Chile & 7 & 7 & 43 & 63 & 23 & 28 & 86 \\
\hline Colombia & 28 & $12^{c, d}$ & 33 & 67 & 13 & 64 & 80 \\
\hline Costa Rica & 5 & 5 & 0 & 35 & 15 & 21 & 86 \\
\hline Denmark & 3 & 3 & 33 & 18 & 74 & 16 & 23 \\
\hline East Africa & 8 & 8 & 13 & 64 & 27 & 41 & 52 \\
\hline Ecuador & 10 & $9^{d}$ & 11 & 78 & 8 & 63 & 67 \\
\hline El Salvador & 6 & 6 & 0 & 66 & 19 & 40 & 94 \\
\hline Finland & 5 & 5 & 60 & 33 & 63 & 26 & 59 \\
\hline France & 45 & $15^{c}$ & 0 & 68 & 71 & 43 & 86 \\
\hline Germany & 39 & $15^{c}$ & 33 & 35 & 67 & 66 & 65 \\
\hline Greece & 7 & 7 & 0 & 60 & 35 & 57 & 112 \\
\hline Guatemala & 2 & 2 & 0 & 95 & 6 & 37 & 101 \\
\hline Hong Kong & 2 & 2 & 100 & 68 & 25 & 57 & 29 \\
\hline India & 146 & $15^{c}$ & 0 & 77 & 48 & 56 & 40 \\
\hline Indonesia & 32 & $14^{c, d}$ & 21 & 78 & 14 & 46 & 48 \\
\hline Iran & 46 & $15^{c}$ & 0 & 58 & 41 & 43 & 59 \\
\hline Ireland & 5 & 5 & 40 & 28 & 70 & 68 & 35 \\
\hline Israel & 4 & 4 & 0 & 13 & 54 & 47 & 81 \\
\hline Italy & 31 & $15^{\mathrm{c}}$ & 0 & 50 & 76 & 70 & 75 \\
\hline Jamaica & 1 & 1 & 100 & 45 & 39 & 68 & 13 \\
\hline Japan & 80 & $15^{c}$ & 13 & 54 & 46 & 95 & 92 \\
\hline Malaysia & 8 & $7^{d}$ & 86 & 104 & 26 & 50 & 36 \\
\hline Mexico & 56 & $15^{c}$ & 20 & 81 & 30 & 69 & 82 \\
\hline New Zealand & 2 & 2 & 100 & 22 & 79 & 58 & 49 \\
\hline Norway & 4 & 4 & 50 & 31 & 69 & 8 & 50 \\
\hline Pakistan & 25 & $14^{\mathrm{c}, \mathrm{d}}$ & 14 & 55 & 14 & 50 & 70 \\
\hline
\end{tabular}




\begin{tabular}{|c|c|c|c|c|c|c|c|}
\hline \multirow[t]{2}{*}{ Country } & \multirow{2}{*}{$\begin{array}{l}\text { Num- } \\
\text { ber of } \\
\text { medical } \\
\text { schools }^{\text {a }}\end{array}$} & \multirow{2}{*}{$\begin{array}{l}\text { Schools } \\
\text { includ- } \\
\text { ed in } \\
\text { study }\end{array}$} & \multirow{2}{*}{$\begin{array}{c}\text { Schools } \\
\text { with in- } \\
\text { tegrated } \\
\text { curricula } \\
(\%)\end{array}$} & \multicolumn{4}{|c|}{ Dimensions of culture } \\
\hline & & & & $\begin{array}{c}\text { PD } \\
\text { score }\end{array}$ & $\begin{array}{l}\text { IND } \\
\text { score }\end{array}$ & $\begin{array}{l}\text { MAS } \\
\text { score }\end{array}$ & $\begin{array}{c}\text { UA } \\
\text { score }\end{array}$ \\
\hline Panama & 3 & 3 & 0 & 95 & 11 & 44 & 86 \\
\hline Peru & 17 & $13^{\mathrm{c}, \mathrm{d}}$ & 8 & 64 & 16 & 42 & 87 \\
\hline Philippines & 30 & $11^{\mathrm{c}, \mathrm{d}}$ & 9 & 94 & 32 & 64 & 44 \\
\hline Portugal & 5 & $4^{d}$ & 0 & 63 & 27 & 31 & 104 \\
\hline Singapore & 1 & 1 & 100 & 74 & 20 & 48 & 8 \\
\hline South Africa & 8 & 8 & 75 & 49 & 65 & 63 & 49 \\
\hline South Korea & 49 & $13^{c, d}$ & 8 & 60 & 18 & 39 & 85 \\
\hline Spain & 26 & $15^{c}$ & 0 & 57 & 51 & 42 & 86 \\
\hline Sweden & 6 & 6 & 67 & 31 & 71 & 5 & 29 \\
\hline Switzerland & 5 & 5 & 60 & 34 & 68 & 70 & 58 \\
\hline Taiwan & 11 & $9^{d}$ & 11 & 58 & 17 & 45 & 69 \\
\hline Thailand & 12 & $10^{d}$ & 40 & 64 & 20 & 34 & 64 \\
\hline $\begin{array}{l}\text { The Nether- } \\
\text { lands }\end{array}$ & 8 & 8 & 88 & 38 & 80 & 14 & 53 \\
\hline Turkey & 33 & $14^{c, d}$ & 50 & 66 & 37 & 45 & 85 \\
\hline United States & 141 & $15^{c}$ & 53 & 40 & 91 & 62 & 46 \\
\hline $\begin{array}{l}\text { United King- } \\
\text { dom }\end{array}$ & 27 & $15^{c}$ & 87 & 35 & 89 & 66 & 35 \\
\hline Uruguay & 1 & 1 & 0 & 61 & 36 & 38 & 100 \\
\hline Venezuela & 9 & $0^{f}$ & & & & & \\
\hline West Africa & 19 & $10^{\mathrm{c}, \mathrm{d}}$ & 0 & 77 & 20 & 46 & 54 \\
\hline Total & 1,195 & 461 & $134(29)$ & & & & \\
\hline
\end{tabular}

Table 1 Percent integrated medical curricula in 49 countries and 3 clusters of countries and their scores on Hofstede's indexes for 4 dimensions of culture. PD = power distance, IND individualism, MAS masculinity, UA uncertainty avoidance

a According to the World Directory of Medical Schools ${ }^{13,15}$

b Dimensions and scores according to Hofstede8

c Random stratified sample of 15

d No data were available for 1 or more universities in this country

e $\quad$ Except 1 university which did not offer pre-clinical training

$f \quad$ Excluded because only 5 curricula could be found

Scatter plots for the variables 'percent integrated curricula in a country' and that country's score on the index for each of the four dimensions of culture are shown in Figure 1. Significant negative correlations were found between percent integrated curricula and a country's score 
on the Power distance index $(\mathrm{CC}=-0.352, \mathrm{P}=0.01)$ and the Uncertainty avoidance index ( $\mathrm{CC}=-0.658, \mathrm{P}=0.00)$, and a significant positive correlation with the score on the Individualism index $(C C=0.387, P=0.01)$. No significant correlation was found between the percentage of integrated curricula in a country and that country's score on the Masculinity index.

\section{Discussion}

A significant correlation was found between the relative number of integrated medical curricula in a country and that country's scores on indexes for three dimensions of culture as defined by Hofstede ${ }^{8}$. In accord with our hypothesis, respectively, a high score on Power distance and a high score on Uncertainty avoidance correlated with a low percentage of integrated curricula in a country. At variance with our working hypothesis a high score of a country on the Individualism index was also found to correlate significant with a high percentage integrated curricula.

In our study focusing on Europe, explanations for the correlation of strong Power distance and strong Uncertainty avoidance with a low percentage integrated curricula were presented. In brief, we reasoned that implementation of an integrated curriculum requires a shift from departmental control over courses to curriculum control by multidisciplinary committees ${ }^{16}$. In schools in countries with strong Power distance professors may independently design the courses in their respective disciplines. By contrast, integration of the curriculum requires discussions with staff from different departments in interdisciplinary settings. Strong Power distance may impede heads of department to effectively participate in such negotiations. Curriculum change in a school in a country with strong Uncertainty avoidance may be difficult due to adherence of staff to existing national laws and university rules. "Fear of the unknown" may hamper curriculum innovation in those countries. Moreover, in some studies a significant correlation has been observed between the cultural dimensions Power distance and Uncertainty avoidance ${ }^{6,17}$.

With respect to Individualism it has been demonstrated that managers in individualistic societies prefer undertaking innovations outside organizational norms, rules and procedures ("renegade championing" ${ }^{\prime 18}$. This may explain the correlation between a high score on the Individualism index and a high percentage of schools with inte- 
grated curricula. Conversely, in a society with strong emphasis on Collectivism, harmony and mutual respect are very important. To change from a departmentally controlled curriculum towards an integrated curriculum negotiations among colleagues from different departments are necessary, which could elicit conflict and therefore may rather be avoided.

Another possible explanation for the correlation between Collectivism and low percentage of integrated curricula may derive from the relation between the Individualism/ Collectivism dimension and gross domestic product (GDP). Strong Collectivism in a society has been shown to correlate with a low national GDP ${ }^{8}$. Obviously innovation of medical curricula (including transformation from non-integrated to integrated curricula) may be obstructed by lack of financial resources. For the countries examined in this study a low percentage of integrated curricula correlated with a low GDP (CC $=0.491, \mathrm{P}=0.000)$ (twotailed).

No correlation was found between the percentage of integrated curricula in a country and its score on the Masculinity index. Departing from the theoretical readiness of students to accept PBL, countries scoring low on Masculinity (and low on Uncertainty avoidance) were reasoned as more likely to adopt integrated curricula than countries scoring high on Masculinity (and high on Uncertainty avoidance) ${ }^{7}$.

However, several limitations of this study must be taken into account when estimating the reliability and validity of the outcomes. First, the definition of culture chosen may have negatively affected the validity of this study. Criticism on Hofstede's dimensions of culture includes doubts about the validity of his concept of 'national culture'. For instance, Baskerville ${ }^{19}$ noted that one nation may harbor several cultures, as demonstrated for instance in the Middle East where - according to the Encyclopedia of World Cultures - 14 nations harbor 35 different cultures ${ }^{20}$. Although analytical descriptions of culture different from Hofstede's are available, none of these assigned 'quantitative' scores on 'cultural dimensions' to individual countries or regions (see for instance Schwartz and Bilsky ${ }^{21}$; Smith and Charles 22 ; Trompenaars and Woolliams ${ }^{23}$ ). Hence these descriptions of culture are not suited for a study as presented here.

Second, the inclusion criteria applied to define the world-wide sample of medical schools may have affected the reliability of the re- 
sults. The World Directory of Medical Schools of 2000 was used to identify medical schools in Europe ${ }^{15}$. To list all schools beyond Europe the 2003 update of WDMS was used because 29 non-European schools were added compared to the 2000 edition $^{13}$. The 2003 WDMS was used rather than a more recent update to ascertain that curricula had been in place for at least 5 years.

Third, overall from $9 \%$ of the schools in the sample no information could be obtained. There may be a bias in those non-responsive schools in terms of these being more conservative (e.g., because they do not feature a website) and having non-integrated curricula.
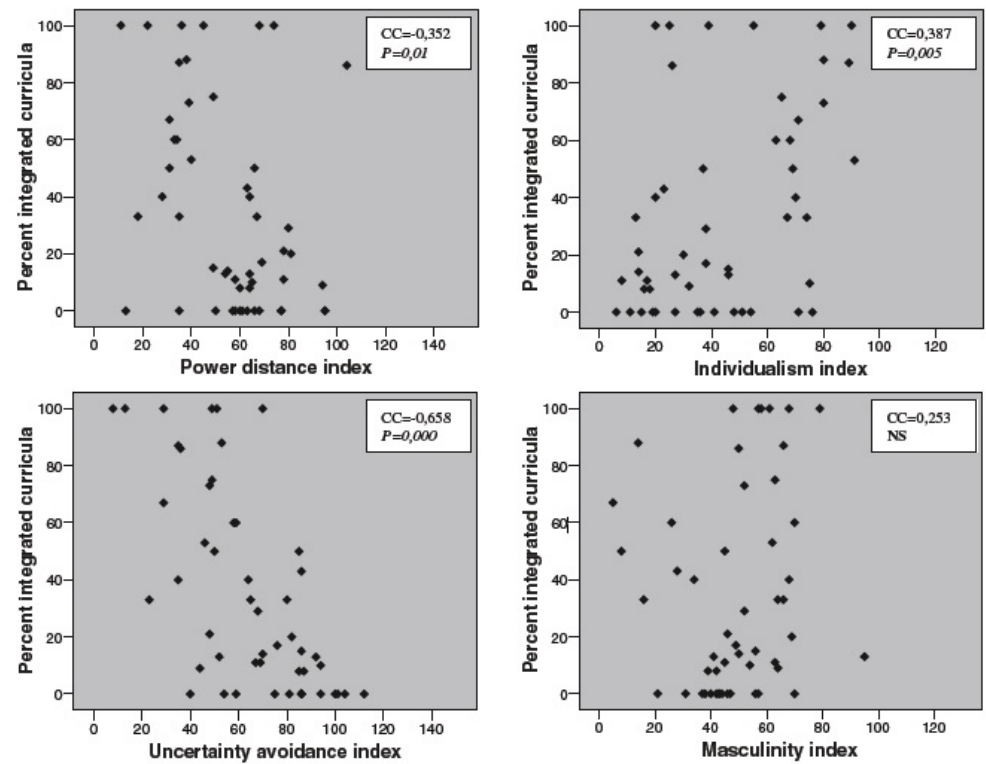

Figure 1: Scatterplots of scores of 49 countries and 3 clusters of countries on indexes for each of 4 dimensions of culture 8 and percent integrated medical curricula. CC $=$ correlation coefficient, NS = not significant.

Fourth, another restriction with respect to the validity of the outcomes pertains to the discrimination of integrated and non-integrated curricula. Although the criterion of presence of two out of three basic sciences courses (i.e., Anatomy, Biochemistry and Physiology) is unambiguous, new names for "old" courses incidentally forced us to judge whether for instance 'functional morphology' was similar toanatomy and 'molecular chemistry' to biochemistry. In some medical curricula of schools in Latin America we found 'morphophysiology' courses occupying a prominent part of the program for the first 2 years including con- 
tent matter from the three basic sciences specified above. Colleagues in Latin America assured us that such 'morphophysiology' courses are taught in the context of organ systems, and therefore should be considered integrated. In Indonesia, Japan, South Korea, as well as in the U.S. we encountered one school with a curriculum which was not integrated in the first and/or second year but clearly integrated in subsequent years. Such curricula may be referred to as 'hybrid curricula'24, ${ }^{25}$. In accord with our criterion these curricula were scored as non-integrated. We verified that changing the classification of these four curricula to 'integrated' did not change the conclusions from this study.

Fifth, another dilemma faced with respect to discriminating integrated and non-integrated curricula regarded schools in the U.S. and Canada, which are usually preceded by bachelor programs. For two reasons we decided to base our curriculum assessment on the first 2 years of the medical schools and to ignore the pre-medical bachelor programs. First, because we intended to assess curricula of medical schools and pre-medical bachelor programs may be offered by different schools. Second, even in medical schools which pioneered with implementation of integrated PBL curricula-like McMaster University in Canada and the University of New Mexico in the U.S.-pre-medical bachelor programs were found to be non-integrated.

To various extent reports in the literature supported our classification of integrated and non-integrated curricula. For the U.S. 70\% of the medical schools were mentioned to have PBL (and thus integrated) curricula ${ }^{26}$; we scored $53 \%$ of the $10.6 \%$ of all U.S. schools in our sample as having integrated curricula. Reports on the individual curricula of Ziauddin Medical University in Pakistan ${ }^{27}$, University of Transkei in South Africa ${ }^{28}$, University of Hong Kong ${ }^{24}$, National University of Singapore ${ }^{29}$, and Rosario University in Argentina ${ }^{30}$ confirmed our independent classification of their curricula as integrated. Three reports described isolated PBL courses offered by different medical schools in India ${ }^{31-33}$. This finding is not incompatible with our conclusion drawn from the sample of $10.3 \%$ of all medical schools in India that all had non-integrated curricula. The same holds for the National Yang-Ming University in Taiwan whose curriculum was assessed as non-integrated whereas some courses were reported to be taught in PBL format ${ }^{34}$. Furthermore, we classified the curriculum of the University of Malaya in Malaysia as non-integrated although from that school an article was published on the process of implementing an integrated cur- 
riculum ${ }^{35}$. Perhaps that school's curriculum changed after our assessment.

Although this study has some limitations it demonstrates that national culture is associated with the propensity of medical schools to adopt integrated curricula. If a medical school is situated in a country with high scores on the indexes for Power distance and/or Uncertainty avoidance and/or a low score on the index for Individualism and considers adoption of an integrated or PBL curriculum, that school should take into account the potential hindering effects of these national cultural factors. To mitigate cultural barriers to curriculum innovation, resources are available providing advice with respect to strategies for change of an organization, both in general ${ }^{36,37}$ and specifically for medical and health professions schools ${ }^{38}$.

We intend to expand our studies in two directions. Firstly, we aim to investigate whether scores on indexes for the three cultural dimensions counteracting curriculum change act independently or synergistically. Secondly, we intend to explore why in some countries with cultural characteristics counteracting curriculum change surprisingly many schools succeeded to implement integrated curricula. Studying the curriculum change processes performed in these 'outliers' may reveal factors which possibly can help to overcome adverse cultural conditions. 


\section{References}

1. Charlesworth ZM. Learning styles across cultures: suggestions for educators. Education Training. 2008;50:115-27.

2. Gwee MC. Globalization of problem-based learning (PBL): cross-cultural implications. Kaohsiung Journal of Medical Sciences. 2008;24(3 Suppl):S14-22.

3. Eldridge K, Cranston N. Managing transnational education: does national culture really matter? Journal of Higher Education Policy and Management. 2009;31(1):67-79.

4. Papa FJ, Harasym PH. Medical curriculum reform in North America, 1765 to the present: a cognitive science perspective. Academic Medicine. 1999;74(2):15464.

5. Harden RM, Sowden S, Dunn WR. Educational strategies in curriculum development: the SPICES model. Medical Education. 1984;18(4):284-97.

6. Jippes M, Majoor GD. Influence of national culture on the adoption of integrated and problem-based curricula in Europe. Medical Education. 2008;42(3):27985.

7. Stevens FCJ. Innovations in medical education. In: Brosnan C, Turner B, editors. Handbook of the sociology of medical education New York, NY: Routledge; 2009. p. 278-95.

8. Hofstede G. Culture's Consequences. Comparing Values, Behaviors, Institutions, and Organizations across Nations. New York: Sage Publications 2001.

9. Bland CJ, Starnaman S, Wersal L, Moorehead-Rosenberg L, Zonia S, Henry R. Curricular change in medical schools: how to succeed. Academic Medicine. 2000;75(6):575-94.

10. Davis WK, \& White, C. B. Managing the curriculum and managing change. In: Norman GR, van der Vleuten CPM, Newble DI, editors. International handbook of research in medical education. Dordrecht: Kluwer; 2002. p. 917-45.

11. Hofstede G. Culture's consequences: International Differences in Work-related values. London: Sage Publications 1980.

12. Aziz. International Handbook of Medical Education. Westport CT: Greenwood Press 1994.

13. WHO. World directory of medical schools: Base year 2000. Updates through 30 june 20032003 [cited 2008 July 21 ]; Available from: http://www.who.int/hrh/ documents/en/wdms_update.pdf.

14. FAIMER. International Medical Education Directory IMED [database on the Internet]2008 [cited 2008 Oct 10]. Available from: https://imed.faimer.org/.

15. WHO. World Directory of Medical Schools. 7th ed. Geneva: World Health Organisation 2000.

16. Majoor GD, Kolle LFJTM. Faculty planning and control in problem-based learning. Education for Health. 1997;10(2):189-98.

17. Hofstede G. Culture's and Organisations: Software of The Mind. London: McGraw-Hill 1991.

18. Shane S, Venkataraman S. Renegade and rational championing strategies. Organization Studies. 1996;17(5):751.

19. Baskerville RF. Hofstede never studied culture. Accounting, Organizations and Society. 2003;28(1):1-14.

20. O'Leary TJ, Levinson D. Encyclopedia of World cultures: GK Hall \& Company 1991.

21. Schwartz SH, Bilsky W. Toward A Universal Psychological Structure of Human Values. Journal of Personality and Social Psychology. 1987;53(3):550-62.

22. Smith PB, Charles S. Values and Culture. Encyclopedia of Applied Psychology. New York: Elsevier; 2004. p. 633-40.

23. Trompenaars F, Woolliams P. Business across cultures. West Sussex: Capstone publishing 2005. 
24. Nandi PL, Chan JN, Chan CP, Chan P, Chan LP. Undergraduate medical education: comparison of problem-based learning and conventional teaching. Hong Kong Medical Journal. 2000;6(3):301-6.

25. Jaffarey NA. Problem based learning. Journal of Pakistan Medical Association. 2001;51(8):266-7.

26. Kinkade SMDM. A Snapshot of the Status of Problem-Based Learning in U. S. Medical Schools, 2003-04. Academic Medicine. 2005;80(3):300-1.

27. Huda N, Brula AQ. An introductory course on study skills forming a bridge between traditional and problem based learning (PBL). Journal of Pakistan Medical Association. 1999;49(2):27-30.

28. Iputo JE. Impact of the problem-based learning curriculum on the learning styles and strategies of medical students at the University of Transkei. South African Medical Journal. 1999;89(5):550-4.

29. Khoo HE, Chhem RK, Gwee MC, Balasubramaniam P. Introduction of problembased learning in a traditional medical curriculum in Singapore - students' and tutors' perspectives. Annals of Academic Medicine Singapore. 2001;30(4):3714.

30. Carrera LI, Tellez TE, D'Ottavio AE. Implementing a problem-based learning curriculum in an Argentinean medical school: implications for developing countries. Academic Medicine. 2003;78(8):798-801.

31. Vyas R, Jacob M, Faith M, Isaac B, Rabi S, Sathishkumar S, et al. An effective integrated learning programme in the first year of the medical course. National Medical Journal of India. 2008;21(1):21-6.

32. Chandra D, Sharma S, Sethi G, Dkhar S. Pharmacotherapeutic education through problem based learning and its impact on cognitive and motivational attitude of Indian students. European Journal of Clinical Pharmacology. 1996;51(1):1-5.

33. Ghosh S, Pandya H. Implementation of Integrated Learning Program in neurosciences during first year of traditional medical course: Perception of students and faculty. BMC medical education. 2008;8(1):44.

34. Yu HY, Wu ZA, Su MS, Yen DJ, Luk HR, Chao YC, et al. Problem-based, smallgroup tutorial learning in clinical neurology for second-year medical students. Zhonghua Yi Xue Za Zhi (Taipei). 2000;63(8):598-604.

35. Azila NM, Sim SM, Atiya AS. Encouraging learning how to fish: an uphill but worthwhile battle. Annals Academy of Medicine Singapore. 2001;30(4):375-8.

36. Kotter JP. Leading Change. Boston: Harvard Business School Press 1995.

37. William B. Managing transitions: Making the most of change. New York, NY: Basic books 2003.

38. Neufeld V KS, Bramble L, Simpson J. Leadership for Change in the Education of Health Professionals. Maastricht: Network Publications 1995. 
INFLUENCE OF NATIONAL CULTURE ON THE ADOPTION OF INTEGRATED MEDICAL CURRICULA $\mathbf{5 9}$ 


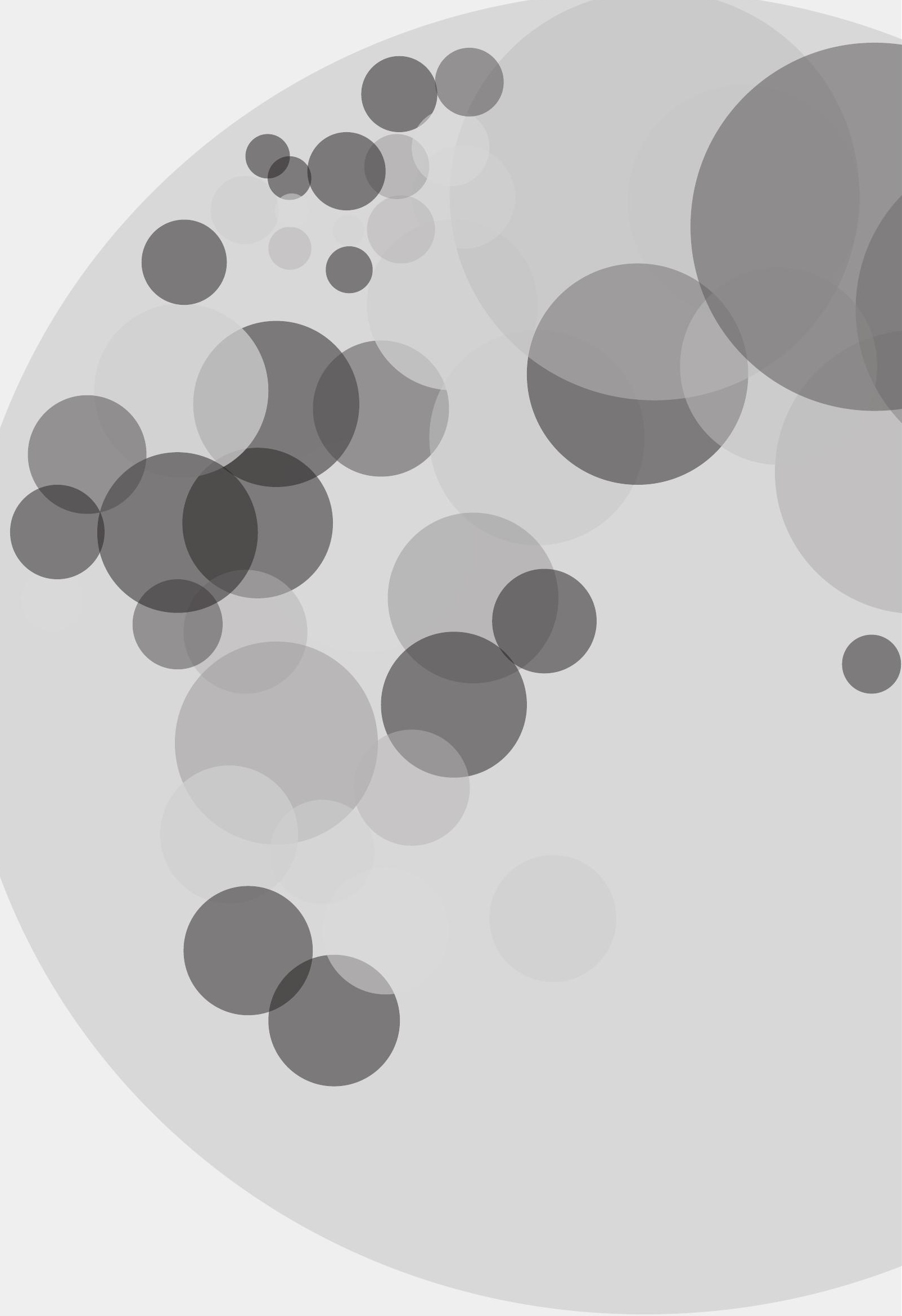




\section{CHAPTER 4}

\section{IMPACT OF NATIONAL CONTEXT AND CULTURE ON CURRICULUM}

CHANGE: A CASE STUDY

Mariëlle Jippes, Erik W. Driessen, Gerard D. Majoor, Wim H. Gijselaers, Arno M.M. Muijtjens, and Cees P.M. van der Vleuten Accepted for publication Medical Teacher 


\section{Abstract}

Purpose: Earlier studies suggested national culture to be a potential barrier to curriculum reform in medical schools. In particular, Hofstede's cultural dimension 'uncertainty avoidance' had a significant negative relationship with the implementation rate of integrated curricula. However, some schools succeeded to adopt curriculum changes despite their country's strong uncertainty avoidance. This raised the question: 'How did those schools overcome the barrier of uncertainty avoidance?' Method: Austria offered the combination of a high uncertainty avoidance score and integrated curricula in all its medical schools. Twentyseven key change agents in four medical universities were interviewed and transcripts analysed using thematic cross-case analysis.

Results: Initially, strict national laws and limited autonomy of schools inhibited innovation and fostered an 'excuse culture': 'It's not our fault. It is the ministry's'. A new law increasing university autonomy stimulated reforms. However, just this law would have been insufficient as many faculty still sought to avoid change. A strong need for change, supportive and continuous leadership, and visionary change agents were also deemed essential.

Conclusions: In societies with strong uncertainty avoidance strict legislation may enforce resistance to curriculum change. In those countries opposition by faculty can be overcome if national legislation encourages change, provided additional internal factors support the change process.

Keywords: National culture; education; curriculum innovation; curriculum integration; organizational innovation; systems integration 


\section{Introduction}

The added value of an integrated medical curriculum compared with a traditional, discipline-based curriculum is widely recognised ${ }^{1-4}$. Integration between basic sciences (horizontal integration) and/or between basic and clinical sciences (vertical integration) favours for instance the recall of information ${ }^{5,6}$. Nevertheless, worldwide only approximately $30 \%$ of all medical schools adopted an integrated curriculum ${ }^{7}$. The same study also showed that medical schools with an integrated curriculum were spread unevenly across countries. This may be due to the change process of a curriculum being affected by cultural characteristics of the country in question. A high score on Hofstede's 'uncertainty avoidance index' in particular appeared to be significantly correlated with a relatively low number of medical schools with an integrated curriculum $^{7-9}$. Hofstede ${ }^{9}$ ranked the uncertainty avoidance scores of 76 countries on an index ranging from 8-112 derived of 117,000 surveys from a databank of IBM employees. According to Hofstede ${ }^{9}$, uncertainty avoidance indicates "to what extent a culture programmes its members to feel either comfortable or uncomfortable in unstructured situations". "Uncertainty avoiding societies try to minimise the occurrence of such situations by strict laws and regulations, safety and security measures and on the philosophical and religious level by a belief in absolute truth" ${ }^{\prime \prime}$. Medical schools in uncertainty avoiding countries may have little room to change their curricula due to strict laws and rules and faculty in these medical schools probably avoid changes as much as possible to prevent uncertain situations ${ }^{7}$.

Although factors influencing curriculum change in medical schools have received considerable attention in the literature ${ }^{10-12}$, little is known about the impact of cultural factors ${ }^{13,14}$. It appears to be increasingly recognised, however, that it is important to consider local context when educational models are being adopted across national borders ${ }^{15}$. Because introducing an integrated curriculum is a complex process involving radical organisational change, simply changing the regulations and procedures in a school will not suffice, and careful consideration of the cultural aspects may be a key factor to the success of a change operation ${ }^{16-19}$. Although the impact of national culture characteristics on the success of innovation has been demonstrated in different organisations, we are not aware of any studies addressing this phenomenon in medical schools ${ }^{20,21}$. Since more insight into factors inhibiting successful curriculum innovation may prevent costly failures 
of ambitious change projects, we set out to explore the role of national cultural characteristics in the innovation of medical curricula.

As the object of study we selected a country presenting the intriguing situation of a high score on Hofstede's uncertainty avoidance index combined with nationwide adoption of integrated medical curricula. This case was deemed to offer a fine opportunity for exploring mechanisms underlying curricular change in a country where the culture may not be particularly conducive to change. We looked for (cultural) factors that could explain how medical schools managed the transition from discipline-based to integrated curricula. We explored this question by interviewing faculty members who had been actively involved in the curriculum change process ('key change agents') and by analysing relevant documents from various sources.

\section{Methods}

\section{Setting and sampling}

The selected case was Austria, where all four medical schools recently implemented integrated curricula in spite of Austria's relatively high score of uncertainty avoidance of 70 on Hofstede's index (range 8-112) (Figure 1$)^{7}$. Key change agents from the medical schools of Innsbruck, Salzburg, Graz and Vienna were identified by 'snowball sampling': existing study subjects were asked for possible future subjects ${ }^{22}$. After completion of the interviews the newly founded private university of Salzburg was excluded, because it had not experienced change from a traditional to an integrated curriculum as it started a vertically integrated curriculum from scratch. In order to collect more contextual information also four experts on Austrian history, society and culture were interviewed.

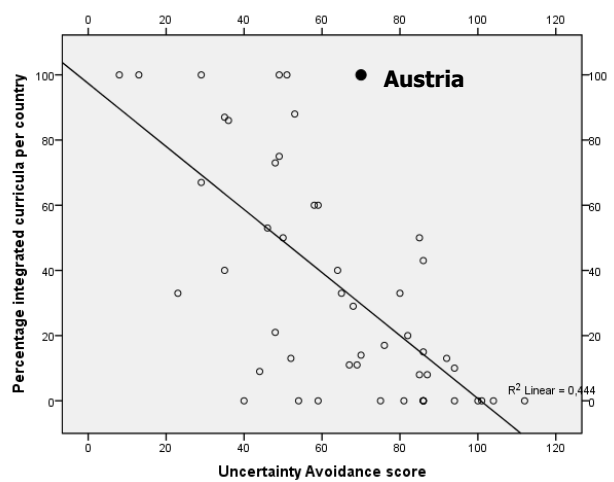

Figure 1: Position of Austria as a country with a high uncertainty avoidance score of 70 where all medical schools have an integrated curriculum (100\%). Data derived from Jippes and Majoor ${ }^{7}$. 


\section{Data collection}

The first author (MJ) was responsible for data collection and analysis. In the four Austrian medical schools 27 individual interviews with key change agents were conducted in March 2011 (Table 1). The semistructured interviews lasted one to two hours and were conducted in English, which all respondents spoke fluently. Although the sample appeared to be larger than necessary to reach saturation, its size enabled detection of consistent patterns across the universities and bolstered confidence in our understanding of the Austrian curriculum change process. Interview questions addressed factors influencing curriculum change as described by Bland ${ }^{10}$ and possibly underexplored factors as described by Kanter ${ }^{23}$, including 'need for change', 'history of change' and 'barriers to implementation' (Appendix A). The interviews started with 'critical incidents': interviewees were asked to describe a negative and a positive critical incident during the change process in their school24. Documents on the curriculum change process, including reform proposals, articles and reports, were gathered from interviewees and the Internet.

\begin{tabular}{|c|c|c|c|c|c|c|}
\hline University & $\begin{array}{l}\text { Inns- } \\
\text { bruck }\end{array}$ & Graz & Vienna & Salzburg & $\begin{array}{l}\text { Oth- } \\
\text { er* }\end{array}$ & Total \\
\hline Clinicians & 1 & 4 & 0 & 2 & 0 & 7 \\
\hline Basic scientists & 5 & 2 & 2 & 0 & 0 & 9 \\
\hline Other & 1 & 3 & 2 & 2 & 4 & 12 \\
\hline $\begin{array}{l}\text { Percent former } \\
\text { members of cur- } \\
\text { riculum change } \\
\text { committee }\end{array}$ & $67 \%$ & $67 \%$ & $100 \%$ & $75 \%$ & $\begin{array}{l}\text { Not } \\
\text { appli- } \\
\text { cable }\end{array}$ & $77 \%$ \\
\hline Total & 6 & 9 & 4 & 4 & 4 & 27 \\
\hline
\end{tabular}

Table 1: Division of the 27 Austrian interviewees over the four Medical Universities, April 2011. *Other includes experts on Austrian history, society and culture.

\section{Analysis}

All interviews were audiotaped and transcribed verbatim. Transcripts were subjected to thematic analysis using Miles and Huberman's approach $^{25}$. Each interview was analysed line-by-line using open coding to explore factors influencing the change process with specific attention to cultural factors. After five interviews had been coded in Atlas-ti, similar or related first level codes were clustered into master codes. A codebook was drawn up containing cluster codes, sub-codes and code 
definitions, which was then used for coding of all transcripts. If deemed necessary, new codes were added and existing codes were extended or merged. In an iterative process the second author (ED) also coded three interviews. Divergent codings were discussed until consensus was reached. Eventually, all transcripts were reviewed again using the final codebook. Finally, cluster codes were combined in themes and a cross-case analysis was performed to compare themes within and between the three medical schools ${ }^{25}$. Background documents were analysed for elaboration of the outcomes of the interviews. Final conclusions were drawn after the full analysis was concluded. The request to all interviewees to comment on a summary of the results led to minor corrections.

\section{Ethical considerations}

All information collected has been treated confidential, research material had been coded and saved separately from the personal information of the participants and only the researchers had access to the data. After receiving an explanation of the aim and purpose of the study, voluntary participation and the confidentiality of the data, all interviewees gave written informed consent. Participants were handed Dutch syrup waffles as a small token of gratitude.

\section{Results}

The medical schools in Graz, Vienna and Innsbruck each changed their discipline-based curriculum into an integrated curriculum in 2002 (Table 2). Integrated curricula were chosen inspired by collaborations and field trips to other schools in Europe that were changing in a similar direction. Furthermore, interaction between staff members from the different Austrian medical schools - in particular Austrian medical education conferences ('Graz conference') - stimulated change in a comparable direction. In a curriculum change process several forces are at work, and success depends on driving forces gaining the upper hand over inhibiting forces (Figure 2). As the factors impacting on the reform showed strong similarities among the three schools, results apply to all schools and differences are only specified if relevant. The strongest stimulating forces in the change process were: 1 ) need for change; 2) political involvement; and 3) continuous supportive leadership. The strongest inhibiting forces were: 1) political involvement; 2) resistance from heads of departments; and 3) low priority for education and 
change (Figure 2). From 1997 political involvement changed from a restraining to a driving force, a process described under the heading 'political involvement'. Results are illustrated by quotations from the interviews and where opportune supported by information from documents. The results section ends with a short summary of the main outcomes of the change processes.

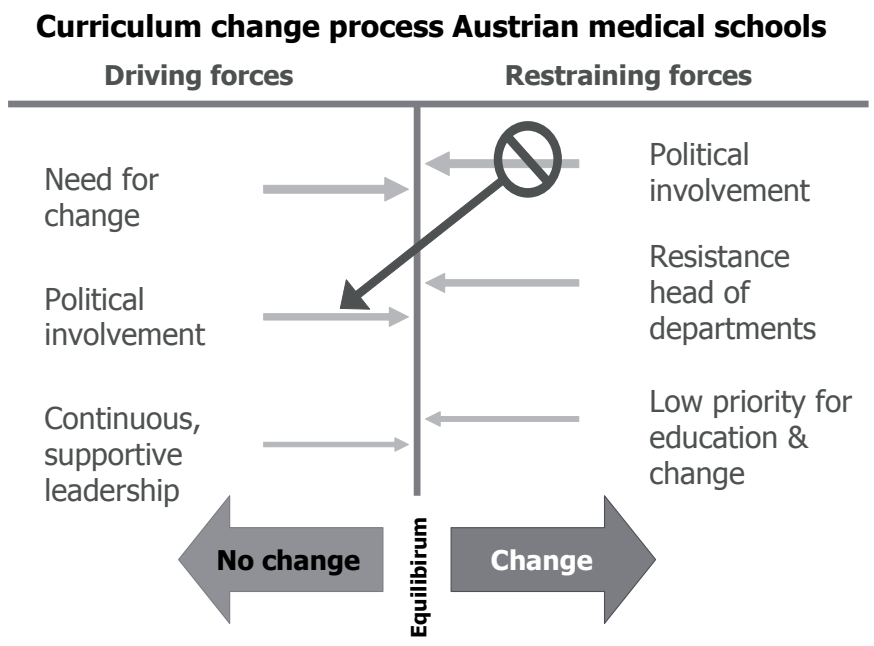

Figure 2: Promoting and inhibiting factors in the three public Medical Universities in Austria during the curriculum change process. Arrow thickness indicates the estimated degree of influence. From 1997 government involvement changed from a restraining to a driving force. Further explanation is described under heading 'political involvement'. Model adapted from Lewin ${ }^{26}$.

\section{Driving forces}

\section{Need for change}

In Austria by the end of the $20^{\text {th }}$ century, strong dissatisfaction with several aspects of medical education was widespread among stakeholders (teachers, students, patients, and postgraduate supervisors). Major concerns were 1 ) the long time to graduation (average time to graduation 16.4 semesters; nominal time 12 semesters (=six years) ${ }^{27}$, 2 ) the high percentage of drop-outs (on average $50 \%$ ) $^{28}$ and 3 ) low attendance at lectures, because students learned mostly from books and by attending oral exams of peers. Additional problems were: 4) overload of oral and subjective examinations, 5 ) overload of theoretical knowledge, 6) limited clinical exposure (preclinical courses required on average 11 instead of 7 semesters, and usually less than the required 5 semesters were spent on clinical courses) $)^{27,29}$ and 7) overcrowding by students ( $a$ total of over 2000 first year students in the three medi- 
cal schools) ${ }^{30,31}$. This situation generated growing dissatisfaction with medical graduates' clinical knowledge and social and clinical skills ${ }^{29,} 32$, 33.

'Basically the problem was that we had a lot of new things to do, we had to place more emphasis on the clinical part and reduce this hydrocephalus of the preclinics' (Graz-6).

\section{Background to the existing problems}

Until 2006, Austrian law forbade medical schools to limit admittance. This was due to the highly valued notion of 'Lernfreiheit', meaning: 'freedom to study for everyone regardless of background, grades or financial means' (Table 2). Medical schools responded to the challenge of having to admit increasing numbers of students by setting extremely difficult exams. Because students needed a long time to prepare for some of the exams, duration of studies increased. For instance, students commonly needed one whole year to complete only the anatomy or pathology courses and on average $25-50 \%$ of students had to re-sit these exams ${ }^{27}$.

'So we had the usual 600 entering. According to the study plan they were reduced to 270 after year one' (Innsbruck-1).

\begin{tabular}{|l|l|}
\hline Date & Event \\
\hline 1975 & $\begin{array}{l}\text { Law of } 1975: \text { open access to universities. Attempt for more democratic or- } \\
\text { ganisation of medical schools with educational committees representing full } \\
\text { and assistant professors and students. }\end{array}$ \\
\hline 1991 & $\begin{array}{l}\text { Failure of the 'Tuppy' project advocating integrated curricula and more clinical } \\
\text { exposure for students }\end{array}$ \\
\hline 1995 & $\begin{array}{l}\text { Preparation for curriculum change. Preparation differed between medical } \\
\text { schools and included meetings with external advisory boards, international } \\
\text { site visits and discussions within the medical schools. First Austrian confer- } \\
\text { ence on medical education (continued annually) }\end{array}$ \\
\hline 1997 & $\begin{array}{l}\text { Law of } 1997: \text { allowed medical schools to develop their own curricula provided } \\
\text { these were implemented before } 2002\end{array}$ \\
\hline 2002 & $\begin{array}{l}2001 \text { Vienna started with pilot group of students in an integrated curriculum. } \\
\text { 2002 Graz, Vienna and Innsbruck started with integrated curriculum. } \\
\text { Law of } 2002: \text { Medical faculties were to become autonomous medical universi- } \\
\text { ties as of 2004, which preparation started in } 2001\end{array}$ \\
\hline 2006 & $\begin{array}{l}\text { Entrance selection of students allowed. EU court decision in } 2005 \text { demanded } \\
\text { the subjection of all students to the same entrance rules which led to an ap- } \\
\text { plication flooding and unbearable situation }\end{array}$ \\
\hline $2006-$ & $\begin{array}{l}\text { Voluntary accreditation Vienna and Graz } \\
2008\end{array}$
\end{tabular}

Table 2: Time-ordered matrix: major events during the period 1975-2008 affecting Austrian Medical Universities. 


\section{Political involvement}

The previously described problems requiring change in medical education had persisted for a long time, and although more and more people realised that change was necessary, the urgency for change was apparently not strong or widespread enough to take action. Several factors may explain this phenomenon. Firstly, respondents explained that Austrians tend to avoid change as long as possible. Secondly, change initiatives were discouraged by the government, which strictly prescribed the curriculum. Indeed, in 1989 the government rejected a serious proposal for changing the medical curriculum, which advocated integrated courses, small group learning and more clinical exposure ${ }^{34}$. The dominant role of the government with regard to the medical curriculum induced an attitude of resignation and an 'excuse climate'35.

'Employees of the universities tended to refrain from taking responsibility: it was the government's fault that things were going the way they were' (Other-P).

However, serious concerns about the rising expenditure on university education induced the Austrian government to introduce several laws giving the universities more autonomy to promote efficiency (Laws of 1997 and 2002; (Table 2) 36, 37. The 1997 law allowed universities to design their own curricula within a certain time frame, and this was perceived by many respondents as an important driver of the change process (Figure 2).

'If this law had not been introduced, I suppose we wouldn't have had this process' (Innsbruck-3).

The 1997 law met with a mixed response: on the one hand, respondents appreciated being finally allowed to develop their own curricula, but on the other hand this opportunity aroused feelings of insecurity and fear. Furthermore many people, mistakenly, felt that change was imposed by law ${ }^{38}$. By way of illustration, the law applied to all faculties of the Austrian universities, such as liberal arts, but none of the other faculties undertook such major curricular reform. The other faculties made only minor adaptations. Even if change had been mandatory, it would not necessarily have meant uniform compliance with the law. Some respondents explained that deliberate evasion of rules is common practice in Austria. Strict regulation seems to go hand in hand with lenient practice.

The law alone would not have changed anything' (Vienna-1) 


\section{Continuous leadership}

Continuous support from university leaders (deans, vice-deans and heads of educational committees) proved to be a key factor in the change processes in Vienna and Graz. By contrast, respondents in Innsbruck reported that the main complication in their change process had been the frequent change of leadership ${ }^{39}$.

'During a period of three years leadership changed four times. This loss of consistent leadership led to a loss of vision and continuity' (Innsbruck-5).

Interestingly, faculty members with a strong vision of change were not primarily the deans, but rather motivated people from the 'Mittelbau', i.e. all faculty except the full professors. Initially the majority of the faculty did not participate in the change process, which might be interpreted as confirmation of the notion that Austrians generally are averse to change or had low priority for the change process (see also under the heading 'low priority for education and change'). The key change agents, who clearly embraced change, were looked upon as odd and, at least initially, were not taken seriously by the majority of the staff.

'Most of them did not think these rebellious idiots could be successful. They knew there were some people working on curriculum change but we were laughed at (Innsbruck-4)'.

\section{Decision-making and conflict avoidance}

According to the respondents, extensive curricular reform proved hard to achieve, due to the Austrian habit of avoiding conflict, reflecting the relative high national levels of uncertainty avoidance ${ }^{40,41}$. Difficult discussions were postponed for as long as possible and, if taking place, often resulted in compromises. Decisions in the medical schools were made by majority vote in the educational committee, which consisted of elected representatives of the full professors, assistant-professors and students (Table 2$)^{42}$. However, there appeared to be a difference between those with formal and informal power.

'...Under the cover of the formal authority of the government strong power groups in the medical faculty did what they wanted. The ministry had no resources to monitor or control processes there. The power did not rest with the formal bodies nor with the dean, but with the informal power structures. Most of the deans were from preclinical 
departments and to some extent they were formal and symbolic figures, and to some extent they balanced the different power groups at the university. But it was the professors in the clinical departments who were really in power, who had the resources and were in control' (Other-S).

After the enactment of the 2002 law the power structure in the medical schools changed, which coincided with the implementation phase of the new curricula (Table 2 ) $^{43}$. More power was given to the rector and the dean which facilitated decision-making during the implementation phase.

\section{Inhibiting forces}

\section{Resistance from heads of departments}

Initially, department heads had almost total control of the educational activities in their departments ${ }^{29}$. The change towards a centrally organised, interdisciplinary curriculum reduced their power. Understandably, the strongest opposition to change came from this group.

'Complete resistance to any change from the old professors. Because in Austria up to that time the professor had been the one who decided on the content of his discipline; he was the last authority in examinations and there was no control over this power' (Graz-8).

Resistance to change by some heads of departments had its origin in their fear of losing teaching hours. As the number of lecture hours of a discipline yielded prestige, loss of hours was perceived as loss of power and consequently caused resistance ${ }^{29}$. One of the aims of the new curriculum was to reduce the average study duration, which meant a loss in teaching hours for many (particularly preclinical) disciplines ${ }^{37}$. On the other hand several clinical professors worried that the new curriculum and the preparation for it would mean an increase in teaching time (and a concomitant loss of income).

'I can perform five procedures, which would earn me so much income, or I can invest the same amount of time in trying to flesh out and write down what aspects are important for a new student of medicine to acquire. Who is going to reimburse me for this loss of income?' (Vienna-3). 
Several successful attempts were made to decrease resistance, mainly through involving faculty members in the change process (Table 3 ). For instance the curriculum change committee in Graz and Innsbruck made each discipline responsible for the coordination of a module, thereby increasing faculty's sense of ownership of the new curriculum.

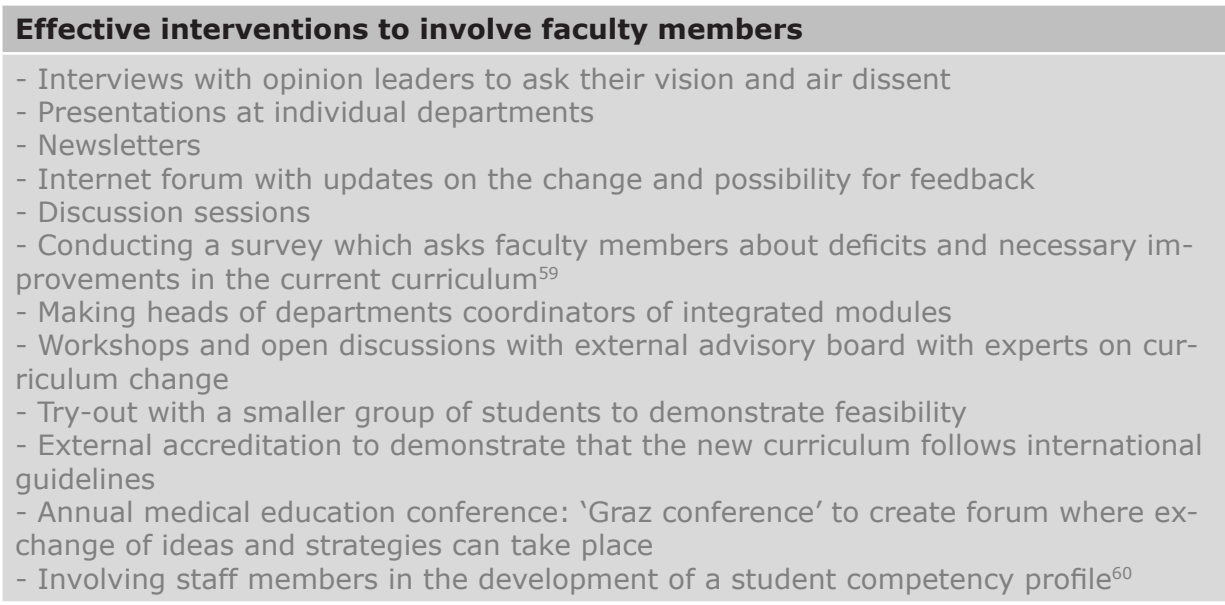

Table 3: Effective interventions to involve faculty members in the change process.

\section{Low priority of education and change}

For the majority of faculty the change process had low priority compared to patient care and research - a persistent problem that seems universal in medical education ${ }^{44}$. In addition, the transformation of medical faculties to autonomous medical universities demanded by the 2002 law required a completely new organisation ${ }^{36}$. Consequently, only a few staff members participated (and resisted) actively in the curriculum reform process, estimated at $5 \%$ in the early years and their number only gradually increased during the implementation.

'The main focus within the university was on building up the new organisation. So they didn't care as much about the new curriculum as they would have done in the old fixed structures' (Vienna-4).

\section{Outcomes}

Obviously curriculum change in the three Austrian medical schools did not solve all the preceding problems at once and continuous adaptations were reported to be necessary. Nevertheless, impressive improvements were made with regards to: reduction of the average study duration to just over 12 semesters, reduction of drop-out rates to about 
$5-10 \%$, and stakeholders in the hospital reporting the entrance of better prepared students. The number of entering students was decreased after a decision by the European Union in 2005 (Table 2). The EU court demanded all European students to be subjected to the same entrance rules, which led to an application increase to Austrian medical schools from 2000 to 13.000 in 2005. This consequence forced the Austrian government to introduce entrance limitations, to the delight of staff members at the medical schools, but causing severe dissatisfaction by students and social democrats who feared the abolition of the freedom to learn for everyone: the 'Lernfreiheit'.

\section{Discussion}

In Austria - a country with an environment less conducive for change - we found that medical schools succeeded in implementing integrated curricula partly thanks to the introduction of a law ${ }^{37}$ that increased the autonomy of medical schools, yielding medical schools an opportunity to design their own curriculum within a certain time frame. When the law was introduced, faculty who were convinced that curriculum change was imperative received strong back-up from this law in overcoming resistance within their schools, partly due to the (unjustified) perception by several faculty that the law was an obligation to change. Nevertheless, top-down pressure for change alone would not have sufficed as many faculty still sought to avoid change: the internally felt need for change, visionary change agents and supportive leaders were generally acknowledged to have made an indispensible contribution.

Several of the factors that influenced the change process in the Austrian medical schools have also been identified in other reports on curriculum change. This suggests that these factors are universal and not specifically related to a country's culture ${ }^{45}$. Firstly, we will take a closer look at the factor 'government involvement' because it played a dominant role in the change process. Everywhere, medical schools have to comply with national laws and regulations and indeed 'politics' was mentioned by Bland ${ }^{10}$ as one of the major factors influencing curriculum change. However, national legislation differs between countries and determines the room for innovation in medical schools. In Austria, strict national laws and regulations prescribing the medical curriculum, initially, were a strong barrier to curriculum innovation, which seems to reflect the country's strong uncertainty avoidance as identified by 
Hofstede $^{9}$ as well as House ${ }^{45}$. This inhibiting force of high national uncertainty avoidance on the adoption of integrated medical curricula confirms previous research? ${ }^{7}$. The strict Austrian laws changed from an obstructive into a driving force after the introduction of a law proposing curriculum change. A similar experience was reported by Hofstede ${ }^{9}$, who found that companies in a country with strong uncertainty avoidance were less innovative but applied a prescribed innovation consistently. Governments in other countries have also proposed or imposed medical curriculum change with varying results. For instance, in Indonesia the government's instruction in 2003 to adopt competency-based education was not immediately acted upon by all medical schools ${ }^{46}$. Several explanations may apply. Perhaps Indonesian medical schools felt lower pressure to change caused by the prescribed change due to the lower national uncertainty avoidance score (48) as compared to Austria (70). Another explanation may be the absence of an urgently felt need for change or lack of visionary change agents in Indonesian medical schools.

Secondly, we will explore the cross-cultural generalizability of the factor need for change. Bland ${ }^{10}$ also identified need for change as a factor influencing medical curriculum change. In addition, this factor resembles the first step in a change process as described by Kotter ${ }^{47}$ : 'Create a sense of urgency'. This factor seems to be universally important, however, the severity of the problems requesting change may determine the impact of this factor. In Austria, where dissatisfaction with the existing situation was strong, both within the medical schools and in the ministry, need for change was found to have played a major role.

Finally, the fact that leadership also features prominently among the decisive factors in (medical curriculum) change processes suggests that it may be a universally important factor in a change process ${ }^{10,45}$. However, which leadership style is most effective depends most likely on a country's culture 9444,45 . For instance in societies with a strong hierarchy, authoritative leadership is likely to be effective because subordinates expect to be given orders. Leaders in less hierarchical societies, on the other hand, should foster egalitarian leadership and participative decision-making ${ }^{44} \cdot{ }^{44}$

In studies into cultural influences the concept of culture is quite a distinctive factor: it is both interesting and elusive. Difficulties arise with respect to causality: e.g. how to ascertain whether national culture 
influences curricular change processes in medical schools? Geertz ${ }^{49}$ has argued that culture has no place in a causal explanation. "Culture is not a power. Not something to which social events, behaviours, institutions or processes can be causally attributed. It is a context, something with which they can be intelligibly (that is thickly) described"49. Even though culture may not be a power in itself, it permeates the conduct of individuals, groups and organisations, contributing to differences in behaviour between countries. Because behaviour is shaped by other factors beyond culture, it can be problematic to determine whether a certain type of behaviour is typical of a certain culture ${ }^{44} .{ }^{44}$ The striking similarities we found between the change processes in the three Austrian medical schools are suggestive of a national commonality - possibly culture.

A limitation of our study is its exclusive focus on Austria. Although there are indications that several of the factors influencing curriculum change identified in this study may similarly apply in other countries, research should be expanded to explore more cultural settings. Earlier research indicated that once countries are wealthier (a Gross Domestic Product (GDP) above $\$ 20,000$ per capita) the relative number of medical schools with an integrated curriculum increases ${ }^{7}$. Therefore, a country with a GDP below $\$ 20,000$ and a high score on the uncertainty avoidance index would be another interesting case for future study.

Another limitation could be the reliance on Hofstede's dimensions of culture, which were based on questionnaires completed by IBM employees, leading to the question whether the same scores apply to medical schools ${ }^{50}$. Nevertheless, Hofstede's dimensions have been replicated in many other settings and his work is the most frequently cited research that enables the cross-cultural comparison of differences between countries ${ }^{51}$. For instance, the Global Leadership and Organizational Behavior Effectiveness (GLOBE) study demonstrated similar dimensions based on multiple organisations in different industries (financial services, food processing and telecommunication), including high uncertainty avoidance score in Austria of 5.16 on a scale of 0-7 on the GLOBE index ${ }^{45}$.

Furthermore, a possible limitation is the selection bias of the interviewees, who were selected based on their active participation in the curriculum change process (i.e. key change agents). Possibly this group had more positive memories on for instance the need for 
change than the average staff members within the medical schools. We deliberately chose to interview these key change agents, because they were expected to give the most extended and rich information on the change processes, a prediction confirmed in the interviews with some people who had been less involved in the change process: they frequently had difficulty answering the questions.

Our study shows that changing from a discipline-based to an integrated curriculum is a complex process involving different stimulating and inhibiting forces, several of which appear to be universal and several which appear to be culture-specific. The existence of unique socio-political forces influencing medical education in every country and the importance of considering these forces was also reported by Segouin and Hodgess ${ }^{52}$. Considering potentially inhibiting universal and culture-specific factors before embarking on curricular reform may facilitate the reform's eventual successful implementation. Many resources provide strategies for curriculum change in medical schools ${ }^{19}$, 53-56 and strategies for dealing with cultural influences on change ${ }^{9,57,}$ 58.43 Future studies should focus on strategies to deal with cultural differences specifically in medical schools. 


\section{References}

1. Papa FJ, Harasym PH. Medical curriculum reform in North America, 1765 to the present: a cognitive science perspective. Academic Medicine. 1999;74(2):15464.

2. Dornhorst AC, Hunter A. Fallacies in medical education. Lancet. 1967; 2(7517):666-7.

3. Gijselaers W. Innovating professional education: the need for curriculum reform. Zeitschrift für Hochschuldidaktik. 1997;3:20-31.

4. Schmidt HG, Machiels-Bongaerts M, Hermans $H$, ten Cate TJ, Venekamp R, Boshuizen HP. The development of diagnostic competence: comparison of a problem-based, an integrated, and a conventional medical curriculum. Academic Medicine. 1996;71(6):658-64.

5. Harden RM, Sowden S, Dunn WR. Educational strategies in curriculum development: the SPICES model. Medical Education. 1984;18(4):284-97.

6. Barrows HS, Tamblyn RM. Problem-Based Learning: An Approach to Medical Education. New York: Springer Publishing Company 1980.

7. Jippes M, Majoor GD. Influence of national culture on the adoption of integrated medical curricula. Advances in Health Sciences Education Theory and Practise. 2011;16(1):5-16.

8. Jippes M, Majoor GD. Influence of national culture on the adoption of integrated and problem-based curricula in Europe. Medical Education. 2008;42(3):27985.

9. Hofstede G. Culture's Consequences. Comparing Values, Behaviors, Institutions, and Organizations across Nations. New York: Sage Publications 2001.

10. Bland CJ, Starnaman S, Wersal L, Moorehead-Rosenberg L, Zonia S, Henry R. Curricular change in medical schools: how to succeed. Academic Medicine. 2000;75(6):575-94.

11. Genn JM. AMEE Medical Education Guide No. 23 (Part 2): Curriculum, environment, climate, quality and change in medical education: a unifying perspective. Medical Teacher. 2001;23(5):445-54.

12. Mennin SP, Krackov SK. Reflections on relevance, resistance, and reform in medical education. Academic Medicine. 1998;73(9 Suppl):S60-4.

13. Simunovic VJ, Hren D, Ivanis A, Dorup J, Krivokuca Z, Ristic S, et al. Survey of attitudes towards curriculum reforms among medical teachers in different socio-economic and cultural environments. Medical Teacher. 2007;29(8):8335.

14. Wong AK. Culture in medical education: comparing a Thai and a Canadian residency programme. Medical Education. 2011;45(12):1209-19.

15. Frenk J, Chen L, Bhutta ZA, Cohen J, Crisp N, Evans T, et al. Health professionals for a new century: transforming education to strengthen health systems in an interdependent world. Lancet. 2010;376(9756):1923-58.

16. Evans R. The Human Side of School Change. Reform, Resistance, and the Reallife Problems of Innovation. San Francisco: Jossey-Bass Publishers 1996.

17. Gijselaers W, Harendza S. Dynamics planned change: when participants talk back. In: Hunt L, Bromage A, Thomkinson B, editors. The Realities of Educational Change. London: Routledge Falmer Press; 2006. p. 101-14.

18. Guilbert J]. Curriculum change and strategies, past and present: why is it taking so long? Education for Health. 2001;14(3):367-72.

19. Prideaux D. Managing Change in Medical Education. CDTLink [serial on the Internet]. 2004 [cited 2011 December 28]; 8(3): Available from: http://www. cdtl.nus.edu.sg/link/nov2004/ic.htm.

20. Shane SA. Why do some societies invent more than others? Journal of business venturing. 1992; 7:29-46. 
21. Everdingen $Y v$, Waarts $E$. The effect of national culture on the adoption of innovations. Marketing Letters. 2003;14(3):217-32.

22. Goodman L. Snowball sampling. The annals of mathematical statistics. 1961:148-70.

23. Kanter SL. Toward better descriptions of innovations. Academic Medicine. 2008;83(8):703-4.

24. Flanagan JC. The critical incident technique. Psychological Bulletin. 1954;51(4):327-58.

25. Miles M, Huberman A. Qualitative Data Analysis. 2nd ed. Thousand Oaks, CA: Sage 1994.

26. Lewin K. Field Theory in Social Science; Selected Theoretical Papers. New York: Harper 1951.

27. Glatz E, Krajic K, Pelikan J. AbsolventInnen im reformierten Medizinstudium an den Fakultäten Wien und Graz. Ausgewahlte Analysen. Gesundheitsberufe /3 [Report on the medical graduates of the faculties Graz and Vienna]. Wien: Ludwig Boltzmann Institut für Medizin und Gesundheidssoziologie 1992.

28. Lischka M. Medical universities in Austria: impact of curriculum modernization on medical education. GMS Zeitschrift für Medizinische Ausbildung. 2010;27(2).

29. Reibnegger G, Haas J, Neges H, Smolle J. The reform of the medical curriculum at the Medical University of Graz. Zeitschrift für Hochschulentwicklung. $2008 ; 3(3): 48-61$.

30. Rásky E. A program for faculty and organizational development for the medical faculty of the University of Graz based upon an analysis of changed educational needs in the medical professions and society [Master of Medical Education (MME) [Thesis]]: Universitat Bern; 2001.

31. Schutz W. Shortcomings of medical education in Austria. Zeitschrift für Hochschuldidaktik. 1998;4:52-3.

32. Glossmann HH, Peskar BA. Bitter pill to swallow over medical education. Nature. 1998;396(6712):614.

33. Schober B, Spiel C, Reimann R. Young physicians' competences from different points of view. Medical Teacher. 2004;26(5):451-7.

34. Pelikan JM, Krajic K, Lischka MF. Studienreform in Medizinstudium. Gutachten im Auftrag des Bundesministeriums für Wissenschaft und Forschung [Report on the improvement of medical education in Austria]. Wien (Austria): Österreichische gesellschaft für medizinsoziologie 1989.

35. Forster R, Braunegger-Kallinger G, Krajic K. Austrian health consumer groups: voices gaining strength? In: Löfgren $\mathrm{H}$, de Leeuw $\mathrm{E}$, Leahy $\mathrm{M}$, editors. Democratizing Health: Consumer Groups in the Policy Process. Cheltenham: Edward Elgar Publishing; 2011. p. 143-60.

36. Austria. Universities act 2002 [cited 2011 Jul 1]: Available from: http://www. bmwf.gv.at/fileadmin/user_upload/wissenschaft/recht/englisch/E_UG.pdf.

37. Austria. Bundesgesetz über die studien an den Universitäten 1997 (Universitäts-studiengesetz -UnivStG 1997) [cited 2011 Apr 1]: Available from: http:// www.ris.bka.gv.at/Dokumente/BgblPdf/1997_48_1/1997_48_1.pdf.

38. März R, Stein J. Reform of the medical curriculum in Austria. A report on the current situation. Zeitschrift für Hochschuldidaktik. 1997;3:7-12.

39. Prodinger $W$. The process of medical curriculum reform in Innsbruck, Austria. Zeitschrift für Hochschulentwicklung. 2008;3(3):1-16.

40. Sully MA. A Contemporary History of Austria. London; New York: Routledge 1990.

41. Holzleithner E, Strasser S, editors. Gender equality, cultural diversity: The Austrian experience. Conference Gender Equality; 2006 June 7-8; Amsterdam.

42. Burtscher $C$, Pasqualoni P, Scot A. Universities and the regulatory framework: the Austria university system in transition. Social epistemology. 2006;20(3):24158. 
43. Pecher H. University autonomy in Austria 2005 [cited 2011 May 1]; HOFO working paper series 05.001: Available from: www.iff.ac.at/hofo/WP/IFF_ hofo.05.001_pechar_autonomy.pdf.

44. Den Hartog DN, House RJ, Hanges PJ, Ruiz-Quintanilla SA, Dorfman PW. Culture specific and cross-culturally generalizable implicit leadership theories: are attributes of charismatic/transformation leadership universally endorsed? Leadership Quarterly. 1999;10:219-56.

45. House R, Hanges P, Javidan M, Dorfman P, Gupta V. Culture, Leadership and Organizations. The GLOBE Study of 62 Societies. New York: Sage publications 2004.

46. Claramita M, Utarini A, Soebono H, Van Dalen J, Van der Vleuten C. Doctorpatient communication in a Southeast Asian setting: the conflict between ideal and reality. Advances in Health Sciences Education. 2011;16(1):69-80.

47. Kotter JP. Leading Change. Boston: Harvard Business School Press 1995.

48. Genis-Gruber A. Impact of culture on perception of charismatic leadership. International Journal of knowledge, culture and change management. 2011;10(6):73-95.

49. Geertz C. Thick Description: Toward an Interpretive Theory of Culture. New York: Basic books 1973.

50. Signorini P, Wiesemes R, Murphy R. Developing alternative frameworks for exploring intercultural learning: a critique of Hofstede's cultural difference model. Teaching in Higher Education. 2009;14:253-64.

51. Kirkman BL, Lowe KB, Gibson CB. A quarter century of Culture's Consequences: a review of empirical research incorporating Hofstede's cultural values framework. Journal of International Business Studies. 2006;37(3):285-320.

52. Segouin C, Hodges B. Educating doctors in France and Canada: are the differences based on evidence or history? Medical Education. 2005;39(12):1205-12.

53. Bland CJ, Wersal L. Effective leadership for curricular change. In: Norman; GR, van der Vleuten C, Newble D, editors. International Handbook of Research in Medical Education. Dordrecht; Boston; London: Kluwer; 2002. p. 969-79.

54. Gale R, Grant J. AMEE Medical Education Guide No. 10: Managing change in a medical context: Guidelines for action. Medical Teacher. 1997;19(4):239-49.

55. Norman GR, Vleuten Cvd, Newble D. International handbook of research in medical education. Dordrecht; Boston: Kluwer Academic 2002.

56. Bordage G, Harris I. Making a difference in curriculum reform and decisionmaking processes. Medical Education. 2011;45(1):87-94.

57. Rogers E. Diffusion of Innovations. 4th ed. New York: Free Press 1995.

58. Trompenaars F, Woolliams P. Business across cultures. West Sussex: Capstone publishing 2005.

59. Schober B, Spiel C, Reimann R. Young physicians' competences from different points of view. Medical Teacher. 2004;26(5):451-7.

60. Merl PA, Csanyi CS, Petta P, Lischka M, Marz R.The process of defining a profile of student competencies at the University of Vienna Medical School. Medical Education. 2000;34:216-221. 


\section{Appendix A. Interview outline}

At forehand the participants received the following explanation about critical incidents by email. The interview started with these critical incident stories.

\section{Critical incidents}

In our meeting you will be requested to tell two critical stories that happened during the process of curricular change in the faculty you were working at. I would like to hear stories that - in your view- greatly impacted on the process of change, in a positive way and in a negative way.

The positive and negative story may include these elements (in any order):

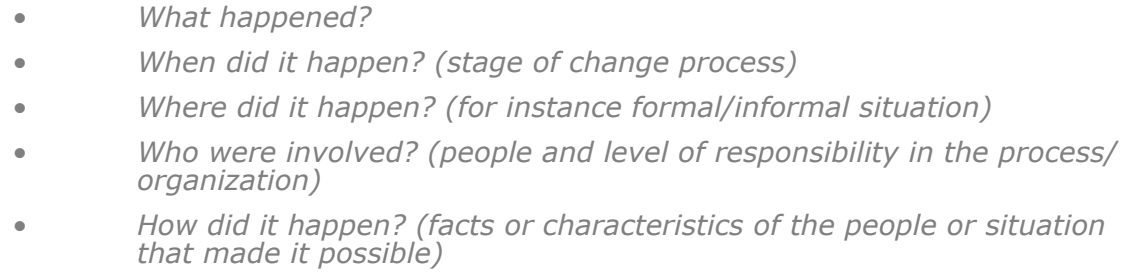

I will continue to ask you some questions about: the reasons of the medical school to decide for this change and how the change of the curriculum was implemented and evaluated.

\section{Problem}

1. Why was there a decision to change the curriculum? What were the problems that forced the curricular change?

2a) Why was there no need to change before? Or why was it now more recognized?

2b) Had there ever been any change projects before?

2c) If yes, is there a history of effective change projects?

3 . Who came up with recognizing the need for change?

$4 a)$ Is there a cooperative/ positive climate for change?

$4 b)$ Was the need for change felt by everyone (all the powerful individuals)?

5 a) Was there a (in)formal network against change?

5b) How was dealt with disagreements among staff/students?

6a) Was the organizational structure departmentalized?

6b) Was there frequent interaction between the disciplines before the change project?

7a). Who where decision makers of the change process?

7b) Which formal bodies/decision makers were important during the change (f.i. government/legislation, dean, organizational committee)

8. Did other universities in Austria view the same problems?

\section{Solution}

1a) Which solutions were available? Why was this particular curriculum chosen and others not?

1b) Was there a theoretical base for this curriculum (evidence)?

1c) How was this curriculum developed?

2. Which strategies were used for choosing this curriculum (other universities/external experts)?

3. Do you know of any differences of this curriculum and the change process in comparison to other universities in Austria? 


\section{Implementation}

1. What was the timeline for the implementation of this change project?

2a) How was the change implemented?

2b) Where there any cross-departmental teams?

2c) How was participation stimulated (rewards/committees)?

2d) How was the change communicated?

2e) How where staff/students prepared for the change (f.i. workshops)?

3. What theories/concepts guided the implementation?

4a) Was there stable leadership during the change process?

4b) Which characteristics of leadership were essential?

5a) Which institutional factors allowed the innovation to work?

5b) Which institutional factors impeded the implementation?

5c) Which barriers were encountered and how was dealt with these barriers?

$5 d)$ Where there any unforeseen events?

5e) Which lessons have been learned from the curricular change?

6a) How did this change project affect/change the environment (staff, students)?

6b) Did this change project change thinking or practise of education among staff /students?

7a) Is there insight in what were the costs of this change project?

7b) From which budget was the change project paid (external, limited duration)?

8. Has the innovation propelled a project /program/discipline forward?

9. What preconditions are needed to implement this innovation in other settings?

\section{Evaluation}

1a) Which milestones were used as indicators of progress of this change project?

1b) How was the change evaluated (accreditation)?

2a) Was this change project implemented successfully?

2b) Has there been a performance dip after the implementation? If yes, how was this handled?

3. Do you think that it is a sustained innovation (which instruments have been used to make it sustainable)?

4. Did this change project initiate new innovations?

5. Did this change project identify new problems?

Thank you very much for your time. In case you come up with any other ideas or documents you think may be useful for my research you can reach me by email (see informed consent)

Would you be available for the concept of member checking? (I will send you an outline on which you can comment for irregularities or clarifications)

As a token of gratitude I would like to hand you this traditional Dutch syrup waffles! 

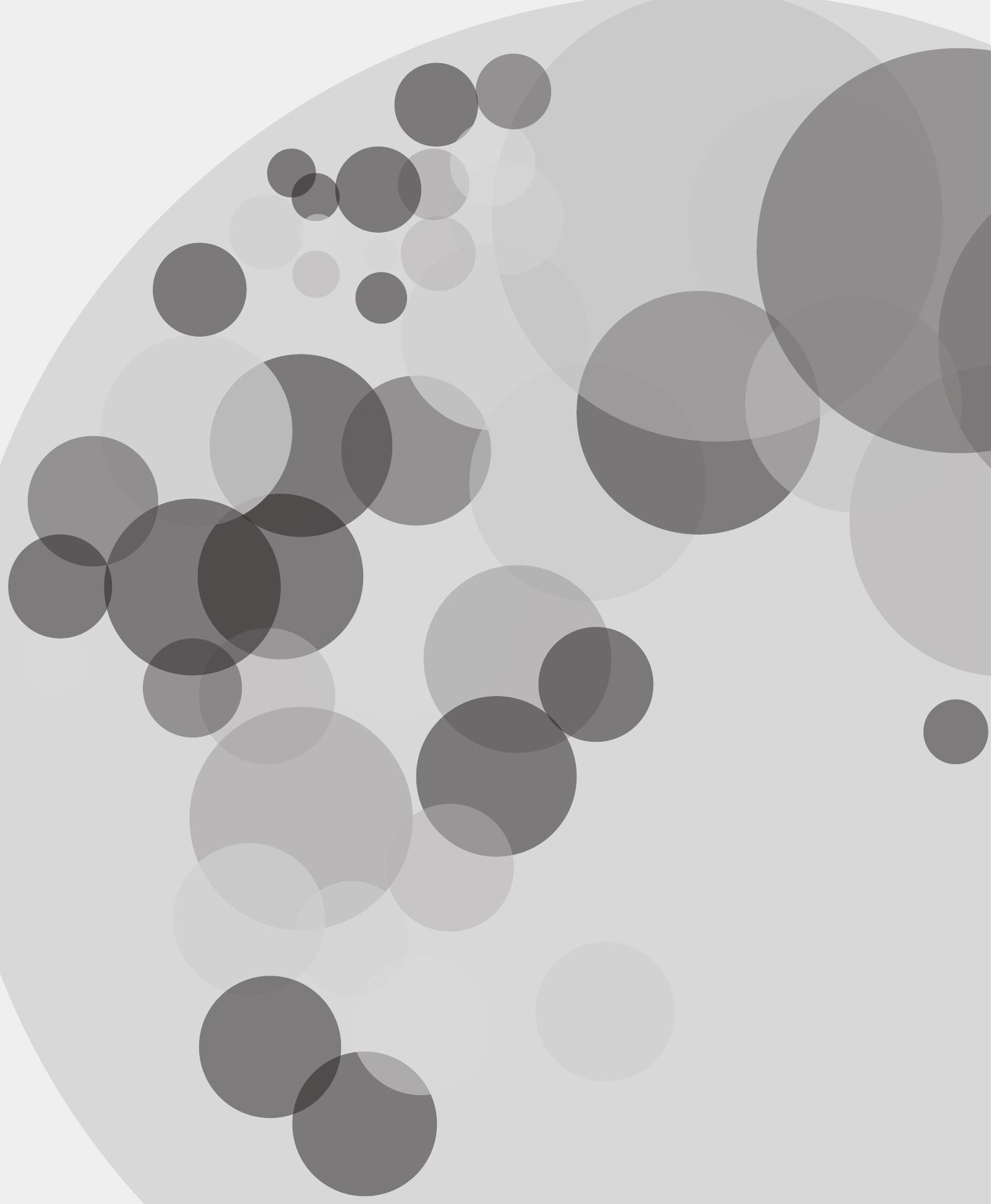


\title{
CHAPTER 5
}

\author{
MEDICAL SCHOOLS' \\ ORGANISATIONAL \\ READINESS FOR \\ CURRICULUM CHANGE: \\ DEVELOPMENT AND \\ VALIDATION OF A \\ QUESTIONNAIRE \\ (MORC)
}

Mariëlle Jippes, Erik W. Driessen, Nick J. Broers, Gerard D. Majoor, Wim H. Gijselaers, and Cees P.M. van der Vleuten Under editorial review 


\section{Abstract}

Introduction: Since organizational readiness for change is critical to the successful implementation of change, we developed and validated a questionnaire to measure Medical school's Organizational Readiness for curriculum Change (MORC) based on a theoretical model of organisational readiness for change.

Method: A preliminary questionnaire was judged and adapted in a Delphi procedure with medical education experts, and the resulting questionnaire was administered worldwide to staff members of medical schools involved in curriculum change. The psychometric properties of MORC were tested using exploratory and confirmatory factor analysis, and generalizability analysis.

Results: The mean relevance score of the Delphi panel $(n=19)$ reached 4.2 on a five-point Likert scale ( $1=$ not relevant and $5=$ highly relevant) in the second round, meeting our criteria for completion of the Delphi procedure. MORC was completed by 991 staff members from 131 medical schools in 56 countries. Exploratory factor analysis yielded three underlying dimensions, motivation, capability, and external pressure, in twelve subscales with 53 items. The scale structure suggested by Exploratory factor analysis was confirmed by confirmatory factor analysis (CFI=0.91-0.95, NNFI=0.89-0.93, RMSEA=0.06-0.07, and SRMR $=0.04-0.05$, ranges for the separate scores on the three dimensions). Cronbach's alpha ranged from 0.67-0.92 for the subscales. Generalizability analysis showed that five to fifteen staff members can reliably evaluate organizational readiness for change.

Discussion: MORC can be a valid and reliable questionnaire for measuring organizational readiness for curriculum change in medical schools. Medical education can use it to identify which elements in a change process require special attention to increase the chance of successful implementation.

Keywords: Medical education; curriculum innovation; curriculum integration; organizational change; cross-cultural comparison; quantitative research 


\section{Introduction}

Changes in medical curricula in response to changes in health care and society appear to be an ongoing feature of medical education worldwide $^{1}$. Sadly, despite hard work, the expected results are not always achieved $^{2}$, and although the failure rate is not well documented, it is presumably comparable to the estimated rate for business organizations of $20-70 \%{ }^{3-5}$. Failure is often due to financial, time, and leadership constraints, while successful change in medical schools ${ }^{6,7}$, health care organizations $\mathbf{s}^{8,9}$, and business organizations ${ }^{10}$ has been attributed to various factors, and to organizational readiness for change in particular $^{3,10,11}$. Organizational readiness for change is reflected in the prevailing beliefs and attitudes among members of an organization regarding the necessity and urgency of change and in the capacity of the organization to successfully implement change ${ }^{11}$. With high levels of readiness, people at all levels within the organization are prepared to invest in change and show perseverance in the face of obstacles and setbacks, thereby increasing the odds in favor of successful implementation $^{3}$. With low levels of readiness, change initiatives may be met with strong resistance ${ }^{3,12}$. Kotter ${ }^{10}$ even ascribes half of all failures to low levels of organizational readiness for change.

The field of medical education might benefit from an instrument that can help in identifying issues that need addressing to facilitate curriculum innovation ${ }^{13,14}$. For business and health care organizations, numerous instruments are available to measure readiness for change ${ }^{3,}$ 15, while for medical schools we know of only a few instruments ${ }^{5,16}$. None of these instruments, however, afford comprehensive measurement of organizational readiness for curriculum change in medical schools. Most instruments are limited to individual16-18 rather than organizational readiness for change ${ }^{3,19}$, have limited evidence of validity and reliability ${ }^{3,15}$, address selected aspects ${ }^{16}$ or related concepts, such as 'openness to change ${ }^{\prime 5}$ and are of doubtful applicability outside the Western cultural setting where most of them originated, with some exceptions ${ }^{16,20,21}$. Curriculum change requires for instance substantial financial investment, which might be a strong restricting force in countries with lower national wealth. Since no existing instrument seemed suitable, we set out to develop and validate a comprehensive questionnaire that can be used internationally to measure Medical school Organizational Readiness for curriculum Change (MORC). 
Before describing the conceptual model that guided MORC's development, we will explain how we conceptualized organizational readiness for change and our stance toward the level, timing, and context of the measurement. In the literature, varying definitions of organizational readiness for change point to conceptual ambiguity and differences of opinion as to how and when readiness for change should be measured $^{22}$. Some definitions focus on psychological factors ${ }^{23}$, others on the availability of resources ${ }^{18}$, but most combine psychological (does the organization want change) and capability factors (is the organization able to change) ${ }^{24}$. Important motivation factors within an organization are perceived need for change, belief in proposed changes, and commitment to the successful implementation of change. Capability factors concern the available capacity for change (expertise, resources, and opportunity) as well as the possibility of deploying that capacity (i.e. the perceived efficacy to implement change). In this study we therefore adopted the following definition: 'Shared motivation and capability among staff in a medical school to implement curriculum change'. Empirical studies have shown that readiness for change increases with adequate self-efficacy for change, provision of information, perceived organizational support, flexible organisational policies and procedures, and active participation, which in turn predict successful change 25,26 .

The three major measurement issues are the level, timing, and context of the measurement. Change is regarded as a multilevel construct that can be measured at the level of the organization, departments, teams, or individuals 22,26 . Since curriculum change is a complex process depending on coordinated collective behaviour ${ }^{24}$, we focused on the organizational level: 'what we think we can do together'22. As for timing, several authors advocate measurement in the initiation phase, before the actual implementation ${ }^{3,24}$ but, like Bouckenooghe ${ }^{27}$, we prefer measurement during both the initiation and the implementation phase, allowing for measurement of changes in readiness after interventions aimed at enhancing successful implementation ${ }^{13}{ }^{14}$. The context issue focuses on the question whether organizational readiness for change should be measured in relation to a specific situation (e.g. substance and magnitude of the change $)^{20}$ or as a general characteristic of an organization ${ }^{13}$. We agree with Werner that the level of organizational readiness for change depends on the type of change that is proposed $^{22}$. For example, a medical school may be quite ready to add skills training to the curriculum, but resist transition toward a Problem- 


\section{Based Learning (PBL) curriculum.}

Despite the measurement of factors on individual level, next to factors on the organizational level, the conceptual model of organizational readiness for change developed by $\mathrm{Holt}^{24}$ was considered to be largely consistent with our views. After adapting the individual level factors to the organizational level, we used this model to guide the development of MORC (Figure 1).

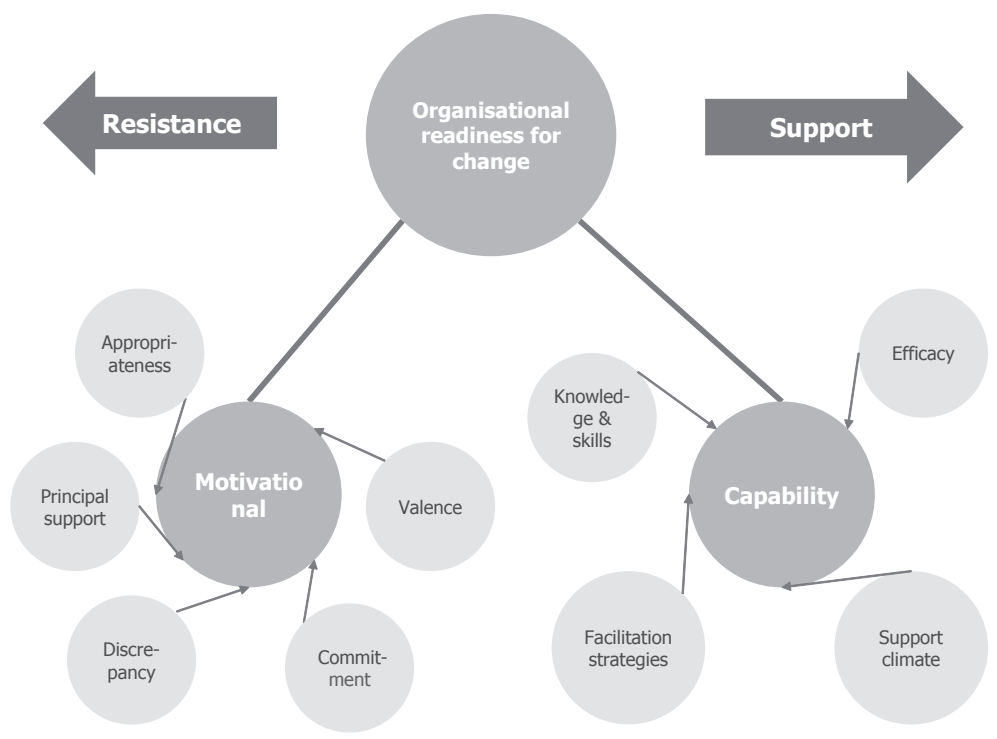

Figure 1: Conceptual model of organisational readiness for change derived from the model of Holt ${ }^{24}$. Appropriateness: belief that a specific change is correct for the situation being addressed. Valence: belief that the change is beneficial. Commitment: shared belief and resolve to pursue courses of action that will lead to successful change. Discrepancy: a difference between the current and a more desirable state. Principal support: belief that formal and informal leaders are committed to the success of the change. Knowledge, skills, ability alignment: extent to which the organizational members' knowledge, skills, and abilities align with the change. Efficacy: shared belief in capabilities to organize and execute the courses of action required to implement change successfully. Support climate: sufficient support of tangible (e.g. funding) and intangible environment (e.g. culture). Facilitation strategies: clear goals and objectives supported by a detailed implementation plan.

To estimate the validity and reliability of the questionnaire, we investigated five research questions (RQ): 1) Does MORC measure organisational readiness for curriculum change in medical schools? 2) Does MORC have a coherent internal factor structure? 3) Is MORC a reliable (reproducible) questionnaire? 4) How many respondents are necessary for a reliable MORC score? 5) Is MORC valid for use in medical schools in different countries? 


\section{Method}

\section{Design}

After designing a preliminary questionnaire based on our conceptual model, we conducted a modified Delphi procedure to examine its relevance. By administering the modified questionnaire to staff of numerous medical schools in different countries we obtained a large dataset, which we analyzed to examine the psychometric properties of the questionnaire (Figure2).

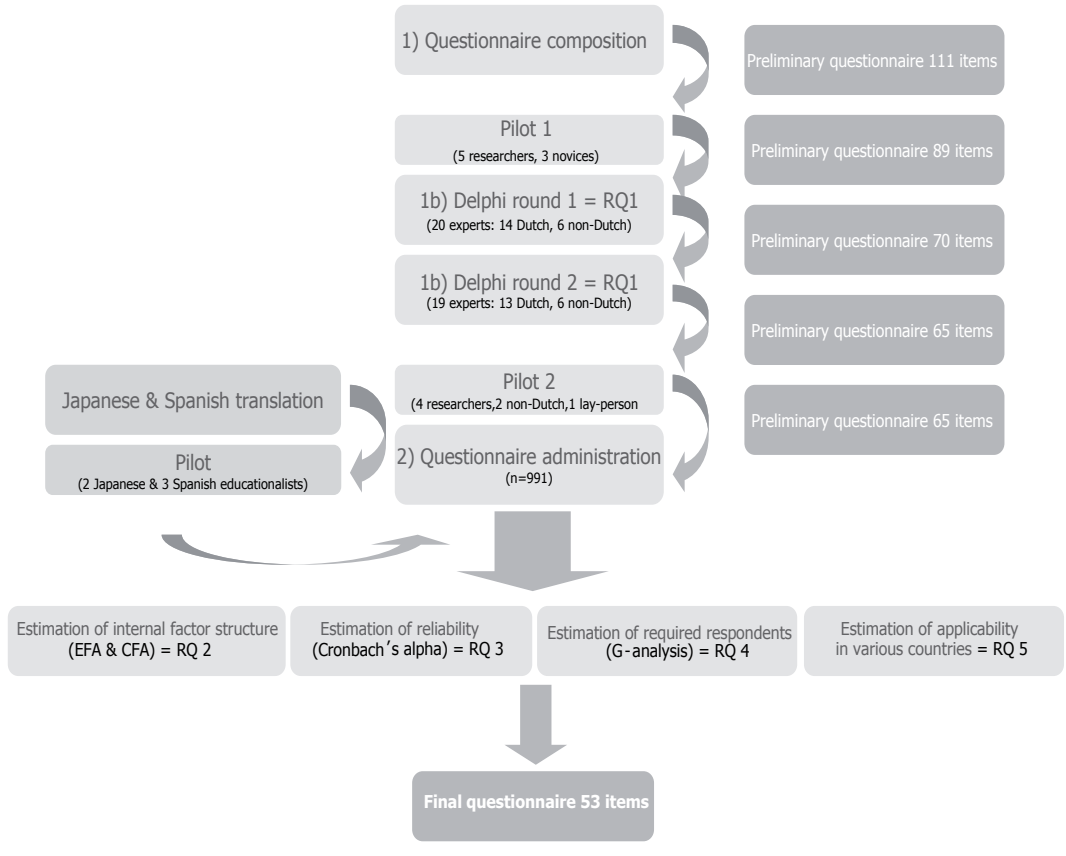

Figure 2: Flowchart of the development of $M O R C . R Q=$ Research Question, EFA= Exploratory Factor Analysis and CFA= Confirmatory Factor Analysis G-study= Generalisability study.

\section{Questionnaire development and modified Delphi procedure}

We composed the initial questionnaire using nineteen subscales with a total of 111 items derived from existing questionnaires for business and health care organizations that best matched our model of organizational readiness for change (Figure 1 and 2). A pilot in which five educational researchers and three higher educated lay persons judged the items on face validity, redundancy, and phrasing resulted in a 89item questionnaire. To examine the applicability of the questionnaire for medical schools (RQ 1), we conducted a modified Delphi procedure, 
comprising different iterations or rounds in which experts indicate their level of agreement with questionnaire items ${ }^{28,29}$. A modified Delphi procedure does not ask experts to generate items, but only to evaluate items selected in another way ${ }^{29,30}$. For the panel, we invited fourteen experts in curriculum change from the Netherlands and eight from other countries. The participants received a $€ 25$ book voucher for rating the relevance to curriculum change of the web-based questionnaire on a five-point Likert scale ( $1=$ not relevant and $5=$ highly relevant). Redundancies, omissions, and textual shortcomings were also evaluated. Items with an average rating of $<4$ or ratings $>4$ by less than $70 \%$ of panelists were either adapted or eliminated, based on the qualitative comments. In the absence of an existing standard, we considered the Delphi procedure complete, when the overall average rating of MORC exceeded four and when $>70 \%$ of panelists rated MORC above four ${ }^{31}$. A summary of the quantitative and qualitative results, and suggested eliminations and adaptations by the main author was discussed by two of the researchers until consensus was reached, which led to the elimination of nineteen items (21\%) in the first round. This summary was sent to the panelists together with the request to rate the modified seventy-item questionnaire. The second round yielded a 65-item questionnaire with 13 subscales after a similar analysis and discussion. A pilot of the resulting 65-item questionnaire by four international educational researchers and one lay person led to textual changes only. Furthermore, the 65-item questionnaire was translated from English into Japanese and Spanish (Figure 2), and differences between the original English version and the translations back into English were discussed. The translated questionnaires were piloted by two Japanese and three Spanish staff members.

\section{Questionnaire administration}

We sent emails to contact persons from medical schools in different countries affiliated with Maastricht University inviting them to participate in the study provided they were preparing for, or implementing curriculum change. Newly established medical schools and schools where curriculum change was completed (i.e. the first students had graduated from the new curriculum) were excluded from participation. Two reminders were sent to invite non-responding contact persons. Contact persons from schools meeting the curriculum change criterion were asked to electronically distribute MORC to at least twenty of their 
colleagues within the school who were actively involved in medical education and preferably represented a mix of professional backgrounds: basic scientists, clinicians, and members of the curriculum committee. After contact persons agreed to cooperate, they received two reminders for the invitation of colleagues in their school. Participants were asked to rate their agreement with the items of the anonymous web-based 65-item MORC questionnaire on a 5-point Likert scale (1= strongly disagree and $5=$ strongly agree) or to select the 'not applicable' option. In countries where we anticipated problems with computer and internet access a paper-based version was used.

For every participant completing the questionnaire $€ 5$ was donated to the charity 'World Wildlife Fund' (www.wwf.org). On request, each participating medical school was sent a report with the anonymized results of their school.

\section{Analysis (RQ 2-5)}

We conducted exploratory (EFA) and confirmatory factor analysis (CFA) to determine the factor structure of MORC (RQ 2). Since the number of participants was too low for EFA and CFA of the full 65-item questionnaire ${ }^{32}$, we aimed to split the questionnaire into two parts according to the two assumed dimensions (motivation and capability). To ensure that the split was made in a valid way, we performed EFA on the sum scores of the subscales (sum scores were required, as the number of participants was still too low to analyze the whole questionnaire at once). In order to determine the sum scores of the subscales in a proper manner, we used exploration, validation, and replication of the factor structure of each subscale to determine whether it was based on one underlying factor. After randomly dividing the dataset into two parts, we conducted EFA for each of the subscales on the first part, and validated the results using CFA. These analyses were repeated for the second half of the dataset to determine if the initial findings could be replicated. As the Component Correlation Matrix indicated correlations between the factors, we used Oblimin rotation for EFA. For CFA we used the following fit indices and criteria: Root Mean Square Error of Approximation (RMSEA<0.08); Comparative Fit Index (CFI>0.9), NonNormed Fit Index (NNFI>0.9), and Standardized Root Mean Square Residual (SRMR $<0.08)^{33,34}$.

To estimate the reliability of the measurements (RQ 3), Cronbach's a was calculated for each subscale and for each dimension. 
For the generalizability study ( $R Q$ 4), we used variance component analysis to measure the contributions of all relevant factors (staff members, medical schools, items, and their interactions) to the measurement of MORC ${ }^{35}$. Generalizability coefficients $(>0.7)$ and Standard Error of Measurement $(S E M<0.26)$ were estimated for each dimension and subscale to estimate the number of participants needed for a reliable score ${ }^{30,36}$. The total number of items was treated as a fixed factor and the number of staff members as random.

To estimate the applicability of MORC irrespective of a country's level of national wealth, we divided the participating schools into higher and lower income countries, using gross domestic product at purchasing power parity (GDP PPP) of $\$ 20,000$ per capita as the cut-off point (RQ 5). GDP PPP is the most widely used variable for comparing wealth among different countries, and successful innovations have been shown to increase significantly in countries with a GDP PPP of over $\$ 20,000$ per capita ${ }^{37}$. We verified whether the generalizability and reliability coefficients and the fit indices remained stable in the two groups.

We used Lisrel structural equation modeling software and Mplus version 5.21 for EFA and CFA, URGENOVA software to analyze generalizability, and SPSS version 19 for all the other analyses.

\section{Ethical considerations}

After explaining the aim and purpose of the study, voluntariness of participation, and confidentiality of the contributions, we obtained informed consent from all participants. The study was approved by the Ethical Review Board of the Dutch Association for Medical Education (NVMO).

\section{Results}

\section{Modified Delphi procedure ( $R Q$ 1)}

Of the total of 22 experts invited to participate, twenty (91\%) participated in the first round. One participant was excluded due to inexperience with curriculum change. The remaining nineteen participants participated in the second round as well (100\%). The average item scores increased from 3.8 in the first round to 4.2 in the second round and from $63 \%$ of panelists rating above 4 in the first round to $84 \%$ in the second round, thus meeting our criteria for completion of the Delphi procedure. 


\section{Questionnaire administration}

Appendix A presents the characteristics of the respondents. The questionnaire was completed by 991 staff members from 131 medical schools in 56 countries (Appendix B). Of the participants $47.9 \%$ was male and the average age was 47 years (21-84 years). For the analysis, missing values and ratings 'not applicable' were replaced by the corresponding mean item score ${ }^{38}$.

\section{Exploratory and confirmatory factor analysis (RQ 2)}

EFA resulted in eight subscales with one, four subscales with two underlying factors and one subscale 'Government readiness' with no underlying factor. The 'Government readiness' subscale showed relatively low scores in the Delphi procedure as well. Considering additionally that many participants answered 'Ministry of Health or Education' in response to the item 'other' in the 'Pressure for change' subscale, we removed the 'Government readiness' subscale, and added the answer option 'Ministry of Health or Education' to the 'Pressure for change' subscale. The twelve remaining subscales had good fit measures in the validation, replication, and the complete sample (RMSEA 0.0-0.11, NNFI 0.95-1.01 and SRMR 0.00-0.04).

EFA of the sum scores of the subscales revealed three dimensions: motivation, capability, and a third dimension which we labeled 'external pressure'. We accordingly divided the questionnaire into three parts, and analyzed these separately using EFA. Suggested relocation of items between subscales that were conceptually valid was applied. The third dimension 'external pressure' was found to consist of two subscales, which we labeled 'extrinsic motivation to change' and 'external barriers to innovation' (Table 1). After these changes, the final MORC questionnaire consisted of three dimensions, twelve subscales, and 53 items (Table 1 and 2).

The three CFA analyses showed good fit indices for the three dimensions ( $\mathrm{CFI}=0.91-0.95, \mathrm{NNFI}=0.89-0.93$, RMSEA $=0.06-0.07$, and SRMR=0.04-0.05) (Table 3).

\section{Reliability analysis (RQ 3)}

Cronbach's alpha varied from 0.67-0.93 for the dimensions (Table 3 ) and from 0.67-0.92 for the final subscales (Table 1). 


\begin{tabular}{|c|c|c|c|c|c|c|}
\hline $\begin{array}{l}\text { Medical school Organizational Readiness for curriculum } \\
\text { Change (MORC) }\end{array}$ & $\mathbf{N}$ & Mean & SD & $\mathbf{a}$ & $\begin{array}{l}\text { Delphi } \\
\text { Mean }\end{array}$ & $\begin{array}{l}\text { Delphi } \\
\text { SD }\end{array}$ \\
\hline $\begin{array}{l}\text { Pressure for change (M1) } \\
\text { Current pressure to change the curriculum comes from: } \\
\text { Bottom-up: }\end{array}$ & & & & 0.68 & & \\
\hline 1. Students in the program & 940 & 3.24 & 1.12 & & 4.4 & 0.6 \\
\hline 2. Teaching staff & 954 & 3.41 & 1.00 & & 4.3 & 0.6 \\
\hline 3. Hospital staff & 873 & 2.88 & 1.05 & & 3.7 & 0.9 \\
\hline \multicolumn{7}{|l|}{ Top-down: } \\
\hline 4. Educational committee & 950 & 4.15 & 0.93 & & 4.2 & 0.7 \\
\hline 5. Dean/Rector & 896 & 4.05 & 1.03 & & 4.5 & 0.5 \\
\hline \multicolumn{7}{|l|}{ External: } \\
\hline 6. Accreditation authorities & 907 & 3.75 & 1.11 & & 4.3 & 0.7 \\
\hline 7. Ministry of Health/Education & New & New & New & New & New & New \\
\hline $\begin{array}{l}\text { Need for change. (M2) } \\
\text { There is a need for change }\end{array}$ & & & & 0.72 & & \\
\hline $\begin{array}{l}\text { 8. There is a significant difference between the current and } \\
\text { the desired state of our curriculum. }\end{array}$ & 965 & 3.90 & 0.92 & & 4.2 & 0.5 \\
\hline 9. We need a major change of our curriculum. & 969 & 3.82 & 0.98 & & 4.1 & 0.7 \\
\hline $\begin{array}{l}\text { Appropriateness (M3) } \\
\text { This change project meets a real need for change. }\end{array}$ & & & & 0.79 & & \\
\hline $\begin{array}{l}\text { 10. This change project is tailored to the needs for change in } \\
\text { our school. }\end{array}$ & 960 & 3.88 & 0.88 & & 4.1 & 0.8 \\
\hline $\begin{array}{l}\text { 11. There is a high priority for the success of this change } \\
\text { project. }\end{array}$ & 970 & 4.05 & 0.85 & & 3.8 & 0.9 \\
\hline $\begin{array}{l}12(R) \text {. The potential benefits of this change are not worth the } \\
\text { costs in time and resources required to implement it. }\end{array}$ & 960 & 2.51 & 1.22 & & 4.1 & 1.0 \\
\hline 13. This change serves an important purpose. & 980 & 4.21 & 0.79 & & 4.3 & 1.1 \\
\hline 14. This change will put us higher on (inter)national rankings. & 969 & 3.96 & 0.93 & & 4.1 & 1.0 \\
\hline $\begin{array}{l}\text { 15. This change will improve the knowledge and skills of our } \\
\text { graduates. }\end{array}$ & 978 & 4.12 & 0.91 & & 4.7 & 0.5 \\
\hline $\begin{array}{l}\text { Efficacy }(\mathrm{C} 1) \\
\text { Shared belief in the conjoint capabilities to implement this } \\
\text { change successfully. }\end{array}$ & & & & 0.67 & & \\
\hline $\begin{array}{l}\text { 16. We have the skills in our school that are needed to imple- } \\
\text { ment this change. }\end{array}$ & 943 & 3.91 & 0.89 & & 4.4 & 0.6 \\
\hline $\begin{array}{l}17(R) . \text { Considering the trouble we have had in previous } \\
\text { change efforts, we will have difficulty implementing this } \\
\text { change successfully. }\end{array}$ & 897 & 2.99 & 1.07 & & 3.9 & 1.0 \\
\hline $\begin{array}{l}\text { 18. We have been through well-executed changes in the } \\
\text { past, and we are confident of our capacity to implement this } \\
\text { change. }\end{array}$ & 886 & 3.56 & 0.95 & & 4.1 & 1.1 \\
\hline $\begin{array}{l}\text { The leaders of this change project ( } \mathrm{C} 2 \text { ) } \\
\text { (such as the head of curriculum change committee): }\end{array}$ & & & & 0.83 & & \\
\hline 19. Are committed to this change. & 925 & 4.01 & 0.84 & & 4.5 & 0.7 \\
\hline 20. Seem to accept full responsibility for this project. & 916 & 3.94 & 0.93 & & 4.2 & 0.6 \\
\hline 21. Have the authority to carry out the implementation. & 917 & 3.93 & 0.88 & & 4.6 & 0.6 \\
\hline 22. Work well with the implementation team. & 897 & 3.87 & 0.89 & & 4.5 & 0.5 \\
\hline 23. Share responsibility for this project. & 909 & 3.88 & 0.78 & & 4.4 & 0.6 \\
\hline $\begin{array}{l}\text { The members of the implementation team (C3) } \\
\text { (e.g. the curriculum change committee): }\end{array}$ & & & & 0.79 & & \\
\hline 24. Have clearly defined roles and responsibilities. & 893 & 3.54 & 0.94 & & 4.5 & 0.6 \\
\hline $\begin{array}{l}\text { 25. Have release time for this change project or can combine } \\
\text { the tasks with their regular work. }\end{array}$ & 898 & 3.24 & 1.02 & & 4.3 & 0.7 \\
\hline
\end{tabular}




\begin{tabular}{|c|c|c|c|c|c|c|}
\hline $\begin{array}{l}\text { 26. Have staff support and other resources required for the } \\
\text { project. }\end{array}$ & 901 & 3.26 & 1.03 & & 4.7 & 0.6 \\
\hline $\begin{array}{l}\text { Staff innovativeness (C4) } \\
\text { The majority of staff members involved with teaching: }\end{array}$ & & & & 0.69 & & \\
\hline $\begin{array}{l}\text { 27. Have a sense of personal responsibility for improving } \\
\text { education. }\end{array}$ & 937 & 3.82 & 0.89 & & 4.3 & 0.7 \\
\hline $\begin{array}{l}\text { 28. Are willing to innovate and/or experiment to improve } \\
\text { teaching. }\end{array}$ & 928 & 3.68 & 0.87 & & 4.2 & 0.8 \\
\hline Communication (C5) & & & & 0.92 & & \\
\hline $\begin{array}{l}\text { 29. There is good communication between project leaders and } \\
\text { staff members about the school's policy towards the change. }\end{array}$ & 923 & 3.42 & 0.99 & & 4.5 & 0.8 \\
\hline 30. The information provided about the change is clear. & 926 & 3.39 & 1.03 & & 4.5 & 0.5 \\
\hline $\begin{array}{l}\text { 31. In this school we are sufficiently informed about the prog- } \\
\text { ress of the change. }\end{array}$ & 924 & 3.28 & 1.02 & & 4.4 & 0.8 \\
\hline 32. Departments are sufficiently consulted about the change. & 913 & 3.28 & 1.04 & & 4.2 & 1.0 \\
\hline $\begin{array}{l}\text { 33. Staff members are sufficiently informed about the reasons } \\
\text { for the change. }\end{array}$ & 924 & 3.44 & 1.03 & & 4.3 & 0.9 \\
\hline $\begin{array}{l}\text { 34. Our medical school has a clear vision regarding this } \\
\text { change project. }\end{array}$ & 931 & 3.73 & 0,95 & & 4.5 & 0.8 \\
\hline $\begin{array}{l}\text { 35. Our vision of this change project is widely communicated } \\
\text { and understood throughout our medical school. }\end{array}$ & 931 & 3.32 & 1.00 & & 4.5 & 0.8 \\
\hline $\begin{array}{l}\text { Project resources (C6) } \\
\text { The following resources are available to make this change } \\
\text { project work: }\end{array}$ & & & & 0.87 & & \\
\hline 36. Financial resources; & 895 & 3.18 & 1.11 & & 4.7 & 0.6 \\
\hline $\begin{array}{l}\text { 37. Staff development (such as courses/workshops regarding } \\
\text { the change project); }\end{array}$ & 921 & 3.43 & 1.07 & & 4.6 & 0.6 \\
\hline 38. Facilities (such as teaching rooms, books, computers etc); & 922 & 3.44 & 1.10 & & 4.5 & 0.6 \\
\hline 39. Sufficient staff; & 922 & 2.99 & 1.13 & & 4.7 & 0.6 \\
\hline $\begin{array}{l}\text { 40. Incentives for staff that support the change project (either } \\
\text { financial, material, or promotional); }\end{array}$ & 900 & 2.71 & 1.12 & & 4.4 & 0.6 \\
\hline 41. Student awareness/needs; & 919 & 3.49 & 0.98 & & 4.1 & 0.7 \\
\hline 42. Evaluation protocol. & 895 & 3.34 & 1.05 & & 4.3 & 0.9 \\
\hline The implementation plan for this change project: $(\mathrm{C} 7)$ & & & & 0.87 & & \\
\hline 43. Identifies specific roles and responsibilities for staff. & 895 & 3.54 & 0.92 & & 4.3 & 0.7 \\
\hline 44. Clearly describes tasks and long term timelines. & 890 & 3.46 & 0.94 & & 4.3 & 0.7 \\
\hline 45. Includes appropriate staff/student training. & 894 & 3.39 & 0.98 & & 4.4 & 0.6 \\
\hline 46. Acknowledges staff input and opinions. & 894 & 3.54 & 0.95 & & 4.4 & 0.8 \\
\hline $\begin{array}{l}\text { External innovativeness inhibition (E1) } \\
\text { The majority of staff members involved with teaching: }\end{array}$ & & & & 0.69 & & \\
\hline $\begin{array}{l}\text { 47. Feel that there is ineffective cooperation between depart- } \\
\text { ments concerning educational issues. }\end{array}$ & 914 & 3.41 & 0.98 & & 3.9 & 0.7 \\
\hline $\begin{array}{l}\text { 48. Feel that many departments are afraid to lose power in } \\
\text { controlling the teaching of their discipline. }\end{array}$ & 916 & 3.44 & 1.06 & & 4.1 & 1.1 \\
\hline 49. Feel that this change will increase their workload. & 917 & 3.75 & 0.94 & & 4.3 & 0.8 \\
\hline 50. Feel restricted by strong hierarchy to express their views. & 913 & 2.93 & 1.08 & & 3.9 & 0.9 \\
\hline $\begin{array}{l}\text { 51. Are afraid to lose income when this change is imple- } \\
\text { mented. }\end{array}$ & 892 & 2.45 & 1.02 & & 3.8 & 1.0 \\
\hline Extrinsic motivation to change ( $E 2)$ & & & & 0.69 & & \\
\hline $\begin{array}{l}\text { 52. We have to change because our management wants us } \\
\text { to change. }\end{array}$ & 961 & 3.15 & 1.10 & & 3.6 & 1.0 \\
\hline $\begin{array}{l}\text { 53. In our school we feel pressure to go along with this } \\
\text { change. }\end{array}$ & 961 & 3.30 & 1.06 & & 3.9 & 0.7 \\
\hline
\end{tabular}


Table 1 (previous 2 pages): Final MORC questionnaire with number of respondents (N), means and standard deviations (SD), Cronbach's alpha scores (a), and results from the second round of the Delphi procedure (Delphi Mean and SD). $(R)=$ Reversed phrased. Scores are original scores. $M=$ Motivation, $\mathrm{C}=$ Capability, $\mathrm{E}=$ External pressure.

\section{Generalizability analysis (RQ 4 and 5)}

The school-related variance in the overall scores of MORC was $4 \%$ as determined by generalizability analysis. As the items were regarded as fixed, the addition of item-related variance resulted in $5.3 \%$ of systemic variance associated with schools. The variance associated with respondents nested within medical schools for the overall MORC score was $16 \%$ (Table 4 ). At least fifteen staff members had to complete MORC to obtain a sufficient generalizability coefficient $(>0.7)$ for all three dimensions. For a sufficient Standard Error of Measurement $(<0.26)$, completion of the questionnaire by at least five staff members was required.

In the two groups with different levels of national wealth the reliability coefficients (Table 3 ) and fit indices remained stable (NNFI= 0.88-0.92, RMSEA=0.061-0.076, SRMR $=0.061-0.076$ ), confirming the international applicability of MORC.

\begin{tabular}{|c|c|c|c|}
\hline Main scales & Subscales & Items & $\begin{array}{l}\text { Original subscale from } \\
\text { which it was adapted }\end{array}$ \\
\hline $\begin{array}{l}\text { M1. Pressure for } \\
\text { change }\end{array}$ & $\begin{array}{l}\text { M1. Pressure for } \\
\text { change }\end{array}$ & 7 & Pressure for change $\mathrm{e}^{13}$ \\
\hline M2. Need for change & M2. Need for change & 2 & Discrepancy ${ }^{12}$ \\
\hline M3. Appropriateness & M3. Appropriateness & 6 & $\begin{array}{l}\text { Valence }{ }^{12} \& \text { Commitment to } \\
\text { change }^{39}\end{array}$ \\
\hline C1. Efficacy & C1. Efficacy & 3 & Efficacy $^{12}$ \\
\hline C2. Support climate & $\begin{array}{l}\text { 1. Leaders of the } \\
\text { change project } \\
\text { 2. Implementation } \\
\text { team } \\
\text { 3. Staff innovative- } \\
\text { ness } \\
\text { 4. Communication } \\
\text { 5. Project resources }\end{array}$ & $\begin{array}{l}5 \\
3 \\
2 \\
7 \\
7\end{array}$ & $\begin{array}{l}\text { 1. Project champion roles } \\
\text { \& Management support } \\
\text { 2. Implementation team } \\
\text { roles }^{40} \\
\text { 3. Staff culture } \\
\text { cohesiveness }^{40} \text { and Staff } \\
\text { 4. Involvement }{ }^{27} \& \text { Com- }^{-} \\
\text {mitment } \\
\text { 5. Project resources }\end{array}$ \\
\hline $\begin{array}{l}\text { C3. Facilitation strate- } \\
\text { gies }\end{array}$ & $\begin{array}{l}\text { C3. Implementation } \\
\text { plan }\end{array}$ & 4 & Implementation plan ${ }^{40}$ \\
\hline $\begin{array}{l}\text { E1. External innovative- } \\
\text { ness inhibition }\end{array}$ & $\begin{array}{l}\text { E1. External innova- } \\
\text { tiveness inhibition }\end{array}$ & 5 & $\begin{array}{l}\text { Staff culture }{ }^{40} \text { and Staff } \\
\text { cohesiveness }^{13}\end{array}$ \\
\hline $\begin{array}{l}\text { E2. Extrinsic motivation } \\
\text { to change }\end{array}$ & $\begin{array}{l}\text { E2. Extrinsic moti- } \\
\text { vation to change }\end{array}$ & 2 & Commitment to change ${ }^{39}$ \\
\hline Total & & 53 & \\
\hline
\end{tabular}

Table 2: Main scales, subscales, number of items per subscale, and the original subscales. M1-3: Motivation factors. C1-C3: Capability factors. E1-2: External pressure factors. 


\begin{tabular}{|l|l|l|l|l|l|l|l|}
\hline Dimension & CFI & NNFI & RMSEA & SRMR & $\begin{array}{c}\text { a } \\
\text { Whole } \\
\text { group }\end{array}$ & $\begin{array}{c}\text { a } \\
\text { GDP } \\
\text { high }\end{array}$ & $\begin{array}{c}\text { a } \\
\text { GDP } \\
\text { low }\end{array}$ \\
\hline Motivation & 0.906 & $\mathbf{0 . 8 9 4}$ & 0.063 & 0.047 & 0.81 & 0.77 & 0.85 \\
\hline Capability & 0.945 & 0.925 & 0.061 & 0.037 & 0.95 & 0.95 & 0.95 \\
\hline External pressure & 0.945 & 0.912 & 0.069 & 0.039 & $\mathbf{0 . 6 7}$ & $\mathbf{0 . 6 9}$ & $\mathbf{0 . 6 6}$ \\
\hline
\end{tabular}

Table 3: Goodness of fit measures from CFA and Cronbach's alpha (a) of the whole group ( $a>0.7$ ), of the group with GDP PPP $>\$ 20.000$ (GDP high) and the group with GDP PPP $<\$ 20.000$ (GDP low) The Comparative Fit Index (CFI $>0.9)$, Non-Normed Fit Index (NNFI $>0.9$ ), Root Mean Square Error of Approximation (RMSEA<0.08); and Standardized Root Mean Square Residual (SRMR $<0.05)$. Bold means beyond range.

\begin{tabular}{|c|c|c|c|c|c|c|}
\hline Subscale & $\mathbf{S}$ & R:S & $\mathbf{I}$ & SI & RI:S,e & MinR \\
\hline 1 Pressure for change (M) & 0.01 & 0.24 & 0.24 & 0.12 & 0.64 & $26(5)$ \\
\hline 2 Need for change (M) & 0.07 & 0.40 & 0.00 & 0.02 & 0.38 & $16(9)$ \\
\hline 3 Appropriateness (M) & 0.06 & 0.27 & 0.06 & 0.07 & 0.46 & $12(5)$ \\
\hline 4 Efficacy (C) & 0.09 & 0.26 & 0.20 & 0.05 & 0.45 & $9(6)$ \\
\hline $\begin{array}{l}5 \text { The leaders of this change project } \\
\text { (C) }\end{array}$ & 0.06 & 0.27 & 0.00 & 0.03 & 0.32 & $11(5)$ \\
\hline $\begin{array}{l}6 \text { The members of the implementa- } \\
\text { tion team }(C)\end{array}$ & 0.06 & 0.44 & 0.03 & 0.03 & 0.36 & $19(8)$ \\
\hline 7 Staff innovativeness (C) & 0.05 & 0.37 & 0.01 & 0.01 & 0.28 & $20(8)$ \\
\hline 8 Communication (C) & 0.10 & 0.51 & 0.02 & 0.02 & 0.33 & $13(8)$ \\
\hline 9 Project resources (C) & 0.11 & 0.44 & 0.08 & 0.07 & 0.46 & $10(8)$ \\
\hline 10 The implementation plan (C) & 0.07 & 0.44 & 0.00 & 0.02 & 0.28 & $17(8)$ \\
\hline $\begin{array}{l}11 \text { External innovativeness inhibi- } \\
\text { tion (E) }\end{array}$ & 0.04 & 0.24 & 0.26 & 0.05 & 0.61 & $16(6)$ \\
\hline $\begin{array}{l}12 \text { Extrinsic motivation to change } \\
\text { (E) }\end{array}$ & 0.09 & 0.50 & 0.01 & 0.02 & 0.52 & $18(11)$ \\
\hline \multicolumn{7}{|l|}{ Dimension } \\
\hline Motivation (M) & 0.03 & 0.18 & 0.15 & 0.09 & 0.62 & $15(4)$ \\
\hline Capability (C) & 0.07 & 0.27 & 0.09 & 0.05 & 0.50 & $10(5)$ \\
\hline Extrinsic pressure (E) & 0.03 & 0.19 & 0.18 & 0.07 & 0.72 & $16(5)$ \\
\hline Total & 0.04 & 0.16 & 0.20 & 0.08 & 0.63 & $11(3)$ \\
\hline
\end{tabular}

Table 4: Variance component estimates and number of raters required for reliable score. Variance component estimates for: $\mathrm{S}=$ schools, $\mathrm{R}: \mathrm{S}=$ raters within schools, $\mathrm{I}=$ items, $\mathrm{SI}=$ school by item interaction and $\mathrm{RI}: \mathrm{S}, \mathrm{e}=$ residual. MinR= Number of raters required for Generalizability coefficient $>0.7$ (and $\mathrm{SEM}<0.26$ ), $\mathrm{M}=$ motivation dimension. $\mathrm{C}=$ capability dimension. $\mathrm{E}=$ external pressure dimension. 


\section{Discussion}

The aim of this study was to develop and validate a questionnaire for measuring Medical school's Organizational Readiness for curriculum Change (MORC). Most studies on questionnaires measuring organizational readiness for change report limited evidence of validity and reliability ${ }^{3,12}$. Our approach comprising a conceptual model, a modified Delphi procedure, EFA, CFA, generalizability analysis, and a large international sample of participants yielded a solid basis for validation. Despite the fact that our conceptual model was based on a Western theory, the results suggest that MORC is a valid questionnaire which is applicable in different cultures and yields reliable results with five to fifteen respondents.

Contrary to our assumption of two underlying dimensions, i.e. 'motivation' and 'capability', the analysis revealed a third dimension, which we labeled 'external pressure', because the items originated from capability subscales addressing external factors inhibiting change and motivational subscales addressing extrinsic motivation. A distinction between intrinsic and extrinsic motivation in relation to organizational change was also made by Herscovitch ${ }^{39}$, who showed that internally motivated organizational members featured higher levels of support for change projects. Since organizational readiness is not a homogenous construct, caution is required in comparing overall MORC scores within and between different medical schools. The potential strength of MORC lies in the comparison of subscale scores, for instance between sequential MORC administrations within one school to measure the effects of an intervention aimed at facilitating curriculum change ${ }^{13,14}$.

A limitation of this study is the relatively large number of missing answers in the questionnaire: up to $8.8 \%$ for MORC and $23.2 \%$ for the general characteristics. Possibly the respondents got 'tired' from the relatively large questionnaire, as the general questions were positioned as final questions.

Another limitation is the inability to provide a response rate of the invited participants. We have been able to provide a response rate for the invited contact persons of Maastricht University(66\%), but because these contact persons were responsible for inviting staff members in their medical schools, we had no insight in how many people in total were invited to participate. 
A further potential limitation is socially acceptable answers ${ }^{42}$. It may not be coincidental that the subscale on the capability of management did not show a coherent factor structure (data not shown). Despite the anonymity of the survey, participants may have been reluctant to judge their superiors.

A third limitation could be the relative low Cronbach Alpha scores for the subscale external pressure (0.67-0.69). The calculation of Cronbach Alpha scores includes the number of items, with a lower number of items deflating the score. The subscale external pressure only consists of three items which could explain the relative low scores.

The validated MORC can be used in medical schools in different countries to shed light on issues related to curriculum change, for instance to determine whether, as has been argued ${ }^{43}$, bottom-up pressure for change is in fact more effective than top-down pressure (subscale 1) or whether the most effective type of pressure varies with the setting and culture of medical schools ${ }^{11,16,18,22,23,26,44}$. Authoritative leadership and top-down pressure may be very effective when they are widely accepted within the organization and members feel sufficiently consulted and informed (subscale 8$)^{45}$. Although MORC is developed for medical schools (preparing) changing their curriculum, with minor adaptations the questionnaire could also be used for other change processes in medical schools and for other settings, such as for allied health professionals education and within hospitals.

Although MORC focuses on faculty to the neglect of students, students obviously have an important contribution to make to curriculum change, and it would be interesting to combine MORC results with students' opinions, for instance obtained using the Dundee Ready Educational Environment Measure (DREEM) questionnaire ${ }^{46}$.

The medical education experts who participated in the Delphi procedure were asked to rate the relevance of aspects of curriculum change, but not to differentiate between the importance of items during different phases of curriculum change ${ }^{8}$. We included participants from schools in the preparation or implementation phase of curriculum change, but it would also be interesting to administer an adapted MORC in medical schools in the institutionalization phase to determine, in retrospect, whether determinants of successful change vary between the phases of curriculum change. 


\section{References}

1. Frenk J, Chen L, Bhutta ZA, Cohen J, Crisp N, Evans T, et al. Health professionals for a new century: transforming education to strengthen health systems in an interdependent world. Lancet. 2010;376(9756):1923-58.

2. Barón M. Innovation in Spanish medical education: hopes and frustrations. In: Majoor G, van der Vleuten C, Vluggen P, Hansen P, editors. MedEd-21: An Account of Initiatives for Change in Medical Education in Europe for the 21st Century. Amsterdam: Thesis Publishers; 1997.

3. Weiner BJ, Amick H, Lee SYD. Conceptualization and measurement of organizational readiness for change - A review of the literature in health services research and other fields. Medical Care Research and Review. 2008;65(4):379436.

4. DeLong Goldman G. Initial Validation of a Brief Individual Readiness for Change Scale (BIRCS) for Use With Addiction Program Staff Practitioners. Journal of Social Work Practice in the Addictions. 2009;9(2):184-203.

5. Malau-aduli BS, Zimitat C, Malau-aduli AEO. Quality assured assessment processes: Évaluation de la réponse des personnels au changement des processus d' assurance qualité: une étude de cas. Higher Education Management and Policy. 2011;23:1-24.

6. Bland CJ, Starnaman S, Wersal L, Moorehead-Rosenberg L, Zonia S, Henry R. Curricular change in medical schools: how to succeed. Academic Medicine. 2000;75(6):575-94.

7. Bordage G, Harris I. Making a difference in curriculum reform and decisionmaking processes. Medical Education. 2011;45(1):87-94.

8. Greenhalgh T, Robert G, Macfarlane F, Bate P, Kyriakidou O. Diffusion of innovations in service organizations: systematic review and recommendations. Milbank Quarterly. 2004;82(4):581-629.

9. Fleuren M, Wiefferink K, Paulussen T. Determinants of innovation within health care organizations Literature review and Delphi study. Quality In Health Care. 2004; 16:107-23.

10. Kotter JP. Leading Change. Boston: Harvard Business School Press 1995.

11. Armenakis AA, Harris SG, Mossholder KW. Creating readiness for organizational change Human Relations. 1993;46(6):681-703.

12. Holt DT, Armenakis AA, Feild HS, Harris SG. Readiness for Organizational Change: The Systematic Development of a Scale. The Journal of Applied Behavioral Science. 2007;43(2):232-55.

13. Lehman WEK, Greener JM, Simpson DD. Assessing organizational readiness for change. Journal of Substance Abuse Treatment. 2002;22(4):197-209.

14. Kraut A. Organizational Surveys: Tools for Assessment and Change: JosseyBass Publishers, San Francisco 1996.

15. Holt DT, Armenakis AA, Harris SG, Feild HS. Toward a comprehensive definition of readiness for change: a review of research and instrumentation. In: Pasmore WA, Woodman RW, editors. Research in organizational change and development. Oxford: Emerald Group Publishing Limited; 2007. p. 289-336.

16. Eslaminejad T, Masood M, Ngah NA. Assessment of instructors' readiness for implementing e-learning in continuing medical education in Iran. Medical Teacher. 2010;32(10):e407-12.

17. Christl B, Harris MF, Jayasinghe UW, Proudfoot J, Taggart J, Tan J, et al. Readiness for organisational change among general practice staff. Quality \& Safety in Health Care. 2010;19:1-4.

18. Ingersoll GL, Kirsch JC, Merk SE, Lightfoot J. Relationship of organizational culture and readiness for change to employee commitment to the organization. Journal of Nursing Administration. 2000;30(1):11-20. 
19. Hagedorn $\mathrm{HJ}$, Heideman PW. The relationship between baseline Organizational Readiness to Change Assessment subscale scores and implementation of hepatitis prevention services in substance use disorders treatment clinics: a case study. Implementation Science. 2010;5(46):1-12.

20. Molla A, Licker PS. Perceived E-Readiness Factors in E-Commerce Adoption : An Empirical Investigation in a Developing Country. International Journal of Electronic Commerce. 2005;10(1):83-110.

21. Sadik A. The Readiness of Faculty Members to Develop and Implement E-Learning: The Case of an Egyptian University. International Journal on E-Learning. 2007;6(3):433-53.

22. Weiner BJ. A theory of organizational readiness for change. Implementation Science. 2009;4(67):1-9.

23. Jones RA, Jimmieson NL, Griffiths A. The impact of organizational culture and reshaping capabilities on change implementation success: The mediating role of readiness for change. Journal of Management Studies. 2005;42(2):361-86.

24. Holt DT, Helfrich CD, Hall CG, Weiner BJ. Are You Ready? How Health Professionals Can Comprehensively Conceptualize Readiness for Change. Journal of General Internal Medicine. 2010;25:50-5.

25. Wanberg CR, Banas JT. Predictors and outcomes of openness to changes in a reorganizing workplace. The Journal of applied psychology. 2000;85:132-42.

26. Eby LT, Adams DM, Russell JEA, Gaby SH. Perceptions of Organizational Readiness for Change: Factors Related to Employees' Reactions to the Implementation of Team-Based Selling. Human Relations. 2000;53(3):419-42.

27. Bouckenooghe D, Devos G, Van den Broeck H. Organizational Change Questionnaire-Climate of Change, Processes, and Readiness: Development of a New Instrument. Journal of Psychology. 2009;143(6):559-99.

28. Fink A, Kosecoff J, Chassin M, Brook RH. Consensus methods: characteristics and guidelines for use. American Journal of Public Health. 1984;74(9):979-83.

29. Jones J, Hunter D. Qualitative Research: Consensus methods for medical and health services research. BMJ. 1995;311(7001):376-80.

30. Boor K, Van Der Vleuten C, Teunissen P, Scherpbier A, Scheele F. Development and analysis of D-RECT, an instrument measuring residents? learning climate. Medical Teacher. 2011;33(10):820-827.

31. Holey E, Feeley J, Dixon J, Whittaker V. An exploration of the use of simple statistics to measure consensus and stability in Delphi studies. BMC Medical Research Methodology. 2007;7(1):52.

32. Violato $\mathrm{C}$, Hecker KG. How to use structural equation modeling in medical education research: a brief guide. Teaching and learning in medicine. 2007; 19(4):362-71.

33. McDonald RP, Ho M-HR. Principles and practice in reporting structural equation analyses. Psychological Methods. 2002;7(1):64-82.

34. Hu L-t, Bentler PM. Fit indices in covariance structure modeling: Sensitivity to underparameterized model misspecification. Psychological Methods. 1998;3(4):424-53.

35. Crossley J, Davies H, Humphris G, Jolly B. Generalisability: a key to unlock professional assessment. Medical Education. 2002;36(10):972-8.

36. Stalmeijer RE, Dolmans DHJM, Wolfhagen IHaP, Muijtjens AMM, Scherpbier AJJa. The Maastricht Clinical Teaching Questionnaire (MCTQ) as a valid and reliable instrument for the evaluation of clinical teachers. Academic Medicine. 2010;85:1732-8.

37. Jippes M, Driessen EW, Majoor GD, Gijselaers WH, Muijtjens AM, van der Vleuten CPM. Impact of national context and culture on curriculum change: A case study. Accepted for publication Medical Teacher.

38. $\quad$ Allison P. Missing data. London: Thousand Oaks: Sage 2001. 
39. Herscovitch L, Meyer JP. Commitment to organizational change: Extension of a three-component model. Journal of Applied Psychology. 2002;87:474-87.

40. Helfrich CD, Li Y-F, Sharp ND, Sales AE. Organizational readiness to change assessment (ORCA): development of an instrument based on the Promoting Action on Research in Health Services (PARIHS) framework. Implementation Science. 2009;4(38):1-13.

41. Molla A, Licker P. eCommerce adoption in developing countries: a model and instrument. Information \& Management. 2005;42:877-99.

42. Gronlund N. How to construct achievement tests. 4th ed. Englewood Cliffs N.J.: Prentice-Hall 1987.

43. Evans R. The Human Side of School Change. Reform, Resistance, and the Reallife Problems of Innovation. San Francisco: Jossey-Bass Publishers 1996.

44. Kovačić ZJ. The Impact of National Culture on Worldwide eGovernment Readiness eGovernment Readiness. Informing Science Journal. 2005;8:143-58.

45. Den Hartog DN, House RJ, Hanges PJ, Ruiz-Quintanilla SA, Dorfman PW. Culture specific and cross-culturally generalizable implicit leadership theories: are attributes of charismatic/transformation leadership universally endorsed? Leadership Quarterly. 1999;10:219-56.

46. Edgren G, Haffling A-C, Jakobsson U, McAleer S, Danielsen N. Comparing the educational environment (as measured by DREEM) at two different stages of curriculum reform. Medical Teacher. 2010;32:e233-8. 


\section{Appendix A}

\begin{tabular}{|c|c|}
\hline Variable & Percentage \\
\hline $\begin{array}{l}\text { Gender } \\
\text { - Male } \\
\text { - Female } \\
\text { - Missing }\end{array}$ & $\begin{array}{l}47,9 \% \\
37,2 \% \\
14,8 \%\end{array}$ \\
\hline $\begin{array}{l}\text { Age } \\
-20-35 \text { years } \\
-36-50 \text { years } \\
-51-65 \text { years } \\
-65-85 \text { years } \\
- \text { Missing }\end{array}$ & $\begin{array}{c}12,5 \% \\
37,8 \% \\
31,3 \% \\
3,0 \% \\
15,4 \%\end{array}$ \\
\hline $\begin{array}{l}\text { Participation } \\
\text { - Active in the change process } \\
\text { - Non- active in the change process } \\
\text { - Missing }\end{array}$ & $\begin{array}{l}53,2 \% \\
32,7 \% \\
14,1 \%\end{array}$ \\
\hline $\begin{array}{l}\text { Type of respondents } \\
\text { - Specialists } \\
\text { - Basic scientists } \\
\text { - Management \& administration } \\
\text { - Other (including educationalist, GP) } \\
\text { - Missing }\end{array}$ & $\begin{array}{c}36,6 \% \\
13,4 \% \\
6,9 \% \\
19,9 \% \\
23,2 \%\end{array}$ \\
\hline $\begin{array}{l}\text { Object of change } \\
\text { - Undergraduate curriculum change } \\
\text { - Postgraduate curriculum change } \\
\text { - Missing }\end{array}$ & $\begin{array}{c}78,1 \% \\
6,3 \% \\
15,6 \%\end{array}$ \\
\hline $\begin{array}{l}\text { Type of change } \\
\text { - All students in completely new curriculum } \\
\text { - Part of students in completely new curriculum } \\
\text { - Exams only } \\
\text { - Skills only } \\
\text { - Missing }\end{array}$ & $\begin{array}{c}60,7 \% \\
19,7 \% \\
0,8 \% \\
2,3 \% \\
16,4 \%\end{array}$ \\
\hline $\begin{array}{l}\text { Phase of change } \\
\text { - Preparation } \\
\text { - Implementation (first } 2 \text { years) } \\
\text { - Implementation ( }>2 \text { years) }\end{array}$ & $\begin{array}{l}42,6 \% \\
28,7 \% \\
28,7 \%\end{array}$ \\
\hline $\begin{array}{l}\text { Size of medical school } \\
\text { - Less than } 50 \text { students per year } \\
\text { - } 51-100 \text { students per year } \\
\text { - } 101-200 \text { students per year } \\
\text { - More than } 200 \text { students per year } \\
\text { - Missing }\end{array}$ & $\begin{array}{l}5,3 \% \\
17 \% \\
32,5 \% \\
30,9 \% \\
14,3 \%\end{array}$ \\
\hline
\end{tabular}

Characteristics of the respondents, their medical schools, and the change processes in the schools. 


\section{Appendix B}

\begin{tabular}{|c|c|c|}
\hline Country & $\begin{array}{l}\text { Number of med- } \\
\text { ical schools }\end{array}$ & $\begin{array}{l}\text { Number of } \\
\text { participants }\end{array}$ \\
\hline Albania & 1 & 9 \\
\hline Australia & 7 & 42 \\
\hline Austria & 2 & 4 \\
\hline Azerbadjan & 2 & 10 \\
\hline Bahrain & 1 & 10 \\
\hline Belgium & 3 & 51 \\
\hline Brazil & 1 & 1 \\
\hline Canada & 5 & 57 \\
\hline Chile & 2 & 26 \\
\hline China & 2 & 8 \\
\hline Colombia & 1 & 7 \\
\hline Dominica & 1 & 3 \\
\hline Ecuador & 1 & 17 \\
\hline El Salvador & 1 & 6 \\
\hline Ethiopia & 1 & 16 \\
\hline Finland & 1 & 1 \\
\hline Georgia & 2 & 14 \\
\hline Ghana & 1 & 9 \\
\hline India & 7 & 7 \\
\hline Indonesia & 8 & 111 \\
\hline Iran & 3 & 3 \\
\hline Israel & 1 & 7 \\
\hline Italy & 4 & 8 \\
\hline Japan & 10 & 42 \\
\hline Kazakhstan & 1 & 3 \\
\hline Kuwait & 1 & 8 \\
\hline Malaysia & 1 & 9 \\
\hline Mexico & 4 & 29 \\
\hline Nepal & 5 & 35 \\
\hline Netherlands & 3 & 23 \\
\hline New Zealand & 2 & 28 \\
\hline Norway & 1 & 5 \\
\hline Oman & 1 & 3 \\
\hline Pakistan & 2 & 13 \\
\hline Phillipines & 3 & 12 \\
\hline
\end{tabular}


104 CHAPTER 05

Appendix B continued

\begin{tabular}{|l|c|c|}
\hline Country & $\begin{array}{l}\text { Number of med- } \\
\text { ical schools }\end{array}$ & $\begin{array}{l}\text { Number of } \\
\text { participants }\end{array}$ \\
\hline Poland & 1 & 18 \\
\hline Romania & 1 & 29 \\
\hline S. Korea & 2 & 20 \\
\hline Saudi Arabia & 2 & 15 \\
\hline Singapore & 2 & 13 \\
\hline Spain & 5 & 30 \\
\hline Sudan & 1 & 11 \\
\hline Sweden & 2 & 14 \\
\hline Switzerland & 4 & 12 \\
\hline Thailand & 1 & 5 \\
\hline Tunisia & 1 & 15 \\
\hline Turkey & 3 & 50 \\
\hline UAE & 1 & 6 \\
\hline Uganda & 3 & 25 \\
\hline UK & 1 & 12 \\
\hline Ukrain & 1 & 13 \\
\hline Uruguay & 3 & 33 \\
\hline USA & 2 & $9 \mathbf{9 1}$ \\
\hline Vietnam & 131 & \\
\hline Yemen & & 2 \\
\hline Total & & \\
\hline & & \\
\hline
\end{tabular}

Number of medical schools and participants per country. 
DEVELOPMENT AND VALIDATION OF MORC $\mid 105$ 

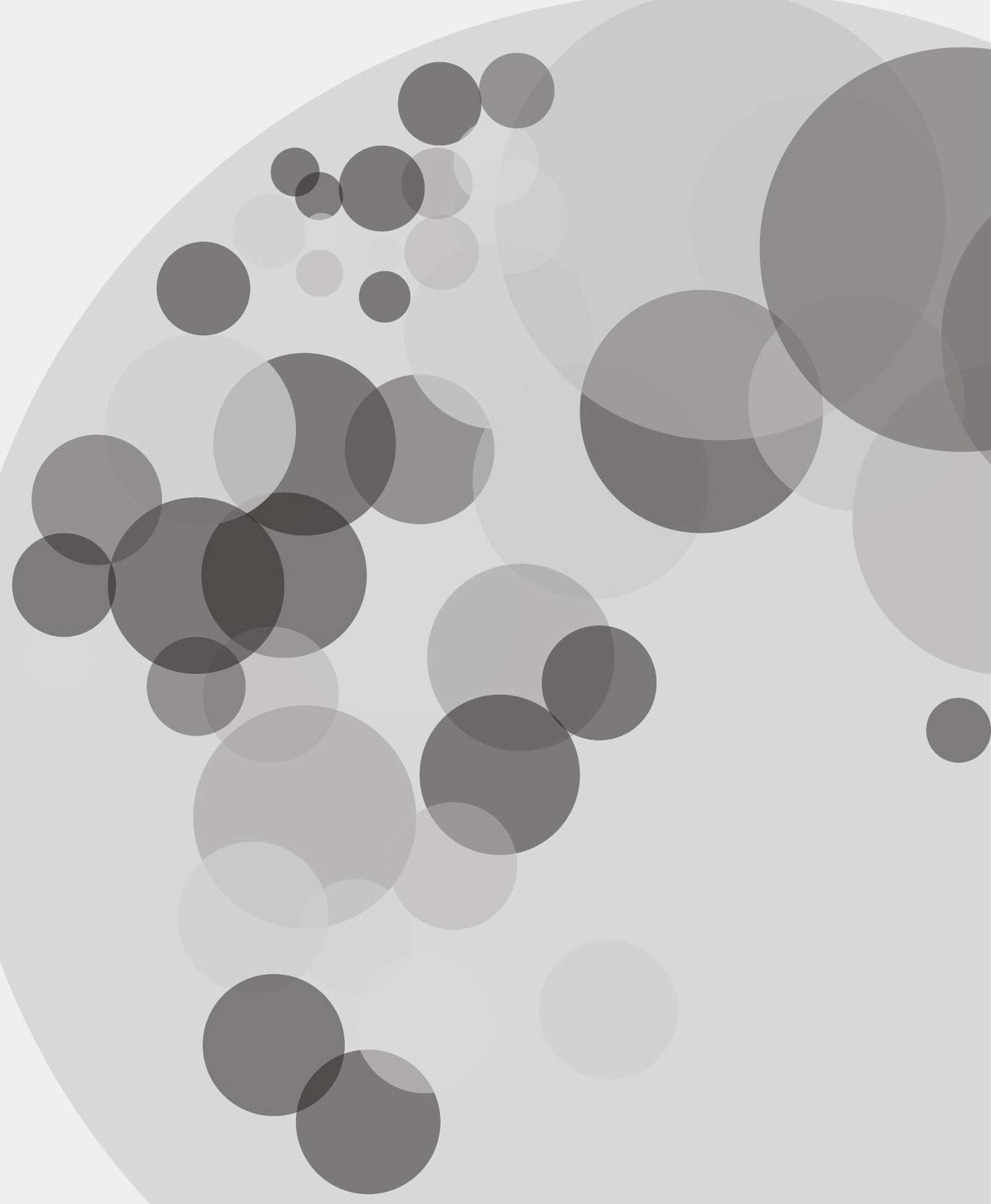


\section{CHAPTER 6}

CULTURE MATTERS

IN SUCCESSFUL

CURRICULUM CHANGE:

THE INFLUENCE OF NATIONAL AND ORGANISATIONAL CULTURE TESTED WITH MULTILEVEL STRUCTURAL EQUATION MODELING

Mariëlle Jippes, Erik W. Driessen, Nick J Broers, Gerard D. Majoor, Wim H. Gijselaers, and Cees P.M. van der Vleuten Under editorial review 


\section{Abstract}

Introduction: Research demonstrated an influence of national culture on successful curriculum change in medical schools. Equally, research conducted in commercial organisations has shown the influence of organisational culture on change processes. Intuitively, national culture influences change through organisational culture, but scarce knowledge exists on this supposed relation. Our aim therefore is to explore the influences of national and organisational culture on successful curriculum change in medical schools.

Method: Cross-sectional survey data were collected in 2012 through contacts of Maastricht University at medical schools (preparing) changing their curriculum, resulting in 991 participants of 131 medical schools in 56 countries. A conceptual model based on existing literature was tested using multilevel structural equation modeling. National culture was operationalised with Hofstede's ${ }^{1}$ dimensions of culture, organisational culture with Quinn's ${ }^{2}$ competing values framework and successful curriculum change with Medical school's Organisational Readiness for curriculum Change (MORC) ${ }^{3}$ and change-related behaviour ${ }^{4}$.

Results: The initial model showed a poor fit, but two suggested modifications improved the fit to a reasonable level. Some characteristics of national culture (power distance and uncertainty avoidance) had an influence on organisational culture (internal process and rational goal respectively). Characteristics of both national (power distance and uncertainty avoidance) and organisational culture (human relations and open systems) were found to have direct effects on successful curriculum change. National culture could explain large differences in readiness for change between different medical schools and organisational culture could explain large differences in readiness for change within different medical schools.

Discussion: Thus, successful curriculum change is influenced by national as well as organisational culture. Medical schools (considering) changing their curriculum should therefore take into the potential impact of their national and organisational culture in the change process. Poor initial fit of our conceptual model may have been due to limited sample size, requiring further research with a larger sample. 


\section{Introduction}

Healthcare continues to be a major topic of debate in many countries. Several issues drive this debate, including rising $\operatorname{costs}^{5}$ and medical errors $^{6,7}$. These problems may in part be addressed by changing the attitude of physicians. A key to change physicians' behaviour may lie in improving their education ${ }^{8-10}$. Medical education faced a rising demand for improvement due to inadequate preparation of graduates for practising medicine, caused by shortcomings of the medical curricula: theoretical overload, lack of practical experience, insufficient community orientation and inefficient teaching methods ${ }^{11-13}$. About one third of all medical schools adopted integrated and Problem-Based Learning (PBL) curricula in response to these issues ${ }^{14}$. Many medical schools failed to change successfully, which has been attributed to national culture ${ }^{14,15}$. Variation in success of organizational change attempts has been attributed to organisational culture as well ${ }^{16-19}$. Intuitively national values, beliefs and practices must influence the values, beliefs and behaviour of organisations in a country ${ }^{20}$. However, empirical research studying the influence of national culture on organisational culture is sparse in business organisations and to our knowledge lacking for medical education $^{20-23}$. In essence, organisations in one country vary due to differences in organisational culture, but organisations in different countries vary even more due to the additional influence of national culture ${ }^{20,22}$.

There is an increasing demand to elaborate the influence of contextual factors on changes in health care and medical education" ${ }^{24}$. More insight in how context factors, including national and organisational culture facilitate or inhibit successful curriculum change could enhance the chance of successful change in medical schools worldwide. In this study we will therefore explore the influence of national and organisational culture on successful curriculum change in medical schools. In the following paragraphs we will elaborate on the existing literature about concepts used (i.e. successful curriculum change, national and organisational culture) and their operationalisations for this study. Presumed relations between elements of these operationalisations based on existing literature have been captured in seven hypotheses $(H)$ and inserted in a conceptual model (Figure 1 ). 


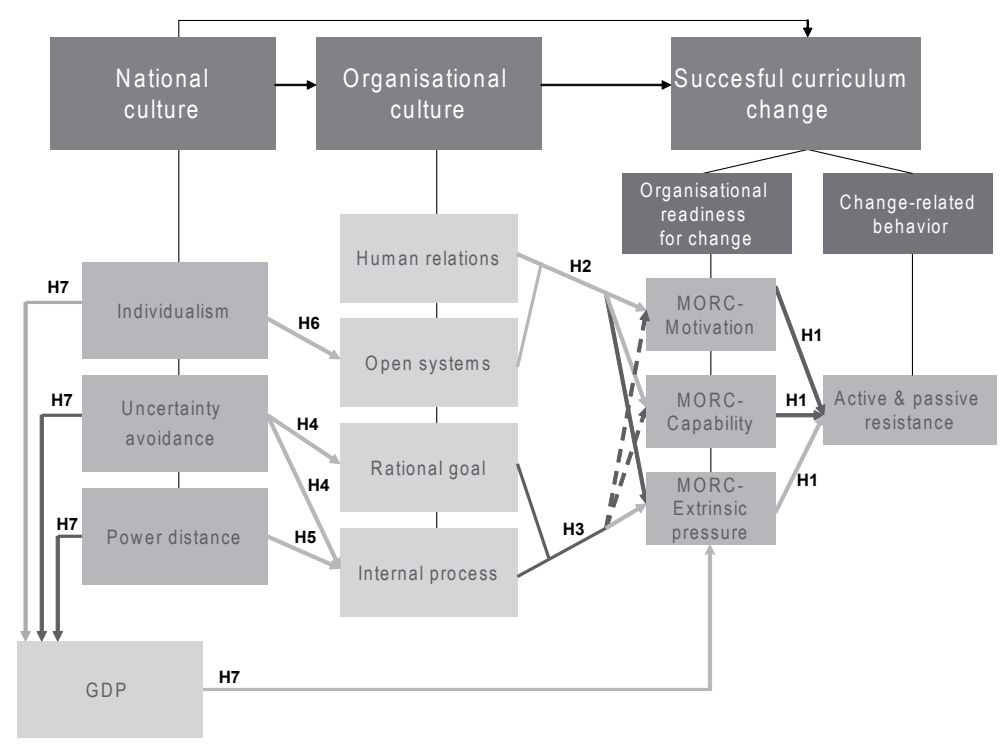

Figure 1: Conceptual model relating national culture, organisational culture and successful change implementation. Note: dark grey boxes with white letters entail the theoretical concepts and the light grey boxes with dark letters represent their operationalisations. $H=$ hypothesis. GDP= Gross Domestic Product. Dark arrows indicate positive relations and light arrows indicate negative relations.

\section{Successful curriculum change}

Although many change attempts are successful, almost as many fail prematurely: change failures in business organisations are estimated between 20 and $70 \%{ }^{25,}{ }^{26}$. Failure has been attributed to various factors, and to an insufficient level of Organisational Readiness for Change (ORC) in particular ${ }^{25,27-29}$. Organizational readiness for change is reflected in the need and capacity of an organization to successfully implement change and is used as one approach to operationalise successful curriculum change in this study ${ }^{29}$.

Positive employee attitudes showed to increase the chance of successful change ${ }^{30}$. Employees' reaction to change ranges from seeing the possible value of change with adjacent chances to grow and learn, towards mainly seeing the possible threats and uncertainties ${ }^{30}$. Therefore the second operationalisation of successful curriculum change in this study is the ratio of supportive versus resistant faculty behaviour with respect to a change initiative. We expected fewer people to resist change in medical schools with higher levels of readiness for change. We derived the following hypothesis:

H1: Medical schools with higher levels of ORC will have lower levels of resistance. 


\section{Organizational culture}

There is a large variety in definitions ${ }^{31}$ and measurement instruments ${ }^{32}$ available to gain a deeper understanding of organizational culture. The survey of Kalliath and colleagues ${ }^{33}$, based on the Competing Values Framework of Quinn seemed most appropriate for our setting and purpose, because it is compact and widely used and was also applied in health care settings ${ }^{32,33}$. The Competing Values Framework was originally developed in an educational organisation and reflects elements of organisational effectiveness constructed through consensus by an expert panel ${ }^{2}$. The criteria of effectiveness were sorted originally according to three axes or value dimensions: flexibility-control, internalexternal, and means-ends. Eventually, the first two dimensions showed to be sufficient to describe the organisational effectiveness construct. The first dimension flexibility-control relates to the organisational focus, either internal with emphasis on employee' well-being, or external with emphasis on the well-being of the organisation itself. The second dimension internal-external relates to the organisational structure, with either a focus on flexibility or stability. These two dimensions form a quadrant with four different competing value types: human relations, open systems, rational goal and internal process (Figure 2). Organisations scoring high on human relations emphasize flexibility and internal focus where trust, belongingness and teamwork are highly valued. Organisations scoring high on open systems emphasize flexibility and external focus where adaptation to the external environment, growth and innovation are dominant values. Organisations scoring high on rational goal emphasize control and external focus where efficiency, performance and goal clarity are main values. Lastly, organisations scoring high on internal process emphasize control and internal focus where routinization, centralization, stability and order are dominant values.

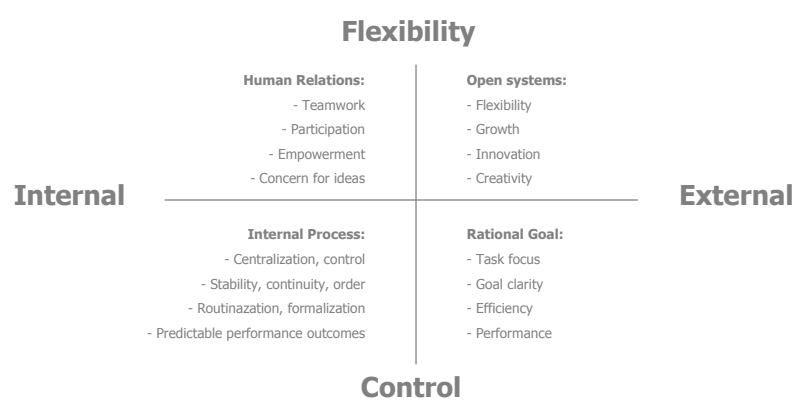

Figure 2: The Competing Values Framework of organizational effectiveness. Figure of the 'The Competing Values Framework' is reproduced with permission from Kalliath et al. ${ }^{33}$ and Quinn and Spreitzer². 
Specific types of organisational culture have been shown to influence change positively. Flexible organisations (human relations and open systems types) often respond more positively towards change than organisations with more controlled policies and procedures (rational goal and internal process types) ${ }^{27,34,35}$. Organisations scoring high on human relations tend to have a more supportive and participative culture, which stimulates organisational readiness for change ${ }^{27}$. This suggests:

H2: Medical schools with more flexible policies and procedures (organisational types human relations and open systems) have higher levels ORC

H3: Medical schools with more controlled policies and procedures (organisational types rational goal and internal process) have lower levels of ORC

\section{National culture}

Several attempts have been made to define and quantify national culture $^{1,23,36-38}$. The most frequently used model of national culture was developed by Hofstede and consists of five dimensions ${ }^{1}$. Power distance describes the degree of tolerance of hierarchical or unequal relationships. Uncertainty avoidance describes the degree of acceptance of uncertainty and the willingness to take risks, which is among others, expressed in need for predictability: a need for written and unwritten rules. Individualism refers to the degree of emphasis placed on an individual's accomplishment and Masculinity refers to degree of appreciation of materialism and assertiveness.

Several characteristics of national culture have been shown to influence the innovativeness of organizations. Organizations in countries with high levels of uncertainty avoidance adopted change less frequently ${ }^{39-42}$. Similar patterns were found in medical schools, with schools in countries with higher uncertainty avoidance adopting less frequently innovative curricula ${ }^{14,15}$. Possibly, strict rules and regulations in uncertainty avoiding countries decrease the level of readiness in medical schools to implement a curriculum change. In addition, characteristics of strong national uncertainty avoidance (such as strict rules and regulations) seem similar to characteristics of the more controlled organisational culture types rational goal and internal process. House et al. $^{23}$ confirmed that national uncertainty avoidance practices and values have a significant effect on organisational uncertainty avoidance practices and values. This implies that: 
H4: Medical schools in countries with higher uncertainty avoidance more frequently feature organisational types rational goal or internal process which cause lower levels of ORC

National levels of power distance were shown to have diverse effects on the innovativeness of organisations, ranging from a negative ${ }^{40-44}$ to a positive effect ${ }^{45}, 46$. These contrasting effects were found for instance on different phases of the change process with a negative effect on the initiation phase and a positive effect on the implementation phase. The initiation phase may be facilitated by low levels of power distance, as employees tend to easier make suggestions to their superiors ${ }^{47,} 48$. The implementation phase on the other hand may benefit from a clear decision structure and tight control in a high power distance society ${ }^{42,43,}$ 45,48 . Less contrasting relations were found in medical schools. Schools in countries with high power distance adopted innovative curricula less frequently ${ }^{14,15}$. Possibly, strong hierarchy in countries with high levels of power distance decreases the organizational readiness in medical schools for a curriculum change. Kovačić ${ }^{9}$ found confirmation of the negative relation between the national level of power distance and organisational readiness for change. According to Armenakis ${ }^{29}$ strong hierarchy in an organisation increases the psychological boundaries felt by individual organisational members, which in turn decrease their readiness for change. In addition, characteristics of strong national power distance (such as strict hierarchy) seem similar to characteristics of the organizational culture type internal process (also designated hierarchical type). In accordance, House ${ }^{23}$ found that $25 \%$ of the variation in organisational power distance was accounted for by the variation in national power distance. We therefore hypothesize:

H5: Medical schools in countries with higher power distance more frequently feature the organisational type internal process which cause lower levels of ORC

Also national levels of individualism were shown to have diverse results on different phases of the change process. High levels of individualism demonstrated to have a positive effect on the adoption of changes in organisations ${ }^{40,45}$. In contrast, some studies suggested that the implementation phase of a change process favors a low level of individualism with more emphasis on teams and a search for consensus ${ }^{43,48,50 .}$ In medical schools a more straightforward relation was found: schools 
in countries with strong individualism adopted changes more frequently ${ }^{14}$. Possibly, strong individual emphasis stimulates championing of new ideas, which may increase the level of organizational readiness in medical schools to adopt a curriculum innovation ${ }^{14,51}{ }^{5}$ In accordance, Kovačić ${ }^{49}$ found that higher national levels of individualism are correlated with higher levels of organisational readiness for change. Furthermore, characteristics of a high national level of individualism seem akin to the organisational culture characteristics of the open systems type (also designated the developmental type): emphasizing adaptation to the external environment, growth and innovation. House ${ }^{23}$ also found confirmation of the effect of national collectivism practices and values on organisational collectivism practices and values. We therefore hypothesized:

H6: Medical schools in countries with higher individualism more frequently feature an open systems organisational culture type, which causes higher levels of ORC and lower levels of resistance

Other studies indicated that national cultural values are also closely related to the average income levels of a country ${ }^{1,49,52}$. Higher income levels were found in countries with higher levels of individualism and lower levels of power distance and uncertainty avoidance ${ }^{1,52}$. The most widely used indicator to compare the economic prosperity of different countries is Gross Domestic Product Purchasing Power Parity (GDP PPP), which is the market value of all goods and services that are produced within a country, corrected for the market value of the countries' currency. It seems obvious that the financial resources of a medical school influence the likelihood of a school to adopt a curriculum innovation. This suggests:

H7: Medical schools in countries with higher power distance or uncertainty avoidance and/or lower individualism levels will have lower GDP levels, which cause lower levels of ORC

The seven hypothesized relations were inserted in a conceptual model (Figure 1). Participants from medical schools all over the world in a curriculum change process were asked to complete a survey and we tested the assumption above in a multivariate statistical approach. 


\section{Methods}

\section{Design}

A multilevel approach was required for this cross-cultural design as participants are nested within schools, and schools are nested within countries ${ }^{53}$. Furthermore, we expected structural (causal) relations, which require Structural Equation Modeling (SEM) ${ }^{54}$. Therefore Multilevel Structural Equation Modeling (MSEM) was used to analyze our data ${ }^{53}$.

\section{Participants and sampling procedure}

Institutional relations of Maastricht University all over the world were contacted by e-mail from January till April 2012 and asked to participate when they were in a process of (preparing) curriculum change. Curriculum change was defined as a change of the curriculum of under- or postgraduate medical education. Newly established medical schools and schools that had finished the implementation process (i.e. when the first students had graduated from the new curriculum) were excluded. Two reminders were sent. Contact persons in medical schools (preparing) changing their curriculum were asked to distribute an anonymous web-based survey to at least 20 staff members in their medical school actively involved in teaching or the organisation of the educational programme. These contact persons were encouraged to invite a mix of people: basic scientists, clinicians and members of the curriculum change committee. After agreement to cooperate, two reminders were sent to the contact persons for the invitation of staff in their school.

For every participant who completed the questionnaire $€ 5$ was transferred to the charity 'World Wildlife Fund' (www.wwf.org). Furthermore, participating schools had the option to receive a report with the anonymized results of their school.

\section{Measurements}

Our study covered 5 domains: 1) National culture; 2) Organisational culture; 3) Organisational readiness for change (ORC), 4) ChangeRelated Behaviour and 5), Gross Domestic Product Purchasing Power Parity (GDP PPP).

\section{National culture}

For the national culture dimensions (uncertainty avoidance, power dis- 
tance and individualism) the original scores on the corresponding indexes of Hofstede were used ${ }^{1}$. Countries without Hofstede's cultural scores were given regional scores when such scores were available (for instance Oman received the score of Arab world and Albania the score for former Yugoslavia) (Appendix A).

\section{Organisational culture}

Organizational culture was measured by 16 questions addressing the four types (human relations, open systems, rational goal and internal process) derived from the Competing Values Survey of Kalliath ${ }^{33}$. Questions were answered on a 7-point Likert scale ranging from 'Not valued at all' to 'Highly valued'.

\section{MORC}

Organisational readiness for change was measured using the Medical school's Organizational Readiness for curriculum Change (MORC) instrument, which we developed and validated in a previous study ${ }^{3}$. This instrument consists of 53 items in three motivational, seven capability and two extrinsic pressure subscales which were scored on a 5-point Likert scale ranging from 'Strongly disagree' to 'Strongly agree'.

\section{Change-Related Behaviour}

Change-Related Behaviour was measured using the five types of behaviour described by Herscovitch and Meyer ${ }^{4}$ : Active resistance, Passive resistance, Compliance, Cooperation and Championing. Participants were asked to rate the behaviour of members of their organisation in relation to the curriculum change by dividing one hundred points over the five behavioural types.

\section{GDP}

The values of GDP PPP per capita were obtained from the website Trading Economics ${ }^{55}$.

\section{Construct Measurement and Reliability}

Prior to testing the model and hypotheses, the reliability of construct scales was estimated. Cronbach's alpha scores of the organisational culture subscales suggested reliable replication of the constructs in our population (Table 1). Validity of the MORC questionnaire was examined in our previous study ${ }^{3}$. 


\begin{tabular}{|l|c|c|}
\hline Constructs & $\begin{array}{c}\text { Cronbach's alpha } \\
(\mathbf{a}>0.7)\end{array}$ & $\begin{array}{c}\text { Intraclass correla- } \\
\text { tions }(>0.05)\end{array}$ \\
\hline Organisational culture-Internal process & 0.80 & 0.057 \\
\hline Organisational culture-Open systems & 0.86 & 0.057 \\
\hline Organisational culture-Rational goal & 0.86 & 0.063 \\
\hline Organisational culture-Human Relations & 0.87 & 0.059 \\
\hline MORC-Motivation & 0.82 & 0.151 \\
\hline MORC-Capability & 0.93 & 0.150 \\
\hline MORC-Extrinsic pressure & 0.67 & 0.108 \\
\hline
\end{tabular}

Table 1: Cronbach's Alpha and intraclass correlations (ICC) for the constructs of organisational culture (internal process, open systems, rational goal and human relations) and the MORC dimensions (motivational, capability and extrinsic pressure).

\section{Analytic strategy}

Before proceeding with data modeling the distributional properties of the variables were examined, which showed that the variables were not normally distributed, requiring robust maximum likelihood estimation $(M L R)^{56,57}$. Robust maximum likelihood estimation produces maximum likelihood parameter estimates and standard errors that are robust to non-normality. In addition, there were no signs of multicollinearity, which means that there were no strong correlations between the predictors (all tolerance values were $>0.10$ ). To check on the betweencluster variability, intraclass correlations (ICC) were computed (Table 1 ). These proved large enough (ICC $>0.05$ ) to support the choice for multilevel structural equation modeling instead of conventional structural equation modeling ${ }^{58}$. Subsequently, our conceptual model (Figure 1) was tested comprising all seven hypotheses by fitting a multilevel structural equation model to the data using the program Mplus version $5.21^{59}$. Observed scores at the individual level were included in the first level: the 'within level'. Participants from the same schools were clustered in the second level: the 'between level'. Observed scores at the national level (national culture and GDP) were also included in the second level, because there were not enough countries in our data set with multiple schools to include these variables in a third level. We assumed random intercepts and fixed slopes across medical schools ${ }^{54}$. The following fit indices and criteria were used: the Root Mean Square Error of Approximation (RMSEA $<0.08)$; the Comparative Fit Index (CFI $>0.9$ ) and the Standardized Root Mean Square Residual $(\text { SRMR }<0.08)^{60,61}$. 


\section{Ethical considerations}

After explaining the aim and purpose of the study, voluntariness of participation, and confidentiality of the contributions, we obtained informed consent from all participants. The study was approved by the Ethical Review Board of the Dutch Association for Medical Education (NVMO).

\section{Results}

The characteristics of the participants are presented in Appendix A and Table 2 contains the means, standard deviations and intercorrelations (Pearson) among all variables. The questionnaire was completed by 991 staff members from 131 medical schools in 56 countries (Appendix $B$ ). Of these participants $47.9 \%$ was male and the average age was 47 years (range 21-84 years). Based on a generalizability analysis of MORC in a previous study, we intended to exclude schools with fewer than five participants ${ }^{3}$. Unfortunately, that led to an unidentified model, because of a resulting insufficient number of medical schools. Therefore, we only excluded schools with one participant to conform to the minimum requirement of two participants per cluster for twolevel modeling. In addition, three medical schools from two countries without national or regional culture scores of Hofstede were excluded, leading to a total of 911 respondents from 87 medical schools in 48 countries and a mean of 10.5 respondents per medical school. For the other measures, missing values and non-applicable answers amounted to no more than $10 \%$ of the total number of observations and were replaced by the means of the respective items ${ }^{62}$.

A poor fit of the two-level structural equation model was found for the collected data (CFI $=0.91, T L I=0.70$, RMSEA $=0.12$, SRM$R_{W}=0.05, S_{R M R}=0.21$ ) (Table 3 ). Addition of two suggested modifications by the Mplus software at the within level, consisting of additional relations between MORC-motivation and MORC-capability and between the organizational type open systems and resistance, yielded a reasonable fit $\left(\mathrm{CFI}=0.96, \mathrm{TLI}=0.87, \mathrm{RMSEA}=0.08, \mathrm{SRMR}_{\mathrm{W}}=0.02, \mathrm{SRMR}_{\mathrm{B}}=\right.$ 0.21 ). These modifications seemed plausible and will be elaborated in the discussion section. Figure 3 presents a summary of the significant parameter estimates and standard error results. 


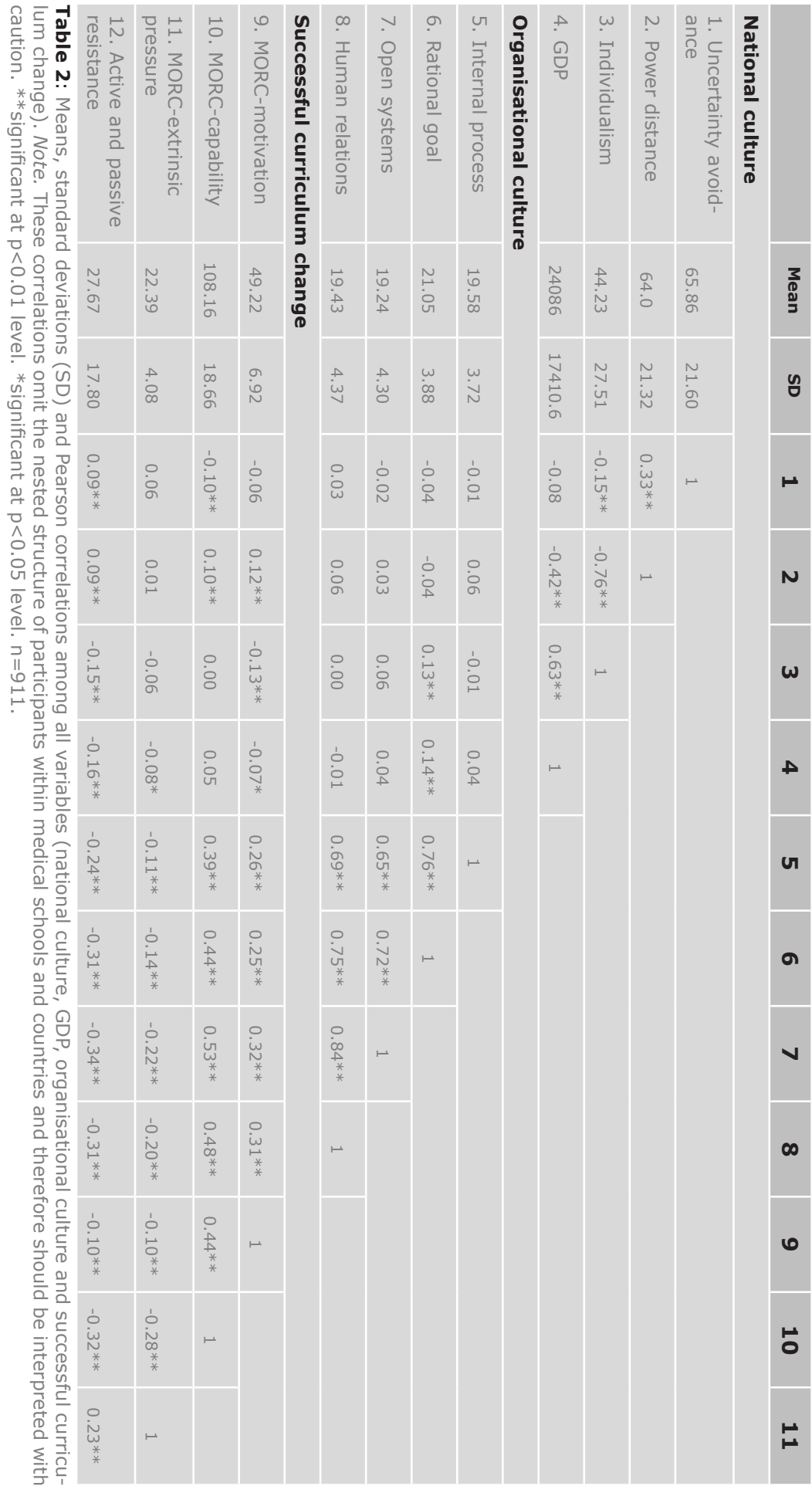




\begin{tabular}{|l|c|c|c|c|c|c|}
\hline Model & Df & $\begin{array}{c}\text { CFI } \\
(>\mathbf{0 . 9})\end{array}$ & $\begin{array}{c}\text { TLI } \\
\mathbf{( > 0 . 9 )}\end{array}$ & $\begin{array}{c}\text { RMSEA } \\
\mathbf{( < 0 . 0 8 )}\end{array}$ & $\begin{array}{c}\text { SRMR } \\
\mathbf{( < 0 . 0 8 )}\end{array}$ & $\begin{array}{c}\mathbf{S R M R}_{\mathbf{B}} \\
\mathbf{( < 0 . 0 8}\end{array}$ \\
\hline Initial model & 25 & $0.905^{*}$ & 0.696 & 0.118 & $0.050 *$ & 0.213 \\
\hline $\begin{array}{l}\text { Addition path MORC- } \\
\text { Motivation and } \\
\text { MORC-Capability }\end{array}$ & 24 & $0.949 *$ & 0.831 & 0.088 & $0.037 *$ & 0.211 \\
\hline $\begin{array}{l}\text { Addition path Open } \\
\text { Systems and Resis- } \\
\text { tance }\end{array}$ & 23 & $0.963^{*}$ & 0.871 & $0.077^{*}$ & $0.019 *$ & 0.208 \\
\hline
\end{tabular}

Table 3: Overview of goodness of fit measures from multilevel structural equation modeling. Df= Degrees of freedom, Comparative Fit Index (CFI>0.9), Tucker-Lewin index (TLI>0.9), Root Mean Square Error of Approximation (RMSEA<0.08); and the Standardized Root Mean Square Residual $(\mathrm{SRMR}<0.08)$ on the $\mathrm{W}=$ within and $\mathrm{B}=$ between level. *within range.

The results support several individual hypotheses of the conceptual model. Supporting hypothesis 1, medical schools with higher levels of Organisational Readiness for change (ORC) showed significantly lower levels of resistance. The results also support hypothesis 2: medical schools that feature the organisational types human relations or open systems had higher levels of ORC. No support could be found for hypothesis 3, which predicted that medical schools with more controlled policies and procedures (rational goal or internal process culture) would have lower levels of ORC. Hypothesis 4 predicted that medical schools in countries with higher uncertainty avoidance feature more often a rational goal or internal process type, which would cause lower levels of ORC. Uncertainty avoidance had an expected negative effect on ORC, but also had an unexpected negative effect on rational goal. Hypothesis 5 predicted that medical schools in countries with high power distance feature more frequently the internal process type, which would cause higher levels of ORC. Power distance had the expected positive effect on the organizational type internal process, but also had an unexpected positive effect on ORC. No significant effect was found for individualism on the organizational type open systems and ORC, thus failing to lend support for hypothesis 6. Partial support was found for the final hypothesis: individualism had a significant positive effect on Gross Domestic Product (GDP), but uncertainty avoidance and power distance had no significant effect on GDP and GDP had no significant effect on ORC. 


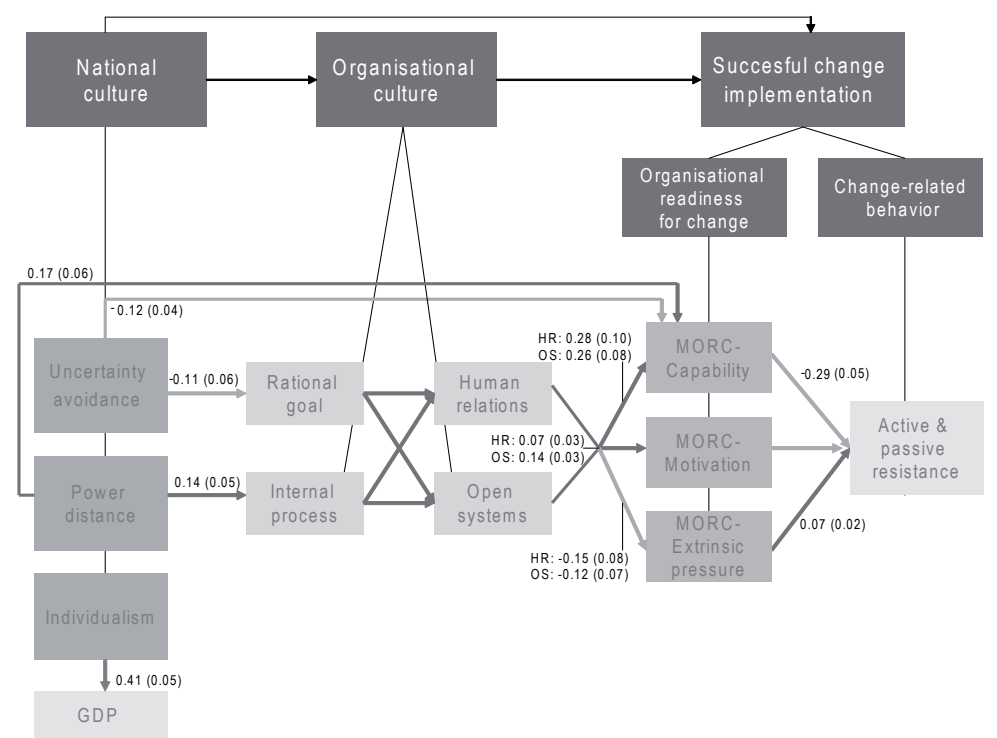

Figure 3: Summary of results from fitting a two-level model to the data: Estimates (and standards errors) for the within and between level. Only significant relations are shown. Light grey lines indicate negative relations and dark grey lines positive relations.

Furthermore, the results demonstrated that two aspects of national culture (uncertainty avoidance and power distance) could explain 40\% of differences in MORC-capability between different faculties. In addition, organisational culture could explain $27.5 \%$ of differences in MORC-capability, $12.3 \%$ of differences in MORC-motivation and 6.5\% of differences in MORC-extrinsic pressure within different faculties.

\section{Discussion}

We found that both national and organisational culture had a significant influence on the success of a medical curriculum change process. This finding confirms previous studies in which successful curriculum change in medical schools was attributed to national culture ${ }^{14,15}$. To our knowledge, the impact of organisational culture on successful curriculum change was never demonstrated before in medical schools, only in business and health care organisations ${ }^{16-19}$. Specifically, a strong national level of uncertainty avoidance had an inhibiting effect, while a strong national level of power distance and the organisational types open systems and human relations had a positive effect on the change process. Furthermore, national culture was able to explain to a large extent variance in organisational readiness for change between different faculties, while organisational culture was able to explain to a large 
extent variance in organisational readiness for change within different faculties, which means that individuals within medical schools have different perceptions of their medical school's organizational readiness for change. Taking together, these findings support the idea that it is important to take the local context in consideration when adopting a (curriculum) innovation 912,24 . Anticipating the potential effect of national and organisational culture increases the chance of successful curriculum change required to improve medical education, an important finding in light of decreasing budgets in health care and education.

Our conceptual model, which predicted an influence of national and organisational culture on successful curriculum change in medical schools, initially showed a poor fit. Modification indices suggested strong significant effects between the underlying dimensions of organisational readiness for change (MORC-capability on MORC-motivation and the inverse), which seemed plausible. Being strongly motivated to change increases the chance that one will also be able to change. Reversely, when someone feels capable of changing, this stimulates this individual's motivation to change. Furthermore, the modification indices suggested direct effects of all four organizational types on resistance, which also seemed plausible, because a medical school's organizational culture may, besides an indirect effect, have a direct effect on the level of resistance to change as well. Application of these suggested modifications at the within level (between MORC-motivation and MORC-capability and between the organizational type open systems and resistance) yielded a reasonable fit.

Organizational culture was measured using the Competing Values Framework (Figure 2). As the name 'competing' suggests, the organisational types on the same side of the framework were expected to have positive correlations and the types on opposite sides were expected to have negative or zero correlations. In this study we found significant positive correlations between all four organisational types. Although several studies confirmed the Competing Value Framework to some extent, there seemed to be none who showed exactly the expected relations ${ }^{2,27,33}$. Other researchers similarly found a strong positive correlation between the opposing types open systems and internal process $^{35}$. According to Kalliath et al. ${ }^{33}$ managers possibly perceived the paradox that in time of turbulent change, stability and order (i.e., values of internal process type) are only possible to acquire through 
innovative and creative problem solving and embracing of new ideas (i.e., values of open system type). Alternatively, the unexpected relations may be explained by the fact that organizations do not feature a single organizational type, but rather two or even all four types are present to some degree (i.e., the cultural profile) ${ }^{2}$. The question whether strong emphasis on one organisational type versus more or less equal presence of different types (called congruence) is most effective for organisational functioning is still a topic of debate ${ }^{2}$. Quinn and Spreitzer ${ }^{2}$ even argued that emphasis on one organisational type could lead to narrowness and inability to adapt to a changing environment. Perhaps, interaction between different organizational types in a medical school may explain some of the deviating results of this study.

Full support was found for hypothesis 2, which predicted the positive effect of flexible policies and procedures (i.e. organizational types human relations and open systems) on organisational readiness for change (ORC). In contrast, hypothesis 3 , which predicted a negative relation between medical schools with more controlled policies and procedures (i.e. organizational types 'internal process' and 'rational goal') and ORC was not supported by our data. Possibly, next to flexible policies and procedures, additional characteristics of medical schools with strong human relations and open systems values stimulated the change processes. An additional characteristic of the organisational type 'human relations' is the emphasize on teamwork, which is uncommon in medical schools with traditional curricula where departments had almost no interaction with each other and where autonomously responsible for the education of their discipline ${ }^{63}$. Changing towards for instance an integrated curriculum requires collaboration in interdisciplinary teams and this may be an explanation for the high level of readiness reported in organisations with strong human relations values. An additional characteristic of the organisational type 'open systems' is the emphasis on adaptation to the external environment, which has been reported an important feature of successful curriculum change ${ }^{64}$. The external environment is a broad term and includes government bodies, accrediting agencies, scholarly societies, health profession organisations, the geographic community of a school and other medical schools. The importance of adapting the curriculum to local community needs was emphasized previously ${ }^{9,12,24}$. In addition, collaboration with other medical schools that are changing in the same region or country could enhance successful change by enabling idea exchange of ef- 
fective and realistic possibilities in the region and by facilitating joint problem solving64,65. Possibly, the organizational types 'human relations' and 'open systems' are more important predictors of successful curriculum change than 'internal process' and 'rational goal'. In a future study it would be interesting to use cluster analysis to further analyze the interaction between the different organisational types by comparing the effect of different organisational culture profiles on successful curriculum change ${ }^{2}$. What if medical schools strongly emphasize human relation values and in the same time feature low levels of open systems values? Suppose medical schools have high levels of all four organisational types? It would also be interesting to explore whether similar profiles of organizational culture exist in medical schools across countries. If confirmed, this would point at a medical school-specific macro-culture, similar to specific hospital cultures reported earlier ${ }^{20,66}$.

Partial support was found for hypothesis 4, which predicted that medical schools in countries with higher uncertainty avoidance more frequently feature organisational types with more controlled policies and procedures (rational goal and internal process) which cause lower levels of ORC. Results confirmed the negative effect of uncertainty avoidance on ORC, but showed an unexpected negative effect of uncertainty avoidance on rational goal and no significant correlation with internal process. Possibly, national levels of uncertainty avoidance impact successful curriculum change through a different mechanism than through more controlled organisational policies and procedures. Perhaps the level of risk-taking behaviour, which also has been shown to depend on the level of uncertainty avoidance, plays a more important role ${ }^{1,23,48}$. Alternatively, medical schools may have different organisational culture characteristics than the organizations of the original participants that contributed to the construction of the Competing Values Framework ${ }^{2}$. Support for this idea was found in the strong positive correlation between organisational types of the control and flexibility dimension, which suggest the absence of the supposed distinction between flexible and controlled organisational policies and procedures.

Hypothesis 5 predicted more medical schools featuring the organizational type 'internal process' in the presence of strong national power distance with a negative effect on ORC. Our results confirmed the positive effect of power distance on internal process, but also disclosed an unexpected positive effect of power distance on ORC. Positive effects of high levels of power distance on the change process were 
reported previously $42,43,45,48$. High levels of power distance has been argued to facilitate the implementation phase of the change process through centralized command which ensures coordination of complex efforts $^{48}$. In earlier studies a negative influence of power distance on the change process in medical schools was found, but these schools were in another phase of the change process, namely the institutionalization phase ${ }^{14,15}$. In this study all schools were either in the preparation $(42.6 \%)$ or implementation phase $(57.4 \%)$ of the change process, which could explain the unexpected positive effect of power distance on ORC. In a future study it would be interesting to explore whether national culture characteristics have distinct effects on different phases of the change process.

Hypothesis 6, which predicted more medical schools featuring the organizational type 'open systems' in the presence of strong national individualism with a positive effect on ORC, was not confirmed. Possibly other factors, such as uncertainty avoidance and power distance are more important predictors of successful curriculum change.

Hypothesis 7, which predicted lower levels of national wealth (GDP) in countries with strong power distance and uncertainty avoidance and/or low levels of individualism with a negative effect on ORC, was partly confirmed. Individualism had the expected positive effect on GDP, but no significant effects were found for power distance or uncertainty avoidance on GDP and similarly no effect was found for GDP on ORC. The correlation matrix showed a significant negative correlation between GDP and resistance (Table 2). Possibly, lack of financial resources increases the level of resistance within a medical school towards change, but this may become negligible when the multilevel structure and national and organisational culture are included.

For the operationalisation of national culture the dimensions of Hofstede were used, with their own limitations, regarding for instance its study population of IBM employees only ${ }^{67}$. Unfortunately, Hofstede's scores were not available for all countries, requiring the allocation of regional scores and deletion of participants from three countries without available regional scores (Appendix A). Although objection against this procedure may be valid, separate analysis in which the missing country scores were substituted by the mean of each dimension had no significant effect on the fit indices of the multilevel structural equation model. 
Although in this study a relatively large cross-national sample was used, the number of respondents still may have been insufficient, which may have caused the initial poor fit indices of our conceptual model. In particular the limited number of medical schools in comparison to the large amount of parameters in the model may have contributed to this problem. In addition, the limited number of medical schools per country forced to include observed scores on the national level in the second level, which prevented the analysis of variance in organisational readiness for change between different countries. Our conceptual model with suggested modifications should therefore be further tested in a larger sample.

The intraclass correlations of both the organisational culture and MORC scores showed small between-group variance in comparison to within-group variance, which means that individuals within medical schools have different perceptions of their medical school's organisational culture and organizational readiness for change. Various explanations for these different perceptions may apply. First, individuals are influenced by their team and department members whose perceptions might be more similar than across the whole medical school, which would require further analysis of variance in perceptions of readiness for change within teams and departments. Next, individual readiness for change differs between organizational members based on their previous experiences, the level of involvement in the change process and their personal preferences, all of which can have an influence on an individual's perception of the whole medical school's readiness for change ${ }^{34}$.

The relation between national and organizational culture includes a fundamental tension as described for commercial organizations ${ }^{20}$. On the one hand, organizations must conform to the forces in their environment, while on the other hand organizations have to innovate, both in order to survive. These combined demands may result in the development of an organizational culture deviating from the dominant national cultural context. Similar tensions are visible in medical schools. Innovative educational methods such as PBL require an open communication style, which seems at first glance less feasible in more collectivistic cultures with a strong fear of loss of face ${ }^{68,69}$. However, many medical schools in collectivistic cultures have changed towards such novel educational methods68,70-74. Either seduced by con- 
tacts with other schools that successfully changed or pressed by their national government, which may seek to conform medical education to 'international standards' ${ }^{\prime}$. Many change attempts lead to successful change, but many attempts also failed partly or completely. This study showed that specific national and organisational cultural characteristics can be conducive for successful change, such as: flexible policies and procedures, a certain level of risk-taking, interdisciplinary teamwork, adaptation to the local community needs and collaborations with regional schools. Medical schools (considering) changing their curriculum should be aware of their potential impact and should design strategies to tackle these potential additional sources of resistance. These strategies may include attempts to adapt the organisational culture, but possibly a more effective strategy could be the conscious deployment of cultural characteristics that might otherwise hinder change. For instance a medical schools' leader in a culture with low risk-taking tolerance may decrease the feeling of risk-taking by emphasizing how potential risks are minimized. A medical school's leader in a high power distance culture could use the centralized organisational structure and top-down decision-making to make fast decisions when necessary, but should also communicate the rationale behind the decisions to the organisational members. 


\section{References}

1. Hofstede G. Culture's Consequences. Comparing Values, Behaviors, Institutions, and Organizations across Nations. New York: Sage Publications 2001.

2. Quinn R, Spreitzer G. The psychometrics of the competing values culture instrument and an analysis of the impact of organizational culture on the quality of life. Research in Organizational Change and Development. 1991;5:115-42.

3. Jippes M, Driessen E, Broers N, Majoor GD, Gijselaers WH, van der Vleuten CPM. Development and validation of an instrument that measures a Medical school's Organisational Readiness for curriculum Change (MORC). Under editorial review 2012.

4. Herscovitch L, Meyer JP. Commitment to organizational change: Extension of a three-component model. Journal of Applied Psychology. 2002;87:474-87.

5. Herzlinger RE. Why innovation in health care is so hard. Harvard Business Review. 2006;84(5):58-66, 156.

6. Berwick DM. Disseminating Innovations in Health Care JAMA. 2003;289(15):196975.

7. Papadakis MA, Teherani A, Banach MA, Knettler TR, Rattner SL, Stern DT, et al. Disciplinary action by medical boards and prior behavior in medical school. The New England Journal of Medicine. 2005;353(25):2673-82.

8. Sales CS, Schlaff AL. Reforming medical education: a review and synthesis of five critiques of medical practice. Social Science \& Medicine. 2010;70(11):1665-8.

9. Blizard PJ. International standards in medical education or national standards/ primary health care--which direction? Social Science \& Medicine. 1991;33:116370.

10. Counte MA, Kimberly JR. Change in physician attitudes toward reform in medical education: the results of a field experiment. Social Science \& Medicine. 1971; 10:547-52.

11. Dornhorst AC, Hunter A. Fallacies in medical education. Lancet. 1967 Sep 23;2(7517):666-7.

12. Frenk J, Chen L, Bhutta ZA, Cohen J, Crisp N, Evans T, et al. Health professionals for a new century: transforming education to strengthen health systems in an interdependent world. Lancet. 2010 Dec 4;376(9756):1923-58.

13. Jones R, Higgs R, de Angelis C, Prideaux D. Changing face of medical curricula. Lancet. 2001;357(9257):699-703.

14. Jippes M, Majoor GD. Influence of national culture on the adoption of integrated medical curricula. Advances in Health Sciences Education Theory and Practise. 2011 Mar; 16(1):5-16.

15. Jippes M, Majoor GD. Influence of national culture on the adoption of integrated and problem-based curricula in Europe. Medical Education. 2008 Mar;42(3):27985.

16. McLean LD. Organizational Culture's Influence on Creativity and Innovation: A Review of the Literature and Implications for Human Resource Development. Advances in Developing Human Resources. 2005;7:226-46.

17. Susanj Z. Innovative climate and culture in manufacturing organizations: differences between some European countries. Social Science Information. 2000;39:349-61.

18. Wang S, Guidice R, Tansky J, Wang Z-m. The moderating role of organizational culture in innovation: evidence from chainge. Academy of Management Proceedings. 2009; Suppl 1.

19. Jaskyte K, Dressler W. Organizational Culture and Innovation in Nonprofit Human Service organizations. Administration in Social Work. 2005;29:23-41.

20. Nelson RE, Gopalan S. Do Organizational Cultures Replicate National Cultures? Isomorphism, Rejection and Reciprocal Opposition in the Corporate Values of Three Countries. Organization Studies. 2003;24:1115-51. 
21. Hofstede G, Neuijen B, Daval Ohayv D, Sanders G. Measuring Organizational Cultures: A Qualitative and Quantitative Study across Twenty Cases. Administrative Science Quarterly. 1990;35:286-316.

22. van Oudenhoven JP. Do organizations reflect national cultures? A 10-nation study. International Journal of Intercultural Relations. 2001;25(1):89-107.

23. House R, Hanges P, Javidan M, Dorfman P, Gupta V. Culture, Leadership and Organizations. The GLOBE Study of 62 Societies. New York: Sage publications 2004.

24. Currie G, Dingwall R, Kitchener M, Waring J. Let's dance: Organization studies, medical sociology and health policy. Social Science \& Medicine. 2012;74:273-80.

25. Weiner BJ, Amick H, Lee SYD. Conceptualization and measurement of organizational readiness for change - A review of the literature in health services research and other fields. Medical Care Research and Review. [Review]. 2008 Aug;65(4):379-436.

26. DeLong Goldman G. Initial Validation of a Brief Individual Readiness for Change Scale (BIRCS) for Use With Addiction Program Staff Practitioners. Journal of Social Work Practice in the Addictions. 2009;9(2):184-203.

27. Jones RA, Jimmieson NL, Griffiths A. The impact of organizational culture and reshaping capabilities on change implementation success: The mediating role of readiness for change. Journal of Management Studies. 2005;42(2):361-86.

28. Kotter JP. Leading Change. Boston: Harvard Business School Press 1995.

29. Armenakis AA, Harris SG, Mossholder KW. Creating readiness for organizational change Human Relations. [Article]. 1993 Jun;46(6):681-703.

30. Wanberg CR, Banas JT. Predictors and outcomes of openness to changes in a reorganizing workplace. The Journal of applied psychology. 2000;85:132-42.

31. Detert JR, Mauriel JJ. A framework for linking culture and improvement initiatives in organisations. Academy of Management Review. 2000;25(4):850-63.

32. Scott $T$, Mannion R, Davies $H$, Marshall M. The Quantitative Measurement of Organizational Culture in Health Care: A Review of the Available Instruments. Health Services Research. 2003;38:923-45.

33. Kalliath TJ, Bluedorn AC, Gillespie DF. A Confirmatory Factor Analysis of the Competing Values Instrument. Educational and Psychological Measurement. 1999;59(1):143-58.

34. Eby LT, Adams DM, Russell JEA, Gaby SH. Perceptions of Organizational Readiness for Change: Factors Related to Employees' Reactions to the Implementation of Team-Based Selling. Human Relations. 2000;53(3):419-42.

35. Zammuto R, Krakower J. Quantitative and qualitative studie of organizational culture. Research in Organizational Change and Development. 1991;5:83-114.

36. Inglehart R, Basáñez M, Menéndez Moreno A. Human values and beliefs: a crosscultural sourcebook: political, religious, sexual, and economic norms in 43 societies; findings from the 1990-1993 world value survey. Ann Arbor: University of Michigan Press 1998.

37. Trompenaars F. Riding the waves of culture: understanding cultural diversity in business. London: The Economist Books 1993.

38. Schwartz SH, Bilsky W. Toward a Theory of the Universal Content and Structure of Values: Extensions and Cross-Cultural Replications. Journal of Personality and Social Psychology. 1990;58(5):878-91.

39. Everdingen $\mathrm{Yv}$, Waarts $\mathrm{E}$. The effect of national culture on the adoption of innovations. Marketing Letters. 2003;14(3):217-32.

40. Shane SA. Why do some societies invent more than others? Journal of Business Venturing. 1992; 7:29-46.

41. Singh S. Cultural differences in, and influences on, consumers' propensity to adopt innovations. International Marketing Review. 2006;23:173-91. 
42. Array A, Kollmann T, Kuckertz A, Breugst N. Organizational Readiness and the Adoption of Electronic Business - The Moderating Role of National Culture in 29 European Countries. Data base. 2009;40(4):117-31.

43. Herbig PA, Miller JC. Culture and Technology. Journal of Global Marketing. 1993; 6(3):75-104.

44. Hasan H, Ditsa G. The Impact of Culture on the Adoption of IT: An Interpretive Study. Journal of Global Information Management (JGIM). 1999;7(1):5-15.

45. Chakrabarti AK, Rubenstein AH. Interorganizational transfer of technology - A study of adoption of NASA innovations. IEEE Transactions on Engineering Management. 1976(EM-23):20-34.

46. Warkentin M, Gefen D, Pavlou PA, Rose GM. Encouraging Citizen Adoption of eGovernment by Building Trust. Electronic Markets. 2002;12(3):157-62.

47. Kolman L, Noorderhaven NG, Hofstede G, Dienes E. Cross-cultural differences in Central Europe. Journal of Managerial Psychology. 2003;18:76-88.

48. Nakata C, Sivakumar K. National Culture and New Product Development: An Integrative Review. Journal of Marketing. 1996;60(1):61-72.

49. Kovačić ZJ. The Impact of National Culture on Worldwide eGovernment Readiness eGovernment Readiness. Informing Science Journal. 2005;8:143-58.

50. Jones GK, Davis HJ. National culture and innovation: Implications for locating global R \& D operation. Management International Review. 2000;40(1):11-39.

51. Shane S, Venkataraman S. Renegade and rational championing strategies. Organization Studies 1996;17(5):751.

52. Cox PL, Friedman BA, Tribunella T. Relationships among Cultural dimensions, National Gross Domestic Product, and Environmental sustainability. Journal of Applied Business and Economics. 2011;12(6):46-56.

53. Cheung MWL, Au K. Applications of Multilevel Structural Equation Modeling to Cross-Cultural Research. Structural Equation Modeling: A Multidisciplinary Journal. 2005;12(4):598-619.

54. Kaplan D, Pamela R. Elliott P. A Model-Based Approach to Validating Education Indicators Using Multilevel Structural Equation Modeling. Journal of Educational and Behavioral Statistics. 1997;22:323 - 47.

55. Fedec A, Sousa A. Trading Economics. GDP per capita; PPP. 2012 [cited 2012 March 15]; Available from: http://www.tradingeconomics.com.

56. Mercken L, Candel M, Willems $\mathrm{P}$, de Vries H. Disentangling social selection and social influence effects on adolescent smoking: the importance of reciprocity in friendships. Addiction. 2007;102:1483-92.

57. Bentler P, Yuan K-H. Structural Equation Modeling with Small Samples: Test Statistics. Multivariate Behavioral Research. 1999;34(2):181-97.

58. Preacher KJ, Zyphur MJ, Zhang Z. A general multilevel SEM framework for assessing multilevel mediation. Psychological methods. 2010;15:209-33.

59. Muthén LK, Muthén BO. Mplus: the comprehensive modeling program for applied researchers: user's guide. Sixth Edit ed. Los Angeles CA: Muthén \& Muthén 2007.

60. McDonald RP, Ho M-HR. Principles and practice in reporting structural equation analyses. Psychological methods. 2002;7(1):64-82.

61. Hu L-t, Bentler PM. Fit indices in covariance structure modeling: Sensitivity to underparameterized model misspecification. Psychological Methods. 1998;3(4):424-53.

62. Allison P. Missing data. London: Thousand Oaks: Sage 2001.

63. Lane IF. Change in higher education: understanding and responding to individual and organizational resistance. Journal of Veterinary Medical Education. 2007 Spring;34(2):85-92.

64. Bland CJ, Starnaman S, Wersal L, Moorehead-Rosenberg L, Zonia S, Henry R. Curricular change in medical schools: how to succeed. Academic Medicine. 2000 Jun;75(6):575-94. 
65. Prideaux D. Think global, act regional: promoting change in medical education. Medical Education. 2005;39(8):756-7.

66. Gerowitz MB, Lemieux-Charles L, Heginbothan C, Johnson B. Top management culture and performance in Canadian, UK and US hospitals. Health Services Management Research 1996;9(2):69-78.

67. Signorini P, Wiesemes R, Murphy R. Developing alternative frameworks for exploring intercultural learning: a critique of Hofstede's cultural difference model. Teaching in Higher Education. 2009;14:253-64.

68. Gwee MC. Globalization of problem-based learning (PBL): cross-cultural implications. Kaohsiung Journal of Medical Sciences. 2008 Mar;24(3 Suppl):S14-22.

69. Hofstede G. Cultural differences in teaching and learning. International Journal of Intercultural Relations. 1986;10(3):301-20.

70. Amin Z, Hoon Eng K, Gwee M, Dow Rhoon K, Chay Hoon T. Medical education in Southeast Asia: emerging issues, challenges and opportunities. Medical Education. 2005;39(8):829-32.

71. Azila NM, Sim SM, Atiya AS. Encouraging learning how to fish: an uphill but worthwhile battle. Annals Academy of Medicine Singapore. 2001;30(4):375-8.

72. Claramita M, Utarini A, Soebono H, Van Dalen J, Van der Vleuten C. Doctorpatient communication in a Southeast Asian setting: the conflict between ideal and reality. Advances in Health Sciences Education. 2011 Mar;16(1):69-80.

73. Khoo HE. Implementation of problem-based learning in Asian medical schools and students' perceptions of their experience. Medical Education. 2003;37(5):401-9.

74. Frambach JM, Driessen EW, Chan L-C, van der Vleuten CPM. Rethinking the globalisation of problem-based learning: how culture challenges self-directed learning. Medical Education. 2012;46:738-47. 


\section{Appendix A}

\begin{tabular}{|c|c|}
\hline Variable & Percentage \\
\hline $\begin{array}{l}\frac{\text { Gender }}{\text { - Male }} \\
\text { - Female } \\
\text { - Missing }\end{array}$ & $\begin{array}{l}47,9 \% \\
37,2 \% \\
14,8 \%\end{array}$ \\
\hline $\begin{array}{l}\text { Age } \\
-20-35 \text { years } \\
-36-50 \text { years } \\
-51-65 \text { years } \\
-65-85 \text { years } \\
- \text { Missing }\end{array}$ & $\begin{array}{l}12,5 \% \\
37,8 \% \\
31,3 \% \\
3,0 \% \\
15,4 \%\end{array}$ \\
\hline $\begin{array}{l}\text { Participation } \\
\text { - Active in the change process } \\
\text { - Non- active in the change process } \\
\text { - Missing }\end{array}$ & $\begin{array}{l}53,2 \% \\
32,7 \% \\
14,1 \%\end{array}$ \\
\hline $\begin{array}{l}\text { Type of respondents } \\
\text { - Specialists } \\
\text { - Basic scientists } \\
\text { - Management \& administration } \\
\text { - Other (including educationalist, GP) } \\
\text { - Missing }\end{array}$ & $\begin{array}{c}36,6 \% \\
13,4 \% \\
6,9 \% \\
19,9 \% \\
23,2 \%\end{array}$ \\
\hline $\begin{array}{l}\text { Object of change } \\
\text { - Undergraduate curriculum change } \\
\text { - Postgraduate curriculum change } \\
\text { - Missing }\end{array}$ & $\begin{array}{l}78,1 \% \\
6,3 \% \\
15,6 \%\end{array}$ \\
\hline $\begin{array}{l}\text { Type of change } \\
\text { - All students in completely new curriculum } \\
\text { - Part of students in completely new curriculum } \\
\text { - Exams only } \\
\text { - Skills only } \\
\text { - Missing }\end{array}$ & $\begin{array}{c}60,7 \% \\
19,7 \% \\
0,8 \% \\
2,3 \% \\
16,4 \%\end{array}$ \\
\hline $\begin{array}{l}\text { Phase of change } \\
\text { - Preparation } \\
\text { - Implementation (first } 2 \text { years) } \\
\text { - Implementation ( }>2 \text { years) }\end{array}$ & $\begin{array}{l}42,6 \% \\
28,7 \% \\
28,7 \%\end{array}$ \\
\hline $\begin{array}{l}\text { Size of medical school } \\
\text { - Less than } 50 \text { students per year } \\
\text { - } 51-100 \text { students per year } \\
\text { - } 101-200 \text { students per year } \\
\text { - More than } 200 \text { students per year } \\
\text { - Missing }\end{array}$ & $\begin{array}{l}5,3 \% \\
17 \% \\
32,5 \% \\
30,9 \% \\
14,3 \%\end{array}$ \\
\hline
\end{tabular}

Characteristics of the respondents, their medical schools and the change processes in their schools. 


\section{Appendix B}

\begin{tabular}{|c|c|c|c|c|c|c|}
\hline Country & $\begin{array}{l}\text { Num- } \\
\text { ber of } \\
\text { medical } \\
\text { schools }\end{array}$ & $\begin{array}{l}\text { Number } \\
\text { of partici- } \\
\text { pants }\end{array}$ & GDP & PD & IDV & UA \\
\hline Albania* $¥$ & 1 & 9 & 8258 & 76 & 27 & 88 \\
\hline Australia & 7 & 42 & 37165 & 36 & 90 & 51 \\
\hline Austria & 2 & 4 & 39799 & 11 & 55 & 70 \\
\hline Azerbadjan*§ & 2 & 10 & 8714 & 93 & 39 & 95 \\
\hline Bahrain*ף & 1 & 10 & 25800 & 80 & 38 & 68 \\
\hline Belgium & 3 & 51 & 36992 & 65 & 75 & 94 \\
\hline Brazil & 1 & 1 & 10408 & 69 & 38 & 76 \\
\hline Canada & 5 & 57 & 38994 & 39 & 80 & 48 \\
\hline Chile & 2 & 26 & 14541 & 63 & 23 & 86 \\
\hline China & 2 & 8 & 6204 & 80 & 20 & 30 \\
\hline Colombia & 1 & 7 & 8960 & 67 & 13 & 80 \\
\hline Dominica*¿ & 1 & 3 & 11968 & & & \\
\hline Ecuador & 1 & 17 & 7741 & 78 & 8 & 67 \\
\hline El Salvador & 1 & 6 & 6680 & 66 & 19 & 94 \\
\hline Ethiopia & 1 & 16 & 884 & 70 & 20 & 55 \\
\hline Finland & 1 & 1 & 38000 & 33 & 63 & 59 \\
\hline Georgia*§ & 2 & 14 & 4905 & 93 & 39 & 95 \\
\hline Ghana & 1 & 9 & 1499 & 80 & 15 & 65 \\
\hline India & 7 & 7 & 3020 & 77 & 48 & 40 \\
\hline Indonesia & 8 & 111 & 3877 & 78 & 14 & 48 \\
\hline Iran & 3 & 3 & 11293 & 58 & 41 & 59 \\
\hline Israel & 1 & 7 & 27652 & 13 & 54 & 81 \\
\hline Italy & 4 & 8 & 33269 & 50 & 76 & 75 \\
\hline Japan & 10 & 42 & 33802 & 54 & 46 & 92 \\
\hline Kazakhstan*§ & 1 & 3 & 11370 & 93 & 39 & 95 \\
\hline Kuwait & 1 & 8 & 52657 & 90 & 25 & 80 \\
\hline Malaysia & 1 & 9 & 14055 & 104 & 26 & 36 \\
\hline Mexico & 4 & 29 & 14741 & 81 & 30 & 82 \\
\hline Nepal*i & 5 & 35 & 1109 & & & \\
\hline Netherlands & 3 & 23 & 42747 & 38 & 80 & 53 \\
\hline New Zealand & 2 & 28 & 29159 & 22 & 79 & 49 \\
\hline
\end{tabular}




\section{Appendix B continued}

\begin{tabular}{|c|c|c|c|c|c|c|}
\hline Country & $\begin{array}{l}\text { Num- } \\
\text { ber of } \\
\text { medical } \\
\text { schools }\end{array}$ & $\begin{array}{l}\text { Number } \\
\text { of partici- } \\
\text { pants }\end{array}$ & GDP & PD & IDV & UA \\
\hline Norway & 1 & 5 & 60490 & 31 & 69 & 50 \\
\hline Oman*ף & 1 & 3 & 26767 & 80 & 38 & 68 \\
\hline Pakistan & 2 & 13 & 2516 & 55 & 14 & 70 \\
\hline Phillipines & 3 & 12 & 3674 & 94 & 32 & 44 \\
\hline Poland & 1 & 18 & 18058 & 68 & 60 & 93 \\
\hline Romania & 1 & 29 & 14658 & 90 & 30 & 90 \\
\hline S. Korea & 1 & 20 & 26877 & 60 & 18 & 85 \\
\hline Saudi Arabia & 2 & 21 & 22334 & 95 & 25 & 80 \\
\hline Singapore & 2 & 15 & 52125 & 74 & 20 & 8 \\
\hline Spain & 2 & 13 & 33201 & 57 & 51 & 86 \\
\hline Sudan*\# & 5 & 30 & 2128 & 64 & 27 & 52 \\
\hline Sweden & 1 & 11 & 39476 & 31 & 71 & 29 \\
\hline Switzerland & 2 & 14 & 45964 & 34 & 68 & 58 \\
\hline Thailand & 4 & 12 & 8013 & 64 & 20 & 64 \\
\hline Tunisia*i & 1 & 5 & 8887 & & & \\
\hline Turkey & 1 & 15 & 14995 & 66 & 37 & 85 \\
\hline UAE & 3 & 50 & 55781 & 90 & 25 & 80 \\
\hline Uganda & 1 & 6 & 1172 & 64 & 27 & 52 \\
\hline UK & 3 & 25 & 36820 & 35 & 89 & 35 \\
\hline Ukraine*§ & 1 & 12 & 7314 & 93 & 39 & 95 \\
\hline Uruguay & 1 & 13 & 12679 & 61 & 36 & 100 \\
\hline USA & 3 & 33 & 46971 & 40 & 91 & 46 \\
\hline Vietnam & 2 & 9 & 2835 & 70 & 20 & 30 \\
\hline Yemen*ף & 1 & 2 & 2446 & 80 & 38 & 68 \\
\hline Total & 131 & 991 & & & & \\
\hline
\end{tabular}

Overview of countries studied with the number of medical schools and participants. Furthermore the national levels of GDP (Gross Domestic Product) per capita and the national culture scores PD (power distance), IDV (individualism) and UA (uncertainty avoidance) are displayed.

*no original score available. $¥$ Used score for Yugoslavia instead. § Used score for Russia instead. ๆ Used score for Arab world instead. \# Used score for East Africa. ¿ No cultural neighbouring country score available. Participants deleted from analysis. 
NATIONAL AND ORGANISATIONAL CULTURE'S IMPACT ON SUCCESSFUL CURRICULUM CHANGE 135 


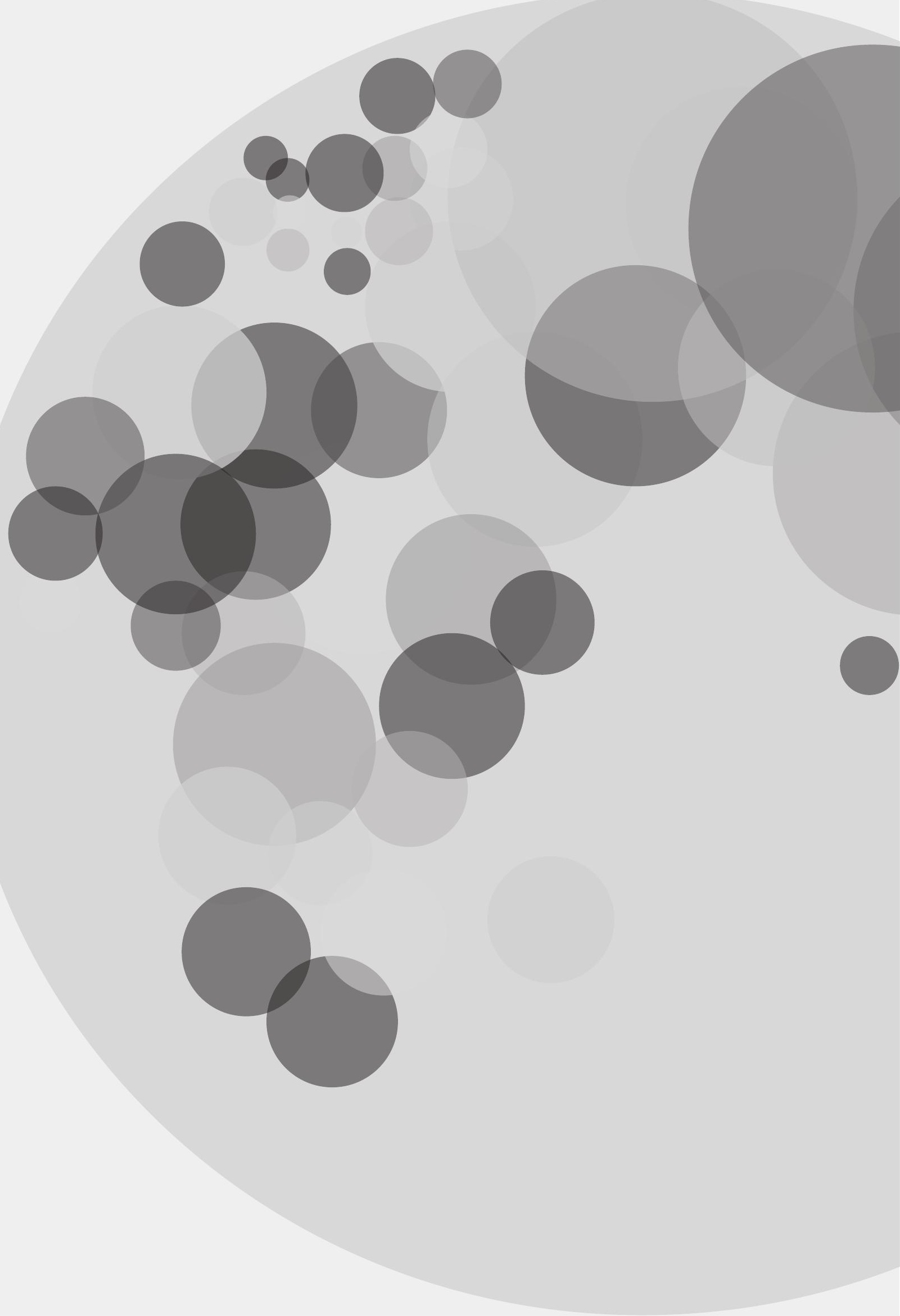




\section{CHAPTER 7}

GENERAL DISCUSSION 
The aim of this thesis is to advance understanding of the factors influencing curriculum change processes in medical schools and especially the role of national culture in this process. This thesis addresses the following problem statements:

1. Does national culture impact on medical curriculum innovation?

2. And if so, how does national culture impact on the curriculum change processes in medical schools?

First, We will summarize the main conclusions of this thesis in relation to these problem statements. Subsequently I will discuss the limitations of this study, the implications and suggestions for further research.

\section{Main conclusions}

Problem statement 1: $\quad$ Does national culture impact on medical curriculum innovation?

Confirmation of the relation between national culture and curriculum innovation in medical schools was found in different chapters (Chapter 2-4 and 6). These findings are important in the light of continuous curriculum change within the field of medical education. Especially, since most of the educational innovations originated in English-speaking countries and were adopted by countries with very different cultural backgrounds ${ }^{1}$. Several authors realised the international differences in healthcare systems and medical schools and stressed the importance of critically adapting educational methods and implementation strategies developed in other settings to the local context and culture ${ }^{2-4}$. Until now, the influence of national culture on curriculum change processes was never previously confirmed empirically in a large cross-cultural study. This thesis shows that differences in values between countries influence the innovativeness of its inhabiting medical schools. Below, the three specific national culture characteristics - power distance, uncertainty avoidance and individualism - that were found to impact on the success of curriculum implementation in medical schools, will be discussed separately. 
Power distance describes the degree of tolerance of hierarchical or unequal relationships ${ }^{5}$. In countries with higher levels of power distance fewer schools changed towards an integrated curriculum (Chapters 2 and 3). By contrast, a positive effect of power distance on successful curriculum change was demonstrated in Chapter 6. These differences could be explained by differences in the phase of change: in the first two chapters medical schools were in the institutionalization phase, while in Chapter 6 schools were either in the preparation or implementation phase. Possibly, power distance could facilitate change in early phases of the process through centralized command which ensures coordination of complex efforts ${ }^{6}$. In later phases of the change process strong hierarchical organisational structures in the presence of strong power distance could have an inhibiting effect instead. The hierarchical structure in medical schools includes the extent to which heads of departments experience sole decision-making power. The fear to loose this decision-making power has been reported to be an important barrier in the process of change7,8; an aspect also emerging from our interview study in Austrian medical schools (Chapter 4). Changing towards an integrated curriculum not only includes losing autonomy and related status associated with the education of medical students, but it also requires cooperation between the different disciplines previously operating in isolation ${ }^{8,9}$. The inevitable loss of teaching hours and autonomy in the new curriculum was perceived by some faculty members as a loss of power ${ }^{8}$, an aspect stressed in the interview study by some Austrian faculty members as well (Chapter 4).

In addition, cultural characteristics also influence the leadership attributes enabling effective curricular change. In a review on factors influencing curriculum change, leadership was the most often cited determinant of effective curricular change ${ }^{10,11}$. Effective leadership for change has often been subject of study, especially in business organisations ${ }^{12}$. However, no generally accepted definition is available for effective leadership. In the last ten years the transformational or (neo) charismatic leadership style received most attention in the leadership literature and was found to be positively associated with leadership effectiveness $^{12,13}$. Transformational/charismatic leaders articulate a realistic vision, which is appealing and inspiring and provides a role model for ethical behaviour, respect and trust. Furthermore, such leaders pay attention to their subordinates' needs, stimulate them intellectually to challenge their assumptions, encourage their creativity and motivate 
them to perform beyond self-interest and expectations ${ }^{13,14}$. Through defining the need for change, creating a new vision and mobilising commitment to this vision, such leaders could ultimately transform organisations ${ }^{14}$. Den Hartog et al. ${ }^{14}$ showed in a large cross-cultural study involving 62 countries that transformational/charismatic leadership is universally preferred as leadership style. However, the shared preference of this leadership style does not exclude differences in the expression of the attributes related to charismatic/transformational leadership. Some attributes of transformational/charismatic behaviour are universally endorsed, such as 'encouraging', 'positive', 'motivational', 'confidence builder', 'inspirational', 'communicative', 'dynamic' and 'visionary'14. The importance of visionary leadership in medical schools was also emphasized by Bland et al. ${ }^{11}$ and emerged from the Austrian interview study as well (Chapter 4). Other attributes of transformational/charismatic behaviour are seen as contingent, which means that an attribute can be regarded as contributing to effective leadership in one country, while in other countries the same attribute is viewed as impeding ${ }^{15}$. A contingent attribute is for instance 'risk-taking', which is seen as reckless in some countries and as a desired behaviour in others. Earlier research demonstrated risk-taking behaviour to depend on the national level of uncertainty avoidance 5, 6, 15. Risk-taking behaviour by leaders is necessary for curriculum innovations to succeed and the ambivalent perception of this attribute in different countries confirms the influence of national culture on curriculum innovations. Another contingent attribute is participative leadership, which is highly appreciated in egalitarian countries (with low levels of power distance), in contrast to societies with high power distance levels ${ }^{14,16,17}$. This seems at variance with the view of Bland et al. ${ }^{11}$ that academic organisations usually prefer participative leadership. Although comparing these contrasting views is difficult due to differences with respect to definitions used for participative leadership: from participation in decision-making of organisational members by Dorfman ${ }^{16}$ to involving organisational members in the change process through open communication and ownership of projects by Bland and Wersal ${ }^{11}$. Hoat's ${ }^{9}$ experience of changing medical schools in Vietnam illustrates possible difficulties of participative decision-making in a high power distance society, where the importance of authoritative leaders is still highly regarded. In Vietnam, project teams were installed intended to make decisions regarding the approval of educational material ${ }^{9}$. However, these project teams did 
not have the necessary authority during the process, which resulted in the ad-hoc installation of official assessment groups of senior teachers. This is understandable in the light of the strong power distance in Vietnam, where subordinates show strong dependency in relation to their superiors, with a preference for centralized decision-making ${ }^{5}$. Therefore, within the Medical schools' Organizational Readiness for Change (MORC) questionnaire developed in Chapter 5 the items related to participation are formulated like 'people are sufficiently consulted'. What is 'sufficient' is determined by organisational members completing the questionnaire. In high power distance societies top-down pressure for change with little participative decision-making will probably be perceived by its members as sufficient.

Uncertainty avoidance describes the degree of acceptance of uncertainty and the willingness to take risks ${ }^{5}$. The feeling of uncertainty avoidance is, among others, expressed in a need for predictability: a need for written and unwritten rules. Medical schools in countries with higher levels of uncertainty avoidance showed lower levels of successful curriculum change (Chapters 2, 3 and 6). Failure of successful change has been ascribed by Levine ${ }^{18}$ to insufficient compatibility (i.e. congruence of organisational norms, values and goals of an organisation with the proposed innovation) and profitability (i.e. satisfying organisational needs) of the innovation. In accordance with our findings, Levine ${ }^{18}$ argued a greater amount of rules to decrease compatibility and to reduce the chance of successful change. More rules are thought to create more rigid organizational boundaries with a more limited range of acceptable organizational norms, values and goals, which leaves limited possibilities for the adoption of innovations.

In addition, the previously described ambivalent perception of 'risk-taking' by leaders as either a preferred style or as reckless is illustrative of different attitudes between countries in relation to change ${ }^{15,19}$. Different attitudes toward change are reflected in different levels of resistance to change, although a certain level of resistance to change will always be present everywhere. Change often provokes a sense of loss of the past and anxiety about the future ${ }^{8}$. People have a natural tendency to preserve their current situation, reflected in the way people give meaning to the world around them ${ }^{20}$. Our construction of meaning is cumulative, which means that the longer we live the more experiences are incorporated into our structure of mean- 
ing. The larger the structure that needs to be revised during a change process, the greater the loss that is experienced. This could explain why older people generally have lower levels of readiness for change and why more profound changes provoke more resistance ${ }^{20}$. Moreover our structure of meaning is loaded with emotional feelings, which explains why our perceptions cannot be changed by rational explanation alone that seems so obvious to for instance the developers of a change project. People must discover their own meaning in changes in order to accept them. The emotional loading of our construction of meaning probably explains why educational changes are often perceived as challenging competences of teachers. Some teachers perceive the proposition of educational change as an attack on the way they are teaching and their academic freedom ${ }^{8}$, an aspect also stressed in the Austrian medical schools (Chapter 4). This phenomenon is amplified by the fact that the way they are teaching usually mimics the way they were taught themselves ${ }^{8}$. Leaders within the medical school have an important role to guide teachers through this transition process from loss to commitment, from old competence to new competence, from confusion to coherence and from conflict to consensus ${ }^{20}$. Adoption of innovations through the different stages of change is highly loaded with uncertainty, which probably explains the incomplete diffusion of curriculum innovations worldwide. According to Rogers ${ }^{21}$ five criteria affect successful diffusion and resistance, including the advantage of the innovation over current practice, which resembles the profitability aspect of Levine ${ }^{18}$ and compatibility of the innovation with existing beliefs, socio-cultural values of the medical school ${ }^{8}$. Sanson-Fisher and Lynagh $^{22}$ described the diffusion of Problem-Based Learning (an example of an integrated curriculum) as successful, which actually can be a subject of debate. Worldwide, only $30 \%$ of medical schools have adopted an integrated curriculum since its introduction in 1968 (Chapter 3). Several causes for the lack of adoption by the rest of the medical schools can be hypothesized. Possibly, schools could feel unable to implement curriculum innovations due to lack of knowledge, training, time or financial resources ${ }^{8}$. A perceived ability to change was also found to be one of the main elements of organisational readiness for curriculum change in medical schools in Chapter 5. Alternatively, some medical schools might be unaware of the existence of these curriculum innovations, because they lack external relations with other medical schools that changed towards an integrated curriculum. On the other 
hand, some schools may feel that these curriculum innovations are not suitable for their schools. Debate exists for instance whether the required skills for Problem-Based Learning, such as speaking up in class with the potential for loss of face, are suitable for Asian, collectivistic societies ${ }^{23-26}$. Gwee ${ }^{23}$ argued that providing a conducive and supportive learning environment for students can overcome the perceived cultural impediments in collectivistic societies. However, Frambach et al. ${ }^{26}$ suggested that instead of a uniform application of Problem-Based Learning in every country, culturally sensitive alternatives might be more adequate. Finally, some schools might feel insufficiently motivated to change, which is the second main element of readiness for change (Chapter 5). The motivation to change is closely related to a belief in the need for change, an important element frequently mentioned in other studies ${ }^{10,27}$. Many different theories exist to gain better insight in the motivation of people, such as Herzberg's ${ }^{28}$ theory with hygiene and motivation factors, Ryan and Deci's Self-Determination Theory ${ }^{29}$, Maslow's ${ }^{30}$ pyramid of needs and McClelland's ${ }^{31}$ Needs Achievement Theory. According to Maslow ${ }^{30}$, higher needs (such as self-actualization) will only become active if more basic needs (such as physiological and social needs) are satisfied. Especially in lower income countries teachers frequently have multiple obligations outside the medical school, for instance at the hospital and in a private practice, in order to gain sufficient income. Possibly the insufficient satisfaction of lower needs in combination with divided attention and lack of time hinder the pursuit of curriculum improvement in lower income countries. Although the universal applicability of these Western theories can be challenged ${ }^{17,} 32$. Maslow's ${ }^{30}$ hierarchy of needs presupposes the motivation for achievement (self-actualization) at the top of the pyramid above social needs. Hofstede ${ }^{17}$ argued this achievement motivation to be especially valued in countries with high levels of masculinity (concern with performance) and low levels of uncertainty avoidance (willingness to accept risks). In contrast, social needs (e.g. the prevention of loss of face) seems more likely to be in the top of the needs' pyramid in Eastern countries $^{33}$ and countries with low masculinity and high uncertainty avoidance scores ${ }^{17}$. Faculty in medical schools in low masculinity and high uncertainty avoiding countries have higher concern for quality of life and relationships between people, with a lower drive to realize aspects which are mainly relevant for their personal development. This lower need for personal growth could be associated with a lower inner need 
by teachers to improve the education of their medical students. In order to change curricula in such countries the importance of creating a sufficient level of need for change is even more important.

Individualism refers to the degree of emphasis placed on an individual's accomplishment. In individualistic societies strong emphasis is usually placed on high autonomy, individual achievement and freedom to make decisions. In countries with higher levels of individualism more schools changed towards an integrative curriculum (Chapter 3). The emphasis on autonomy and achievement could possibly explain differences in innovativeness between countries with different levels of individualism through differences in motivation. The 'need for autonomy' is one of the three central elements in the Self-Determination Theory of Ryan and Deci ${ }^{29}$, next to the 'need for competence' and 'psychological relatedness'. Satisfaction of these three needs yields pro-active and intrinsically motivated individuals, whereas thwarted satisfaction of these needs leads to diminished motivation and well-being. Intrinsically motivated individuals feel that their own actions determine what happens to them, instead of externally motivated individuals who feel that what happens to them is determined by fate, luck, chance or powerful forces beyond their control ${ }^{34,35}$. Herscovitch and Meyer $^{36}$ demonstrated that intrinsic motivation (affective or normative commitment) is associated with higher levels of support for organizational change than extrinsic motivation (normative commitment). Ryan and $\mathrm{Deci}^{29}$ argue that the three needs - autonomy, competence and self-relatedness - are universal and developmentally persistent. Although they also emphasize that the expression and satisfaction of the three needs and their relation to well-being are culture-bound. Intrinsically motivated individuals perceive an internal locus of control: they feel that they have influence over outcomes through ability, effort or skills ${ }^{37}$. Mueller and Thomas ${ }^{37}$ found in a cross-cultural study of nine countries that individualistic cultures have an increased likelihood of an internal locus of control in comparison with collectivistic cultures, where an external locus of control is more prevalent. Faculty in medical schools in individualistic cultures probably perceive more influence over the quality of education in their school and their ability to improve this quality through change initiatives. Advice for leaders of schools in collectivistic cultures is not unambiguous. Leaders could try to stimulate the intrinsic motivation of the organizational members by increasing the individual's and group's 
feeling of responsibility for the current situation. Furthermore, leaders could try to increase the feeling of importance and appropriateness of the proposed change and feelings of individual competence, for the change process itself and for the new situation, aspects that are important in individualistic cultures as well. However, increasing the intrinsic motivation seems to require a change in locus of control, questioning the feasibility of such an approach. If such a locus of control is culturebound could this be changed by one leader? If even possible, should changing the existing culture be the aim? On the other hand, cultures seem to be subject of (slow) change themselves, due to for instance increase in national wealth, which advocates deliberate efforts to change the existing culture. Another strategy could be to strategically use the advantages of a certain culture: to use the external locus of control and fear of loss of face in order to attain the desired results in a collectivistic culture. For instance, a medical school's leader in a collectivistic culture could try to increase the need for change by emphasizing the possible loss of face of the faculty when educational levels leave behind in comparison to other (regional) schools which improved their curriculum.

Characteristics of national culture have been shown to have a relation with the levels of national wealth and innovativeness of medical schools. Low levels of national wealth, often measured as Gross Domestic Product (GDP) per capita, have been related with materialism, which emphasizes rule orientation, and economic and physical security ${ }^{38,39}$, resembling Maslow's ${ }^{30}$ more basic needs (i.e. social and physical needs). With increasing levels of affluence, countries tend to focus more on postmaterialistic values, such as freedom, self-expression, quality of life and better educational systems ${ }^{39,40}$, resembling Maslow's ${ }^{30}$ higher needs (i.e. autonomy and self-actualisation). Sufficient financial resources enable the financial investment required for educational innovation. In addition, the opportunities increase for medical school's faculty to travel to conferences and follow external educational courses, which promote contacts with schools that already adopted new educational approaches. National wealth indeed demonstrated to have a positive influence on curriculum innovations in medical schools (Chapter 3). Furthermore, in a study by Dodor and Rana ${ }^{41}$ specific national values, such as high individualism, low power distance and uncertainty avoidance, explained $69 \%$ of wealth distribution in 53 countries. Moreover, national culture and economic development prob- 
ably mutually influence each other ${ }^{42}$. Economic development might also cause value changes, for example in East-Asia where new generations of Chinese managers have placed higher value on individualism and less importance on Confucian values than older generations of managers ${ }^{38,43}$. Higher levels of affluence of a society allow individuals to become more socially and emotionally independent, with priority for personal rather than in-group goals, which can make societies more individualistic ${ }^{44}$. Thus, we can conclude that national culture has an influence on medical curriculum innovation and thus positively answer the first problem statement.

Problem statement 2:

How does national culture impact on the curriculum change processes in medical schools?

In the absence of an existing instrument measuring successful curriculum change, we developed and validated an instrument to measure Medical schools' Readiness for curriculum Change (MORC) (Chapter 5). A causal pathway of national culture's influence on successful curriculum change was demonstrated using MORC (Figure 1) (Chapter 6). In addition to characteristics of national culture (power distance and uncertainty avoidance), characteristics of organisational culture (human relations and open systems) demonstrated to impact on successful change implementations, which confirmed previous research in business and health care settings ${ }^{45-47}$. Furthermore, national culture could explain to a large extent variance in organisational readiness for change between different medical schools, while organisational culture could explain a large portion of variance in organisational readiness for change within different medical schools (Chapter 6).

The previous section answering problem statement 1 already described to a large extent the relation between national culture characteristics and successful curriculum changes in medical schools. This section will focus mainly on the relation between organisational culture and successful medical curriculum change. Two specific characteristics of organisational culture were found to impact on organisational readiness for change in medical schools - human relations and open systems. These will be discussed separately. 


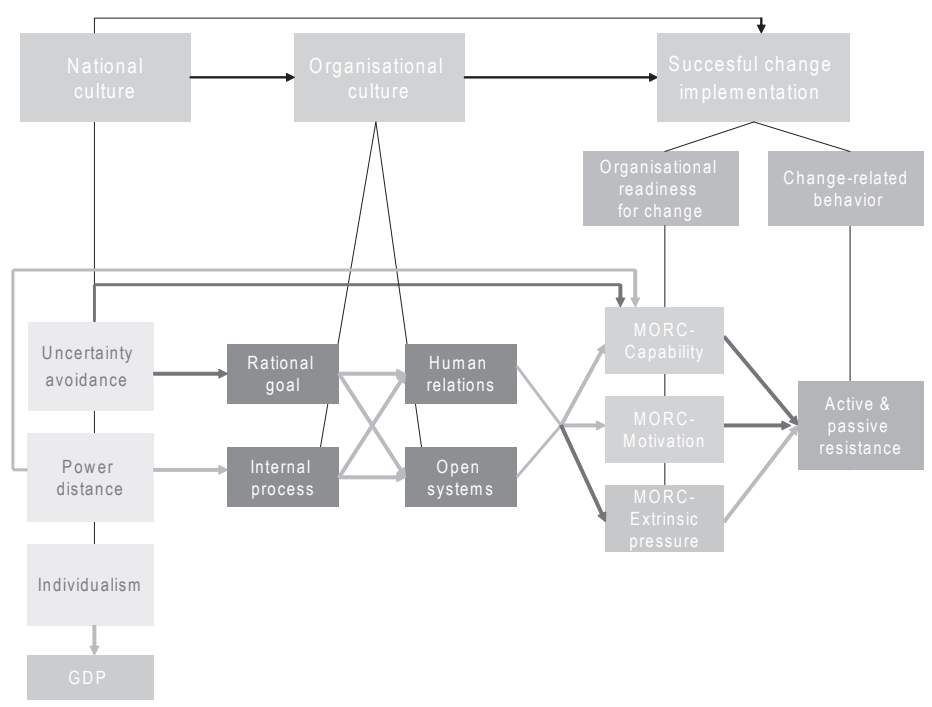

Figure 1: Summary of results of Chapter 6 incorporating the effect of national and organisational culture on successful change implementation. Dark grey lines indicate negative relations and light grey lines indicate positive relations.

Organisations scoring high on the human relations type emphasize flexibility and internal focus where trust, belongingness and teamwork are highly valued. Medical schools which featured strong human relations values demonstrated more successful change (Chapter 6). Changing an organisation requires 'learning characteristics': risk-taking, experimentation, acquisition and sharing of knowledge ${ }^{48-50}$. Knowledge sharing can be promoted through knowledge management and interpersonal contacts in social networks.

Knowledge management aims to actively disseminate knowledge within an organization, for instance through the installation of ICT systems such as electronic learning environments or facilitating workshops or training for organisational members ${ }^{50}$. ICT can facilitate knowledge sharing, but one should be aware of the ICT trap: ICT alone is not sufficient for knowledge sharing and does not replace the importance of interpersonal contacts, especially since most knowledge is difficult to capture in a database ${ }^{50}$. Learning through training or workshops directed at individual organisational members does not guarantee knowledge sharing either. The interorganizational flow of knowledge gained by individual members can be hindered, because the academic culture rewards isolationism ${ }^{8}$. Staff members are mainly rewarded for (personal) research productivity, which evokes competition for human or financial resources with other organisational members or depart- 
ments (also called micropolitics) ${ }^{8,50}$. Obstructive competition between different organisational members or departments could be reduced by encouraging individuals to focus on organisational-level goals of the medical school (with adjacent reward structure) instead of personal or departmental goals. Sherif ${ }^{51}$ demonstrated for instance that boys in a summer camp competing each other exhibited hostile behaviour. In contrast, when competition shifted towards another camp across the lake, their behaviour became amicable and friendly. Translation of these results towards organisational behaviour promotes creating competition outside the organisation, which is argued to increase sharing of knowledge within the organisation ${ }^{50}$. In order to achieve such organisational-level goals, training directed to individuals is considered less effective than collective learning processes ${ }^{49}$. Edmondson ${ }^{52}$ found in a qualitative field study of 16 hospitals implementing an innovative technology for cardiac surgery that team learning processes determined the success of implementation. Successful implementation depended on a leader who created psychological safety (e.g. feeling free to ask questions) and who stimulated the internal interaction (e.g. preparation as a team) and interaction with other groups outside the team (e.g. to create awareness by affected teams) ${ }^{52}$. This thesis showed that medical schools with strong human relations values demonstrated more successful curriculum changes, which is probably due to teamwork aspects that are highly valued in those organizations. Medical schools aiming to change towards for instance an integrated curriculum should therefore stimulate collective learning in interdisciplinary teams, which could include for instance one or more workshops (i.e. by external experts) for members from different departments, a strategy also applied successfully in Austrian medical schools (Chapter $3)$. Such a workshop should allow discussions, questions and feedback, which have been found essential aspects for the transfer of knowledge $^{50}$. Within the hospital, collective learning could include training with both nurses and physicians, similar to the collective learning exercises between pilots and cabin crew in the aviation industry.

Contrary to knowledge management, interpersonal contacts in social networks enable the (unplanned) diffusion of knowledge. Other studies demonstrated that structure, size and quality of social networks influenced the adoption of innovations ${ }^{53,54}$. In addition, Jippes et al. ${ }^{55}$ demonstrated that learning through interpersonal contacts in social networks can even be more effective than through individual 
training. Traditionally, faculty in medical schools were teaching in isolation, with little interaction with other faculty members ${ }^{8}$. In this thesis medical schools emphasizing human relations values demonstrated more successful curriculum changes, probably due to the emphasis on teamwork aspects. Teamwork constitutes sharing of knowledge between team members, which includes the flow of information regarding the change process. Medical schools aiming to change their curricula should therefore stimulate interaction between faculty members in for instance multidisciplinary committees and communities of practice ${ }^{56}$. A community of practice is "a social network of individuals who share and develop an overlapping knowledge base, set of beliefs, values, history and experiences focused on a common practice and/or mutual enterprise" 56 .

Organisations scoring high on the open systems type emphasize flexibility and external focus where adaptation to the external environment, growth and innovation are dominant. Medical schools which featured strong open systems values, demonstrated more successful curriculum changes (Chapter 6 ). The positive influence of an open systems organisational type on successful change was also demonstrated in other studies ${ }^{57-59}$. The emphasis on innovation and growth in schools with strong open systems values may manifest itself in support for new ideas, willingness to take risks and to tolerate failure, creativity, competition, constantly improving knowledge and skills, informal communication, an emphasis on collaboration and teamwork and searching for new information in the external environment $45,46,60$. The importance of adaptation to the external environment in schools with strong open system values possibly explains high levels of successful curriculum changes. Adaptation of the innovation to the needs of the external environment is reported an important feature of successful curriculum change within medical schools ${ }^{10}$. The external environment may include government bodies, accrediting agencies, scholarly societies, health profession organisations, the geographic community of a school and other medical schools. Adaptation of the curriculum to the health needs of the community and to the local context was emphasized in other studies $^{3,4}$ and emerged in several chapters in this thesis as important predictor of successful change. Furthermore, collaborations with other medical schools that are changing in similar directions facilitate the exchange of ideas, sharing of successes and joint problem solving ${ }^{10}$. 
In addition, regional collaborations of medical schools are thought to stimulate change and in the same time provide a common view of effective and realistic possibilities in the region ${ }^{61}$. Medical schools aiming to change their curriculum should adapt the curriculum innovation to the local needs and may collaborate with other (regional) schools that are changing or have changed in similar directions. Thus, we can conclude that specific characteristics of national and organisational culture can be conducive for successful curriculum change.

\section{Limitations}

\section{National culture}

The concept of national culture and its assessment have caused fierce debates which focus on several elements, including whether national cultures are changing, and if they do whether intercultural differences are becoming smaller (convergence) or larger (divergence) ${ }^{62}$. Methods of measuring national culture are another subject of debate. Anthropologists argue that culture is not supposed to be measured quantitatively ${ }^{63}$. However, our research questions required a quantitative approach in order to compare cross-cultural differences between medical schools and Hofstede's ${ }^{5}$ cultural dimensions appeared to be the most useful framework. A limitation of this thesis may be the strong reliance on Hofstede's cultural dimensions. Criticism on Hofstede's dimensions of culture include doubts about the validity of his concept of national culture ${ }^{64,65}$. For instance, Hofstede's assumption that every country contains one culture was challenged by Baskerville ${ }^{65}$. Baskerville $^{65}$ debates that one nation may actually contain several cultures, for example 'the Middle East' harbors according to the Encyclopedia of World Cultures 14 nations and 35 different cultures ${ }^{66}$. Hofstede ${ }^{67}$ recognized that nations may not be the best unit for studying culture, but claimed that it is most often the only available unit for comparison. Other criticism on Hofstede's methodology includes his population sample of IBM employees. Hofstede's 116.000 questionnaires were completed by IBM employees only, leading to the question whether the scores are applicable in other settings, such as medical schools ${ }^{64}$. For instance in Austria power distance was supposed to be very low with a score of 17 on a scale ranging from 11 to 104 . Several findings suggest that (in medical schools) the Austrian level of power distance and related hierarchy may be underestimated. Hofstede ${ }^{5}$ also thought this low score on the dimension of power distance in Austria to be 
striking. His explanation was that perhaps power distance in Austria is so strong that employees by the question 'How often, in your experience, are subordinates afraid to contradict their boss?' answered 'never' because the possibility of contradicting their boss did not even come to their mind ${ }^{5}$. Another possible explanation could be that Hofstede measured the 'wanted' power distance score in Austria, which was according to House et al. ${ }^{15}$ also very low (2.44 on a Likert scale of 1-7), while instead the 'perceived' power distance score was according to House very high (4.95). Findings from our own research in Austria indicated a high level of power distance as suggested by the following quote from the interview study (Chapter 4): '... because Austrian society is strongly hierarchical. Strongly embedded in traditional norms of hierarchy. Something you could also see in universities, which were very hierarchical, and this was true very much for the medical profession. Although the exploitation of the younger assistants is changing, it is still more hierarchical and sometimes even oppressive compared to our liberal arts situation' (Austrian history professor). Replication of national culture scores based on medical schools would have been favourable and the administration of Hofstede's questionnaire next to MORC was even discussed in our research team (Chapter 6). However, an already lengthy questionnaire unfortunately prompted us to refrain from this idea. Nevertheless, Hofstede's cultural dimensions have been replicated in many other settings and his research is the most frequently cited framework that enables the cross-cultural comparison of differences between countries ${ }^{68}$.

\section{Organisational culture}

A limitation may reside in the use of Quinn and Spreitzer's ${ }^{69}$ Competing Values Framework for the measurement of organizational culture. Organisational types on opposite sides of the framework (human relations versus rational goal and open systems versus internal process) did not have the expected negative correlations but strong positive correlations instead (Chapter 6). A possible explanation could be that the organisational culture characteristics of medical schools are different from the organizations of the participants from which the Competing Values Framework originally was derived ${ }^{69}$. An alternative explanation may be that medical schools featured two or more organisational types (i.e. cultural profile), which possibly interacted with each other. Additional cluster analysis of the cultural profiles may improve insight 
in the organisational culture in medical schools and further analysis may reveal which cultural profiles are most successful for curriculum change.

\section{MORC}

A limitation in the development of MORC is the sample size (Chapter 5). Although a large number of schools and countries were included in the validity study, it was still not enough to perform an exploratory factor analysis on the whole dataset. Therefore we had to do separate analysis of the three underlying dimensions of MORC (capability, motivation, extrinsic pressure). A follow-up study tested our conceptual model of national and organisational cultures impact on successful curriculum change (measured with MORC) (Chapter 6). Based on generalizability analysis, we intended to exclude all medical schools with less than five respondents per school, but unfortunately this was not feasible due to a larger amount of parameters to be estimated in comparison with the number of medical schools in the sample. The fact that our conceptual model demonstrated poor model fit was probably also caused by the limited sample size.

\section{Theoretical and practical implications and suggestions for fur- ther research}

National and organisational culture and curriculum innovation in medical schools

National culture's impact on successful change was already demonstrated in business organisations ${ }^{5,}{ }^{70-73}$. Yet little was known about the role of national culture on adoption of innovations in medical schools, exceptions being the work of Simunovic ${ }^{74}$ and Segouin ${ }^{75}$ as described in the introduction. To our knowledge, the impact of organisational culture on successful change was not previously demonstrated in medical schools, only in business and health care organisations ${ }^{45-47,76}$. The findings of this thesis add empirical confirmation that national and organisational culture influences the success of curriculum innovations in medical schools. Results showed that specific national and organisational culture characteristics were conducive for successful curriculum change, such as: flexible policies and procedures (low uncertainty avoidance), a certain level of risk-taking (low uncertainty avoidance), intrinsic motivation to change and internal locus of control (high individualism), interdisciplinary teamwork (strong human relations 
values), adaptation to the local community needs and collaborations with regional schools (strong open systems values). However, medical schools in countries with cultural environments possibly less conducive for change do not have to refrain from changing their curricula. Schools in such countries should be aware of potential (additional) sources of resistance rooted in the national or organisational culture, and the possibility to design in advance strategies to tackle this resistance. Such strategies might include attempts to adapt the cultural characteristics, but perhaps it would be more effective to consciously deploy the cultural characteristics that might otherwise hinder change. For instance a medical school's leader in a culture with a low risk-taking tolerance (high uncertainty avoidance) might decrease the feeling of risk-taking by emphasizing how potential risks are minimized. In addition, a medical school's leader in a collectivistic culture could try to increase the need for change by emphasizing the possible loss of face of the faculty when educational levels leave behind in comparison to other (regional) schools which improved their curriculum. This thesis offered the start of the exploration of cultural influences on curriculum change processes and offers some recommendations for schools (preparing) changing their curriculum (Table 1). Further research is required, for instance to further investigate effective strategies for change in different cultures.

Medical schools with strong 'human relations' values, including trust, belongingness and teamwork, demonstrated more successful curriculum changes. The teamwork aspects might have played a main role. Interdisciplinary teams facilitate interpersonal contacts in social networks, which stimulate the diffusion of knowledge and innovations ${ }^{53,54}$. Social network analysis investigates the relations between individuals in a population and structure, size en quality of social networks appeared to play an important role in the diffusion of innovations in business ${ }^{21}$ and health care organisations ${ }^{53,54,77}$. The field of medical education seems to lag behind in the application of social network analysis, with some exceptions such as the work of Hommes et al. ${ }^{78}$ who studied the role of informal social networks on student learning. In addition, many network studies were conducted in single organisations and often neglected the role of culture ${ }^{79,80}$. Further research could study the impact of social networks in medical schools on curriculum innovations and could compare networks between different schools and countries in order to explore the role of national and organisational culture. 


\section{Recommendations for implementing a curriculum change}

- Create a sufficient level of need for change in the whole medical school by emphasizing the gap between the current performance and the desired performance

- Be aware of the culturally determined locus of control and adapt the strategy (e.g. emphasize possible loss of face in collectivistic cultures and increase re sponsibilities in individualistic cultures)

- Make sure that the curriculum is appropriate for the local context (i.e. health needs of the community) and meets the need for change

- Create sufficient belief by staff members in their capability to change through for instance training and workshops

- Pay attention to the personal consequences (such as loss of teaching hours or power) of staff members and support them in the transition they have to make

- Be aware of the culturally determined level of risk-taking in your school and emphasize how potential risks are minimized

- Communicate: about the reasons for change, desired goals, progress of the change, etc.

- Stimulate interaction between staff members through interdisciplinary committees and communities of practise

- Create sufficient financial resources, staff and facilities

- Make a clear plan for the implementation and evaluation of the change and specify who is responsible

- Stimulate organisational levels goals with adjacent reward structure instead of personal or department goals

- Collaborate with other (regional) medical schools to exchange ideas, share successes and jointly solve problems

- Be aware of the culturally determined organisational hierarchy and the appreciation for centralized command or more participative leadership

- Evaluate the organisational readiness in your school for curriculum change

Table 1: Recommendations for implementing a curriculum change

Medical schools with strong 'open systems' values, including adaptation to the external environment, growth and innovation, demonstrated more successful curriculum innovations. Specific characteristics have been described that demonstrate an innovative culture, such as support for new ideas ${ }^{45}$. In the medical school and in the hospitals where the first author (MJ) obtained her medical training she noticed that there are many people with innovative ideas aiming to improve either education or patient care. Unfortunately many of these ideas are not implemented, probably due to a lack of time and expertise in organisational change management to implement these ideas. Ackerman ${ }^{50}$ describes this phenomenon as the inability to effectively share individual knowledge and to turn it into organisational knowledge. Both medical schools and hospitals would prosper in the availability of a Research and Development (R\&D) department, which could facilitate the implementation of ideas by organisational members (bottom-up change). 
This could be visualised as follows: An individual organisational member presents his/her idea in a face-to-face meeting with someone from the R\&D department, who discusses this idea with the concerned superiors that have decision-making authority. The R\&D department subsequently writes a research or implementation proposal (which could also be used for possible grant applications) and facilitates the implementation of the idea together with the individual member that initially proposed the idea.

This thesis focussed explicitly on the influence of national culture on innovations. However, there are indications that national culture characteristics and curriculum innovations in medical schools have mutual influence on each other ${ }^{26}$. For instance in a medical school in Ghana, the introduction of PBL encouraged students to stand up for themselves and to start a student council in order to improve necessary aspects of their education ${ }^{81}$. Probably students learned to speak up during the PBL sessions, because within Ghana's collectivistic culture speaking up is normally avoided in order to prevent losing face. Further research could focus on the influence of the adoption of (foreign) educational innovations on the values and behaviour of the students and teachers.

\section{Curriculum change and (M)ORC}

Most theories on factors influencing successful change seem to include the two main aspects of organisational readiness for change: motivation and capability. Motivation aspects can be recognized in for instance the 'profitability' factor of Levine ${ }^{18}$ and 'the advantage of the innovation over current practice' described by Rogers ${ }^{21}$. Similarly, capability aspects can be recognized in the 'compatibility' factor described by both Levine and Rogers ${ }^{18,21}$. Organisational readiness for change was conceptualized as a shared organisational level property: a psychological state which organisational members hold in common ${ }^{82}$. However, intraclass correlations (ICC) demonstrated relatively low agreement of organisational members in their perception of organisational readiness for change of their medical school (Chapter 6). Possibly, the individual perception of organisational readiness for change is influenced by the members of someone's team and department, leading to high variation within one medical school in the perception of organisational readiness for change and lower variation within teams or departments ${ }^{83}$. Further research could compare variance in perceptions of readiness 
for change within teams, departments and the whole medical school. The main source which identified factors influencing successful curriculum change was an extensive American-based literature review by Bland et al. ${ }^{10}$. To our knowledge no questionnaire existed that measured factors influencing successful curriculum change, a gap closed with the development and validation of MORC (Chapter 5). Most factors described in the review by Bland et al. ${ }^{10}$ are covered by the MORC questionnaire (Table 2). MORC's subscale 'pressure for change' was not covered by one of Bland's factors and adds information on the origin of the pressure for change. For instance, knowing whether the change is perceived by a medical school's members to be forced only from management (top-down) could indicate a potential source of resistance in cultures with low levels of power distance ${ }^{14,16,17,42}$. This seems at variance with the view of Bland and Wersal ${ }^{11}$ that academic organisations usually prefer participative leadership, which could reflect the American culture. In addition to Bland et al. ${ }^{10}$, MORC also pays attention to the source of the motivation to change: either intrinsic or extrinsic. External motivated organisational members demonstrated lower levels of support for change ${ }^{36}$. Extrinsic motivation to change may be more prone to decreased effort to change, especially if external pressure (e.g. from management) decreases. Bland's ${ }^{10}$ factor 'performance dip' (a decrease in an organisation's performance after the introduction of a new program) is not incorporated in MORC, but could be demonstrated by comparing results of administrating MORC on several moments before and after the adoption of an innovative curriculum. A decrease in efficacy and the need for change could indicate the existence of a performance dip. MORC enables medical schools (preparing) changing their curriculum to improve the chance of successful implementation by indicating aspects that need further attention. Furthermore, MORC can be used to shed light on issues related to curriculum change, for instance, to investigate the effectiveness of a management strategy based on a initial MORC administration with a second administration of MORC a couple of months later.

\section{Medical education}

Several aspects of the medical field are subject of continuous change, including under- and postgraduate medical education, which became evident as almost all schools that were contacted for the studies presented in Chapter 5 and 6 were either preparing, implementing or 
evaluating change. In the available literature there appears to be a bias towards the presentation of mainly the success stories of medical curriculum change projects, while there are probably large numbers of more of less unsuccessful change projects, which could be even more informative for schools (preparing) changing their curriculum. In addition, physician's possibilities for diagnosis and treatment are continuously improving, requiring continuous adaptation of medical practise. Furthermore, the organisation of health care is subject of continuous change due to an increased need for cost-efficiency, transparency and safety. As medical graduates will inevitable enter a changing world in which they will have to play a key role, it is necessary that within the medical curriculum time is devoted to change management and leadership skills.

In sum, we can conclude that specific characteristics of national and organisational culture can be conducive for successful change. Beside the theoretical relevance of the findings in this thesis, this thesis also provides some practical recommendations (Table 1) and a questionnaire which can be used for medical schools (preparing) changing their curriculum. We hope that the findings of this thesis will be useful for medical schools aiming to improve their curricula to increase the success of their change projects. 


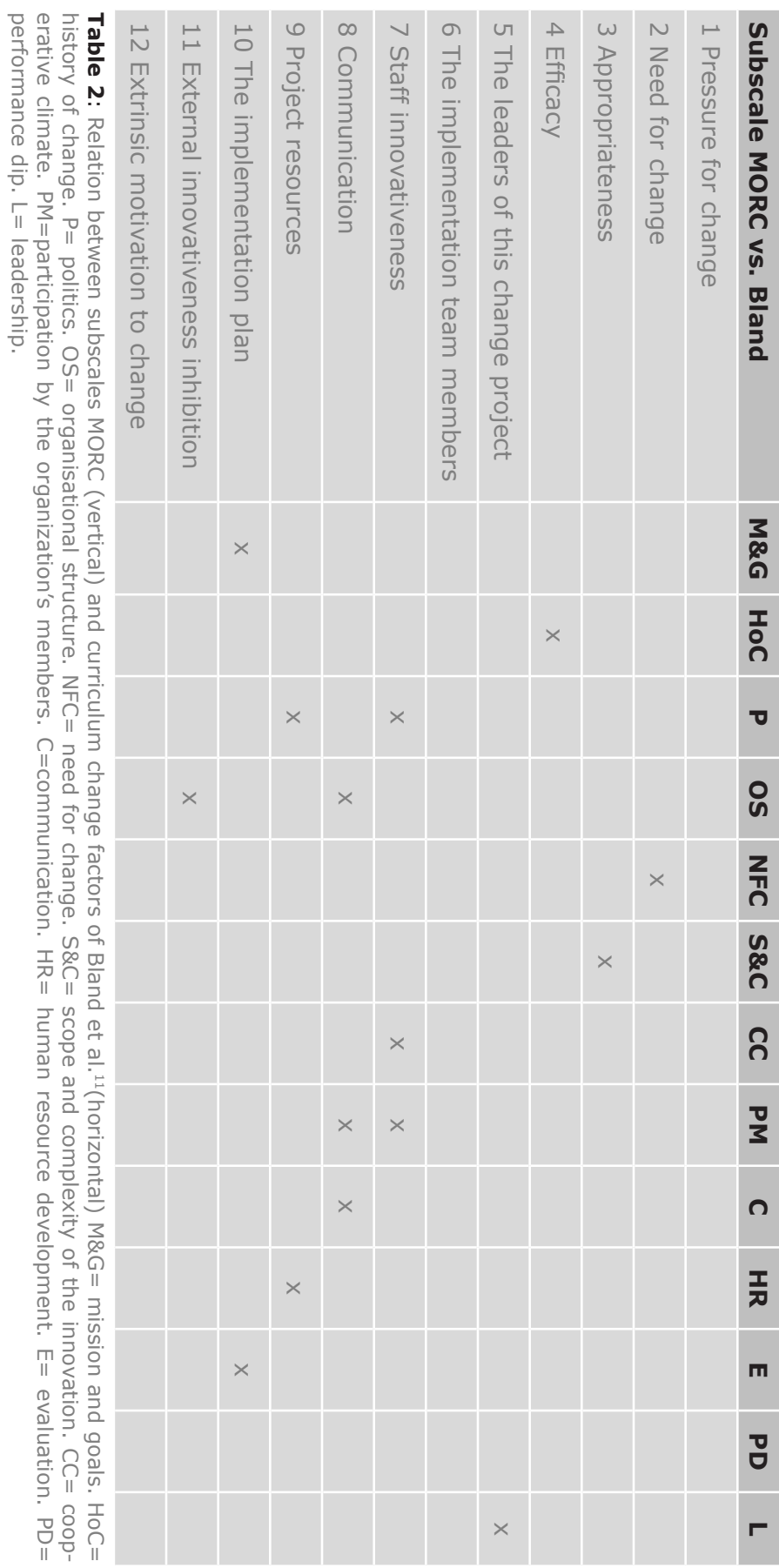




\section{References}

1. Palfreyman D. Learning and teaching across cultures in higher education. New York: Palgrave Macmillan 2007.

2. WHO. Community-based education of health personnel. Geneva: WHO 1987.

3. Blizard PJ. International standards in medical education or national standards/ primary health care--which direction? Social Science \& Medicine. 1991;33:116370.

4. Frenk J, Chen L, Bhutta ZA, Cohen J, Crisp N, Evans T, et al. Health professionals for a new century: transforming education to strengthen health systems in an interdependent world. Lancet. 2010 Dec 4;376(9756):1923-58.

5. Hofstede G. Culture's Consequences. Comparing Values, Behaviors, Institutions, and Organizations across Nations. New York: Sage Publications 2001.

6. Nakata C, Sivakumar K. National Culture and New Product Development: An Integrative Review. Journal of Marketing. 1996;60(1):61-72.

7. Bernier G, Adler S, Kanter S, Meyer WJ. On changing curricula: lessons learned at two dissimilar medical schools. Academic Medicine. 2000;75(6):595-601.

8. Lane IF. Change in higher education: understanding and responding to individual and organizational resistance. Journal of Veterinary Medical Education. 2007 Spring;34(2):85-92.

9. Hoat LN. Moving the mountain: renovating medical education in a changing Vietnam [PhD thesis]. Amsterdam: VU 2008.

10. Bland CJ, Starnaman S, Wersal L, Moorehead-Rosenberg L, Zonia S, Henry R. Curricular change in medical schools: how to succeed. Academic Medicine. 2000 Jun;75(6):575-94.

11. Bland CJ, Wersal L. Effective leadership for curricular change. In: Norman; GR, van der Vleuten C, Newble D, editors. International Handbook of Research in Medical Education. Dordrecht; Boston; London: Kluwer; 2002. p. 969-79.

12. Gardner WL, Lowe KB, Moss TW, Mahoney KT, Cogliser CC. Scholarly leadership of the study of leadership: A review of The Leadership Quarterly's second decade, 2000-2009. Leadership Quarterly. 2010;21:922-58.

13. Avolio BJ, Walumbwa FO, Weber TJ. Leadership: Current Theories, Research, and Future Directions. The Annual Review of Psychology 2009;60:421-49.

14. Den Hartog DN, House RJ, Hanges PJ, Ruiz-Quintanilla SA, Dorfman PW. Culture specific and cross-culturally generalizable implicit leadership theories: are attributes of charismatic/transformation leadership universally endorsed? Leadership Quarterly. 1999;10:219-56.

15. House R, Hanges P, Javidan M, Dorfman P, Gupta V. Culture, Leadership and Organizations. The GLOBE Study of 62 Societies. New York: Sage publications 2004.

16. Dorfman PW, Howell JP, Lee JK, Tate U. Leadership In Western And Asian Countries: Commonalities And Differences In Effective Leadership Processes Across Cultures. Leadership Quarterly. 1997;8(3):233-74.

17. Hofstede G. Motivation, leadership and organization: do American theories apply abroad? Organizational Dynamics. 1980;9(1):42-63.

18. Levine A. Why innovation fails. Albany: State University of New York Press 1980.

19. Rippl S. Cultural theory and risk perception: a proposal for a better measurement. Journal of Risk Research. 2002;5:147-65.

20. Evans R. The Human Side of School Change. Reform, Resistance, and the Reallife Problems of Innovation. San Francisco: Jossey-Bass Publishers 1996.

21. Rogers E. Diffusion of Innovations. 4th ed. New York: Free Press 1995.

22. Sanson-Fisher RW, Lynagh MC. Problem-based learning: a dissemination suc- 
cess story? Medical Journal of Australia. 2005 Sep 5;183(5):258-60.

23. Gwee MC. Globalization of problem-based learning (PBL): cross-cultural implications. Kaohsiung Journal of Medical Sciences. 2008 Mar;24(3 Suppl):S14-22.

24. Hofstede G. Cultural differences in teaching and learning. International Journal of Intercultural Relations. 1986;10(3):301-20.

25. Khoo HE. Implementation of problem-based learning in Asian medical schools and students' perceptions of their experience. Medical Education. 2003;37(5):4019.

26. Frambach JM, Driessen EW, Chan L-C, van der Vleuten CPM. Rethinking the globalisation of problem-based learning: how culture challenges self-directed learning. Medical Education. 2012;46:738-47.

27. Kotter JP. Leading Change. Boston: Harvard Business School Press 1995.

28. Herzberg F. The motivation-hygiene concept and problems of manpower. Personnel Administration. 1964;27:3-7.

29. Ryan RM, Deci EL. Self-determination theory and the facilitation of intrinsic motivation, social development, and well-being. American Psychologist. 2000;55(1):68-78.

30. Maslow AH. A theory of human motivation. Psychological Review. 1943;50(4):370-96.

31. McClelland DC, Steele RS. Human motivation; a book of readings. Morristown, N.J.: General Learning Press 1973.

32. Iguisi O. Motivation-related values across cultures. 2009;3:141-50.

33. Pinto D. Intercultural Communication: A three-step method for dealing with differences. Leuven: Garant 2000.

34. Hsieh TT-y, Shybut J, Lotsof EJ. Internal Versus External Control And Ethnic Group Membership: A Cross Cultural Comparison. Journal of Consulting and Clinical Psychology. 1969;33(1):122-4.

35. Rotter JB. Some Problems and Misconceptions Related to the Construct of Internal Versus External Control of Reinforcement. Journal of Consulting and Clinical Psychology. 1975;43(1):56-67.

36. Herscovitch L, Meyer JP. Commitment to organizational change: Extension of a three-component model. Journal of Applied Psychology. 2002;87:474-87.

37. Mueller SL, Thomas AS. Culture And Entrepreneurial Potential : A Nine Country Study Of Locus Of Control And Innovativeness. Journal of Business Venturing. 2001; 16:51-75.

38. Tang L, Koveos PE. A framework to update Hofstede's cultural value indices: economic dynamics and institutional stability. Journal of International Business Studies. 2008;39(6):1045-63.

39. Inglehart R. Economic security and value change. The American Political Science Review. 1994;88(2):336-54.

40. Cox PL, Friedman BA, Tribunella T. Relationships among Cultural dimensions, National Gross Domestic Product, and Environmental sustainability. Journal of Applied Business and Economics. 2011;12(6):46-56.

41. Dodor JBK, Rana DS. Culture and economic development: an investigation using Hofstede cultural dimensions. International Journal of Business Research. $2007 ; 7$.

42. Leung K. The rise of East Asia: Implications for research on cultural variations and globalization. Journal of international management. 2006;12(2).

43. Ralston DA. Doing business in the 21st century with the new generation of Chinese managers: A study of generational shifts in work values in China. Journal of International Business Studies. 1999;30(2):415-27.

44. Triandis HC. The self and social behavior in differing cultural contexts. Psychological Review. 1989;96(3):506-20.

45. McLean LD. Organizational Culture's Influence on Creativity and Innovation: A 
Review of the Literature and Implications for Human Resource Development. Advances in Developing Human Resources. 2005;7:226-46.

46. Susanj Z. Innovative climate and culture in manufacturing organizations: differences between some European countries. Social Science Information. 2000;39:349-61.

47. Wang S, Guidice R, Tansky J, Wang Z-m. The moderating role of organizational culture in innovation: evidence from chainge. Academy of Management Proceedings. 2009; Suppl 1.

48. Bates R, Khasawneh S. Organizational learning culture, learning transfer climate and perceived innovation in Jordanian organizations. International Journal of Training and Development. 2005;9:96-109.

49. Senge P. The fifth discipline : the art and practice of the learning organization. New York: Doubleday/Currency 1990.

50. Ackerman M. Sharing expertise beyond knowledge management. Cambridge, Mass: MIT Press 2003.

51. Sherif M. Group conflict and co-operation: Their social psychology. Londen: Routledge \& Kegan Paul 1967.

52. Edmondson A. Disrupted Routines: Team Learning and New Technology Implementation in Hospitals. Administrative Science Quarterly. 2001;46(4).

53. Greenhalgh T, Robert G, Macfarlane F, Bate P, Kyriakidou O. Diffusion of innovations in service organizations: systematic review and recommendations. The Milbank Quarterly. 2004;82(4):581-629.

54. West E, Barron DN, Dowsett J, Newton JN. Hierarchies and cliques in the social networks of health care professionals: implications for the design of dissemination strategies. Social Science \& Medicine. 1999;48(5):633-46.

55. Jippes E, Achterkamp MC, Brand PL, Kiewiet DJ, Pols J, van Engelen JM. Disseminating educational innovations in health care practice: training versus social networks. Social Science \& Medicine. 2010;70(10):1509-17.

56. Kaufman DM, Mann KV. Teaching and Learning in Medical Education: How Theory can Inform Practice. In: Swanwick T, editor. Understanding Medical Education: Evidence, Theory and Practice. Oxford, UK: Wiley-Blackwell; 2010.

57. Eby LT, Adams DM, Russell JEA, Gaby SH. Perceptions of Organizational Readiness for Change: Factors Related to Employees' Reactions to the Implementation of Team-Based Selling. Human Relations. 2000;53(3):419-42.

58. Zammuto R, Krakower J. Quantitative and qualitative studie of organizational culture. Research in Organizational Change and Development. 1991;5:83-114.

59. Jones RA, Jimmieson NL, Griffiths A. The impact of organizational culture and reshaping capabilities on change implementation success: The mediating role of readiness for change. Journal of Management Studies. 2005;42(2):361-86.

60. Williams I. Organizational readiness for innovation in health care: some lessons from the recent literature. Health Services Management Research. 2011;24(4):213-8.

61. Prideaux D. Think global, act regional: promoting change in medical education. Medical Education. 2005;39(8):756-7.

62. Nelson RE, Gopalan S. Do Organizational Cultures Replicate National Cultures? Isomorphism, Rejection and Reciprocal Opposition in the Corporate Values of Three Countries. Organization Studies. 2003;24:1115-51.

63. Creighton MR. Revisiting Shame and Guilt Cultures: A Forty-Year Pilgrimage. Ethos. 1990;18(3):279-307.

64. Signorini $\mathrm{P}$, Wiesemes R, Murphy R. Developing alternative frameworks for exploring intercultural learning: a critique of Hofstede's cultural difference model. Teaching in Higher Education. 2009;14:253-64.

65. Baskerville RF. Hofstede never studied culture. Accounting, Organizations and Society. 2003;28(1):1-14.

66. O'Leary TJ, Levinson D. Encyclopedia of World cultures: GK Hall \& Company 
1991.

67. Hofstede G. What is culture? A reply to Baskerville. Accounting, Organizations and Society. 2003;28(7-8):811-3.

68. Kirkman BL, Lowe KB, Gibson CB. A quarter century of Culture's Consequences: a review of empirical research incorporating Hofstede's cultural values framework. Journal of International Business Studies. 2006;37(3):285-320.

69. Quinn R, Spreitzer G. The psychometrics of the competing values culture instrument and an analysis of the impact of organizational culture on the quality of life. Research in Organizational Change and Development. 1991;5:115-42.

70. Tellis GJ, Yin E, Bell S. Global Consumer Innovativeness: Cross-Country Differences and Demographic Commonalities. Journal of International Marketing. 2009; 17:1-22.

71. Everdingen $Y V_{1}$, Waarts $E$. The effect of national culture on the adoption of innovations. Marketing Letters. 2003;14(3):217-32.

72. Singh S. Cultural differences in, and influences on, consumers' propensity to adopt innovations. International Marketing Review. 2006;23:173-91.

73. Yaveroglu IS, Donthu N. Cultural Influences on the Diffusion of New Products. Journal of International Consumer Marketing. 2002;14(4):49-63.

74. Simunovic VJ, Hren D, Ivanis A, Dorup J, Krivokuca Z, Ristic S, et al. Survey of attitudes towards curriculum reforms among medical teachers in different socio-economic and cultural environments. Medical Teacher. 2007;29(8):8335 .

75. Segouin C, Hodges B. Educating doctors in France and Canada: are the differences based on evidence or history? Medical Education. 2005;39(12):1205-12.

76. Jaskyte K, Dressler W. Organizational Culture and Innovation in Nonprofit Human Service organizations. Administration in Social Work. 2005;29:23-41.

77. Keating NL, Ayanian JZ, Cleary PD, Marsden PV. Factors affecting influential discussions among physicians: a social network analysis of a primary care practice. Journal of General Internal Medicine. 2007;22:794-8.

78. Hommes J, Rienties B, de Grave W, Bos G, Schuwirth L, Scherpbier a. Visualising the invisible: a network approach to reveal the informal social side of student learning. Advances in Health Sciences Education: Theory and Practice [serial on the Internet]. 2012 [cited 2012 Febr 1].

79. Salk JE, Brannen MY. National Culture, Networks, and Individual Influence in a Multinational Management Team. The Academy of Management Journal. 2000;43:191-202.

80. Emirbayer M. Network Analysis, Culture, and the Problem of Agencyl. American Journal of Sociology. 1994;99:1411-54.

81. Broos CE, Jippes M. Report about Visit FMHS-UDS in Tamale2008.

82. Weiner BJ. A theory of organizational readiness for change. Implementation Science. 2009;4 (67):1-9.

83. Klein K, Sorra S. The Challenge of Innovation Implementation. The Academy of Management Review. 1996;21:1055-80. 
\begin{tabular}{l|l} 
GENERAL DISCUSSION & 163
\end{tabular} 


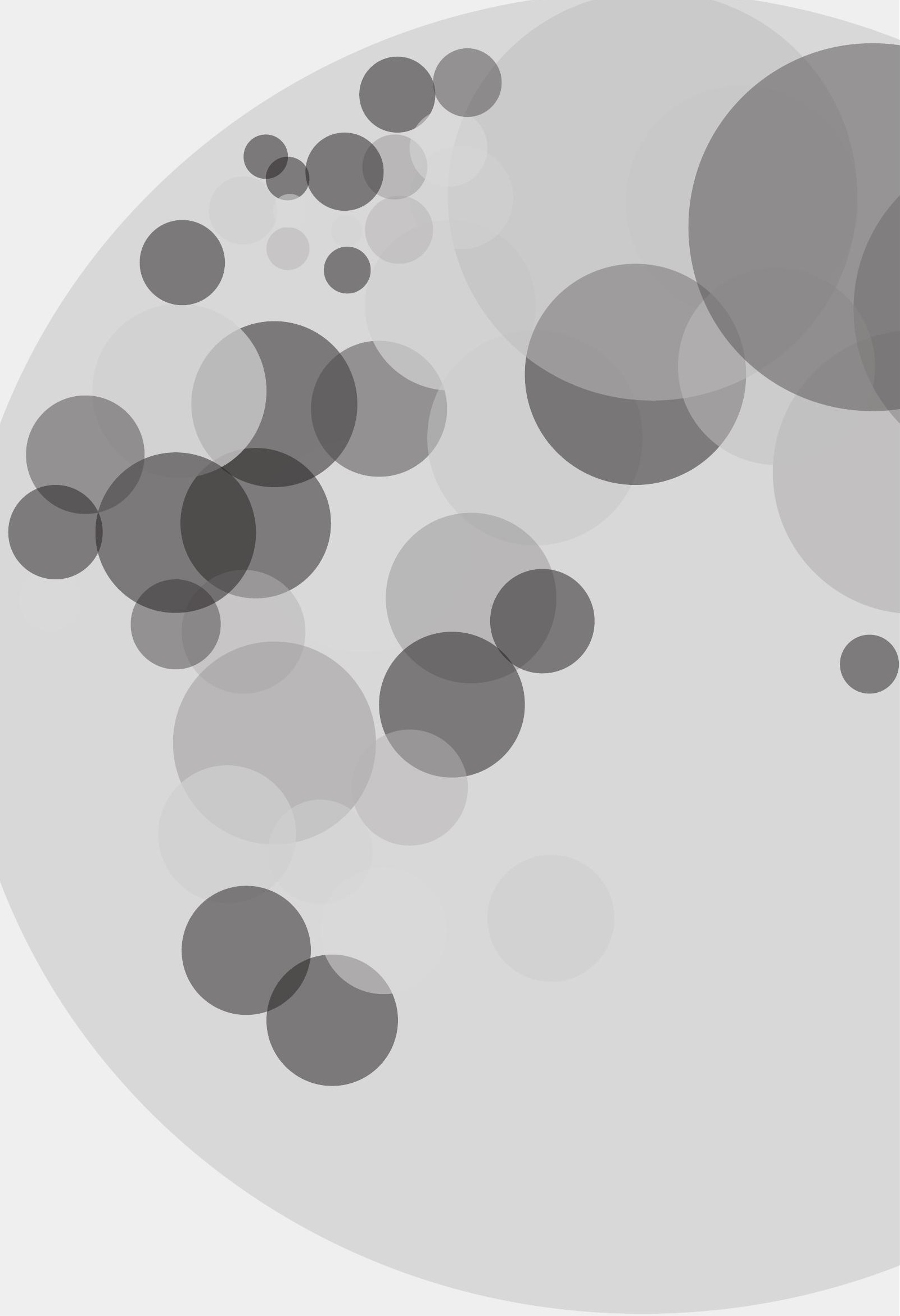




\section{SUMMARY}

SAMENVATTING 
Introduction (Chapter 1). This thesis addressed the impact of national culture characteristics on curriculum changes in medical schools. The medical curriculum is currently subject of change in many medical schools throughout the world. However, the implementation of innovative curricula is not always equally successful everywhere and complete or partial failure of the implementation is not uncommon. More insights in factors that promote successful change could possibly prevent costly failures and frustrations. Knowledge about the cultural influences on medical curriculum change is scarce. Therefore, the first chapter first gives an overview of the literature on medical curriculum change and subsequently an overview of the literature on cultural influences on change processes in general. Thereafter, the (mostly hypothesized) combination of these two components follows, leading to the central problem statements for this thesis: Does national culture impact on medical curriculum innovation? And if so, how does national culture impact on the curriculum change processes in medical schools?

The studies described in chapters $\mathbf{2}$ and $\mathbf{3}$ analyzed whether a relation exists between the national culture dimensions of Hofstede ${ }^{1}$ and the portion of medical schools in a country with an innovative curriculum. The results of the second chapter showed that within 17 European countries such relation exists. Two out of the four dimensions of culture of Hofstede, namely 'power distance' and 'uncertainty avoidance' had a significant correlation with the percentage of medical schools per country with an integrated curriculum. Similar results were found for the extended dataset with 63 countries worldwide in the second chapter. In addition, in this dataset 'individualism' also showed to have a significant correlation with the portion of medical schools per country with an innovative curriculum. Thus, countries scoring high on uncertainty avoidance and/or power distance and/or scoring low on individualism harboured less medical schools that changed to an integrated curriculum. Possibly, schools in countries with high power distance featured high levels of hierarchy that obstructed the necessary interdisciplinary communication between different departments. Furthermore, department heads who were previously almost autonomously responsible for the education in their discipline had to hand over part of their power to a central educational committee, which probably induced resistance. Furthermore, high uncertainty avoidance possibly impeded curriculum innovation due to the avoidance of risk-taking and adherence to the strict rules and regulations of the faculty and the government. Finally, 
high levels of collectivism possibly prevented change initiatives through the emphasis on group culture and preservation of harmony in order to avoid conflicts.

In chapter 4 we explored how medical schools in an unconducive environment for change managed the transition towards an innovative curriculum. Chapters 2 and 3 showed that countries with high levels of uncertainty avoidance and/or power distance and/or low levels of individualism harbored less medical schools which changed to an innovative curriculum. However, not all countries kept strictly to this observation and some countries with less conducive environments for change unexpectedly harbored many innovative medical schools. Studying such schools that had been able to change despite a less conducive environment for change was thought to yield insight in how culture impacts on curriculum change processes, and how obstructing effects could be possibly tackled. Uncertainty avoidance demonstrated to have the strongest inhibiting force. Therefore a qualitative interview study was conducted with key change agents in Austria, where all three public medical schools succeeded to implement integrated curricula despite their high national level of uncertainty avoidance. Several factors were identified that promoted and inhibited the implementation processes, which were fairly similar among the three medical schools. One of the main stimulating factors within the change processes was the introduction of a law by the government allowing curriculum change in a certain time period. Earlier, the governments' restrictive legislation had acted as an inhibiting factor and fostered an excuse culture 'It's not our fault. It is the ministry's'. Confirmation of the impact of strong uncertainty avoidance was found in the strict rules and regulations and in general avoidance of uncertain situations by many staff members. Opposition by faculty was overcome through this national legislation, that encouraged change together with additional internal factors supporting the change: a strongly felt need for change, supportive and continuous leadership, and visionary change agents.

Chapter 5 describes the development and validation of a new questionnaire aimed to measure the predictors of a successful curriculum change: Medical schools' Organizational Readiness for curriculum Change (MORC). Various questionnaires measuring organisational readiness for change existed for business and health care organisations, but to our knowledge no comprehensive instrument existed that 
was applicable for medical schools. Elements of existing questionnaires were combined in a preliminary questionnaire and the applicability of this questionnaire for medical schools was reviewed by a panel consisting of 19 medical curriculum change experts who in a modified Delphi procedure reached consensus in two rounds. Subsequently the preliminary MORC questionnaire was psychometrically tested in a population of 991 staff members in 131 medical schools from 56 countries that were - at the time of administration - in a curriculum change process. Exploratory factor analysis resulted in the final 53-item MORC questionnaire comprising twelve subscales with three dimensions, a structure confirmed by confirmatory factor analysis. Furthermore, generalizability analysis demonstrated that five to fifteen staff members suffice to reliably evaluate a medical school's organisational readiness for change.

In chapter 6 we examined the impact of national and organisational culture on successful implementation of medical curriculum change. This study combined the results of the previous five chapters. Chapters two and three confirmed the existence of a relation between national culture and successful curriculum change, without further amplifying how the cultural characteristics influenced the change process in medical schools. The MORC questionnaire developed in the fifth chapter measured the predictors of successful curriculum change, which enabled further exploration of the way national culture impacts on curriculum change. Organizational culture was hypothesized to influence the relation between national culture and successful curriculum change and was measured using the Competing Values Framework questionnaire of Quinn ${ }^{2}$. A conceptual model incorporating the national culture dimensions of Hofstede, the organizational culture types of Quinn and the MORC questionnaire with the predictors of successful curriculum change was analyzed using multilevel structural equation modeling of the available dataset of 991 staff members in 131 medical schools from 56 countries. Results confirmed the influence of characteristics of both national and organizational culture on (the predictors of) successful curriculum change. National culture was demonstrated to explain a large part of variance in organisational readiness for change (MORC) between different medical schools and organisational culture could explain a large part of variance within different medical schools. 
Chapter 7 General discussion. This chapter summarizes the previous chapters and draws several conclusions; describes the strengths, weaknesses and implications of the studies and provides suggestions for further research.

From Chapter 2, 3, 4 and 6 we can conclude that national culture has an influence on medical curriculum innovation and thus positively answer the first problem statement. Three specific national culture characteristics - power distance, uncertainty avoidance and individualism - showed to either stimulate or inhibit the change process. The second problem statement of this dissertation aimed to investigate how national culture impacts on the curriculum change processes in medical schools. First indications on how culture influences on curriculum change processes were found in the qualitative interview study in Chapter 4. In the absence of an existing instrument measuring successful curriculum change, we developed and validated an instrument to measure Medical schools' Readiness for curriculum Change (MORC) (Chapter 5). A causal pathway of national culture's influence on successful curriculum change was demonstrated using MORC (Chapter 6). This study indicated that successful curriculum change is influenced by national as well as organisational culture.

This thesis demonstrated that specific national and organisational culture characteristics had a positive or negative impact on the change process. The following cultural attributes appeared to be conducive, such as: a certain level of risk-taking (low national level of uncertainty avoidance), sufficient intrinsic motivation to change and internal locus of control (high national level of individualism), interdisciplinary learning in teams (high organisational emphasis on human relations), and an emphasis on innovation (high organisational emphasis on open systems). In a time of continuous demand for innovation of medical education all over the world, the practical implication is not that medical schools in countries with cultural environments possibly less conducive for change should refrain from changing their curricula. These medical schools should be aware of potential additional sources of resistance caused by their national and organisational culture, and design strategies prior to and during the change process to tackle this resistance. MORC may be used to analyse potential sources of resistance for curriculum changes and adaptation of the identified factors by MORC could improve the chance of successful change.

The strengths of this thesis lie in the use of both quantitative 
and qualitative methods, the various methodologies used to validate MORC and the practical applicability of MORC for medical schools (preparing) changing their curriculum. Weaknesses are the strong reliance on Hofstede's cultural dimensions, inability to completely replicate the Competing Values Framework of organisational culture, and the limited sample of medical schools participating in the studies presented in Chapter 5 and 6.

Several directions for further research are recommended. Further research could: 1) investigate effective strategies for curriculum change in different cultures (for instance by using the MORC questionnaire), 2) investigate the influence of adoption of educational innovations imported from abroad on the values and behaviour of staff and students, 3) focus on variance in perceptions of readiness for change within teams, departments and the whole medical school, and 4) differences in structure and size of social networks in medical schools in various countries and their influence on innovations.

\section{References}

1. Hofstede G. Culture's Consequences. Comparing Values, Behaviors, Institutions, and Organizations across Nations. New York: Sage Publications 2001.

2. Quinn R, Spreitzer G. The psychometrics of the competing values culture instrument and an analysis of the impact of organizational culture on the quality of life. Research in Organizational Change and Development. 1991;5:115-42. 
Introductie (Hoofdstuk 1). In dit proefschrift wordt ingegaan op de impact van kenmerken van nationale cultuur op curriculumverandering in de opleiding geneeskunde. Het medische curriculum is op dit moment onderwerp van verandering in veel medische faculteiten over de hele wereld. De implementatie van innovatieve curricula verloopt echter niet altijd overal even succesvol en geheel of gedeeltelijk mislukken van de implemenatie is niet ongebruikelijk. Meer inzicht in factoren die een succesvolle verandering stimuleren zou kostbare mislukkingen en frustraties kunnen voorkomen. Kennis over de culturele invloeden op veranderingen zijn echter schaars. Het eerste hoofdstuk geeft daarom eerst een overzicht van de literatuur over veranderingen van het medisch curriculum en vervolgens een overzicht van de literatuur over culturele invloeden op veranderingsprocessen in het algemeen. Daarna volgt de (meestal gehypothetiseerde) combinatie van deze twee componenten, wat uiteindelijk leidt tot de centrale vraagstellingen van dit proefschrift: Heeft nationale cultuur een invloed op innovaties van het medisch curriculum? En zo ja, hoe heeft nationale cultuur invloed op veranderingsprocessen van het medisch curriculum?

De studies beschreven in hoofdstuk 2 en $\mathbf{3}$ onderzochten de aanwezigheid van een verband tussen nationale cultuur - gedefinieerd met behulp van de dimensies van Hofstede ${ }^{1}$ - en medische curriculum innovaties, bepaald als het deel medische faculteiten in een land dat een geïntegreerd medisch curriculum geïmplementeerd heeft. De resultaten van het tweede hoofdstuk toonden in een steekproef van 17 Europese landen een dergelijke relatie aan. Twee van de vier culturele dimensies van Hofstede, namelijk 'machtsafstand' en 'onzekerheidsvermijding' hadden een significante correlatie met het percentage medische faculteiten per land met een geïntegreerd curriculum. Vergelijkbare resultaten werden gevonden in het derde hoofdstuk voor een uitgebreidere dataset met 63 landen wereldwijd. Daarnaast werd in deze dataset ook voor 'individualisme' een significante correlatie gevonden met het aandeel medische faculteiten per land met een innovatief curriculum. Dus, landen die hoog scoren op onzekerheidsvermijding en/ of machtsafstand en/of laag scoren op individualisme hebben minder medische faculteiten die zijn veranderd naar een geïntegreerd curriculum. Mogelijk heerst er in faculteiten in landen met een hoge machtsafstand een hogere mate van hiërarchie die belemmerend werkte op de noodzakelijke interdisciplinaire communicatie tussen verschillende afdelingen. Bovendien, afdelingshoofden die voorheen vrijwel autonoom 
verantwoordelijk waren voor het onderwijs in hun discipline moesten een deel van hun macht afstaan aan een centrale opleidingscommissie, wat waarschijnlijk weerstand veroorzaakte. Daarnaast belemmerde een hoge mate van onzekerheidsvermijding waarschijnlijk curriculum innovaties door het vermijden van risico's en het vasthouden aan de strenge regels en voorschriften van de faculteit en de overheid. Tot slot remde een hoge mate van collectivisme mogelijk veranderingsinitiatieven door de nadruk op de groepscultuur en het behoud van harmonie waarbij geprobeerd wordt conflicten zoveel mogelijk te voorkomen.

In hoofdstuk 4 is onderzocht hoe medische faculteiten in een minder gunstige omgeving voor verandering in staat zijn geweest de overstap te maken naar een innovatief curriculum. Hoofdstukken 2 en 3 lieten zien dat in landen met een hoge mate van onzekerheidsvermijding en/of machtsafstand en/of een laag niveau van individualisme minder medische faculteiten veranderden naar een innovatief curriculum. Echter, niet alle landen hielden zich strikt aan deze observatie en in een aantal landen met een minder gunstig klimaat voor verandering zijn er onverwacht veel innovatieve medische faculteiten. Het bestuderen van dergelijke faculteiten die ondanks een minder gunstig klimaat in staat zijn geweest te veranderen, zou inzicht kunnen verschaffen in hoe cultuur invloed heeft op curriculumveranderingsprocessen en hoe belemmerende effecten zouden kunnen worden aangepakt. Onzekerheidsvermijding bleek van de verschillende nationale cultuur kenmerken de sterkst remmende invloed te hebben. In dit hoofstuk is daarom een kwalitatieve interview studie uitgevoerd met de belangrijkste veranderaars ('key change agents') in Oostenrijk, waar alle drie openbare medische faculteiten veranderd zijn van een traditioneel naar een geintegreerd curriculum, ondanks het hoge nationale niveau van onzekerheidsvermijding. Verschillende stimulerende en remmende factoren die de veranderingsprocessen beïnvloedden werden geïdentificeerd. Deze factoren kwamen grotendeels overeen tussen de drie medische faculteiten. Een van de belangrijkste stimulerende factoren bleek de invoering van een nationale wet die curriculumverandering toestond binnen een bepaalde tijdsperiode. Voorheen had de restrictieve nationale wetgeving een remmende invloed op veranderingen en bevorderde zij een excuus cultuur: 'Het is niet onze schuld. Het is de schuld van het ministerie'. Bevestiging van de impact van de sterke onzekerheidsvermijding werd gevonden in de strenge regels en voorschriften en de naleving daarvan, en de algemene tendens om veranderingen 
- en daaruit voortkomende onzekere situaties - te voorkomen bij veel stafleden van de faculteit. Oppositie door stafleden van de faculteit werd overwonnen door deze nieuwe nationale wetgeving die verandering aanmoedigde, samen met aanvullende interne factoren die de verandering stimuleerden: een intern sterk gevoelde behoefte aan verandering, ondersteunend en ononderbroken leiderschap en veranderaars met een duidelijke visie.

Hoofdstuk 5 beschrijft de ontwikkeling en validatie van een nieuwe vragenlijst voor het meten van de voorspellers van een succesvolle curriculum verandering: bereidheid tot curriculumverandering in medische faculteiten (MORC). Diverse bestaande vragenlijsten waren beschikbaar voor het meten van bereidheid tot organisatieverandering in bedrijven en zorginstellingen, maar bij ons weten bestond er geen instrument dat geschikt was voor medische faculteiten. Elementen van bestaande vragenlijsten werden gecombineerd in een voorlopige vragenlijst en de toepasbaarheid van deze vragenlijst voor medische faculteiten werd beoordeeld in een gemodificeerde Delphi procedure. In deze procedure bereikte een panel bestaande uit 19 experts op het gebied van medische curriculumveranderingen na twee rondes consensus over de toepasbaarheid van de lijst voor medische faculteiten. Vervolgens is de voorlopige MORC vragenlijst psychometrisch getest in een populatie van 991 medewerkers in 131 medische faculteiten uit 56 landen die zich - op het moment van afname - in een veranderingsproces van het curriculum bevonden. Exploratieve factoranalyse resulteerde in de uiteindelijke MORC vragenlijst met 53 items bestaande uit twaalf subschalen en drie dimensies, een structuur die werd bevestigd met behulp van confirmatieve factoranalyse. Generaliseerbaarheidsanalyse toonde bovendien aan dat vijf tot vijftien medewerkers van een faculteit op betrouwbare wijze de bereidheid tot organisatieverandering in een medische faculteit kunnen beoordelen.

In hoofdstuk 6 onderzochten we de invloed van nationale en organisatiecultuur op een succesvolle verandering van het medisch curriculum. Dit hoofdstuk combineerde de resultaten van de vorige vijf hoofdstukken. In hoofdstuk twee en drie werd het bestaan van een relatie tussen nationale cultuur en succesvolle curriculum veranderingen bevestigd, zonder verder uit te weiden hoe nationale culturele kenmerken het veranderingsproces van een medisch curriculum beïnvloeden. De MORC vragenlijst die werd ontwikkeld in het vijfde hoofdstuk meet 
de factoren die een succesvolle curriculumverandering beinvloeden en maakte verdere exploratie mogelijk van de manier waarop nationale cultuur invloed heeft op curriculumveranderingen. Organisatiecultuur werd verondersteld de relatie tussen nationale cultuur en succesvolle curriculumverandering te beïnvloeden en werd in deze studie gemeten met behulp van de vragenlijst van Quinn². Een conceptueel model met de nationale cultuur dimensies van Hofstede, de organisatiecultuur typering van Quinn en de MORC vragenlijst met de factoren die een succesvolle curriculumverandering voorspellen, werd geanalyseerd met behulp van 'multilevel structural equation modeling' op de beschikbare dataset van 991 medewerkers in 131 medische faculteiten uit 56 landen. De resultaten bevestigden de invloed van kenmerken van zowel nationale als organisatie cultuur op (de voorspellers van) een succesvolle curriculumverandering. Nationale cultuur verklaarde met name grote verschillen in veranderingsbereidheid tussen verschillende medische faculteiten en organisatie cultuur verklaarde met name grote verschillen in veranderingsbereidheid binnen verschillende medische faculteiten.

Algemene discussie (Hoofdstuk 7). In dit hoofdstuk worden de voorgaande hoofdstukken samengevat, een aantal conclusies getrokken en de praktische implicaties daarvan besproken. Daarnaast worden de sterke en zwakke punten van dit proefschrift beschreven en suggesties gedaan voor verder onderzoek.

Uit hoofdstuk 2, 3, 4 en 6 kunnen we concluderen dat nationale cultuur een invloed heeft op innovaties van het medische curriculum en hiermee de eerste centrale vraag positief beantwoorden. Drie specifieke nationale cultuur kenmerken - machtsafstand, onzekerheidsvermijding en individualisme - stimuleren danwel remmen het veranderingsproces. De tweede centrale vraag van dit proefschrift streefde te onderzoeken hoe nationale cultuur effect heeft op veranderingsprocessen van het medische curriculum. Eerste aanwijzingen voor de manier waarop cultuur invloed kan hebben op curriculumveranderingen werden gevonden in de kwalitatieve interview studie in hoofdstuk 4. In verband met het ontbreken van een bestaand instrument om succcessvolle curriculum veranderingen te meten is in hoofdstuk 5 een nieuw instrument ontwikkeld en gevalideerd dat de bereidheid tot curriculumverandering in medische faculteiten kan meten (MORC). Een causaal verband tussen nationale cultuur en succesvolle curriculumveranderingen werd aangetoond met behulp van MORC (Chapter 6). Deze studie 
liet zien dat een succesvolle curriculumverandering wordt beïnvloed door zowel nationale als organisatiecultuur.

In dit proefschrift is aangetoond dat specifieke kenmerken van nationale en organisatie cultuur een positieve of negatieve invloed hebben op het veranderingsproces van een medisch curriculum. Verschillende culturele aspecten bleken een gunstige invloed te hebben, zoals een bepaalde mate van risico's durven nemen (laag nationaal niveau van onzekerheidsvermijding), voldoende intrinsieke motivatie om te veranderen en het gevoel zelf invloed te hebben (hoog nationaal niveau individualisme), sterke mate van interdisciplinair leren in teams (sterke nadruk op human relations), en een sterke wil tot verbeteren (sterke nadruk op open systems). In een tijd van voortdurende vraag naar vernieuwing van het medische onderwijs over de hele wereld is de praktische implicatie niet dat medische faculteiten in landen met een cultureel minder gunstig klimaat voor verandering af moeten zien van curriculumveranderingen. Deze medische faculteiten moeten zich echter wel bewust zijn van mogelijke bijkomende bronnen van weerstand die worden veroorzaakt door hun nationale en/of organisatie cultuur, en zij zouden vooraf en tijdens het veranderingsproces strategieen kunnen ontwikkelingen om deze weerstand te verminderen. MORC zou bijvoorbeeld gebruikt kunnen worden om potentiële bronnen van weerstand voor curriculumverandering vast te stellen en aanpassingen van de door MORC geïdentificeerde factoren kan de kans op een succesvolle verandering verhogen.

De sterke punten van dit proefschrift liggen in het gebruik van zowel kwantitatieve als kwalitatieve onderzoekstechnieken, het gebruik van verschillende methodes voor de validatie van MORC en de praktische toepasbaarheid van MORC voor medische faculteiten die bezig zijn met (de voorbereiding van) een curriculumverandering. Zwakke punten zijn het sterk leunen op de culturele dimensies van Hofstede, het onvermogen om de organisatiecultuur typering van Quinn volledig te reproduceren, en de beperkte steekproef van deelnemende medische faculteiten in hoofdstuk 5 en 6.

Verschillende richtingen voor verder onderzoek worden aanbevolen. Nader onderzoek zou zich kunnen richten op het onderzoeken van: 1) effectieve strategieën voor curriculumverandering in verschillende culturen (bijvoorbeeld door middel van het gebruik van MORC), 2 ) invloed van de invoering van uit het buitenland geïmporteerde onderwijsvernieuwingen op de normen, waarden en het gedrag van staf 
en studenten, 3) variatie in de perceptie van veranderingsbereidheid binnen teams, afdelingen en de hele medische faculteit, en 4) verschillen in de structuur en omvang van sociale netwerken in medische faculteiten in verschillende landen en de invloed daarvan op innovaties.

\section{Referenties}

1. Hofstede G. Culture's Consequences. Comparing Values, Behaviors, Institutions, and Organizations across Nations. New York: Sage Publications 2001.

2. Quinn R, Spreitzer G. The psychometrics of the competing values culture instrument and an analysis of the impact of organizational culture on the quality of life. Research in Organizational Change and Development. 1991;5:115-42. 
\begin{tabular}{l|l} 
SAmenvatting & 177
\end{tabular} 


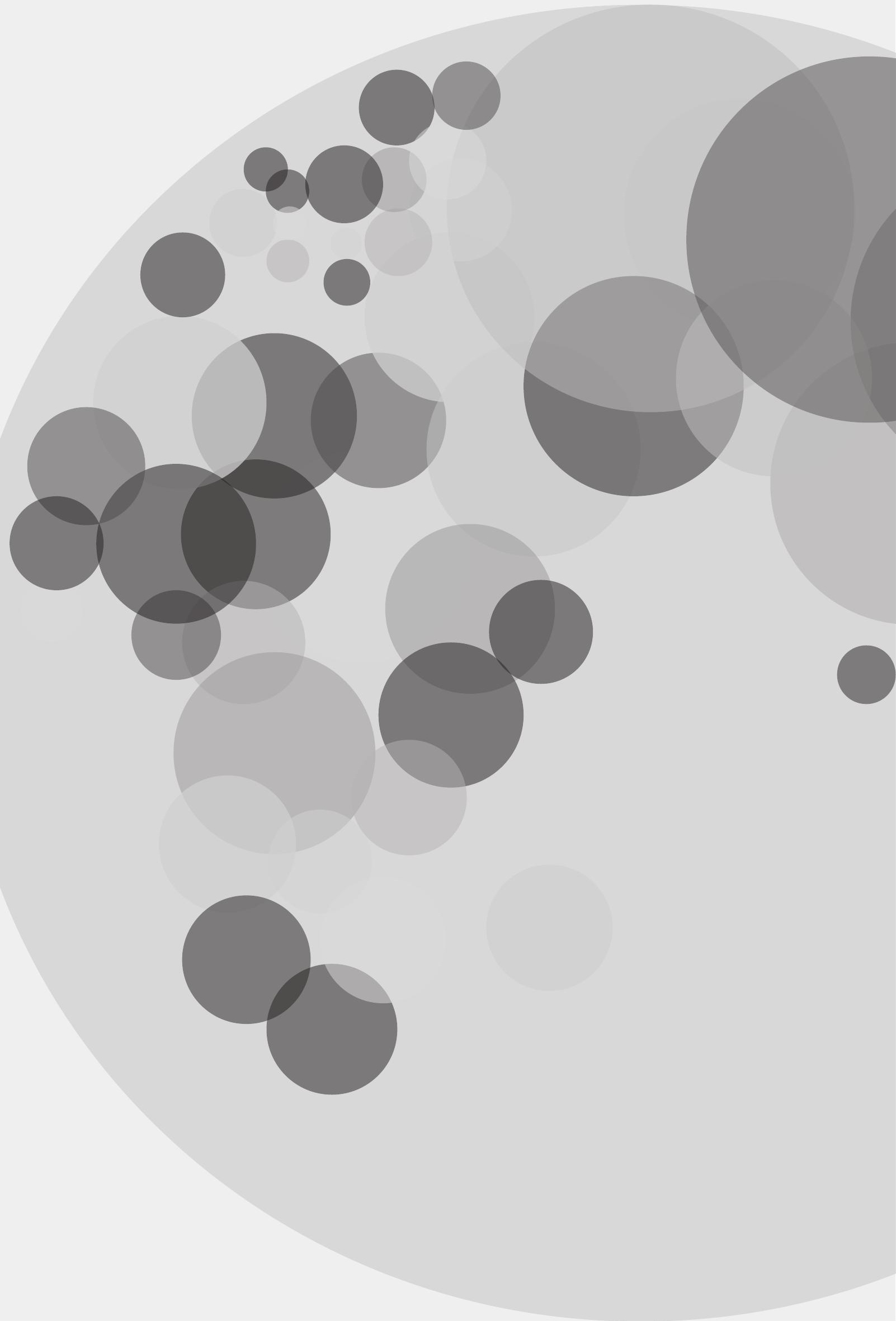




\section{DANKWOORD}


Gisteren wees mijn supervisor in mijn nieuwe functie mij erop dat ik wel erg vaak bedankt zeg. 'Thanks' tegen de OK zuster als ze mij iets aangeeft en tegen mijn supervisor als hij mij snel terugbelt nadat ik hem geprobeerd had te bereiken met een vraag over een patiënt. 'Je moet oppassen dat het geen stopwoord wordt', zei hij me. Goed punt, raak gesproken? Op het moment dat je op de SEH staat en een instabiele patiënt behandeld is het niet heel efficiënt om de verpleegkundige te bedanken voor iedere spuit die ze geeft en elke bloeddruk die ze meet. Maar als er geen sprake is van tijdnood: kun je dan te vaak je dankwoord uitten? Nadat ik mijn supervisor heb mogen assisteren bij een operatie, waarbij we met een stukje huid van de onderarm een nieuwe tong hebben gereconstrueerd, wens ik hem een goed weekend en bedank ik hem voor de leuke dag. Terwijl ik het zeg zie ik hem kijken: 'wat heb ik je nou gezegd, je moet niet de hele tijd bedankt zeggen!' Hardleers noemen we dat ook wel..

Het goede nieuws is dat ik nu een hoofdstuk mag schrijven waarin ik me vol overgave mag storten op datgene wat ik zo graag doe: mensen bedanken. Yes!

Zo'n zes jaar geleden, tijdens mijn tweede jaar geneeskunde had ik een bijbaantje als student-assistent in het Skillslab. Op 25 februari 2006 tijdens het printen zag ik op een verjaardagslijstje dat Gerard Majoor jarig was. Gerard had ik één keer eerder gezien tijdens mijn sollicitatiegesprek voor het internationale traject van geneeskunde en ik besloot bij hem binnen te lopen en hem te feliciteren. Zijn moment van verbazing gebruikte ik om uit te leggen dat ik graag onderzoek wilde doen en een lange zomervakantie had, maar dat ik geen idee had hoe ik dat moest aanpakken en of hij misschien een idee had hoe ik dat zou moeten doen (met in mijn achterhoofd de onuitgesproken vraag: of hij niet 1 of andere chirurg kende). Geheel onbewust van het bestaan van het vakgebied 'onderzoek van medisch onderwijs' was ik op mijn beurt verbaasd door zijn voorstel een paar maanden later om onderzoek te doen naar probleem-gestuurd onderwijs in medische faculteiten in Europa. Gecharmeerd door het idee ging ik die zomer aan de slag met de websites van o.a. Turkse en Finse medische faculteiten en translate. google.com wat uiteindelijk zou resulteren in onze eerste publicatie. Gerard zonder jou had ik hier niet gestaan. Jij bent niet alleen degene geweest die met het idee kwam voor het eerste onderzoek, maar je hebt er ook voor gezorgd dat mijn beloofde promovendi aanstelling 
uiteindelijk niet strandde door de vacaturestop van de UM. Ik wil je daarnaast bedanken voor je altijd kritische blik op letterlijk iedere punt en komma en steady niet-opbouwende kritiek, zoals: 'Enerzijds vinden Cees en Erik kennelijk dat het zo OK is, anderzijds is mijn inschatting dat het verhaal in deze versie (bij Medical Education) kansloos is. (..) Er zitten herhalingen in en "vrijblijvend geleuter". Maar no worries van jou kan ik het hebben, omdat ik weet dat het uit een goed hart komt. Annewies ook bedankt dat ik Gerard zijn tijd mocht gebruiken, zelfs na zijn pensioen en voor je geweldige kookkunsten!

Even terug naar die paar maanden in 2006 dat ik moest wachten op Gerard zijn reactie. Een studiegenoot vertelde me dat ze onderzoek deed voor Erik Driessen bij het onderwijsinstituut. Na haar enthousiaste verhalen over onderwijsonderzoek en buitenlandse congressen en met het idee 'op meerdere paarden te wedden' mailde ik Erik met de vraag of ik onderzoek voor hem kon doen. Helaas kreeg ik vrij snel terug dat je geen plek had voor mij. Totdat Cees je drie jaar later vroeg of je mijn co-promotor wilde zijn: ik ben erg blij dat je me geen tweede keer afwees. Erik, heel erg bedankt voor je eeuwig positieve instelling en kritische blik. Als ik weer eens met duizend-en-één ideeën kwam over wat ik bijvoorbeeld in 18 weken onderzoeksstage wilde doen wist je mij weer enig inzicht in de onhaalbaarheid van mijn plannen te verschaffen. Tot slot, never a dull moment in jouw aanwezigheid: van nachtelijk tafeltennis bij het NVMO, spinnen bij topfit, je been breken een week voordat je kind geboren wordt tot je pink breken een week voordat je gaat verhuizen.

Over mijn promotor Cees van der Vleuten moet ik eerst wat achtergrondinformatie vertellen. Gekscherend noemen we hem wel eens de 'olympiër' van zijn vakgebied. Een soort 'ubermensch' die (volgens zijn CV van 1 januari 2012 dus inmiddels al hopeloos gedateerd) 624 publicaties heeft voortgebracht, 50 succesvolle promoties heeft begeleid en op dit moment nog eens 38! Promovendi superviseert. En op de een of andere manier als ik Cees een mailtje stuur met een vraag heb ik binnen een dag en vaak binnen 2 uur antwoord (ook in het weekend!). Cees ik wil jou dan ook bedanken voor je supersnelle feedback, kritische blik en het veilige leerklimaat wat je altijd hebt gecreëerd. Mijn dank ook dat ik jouw netwerk en goede naam heb mogen gebruiken wat tot een geweldige internationale respons heeft geleid in hoofdstuk 5 en 6. 
Mijn begeleidingscommissie bestaat officieel uit deze drie musketiers, maar er is één iemand die ook een belangrijke rol heeft gespeeld en die ik tot mijn 'externe consultant' heb benoemd: Wim Gijselaers. Op verschillende momenten tijdens het promotie traject, met name wanneer ik het even niet meer zag zitten, heb ik bij jouw advies ingewonnen. Ook heeft jouw netwerk in Oostenrijk ervoor gezorgd dat ik daar met open armen werd ontvangen voor de studie in hoofdstuk 4. Wim, wat ik heel bijzonder aan jou vind is je inlevingsvermogen. Op de een of andere manier wist jij razendsnel waar ik mee aan het vechten was in mijn hoofd en wist jij deze donderwolken open te breken en mij weer met een open blik te laten kijken. Bedankt voor je gastvrijheid in de economie faculteit en in Mheer. Hoewel er bij mij misschien wat alarmbelletjes hadden moeten gaan rinkelen toen je zei dat het naar Mheer toe fietsen 40 minuten kostte en terug slechts 25 minuten. Een OV-fiets zonder versnellingen is geen aanrader. .

Iets meer op de achtergrond is een vijfde man belangrijk geweest: Albert Scherpbier. Destijds als onderwijsdirecteur steunde je mijn aanstelling als student-onderzoeker en als decaan van de faculteit geneeskunde en gezondheidswetenschappen heb je mede gezorgd dat mijn promovenda aanstelling niet sneuvelde in de vacaturestop. Mijn dank daarvoor. Nu klinkt het bijna alsof je alleen als suikeroom een rol hebt gespeeld. Ik wil je echter ook bedanken voor de inspirerende gesprekken, tijdens bijvoorbeeld de AMEE in Malaga waar je me verbaasde doordat bleek dat je al kleinkinderen had, maar dit bleek geen reden om niet mee te gaan naar de discotheek.

Mereke Gorsira, jij hebt echt een uniek talent. Onwijs bedankt voor het editen van de manuscripten. Erg bijzonder hoe jij alles net even anders weet op te schrijven: bondiger en chiquer.

Hoewel ik geen vaste werkplek had, omdat ik veel thuis in Scheveningen werkte, ben ik altijd met open armen ontvangen in de AIO kamer op de vijfde. Heel erg bedankt voor jullie gastvrijheid en voor de leerzame journal clubs en kwalitatief onderzoek bijeenkomsten. Jullie kritische blik heeft mijn artikelen enorm verbeterd. In het speciaal wil ik Janneke Frambach bedanken. Als buitenbeentjes die zich allebei met cultuur bezighielden hadden we elkaar gevonden. Jouw feedback en onze gesprekken zijn een enorme inspiratiebron geweest. Niet alleen in Maastricht werd ik gastvrij ontvangen. Ook bij de journal club 
van AMC/VU/UMCU was ik altijd welkom op de vrijdagmiddag en heb ik met zwetende handjes goede feedback mogen ontvangen op mijn artikelen. In het bijzonder wil ik Renee van der Leeuw bedanken. Lieve Rens, ik ben enorm blij dat ik je heb leren kennen zowel als één van mijn beste vriendinnetjes als uiteindelijk als collega AIO in het medisch onderwijs. Dank dat je me geïntroduceerd hebt bij je lieve collega's en voor jouw aanstekelijke positieve kijk op het leven.

Zoals het een echte geneesco betaamt had ik vrijwel nul kennis van statistiek. Zonder Arno Muijtjens en Nick Broers had ik mij nooit door de ingewikkelde analyses (multilevel SEM: ik had daar tot een jaar geleden zelfs nog nooit van gehoord!) heen weten te werken. Mijn dank voor jullie geduld en tijd.

My gratitude goes to my colleagues all over the world (including PhD and MHPE (alumni)students of Maastricht University and members of The Network: Towards Unity for Health) for so kindly participating in our studies. Your contribution was essential. Special thanks are reserved for Olle ten Cate for his contacts and inclusion of participants in Eastern Europe. Special gratitude goes to to my Austrian colleagues: thank you for the warm welcome in Austria.

Wonende in Scheveningen kon ik het niet laten om stiekem steeds iets meer te gaan beachvolleyballen. Het hoge aantal zonuren afgelopen jaar heeft zeker positief bijgedragen aan het op tijd afkrijgen van het manuscript. Beach Team Den Haag en in het bijzonder Sanne onwijs bedankt voor deze welkome afleiding en geweldige ervaring!

Voor de welkome afleiding in Maastricht en inmiddels uitgewaaierd over heel Nederland wil ik graag mijn lieve vriendinnetjes van Linque bedanken. Ik ben trots dat ik als eerste en zeker niet de laatste van ons dispuut mijn promotie onderzoek zal mogen verdedigen. De kleur van de omslag is niet geheel willekeurig gekozen..

Er zijn een aantal vriendinnen die ik in het bijzonder wil noemen: Eva Malschaert onwijs bedankt voor de geweldige lay-out. Eef, ik ben enorm trots dat mijn boekje jouw ontwerp mag dragen: niet alleen omdat je een enorm talentvolle ontwerper bent, maar ook omdat ik het heel speciaal vind dat zo'n goede vriendin (hoogzwanger!) deze taak op zich heeft genomen. Floortje Steegh, het was echt heel fijn om onze promotie dieptepunten en pieken te kunnen delen zowel tijdens onze 
studie als erna. Floor bedankt voor je onuitputtelijke vertrouwen in mij, de gezellige sleep-overs en koffiemomenten. Jeanette, bedankt voor je lieve interesse, gastvrijheid en warmte. Sitsi, vaker niet dan wel in het zelfde land, heb je me zelfs vanuit de rimboe geholpen: bedankt voor de Spaanse vertalingen. Dan de Fatties: Ca, Rens, Floor en San, bedankt voor alles. Voor het me compleet mezelf laten zijn en de gezellige avonden en vakanties: Gotschna is waiting for us..

Caroline Broos, daar staan we dan: Jip en Ca Hoofdstuk 12: promoveren. Chronologisch volgend na hoofdstuk Assen, Maastricht, geneeskunde, Saurus, Bootdelicious, roeien, Linque, wereldreis, afstuderen, eerste baan en Erasmus MC. Mijn dankbaarheid voor jou valt niet in woorden uit te drukken en met jou als beste vriendin durf ik de hele wereld aan.

De één na laatste alinea is voor mijn familie: Papa, Mama, Kelly, Erik, David, Marjon, Myron, Saar, Opa en Oma. Papa en Mama, voor de $2^{\mathrm{e}}$ keer in een jaar tijd zijn jullie getuige van de promotie van één van je kinderen. Ik denk dat dit geen toeval is, maar een resultaat van jullie onvoorwaardelijke steun en liefde. Ik kan jullie hiervoor nooit voldoende bedanken.

Oma, jij hebt een speciaal plekje in mijn hart. Bedankt voor het altijd voor mij klaar staan.

Kelly, mijn grote zus, dank voor het luisterend oor en het produceren van de meest geweldige kinderen ter wereld. Mijn zorgen losten op in de lucht bij het zien van de grote ogen van Myron en haar woorden: 'kijk, ik heb een taart voor je gebakken'. Speciaal voor mij.

Erik, mijn grote broer. Ik heb het een enorme eer gevonden om jouw paranimf te zijn en ik vind het heel bijzonder dat we nu de rollen hebben omgedraaid. Bedankt voor jouw belangrijke bijdrage: zowel voor je inhoudelijke adviezen als voor de steun op momenten dat ik zin had om mijn laptop door het raam te slingeren.

Op de vijfde pagina van dit boek staan twee woorden die deze alinea samenvatten: Voor Tom. Mijn steun en toeverlaat die alle pieken en dalen heeft meegekregen van mijn leven de afgelopen 8,5 jaar. Lieve Tom ik wil dit boek graag aan jou opdragen, omdat met jou samen het leven nog mooier is. 
\begin{tabular}{l|l} 
DANKWOORD & 185
\end{tabular} 


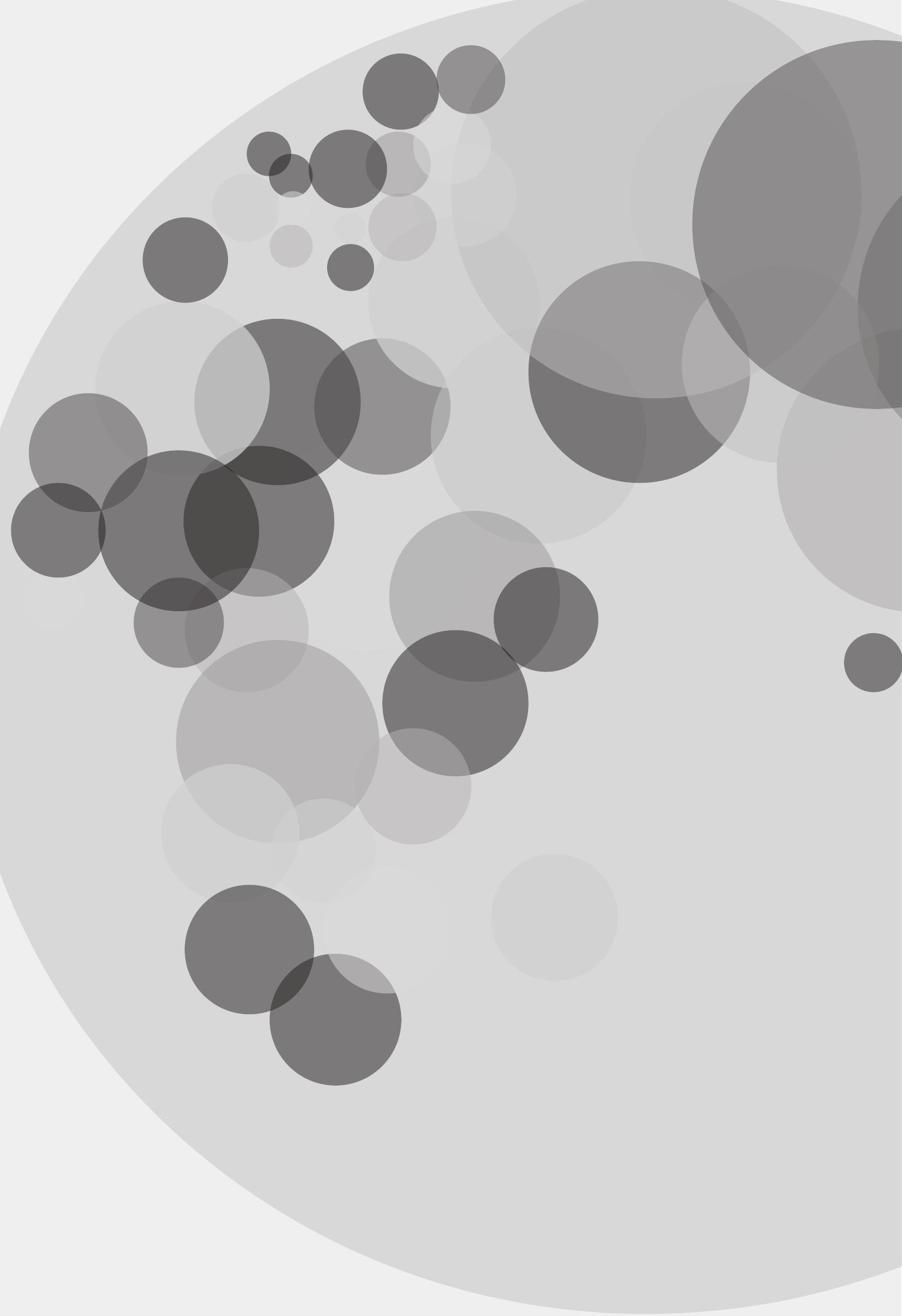


ABOUT THE AUTHOR 
Mariëlle Jippes was born on January 23rd 1986 in Beilen, The Netherlands. She attended Atheneum at Dr. Nassau College in Assen where she graduated cum laude in 2004. The same year she commenced her Medicine study at Maastricht University. In her second study year she initiated the first research project described in this thesis with Gerard Majoor on curriculum innovations in Europe. After receiving her Bachelor degree in 2007 she took a sabbatical in which she: worked at the liver surgery department in the Academic Hospital in Maastricht (prof. Prof. CHC de Jong en Dr. Van Dam), worked at the University of Development studies in Tamale, Ghana - where they just started with Problem-Based Learning- and travelled through Central America and Africa. In 2008 she started with her master of Medicine in which she discovered the unimaginable possibilities of Plastic, Reconstructive and Hand surgery, the speciality with which she completed her Master in 2011 after an 18 weeks clerkship. Within a one year full appointment she completed her dissertation at the department of Educational Development and Research at Maastricht University. Directly thereafter in September 2012 she will start as a resident at the Plastic, Reconstructive and Hand surgery department at the Erasmus Medical Centre in Rotterdam. Diretly thereafter in September 2012 she started as a resident and from April 2013 she will start with her specialty training at the Plastic, Reconstructive an Hand surgery department at the Erasmus Medical Centre in Rotterdam.

In her spare time she loves to play beach volleyball and to travel all over the world. She lives in The Hague with Tom, as close as possible to the beach. 


\section{Publications:}

1. Jippes M, Majoor GD. (2011). Influence of national culture on the adoption of integrated medical curricula. Advances in Health Sciences Education;16(1):5-16.

2. Jippes M, Majoor GD. (2008). Influence of national culture on the adoption of integrated and problem-based curricula. Medical Education; 42: 279-285.

3. Jippes M, Driessen EW, Majoor GD, Gijselaers WH, Muijtjens AMM, Van der Vleuten CP. Impact of national context and culture on curriculum change: A case study. Accepted for publication Medical Teacher.

4. Jippes M, Driessen EW, Broers NJ, Majoor GD, Gijselaers WH, Van der Vleuten CP. Medical schools' Organisational Readiness for curriculum Change: Development and validation of a questionnaire (MORC). Under editorial review.

5. Jippes $M$, Driessen EW, Broers NJ, Majoor GD, Gijselaers WH, Van der Vleuten CP. Culture matters in successful curriculum change: the influence of national and organisational culture tested with multilevel structural equation modeling. Under editorial review.

6. Van Veelen M, Jippes M, De Rooi J, Mathijssen I, Van Adrichem L. Head circumference and volume measurements after extended strip versus total cranial remodelling for scaphocephaly. In preparation.

\section{Presentations/workshops:}

2012 Association Medial Education Europe (AMEE) conference, Lyon, France. How ready for curriculum change is your medical school? A practical tool to improve the chance of successfully implementing changes (workshop).

2012 Association Medial Education Europe (AMEE) conference, Lyon, France. Impact of national context and culture on curriculum change: A case study (presentatie).

2012 Nederlandse Vereniging van Plastische en Reconstructieve chirurgie (NVPC) congres. Volume metingen na brede stripcraniëctomie versus totale craniële remodellering voor scaphocephalie (presentatie). 
2012 Graz conference on medical education, Timisoara, Romania. How ready for curriculum change is your medical school? A practical tool to improve the chance of successfully implementing changes (invited workshop).

2011 Nederlandse Vereniging Medisch onderwijs (NVMO) congres, Egmond aan Zee, Nederland. Invloed van nationale cultuur op implementatie geïntegreerde curricula: een case study (presentatie).

2011 Promovendidag Nederlandse Vereniging Medisch onderwijs (NVMO), Utrecht, Nederland. Curriculum veranderingen in medische Faculteiten in Oostenrijk (presentatie).

2010 Knowledge, culture \& change in organizations conference, Montréal, Canada. Influence of national culture on the adoption of integrated medical curricula (presentatie).

2009 Nederlandse Vereniging Medisch onderwijs (NVMO) congres, Egmond aan Zee, Nederland. Invloed van nationale cultuur op de adoptie van geïntegreerde medische curricula in 63 landen (presentatie).

2009 Association Medial Education Europe (AMEE) conference, Malága, Spain. Influence of national culture on the adoption of integrated medical curricula (presentatie).

2009 Landelijk Medisch Studenten Overleg (LMSO) congres, Leiden, Nederland. Invloed van nationale cultuur op de adoptie van geïntegreerde en probleem-gestuurde medische curricula in Europa (presentatie).

2007 Nederlandse Vereniging Medisch onderwijs (NVMO) congres, Egmond aan Zee, Nederland. Invloed van nationale cultuur op de adoptie van geïntegreerde en probleem-gestuurde medische curricula in Europa (presentatie).

\section{Posters:}

2009 AMEE Association Medial Education Europe conference, Malága, Spain. Influence of national culture on the adoption of integrated curricula in 63 countries.

2007 The Network Towards Unity for Health conference, Kampala, Uganda. Influence of national culture on the adoption of integrated and problem based curricula. 


\section{SHE dissertation series}

In the SHE Dissertation Series dissertations are published of $\mathrm{PhD}$ candidates from the School of Health Professions Education (SHE) who defended their PhD thesis at Maastricht University. The most recent ones are listed below. For more information go to: www.maastrichtuniversity. $\mathrm{nl} / \mathrm{she}$

Duvivier, R. (12-12-2012) Teaching and Learning Clinical Skills: Mastering the Art of Medicine

Prescott-Clements, L. (9-11-2012) Ensuring the competence of dental practitioners through the development of a workplace-based system of assessment.

De Feijter, J. (9-11-2012), Learning from error to improve patient safety

Cilliers, F.J. (05-09-2012) The Pre-assessment Learning Effects of Consequential Assessment: Modelling how the Examination Game is Played

Spanjers, I. A.E. (05-07-2012) Segmentation of Animations: Explaining the Effects on the Learning Process and Learning Outcomes

Al-Kadri, H.M.F. (28-06-2012) Does Assessment Drive Students' Learning?

Leppink, J. (20-06-2012) Propositional manipulation for conceptual understanding of statistics

Van Zundert, M.J. (04-05-2012) Conditions of Peer Assessment for Complex Learning

Claramita, M. (30-03-2012) Doctor-patient communication in a culturally hierarchical context of Southeast Asia: A partnership approach

Kleijnen, J.C.B.M. (21-03-2012) Internal quality management and organizational values in higher education

Persoon, M.C. (19-01-2012) Learning in Urology; The influence of simulators and human factors

Pawlikowska, T.R.B. (21-12-2011) Patient Enablement; A Living Dialogue

Sok Ying Liaw, (14-12-2011) Rescuing A Patient In Deteriorating Situations (RAPIDS): A programmatic approach in developing and evaluating a simulation-based educational program

Singaram, V.S. (7-12-2011) Exploring the Impact of Diversity Factors on Problem-Based Collaborative Learning

Balslev, T. (24-11-2011) Learning to diagnose using patient video cases in paediatrics: Perceptive and cognitive processes

Widyandana, D. (19-10-2011) Integrating Pre-clinical skills training in skills laboratory and primary health care centers to prepare medical students for their clerkships

Durning, S.J. (09-09-2011) Exploring the Influence of Contextual Factors of the Clinical Encounter on Clinical Reasoning Success (Unraveling context specificity)

Govaerts, M.J.B. (08-09-2011) Climbing the Pyramid;Towards Understanding Performance Assessment 
Stalmeijer, R. E. (07-07-2011) Evaluating Clinical Teaching through Cognitive Apprenticeship.

Malling, B.V.G. (01-07-2011) Managing word-based postgraduate medical education in clinical departments

Veldhuijzen, J.W. (17-06-2011) Challenging the patient-centred paradigm: designing feasible guidelines for doctor patient communication.

Van Blankenstein, F. (18-05-2011) Elaboration during problem-based, small group discussion: A new approach to study collaborative learning.

Van Mook, W. (13-05-2011) Teaching and assessment of professional behavior: Rhetoric and reality.

De Leng, B. (8-12-2009). Wired for learning. How computers can support interaction in small group learning in higher education.

Maiorova, T. (29-05-2009). The role of gender in medical specialty choice and general practice preferences.

Bokken, L. (04-03-2009). Innovative use of simulated patients for educational purposes.

Wagenaar, A. (18-09-2008). Learning in internships. What and how students learn from experience.

Driessen, E. (25-06-2008). Educating the self-critical doctor. Using portfolio to stimulate and assess medical students' reflection.

Derkx, H. (18-06-2008). For your ears only. Quality of telephone triage at out-of-hours centres in the Netherlands.

Niessen, Th. (30-11-2007). Emerging epistemologies: making sense of teaching practice.

Budé, L. (05-10-2007). On the improvement of students' conceptual understanding in statistics education.

Niemantsverdriet, S. (26-07-2007). Learning from international internships: A reconstruction in the medical domain.

Marambe, K. (20-06-2007). Patterns of student learning in medical education - A Sri Lankan study in traditional curriculum.

Pleijers, A. (19-01-2007). Tutorial group discussion in problem-based learning.

Sargeant, J. (21-09-2006). Multi-source feedback for physician learning and change.

Dornan, T. (12-06-2006). Experience-based learning.

Wass, V. (12-05-2006). The assessment of clinical competence in high stakes examinations.

Prince, K. (21-04-2006). Problem-based learning as a preparation for professional practice. 